\title{
EFFECTS OF NOISE OF OFFSHORE OIL AND GAS OPERATIONS ON MARINE MAMMALS - AN INTRODUCTORY ASSESSMENT
}

RS Gales

September 1982

Research report: 1980-1981

Prepared for the Bureau of Land Management, Department of Interior
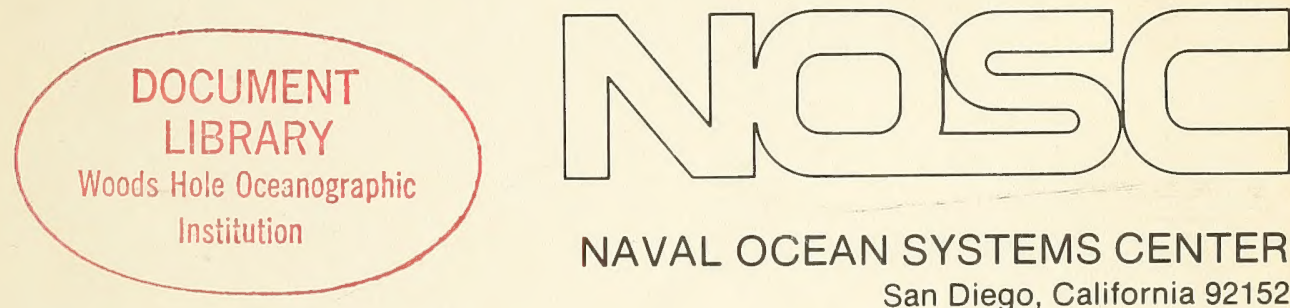

NAVAL OCEAN SYSTEMS CENTER San Diego, California 92152 


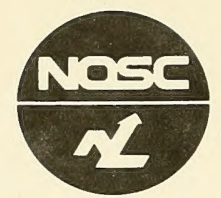

NAVAL OCEAN SYSTEMS CENTER, SAN DIEGO, CA 92152

AN A C T IVITY OF THE NAVALMATER I A L COMMAND
JM PATTON, CAPT, USN
Commander
Technical Director

\section{ADMINISTRATIVE INFORMATION}

The work described in this report was conducted in 1980 and 1981 for the Bureau of Land Management (BLM) of the U.S. Department of Interior under Interagency Agreement No. AA851-IA0-5 entitled, "Study of the Effects of Sound on Marine Mammals: (NOSC Project 513-MM28). The work was sponsored by the New York Outer Continental Shelf office of BLM under the general supervision of J. Philip Thomas and Eiji Imamura. Jeffery P. Petrion of BLM Code 851 served as contracting officer. This research was performed by the Naval Ocean Systems Center (NOSC). Computer Sciences Corporation (CSC) provided services under contract to NOSC. The work was done by the task group managed by Dr. Elek Lindner of the NOSC Marine Sciences Division. Principal members of the task team were: R.S. Gales, Acoustics, J.A. Hoke, Instrumentation, and D.R. Schmidt, Data Recording and Analysis. Participants from CSC were: Alma Church, Head Bio Science and Surface Surveillance Section, D. MacCormack, and R. Christensen, who performed the source spectrum analysis.

Released by

S Yamamoto,

Marine Sciences Division
Under authority of

HO Porter, Head

Biosciences Department

This report has been reviewed by the Bureau of Land Management and approved for publication. The opinions expressed in this report are those of the authors and not necessarily those of the Bureau of Land Management, U.S. Department of the Interior. The use of trade names or identification of specific products or equipment by manufacturer does not constitute endorsement or recommendation for use. 
UNCLASSIFIED

SECURITY CLASSIFICATION OF THIS PAGE (When Data Entered)

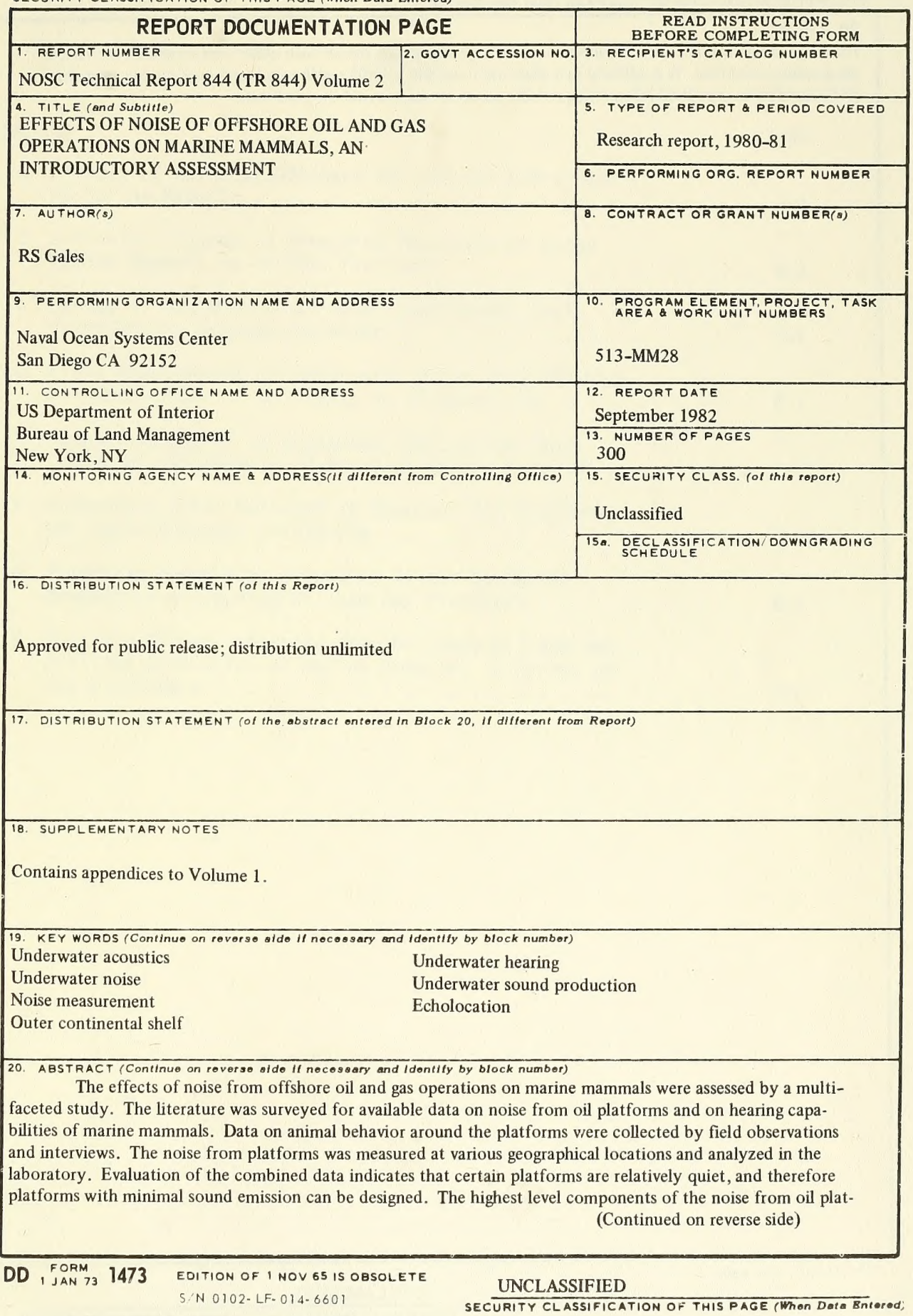


20. Continued

forms are below $100 \mathrm{~Hz}$. The distances at which large whales can detect such noise were estimated for various geographical locations. It is unlikely that platform noise will interfere with echolocation of marine mammals, and according to anecdotal information, whales ignore or easily avoid the platforms. 
A Effects of Noise of Offshore $0 i 1$ and Gas Operations on Marine Mammals ................ . . . A-1

B Interview Program to Determine Proximity of Large Marine Mammals to 0il/Gas Platforms............ B-1

C Survey of the Effects of Outer Continental Shelf Platforms on Cetacean Behavior .............. C-1

D Field Measurements of Underwater Noise from Offshore 0 i1 Operations 1 January to 20 June 1980 ...... D-1

E Summary Report of 30 September 1980 on BLM Task: "Study of the Effects of Sound on Marine Mammals" . . . . . . E-1

F Underwater Noise Measured at Fourteen $0 i 1$ Platforms Off Santa Barbara, California.............. . . F-1

G Estimated Underwater Detection Ranges by Marine Mammals of Noise from $0 i 1$ and Gas Platforms . . . . . . . . G-1

H Possible Effects of Noise from Offshore $0 i 1$ and Gas Drilling Activities on Marine Mammals: A Survey of the Literature . . . . . . . . . . . . . . . H-1 
APPENDIX A 
I. Underwater Noise from Offshore 0i1 Operations

and

II. Underwater Hearing and Sound Productions of Marine Mammals.

Compiled by

Charles W. Tur]

Edited by

Elek Lindner

Naval Ocean Systems Center

San Diego, California

June 1980 
The rapid increase in offshore petroleum operations during the past decade, and the more rapid increase that is anticipated for the next two decades, suggests that the noise generated during these operations may pose serious noise pollution problems for a variety of acoustic sensors (Underwater Systems, 1973). The discovery of oil in deep water and the development of mobile drilling platforms, which have the capability for drilling in water depths of several thousand feet, suggests that the past trend of drilling platforms in a few shallow shelf regions (e.g. Gulf of Mexico) can be augmented by exploration and production wells out to water depths of several thousand feet. Location of these noise sources in greater water depths will thus provide better acoustic coupling to deep oceanic waters.

The acoustic environment in the area of offshore drilling activities may influence the behavior and distribution of marine mammals in outer continental shelf waters. The protection of wildlife and the acoustic problems relating to human noise pollution form but a fraction of the whole subject that relates to human-wildlife interactions (Busnel, 1978).

There is general agreement among biologists that the acoustical sense of aquatic animals probably constitutes their most important distance receptor system. Studies of the acoustic activities of marine animals suggests that an animal's acoustical system can, and does, provide its owner appropriate information readily and rapidly, on a variety of functions relative to food, competitors, potential mates and predators (Myrberg, 1978).

Noise measurement data from offshore drilling activities are sparse. A survey of the published literature and contacts with private industry revealed that much of the available information is bandwidth limited. Measurements that have been made were with equipment which was either 1 imited in its high-frequency response or was "rolled off" at the lower frequency limits due to high ambient noise levels. Shallow water ambient noise levels in areas of offshore drilling activity are also limited. In the relatively shallow waters of drilling activities, the problem of multi-paths becomes significant in terms of making accurate measurements. The acoustic wave may reflect off the 
surface, the bottom, and the sub-bottom at several levels before it reaches the measurement station (Drouin, 1974). Many of the data presented in this report show a large amount of variability, probably due to shallow-water propagation characteristics.

Information on the effects of sustained, sub-critical levels of noise on the behavior and responses of marine animals is poorly understood. Although underwater hearing threshold data is available for some species, this information is not sufficient by itself to predict the effects of noise on behavior.

This report is divided into two sections. Section I summarizes published acoustic data from drilling platforms, construction sites, and support craft associated with offshore drilling activities. These data are presented as source levels and specify the amount of sound radiated by a projector. Source level is defined as the ratio of the intensity of radiated sound in decibels to the intensity of a plane wave of rms pressure $1 \mathrm{u} P \mathrm{a}$ referred to a point $1 \mathrm{~m}$ from the acoustic center of the projector in the direction of the target.

Section II, discusses the underwater hearing and underwater hearing thresholds for cetaceans and pinnipeds, and discusses sound production by large whales. 
ESTIMATED SOURCE LEVELS FROM OFFSHORE OIL AND GAS DRILLING ACTIVITIES.

Source levels for six activities and ambient noise spectra corresponding to these areas are shown in figures 1-6. Each figure contains two pieces of information that describe the acoustic environment in the vicinity of the drilling activity. The source level data for an activity is plotted in the upper half of each figure, and ambient noise spectrum levels are plotted for the general area in which the measurements were made in the lower half of each figure. Data at 20,100, 200 and $300 \mathrm{~Hz}$ are from the ASEPS prediction model, and are plotted as the average of four predicted values plus or minus a standard deviation for winter $(0)$ and summer $($.$) seasons. (ASEPS prediction$ model data were obtained from NOSC, San Diego, for specific lease areas.) The ambient noise levels as a function of shipping traffic and wind speed are from published sources (Urick, 1967).

Signal-to-noise $(S / N)$ ratios may be estimated from these figures by subtracting the spectrum level noise from the source level at a particular frequency. The $S / N$ ratio can be used to estimate the maximum range at which the sound may be detectable for these ambient noise conditions.

\section{Prudhoe Bay Area}

Figure I shows the major tonal components from two drilling sites in the Prudhoe Bay area: the NIAKUK 3 well, on a man-made gravel island, and the Reindeer Island Coast well, on a natural barrier beach island (Malme and Lawski, 1979). The source levels are plotted as averages of received levels from several ranges $(1,000$ to $1,600 \mathrm{~m})$ corrected for attentuation. The variability indicated by the standard deviation probably indicates changes in (1) propagation characteristics in shallow water, and (2) wind speed, ice movement and activity levels at these sites during the measurements.

These data show little difference in the noise levels; however, they have different tonal components. Although the bandwidth of the receiving equipment was reported to be at least $20 \mathrm{kHz}$, the authors noted that no useful data were obtained at frequencies higher than $8 \mathrm{kHz}$, and that the acoustic levels in this high frequency region were low. 
Tufts Point Dredging Site - Arnak Artificial Island Construction Site

Figures 2, 3 and 4 shows the noise generated from two construction locations in the Beaufort Sea area (Ford, 1977). Although not platform noise, the sounds from construction activities are nevertheless associated with offshore operations.

At the Tufts Point dredging site, noise sources included a suction dredge, several crew boats and tugs pushing barges into and out of the area. Noise measurements were made at several ranges (90 to 4,000 $\mathrm{m}$ ) in four different directions from this site. An artificial breakwall extends northwest from the site, and is the probable reason the noise was lowest from that direction (Figure 2). The average noise levels from the other three directions are similar in frequency and amplitude.

Transient sounds were also recorded at the Tufts Point site. Noisy couplings in the floating pipeline probably produced the short duration sounds plotted in Figure 3.

At the Arnak artificial construction site, operating machinery included a suction dredge, a tending tug, a clamshell shovel and several crew boats. Figure 4 shows tonal components measured from this site. The frequency band and amplitudes from the Tufts Point and the Arnak site are similar.

The author did not report any data for frequencies below $250 \mathrm{~Hz}$. Either they were not included if present or they were of such a low amplitude as not to be detectable.

\section{Logistic Traffic Noise at the Tufts Point Site}

Figure 5 shows source levels for major tonal components from tugs, tugs pushing barges (empty and ful1) and crew boats (Ford, 1977). The frequency spectra and amplitudes are comparable to those shown in Figure 2. Although these levels are slightly higher, this is probably a result that these sources were included with those measurements for the composite sounds that were shown in Figure 2.

Semi-Submersible Platform (SEDCO J) in the North Atlantic

Figure 6 shows source levels for low frequency tonals from a semi-submersible platform during drilling and tripping operations (Kramer and Wing, 1976). These values are of a similar level as those shown in Figure 1; 
however, they do not show the variability. This is probably due to the fact that these measurements were taken in "deep" water, and that all measurements were made from a single, distant measuring site.

The data shown in figures 1-6 indicate that based on available sources, the noise from offshore oil and gas drilling activities can potentially cover a broad frequency range $(10 \mathrm{~Hz}$ to $10 \mathrm{kHz}$ ) with average source levels from 130 to $180 \mathrm{~dB}$ re $1 \mu \mathrm{Pa}$ at $1 \mathrm{~m}$. The major tonal components are below $1.0 \mathrm{kHz}$ with the major energy below $200 \mathrm{~Hz}$. Signal-to-noise ratios may approach 80 to 100 $\mathrm{dB}$ above the ambient levels, which means that levels of this magnitude would not be completely attentuated until they reached a point 30 to 50 nautical miles from the source. 


\section{SECTION II}

\section{UNDERWATER HEARING AND SOUND PRODUCTION OF MARINE MAMMALS}

Anatomy

The anatomy and function of the auditory and associated neural structure for several species of odontocete cetaceans has been reviewed by several authors (Fraser and Purves, 1960; Morgane and Jacobs, 1972; Bullock, Grinnel1, Ikezono, Kameda, Katsuki, Nonoto, Sato and Yanagisawa, 1968; McCormick, Wever, Palin and Ridgway, 1970; Wever, McCormick, Palin and Ridgway, 1971). The sound path to the inner ear is not well understood. One theory (Fraser and Purves, 1960) concludes that the dolphin receives sound via the external auditory meatus, while Norris (1969) suggests that the sound is received via bone conduction through the fat layer of the lower jaw. Electrophysiological recordings and cochlear microphonic measurements (McCormick, Wever, Palin and Ridgway, 1970) has demonstrated that sound passing through the lower jaw excites cochlear and mid-brain with greater intensity than those sounds presented in the area of the external auditory meatus. These finding support the theory presented by Norris (1969).

The hearing capabilities of large whales are difficult to establish. Anecdotal evidence is available suggesting that mysticetes respond to ship noises, sonar pings and low-flying aircraft (Norris and Reeves, 1978). The anatomical structure of the mysticete auditory structure has been reviewed by several authors (Reysenbach de Haan, 1957; Dudok van Heel, 1962; Purves, 1966). Fleischer (1976) compared cochlear morphometrics in extinct and extant cetaceans, and concluded that mysticete cochlea have structurally evolved for sensitivity to low frequency sounds as compared to odontocete high-frequency sensitivity, although mysticete hearing for high frequency is probably very good.

The outer ear structure of pinnipeds has undergone considerable modification. The external ear of the sea lion is very reduced and may serve to close off the ear canal during diving; true seals have no external ears. The middle ear of pinnipeds has undergone additional modification in order to function in an aquatic environment; yet despite these modifications the pinniped ear must also function in air. One theory suggests that with 
pinniped underwater hearing the sound enters the head and proceeds directly to the organ of corti, whereas aerial sound transmission is apparently accomplished in a typical marmalian pattern -- from the tympanic membrane via the middle ear to the oval window (Reppening, 1972).

\section{Marine Mammal Auditory Threshold}

In the early 1950 's scientific observations began on the auditory capabilities of cetaceans. These were prompted in part by the hypothesis of McBride (1956) and others in the 1940's that some cetaceans were capable of echolocation. The experimental designs of these studies range from the initial "naturalistic observations" of Kellogg and Kohler (1952) to the more detailed experimental paradigms pioneered by Johnson in 1966 .

A wide variety of techniques has been devised to deterine the auditory thresholds of a mammal (Francis, 1975). These can be broadly separated into behavioral and electrophysiological measurement techniques. Both measurement techniques have been used with marine mamals. The goal of each study is the measurement of hearing sensitivity (in $\mathrm{dB}$ ) as a function of frequency $(\mathrm{Hz})$. These may be referred to as audiograms (Stevens, 1951) or absolute auditory threshold curves (Licklider, 1951). This report will use the term audiogram.

Behavioral audiograms have been obtained by training marine mammals to respond to the perception of a tone with operant or Pavlovian conditioning techniques. Electrophysiological audiograms are obtained by a) monitoring evoked potentials to auditory stimuli; and b) measuring the cochlear microphonics at the round window of the cochlea.

The auditory capabilities of the following cetaceans have been behaviorally tested: Tursiops truncatus truncatus and Tursiops truncatus gilli, Phocoena phocoena, Delphinus delphis, Orcinus orca, Inia geoffrensis and Delphinapterus leucas. Data from these tests are presented in Table 1. Studies giving frequency and intensity thresholds are graphed in Figures 7 and 8.

The following pinnipeds have been behaviorally tested: Phoca vitulina, Pagophilus groenlandicus, Pusa hispida and Zalophus californianus. Data from these tests are presented in Table 2 and figures 9 and 10.

The following marine mammals have been tested using electrophysiological measurement techniques: Stenella coeruleoalba, Stenella attenuata, Steno 
bredanensis, Tursiops truncatus gilli, Tursiops truncatus truncatus, Lagenorhynchus obliquidens, Zalophus californianus, Phoca vitulina, and Halichoerus grypus. Auditory data are summarized for both pinnipeds and cetaceans in Table 3. Studies giving frequency and intensity thresholds are graphed in figure 11.

Behavioral Tests - Cetacea

Kellogg and Kohler (1952) made the first systematic observations of cetacean hearing by playing tones to a group of free-swimming captive Tursiops truncatus and Stenella plagiodon. No training techniques were used, and changes in the animals' natural swimming behavior at the onset of a tone were used as criteria for tone perception. Tones between $100 \mathrm{~Hz}$ and $200 \mathrm{kHz}$ were used to obtain a rough outline of the test subjects hearing range. No attempt was made to determine $d B$ intensity sensitivity thresholds. Tonal intensities were maintained at a minimum sound pressure level of 4.03 dynes $/ \mathrm{cm}^{2}$ at four meters (118 dB re $1 \mu \mathrm{Pa}$ ) (unless otherwise stated, all $\mathrm{dB}$ re $1 \mu \mathrm{Pasca}$ ). Behavioral differences were noted from $100 \mathrm{~Hz}$ to $50 \mathrm{kHz}$. Later tests on other Tursiops truncatus (Kellogg, 1953) at other locations indicated frequency responses from $100 \mathrm{~Hz}$ to $80 \mathrm{kHz}$.

Schevill and Lawrence (1953) tested the hearing range of a single free swimming captive Tursiops truncatus. The animal was tested at frequencies from $150 \mathrm{~Hz}-153 \mathrm{kHz}$, the upper limit of the equipment. Intensity levels were maintained between 100 and $110 \mathrm{~dB}$. The animal had been trained by operant conditioning to swim to a trainer for a fish reward if it perceived a tone. Responses were noted throughout the frequency band tested, from $150 \mathrm{~Hz}$ - $120 \mathrm{kHz} 50 \%$ of the time, at $130 \mathrm{kHz} 30 \%$ of the time, and from $151-153 \mathrm{kHz}$ $13 \%$ of the time.

Thirteen years later the first true audiogram giving frequency and intensity thresholds for a marine mammal was made by Johnson (1966) on a Tursiops truncatus. The test subject responded from $75 \mathrm{~Hz}-150 \mathrm{kHz}$. The single test subject was trained using standard operant conditioning techniques to respond to the presentation of a signal by pushing the appropriate 
manipulandum or remaining at station if no signal was presented or perceived. Frequency results were in close agreement with the earlier work of Schevill and Lawrence (1953). The maximum $d B$ intensity threshold was at $45 \mathrm{~dB}$ at 50 $\mathrm{kHz}$. The frequency band of high sensitivity was from $12-115 \mathrm{KHz}$. The frequency band of high sensitivity is defined as the frequency band where $d B$ intensity thresholds are within $10 \mathrm{~dB}$ of the frequency of maximum sensitivity. In this case, it is the frequency band with at least a $55 \mathrm{~dB}$ threshold. The $10 \mathrm{~dB}$ criterion is arbitrary. It is an approximation of the frequency bandwidth where the test subject has acute hearing. Below $50 \mathrm{kHz}$, the $\mathrm{dB}$ sensitivity gradually decreased to approximately $52 \mathrm{~dB}$ at $20 \mathrm{kHz}(6$ $\mathrm{dB} /$ octave). Below $15 \mathrm{kHz}$ sensitivity decreased by approximately $12 \mathrm{~dB} /$ octave to $1 \mathrm{kHz}$. Above $50 \mathrm{kHz}$ intensity thresholds decreased to $55 \mathrm{~dB}$ at $100 \mathrm{kHz}(10$ $\mathrm{dB} /$ octave) and then rapidly to $135 \mathrm{~dB}$ at $150 \mathrm{kHz}$, an approximate decrease in sensitivity of $700 \mathrm{~dB} /$ octave.

Ljungblad (pers. comm.) recently completed an audiogram for a single Pacific bottlenose dolphin (Tursiops truncatus gil1i). Frequencies from 1 $160 \mathrm{kHz}$ were tested. The animal responded from 2 - $135 \mathrm{kHz}$. Maximum sensitivities at $47 \mathrm{~dB}$ at $20 \mathrm{kHz}$ and $46 \mathrm{~dB}$ at $50 \mathrm{kHz}$ were recorded. Decibel intensity thresholds included $115 \mathrm{~dB}$ at $2 \mathrm{kHz}, 58 \mathrm{~dB}$ at $25 \mathrm{kHz}, 46 \mathrm{~dB}$ at 50 $\mathrm{kHz}, 74 \mathrm{~dB}$ at $100 \mathrm{kHz}$, and $118 \mathrm{~dB}$ at $135 \mathrm{kHz}$. Frequency and intensity thresholds and maximum sensitivities were slightly lower than the Atlantic bottlenose dolphin tested by Johnson (1966).

Cetacean psychophysics has also been studied in the Soviet Union. Golubkov, Ershova and Zhezherin (1969) reported that Tursiops truncatus responded to signals up to $500 \mathrm{kHz}$. Intensity sensitivities were not determined. Morozov, Akopian, Burdin, Donskov, Zaitseva and Sokovykh (1971) reported an audiogram for Tursiops truncatus from delivered frequencies of 5 $140 \mathrm{kHz}$. High sensitivity to pure tones was from $10-100 \mathrm{kHz}$, with maximum intensity threshold of $60 \mathrm{~dB}$ at $80 \mathrm{kHz}$. Sensitivity below $30 \mathrm{kHz}$ decreased by approximately $10 \mathrm{~dB} /$ octave and above $100 \mathrm{kHz}$ by $67 \mathrm{~dB} /$ octave. Note should be taken of the decreased intensity thresholds as compared to those of Johnson (1956).

An audiogram for Phocoena phocoena was reported by Andersen (1970). A single animal was tested from $1-150 \mathrm{kHz}$, the Tower and upper limits of the equipment. 
Responses were noted throughout those frequencies with maximum sensitivities found at approximately $45 \mathrm{~dB}$ at 8 and $32 \mathrm{kHz}$. High sensitivity was noted from 4 - $64 \mathrm{kHz}$. Below $4 \mathrm{kHz}$ the thresholds decreased to $85 \mathrm{~dB}$ at $1 \mathrm{kHz}$ (15 $\mathrm{dB} /$ octave). Above $40 \mathrm{kHz}$ thresholds decreased to $70 \mathrm{~dB}$ at $150 \mathrm{kHz}$ (15 $\mathrm{dB} /$ octave) and to at least $150 \mathrm{~dB}$ at $150 \mathrm{kHz}$ (700 dB/octave).

Sukhoruchenko (1973) used a respondent (Francis, 1975) or Pavlovian conditioning training technique. This was the only behavioral measurement technique not to use operant conditioning. Twenty Phocoena phocoena were preconditioned with a mild shock to the presentation of a tone. An electromyogram (EMG) was produced from skin-mounted electrodes monitoring the muscle twitch in the skin resulting from the shock. The shock was faded out of the experiment after the muscular action was conditioned to the tone. By monitoring the EMG to the onset of tones with varying frequency and intensities, an audiogram was obtained from 3 - $190 \mathrm{kHz}$. Maximum sensitivity was at $60 \mathrm{~dB}$ at $64 \mathrm{kHz}$. High sensitivity was from $10-90 \mathrm{kHz}$. The results reported are averages of the twenty test subjects.

The auditory studies of Delphinus delphis report only frequency thresholds (Bel'kovich and Solntseva, 1970). Correct responses to the signal were indicated by the animal swimming towards a lever and vocalizing. Four series of test frequencies were run. The first series contained frequencies from $660 \mathrm{~Hz}-206.6 \mathrm{kHz}$. Responses up to $119.2 \mathrm{kHz}$ were noted. Frequencies from 120 - $206 \mathrm{kHz}$ elicited a negative response (tail slaps and fast swimming). The authors reported this was due to the animal's dislike of the signal. They felt this warranted inclusion in the threshold report. The third series of tests were run from $16 \mathrm{~Hz}-3.73 \mathrm{kHz}$ and elicited responses in every case. In the final series, frequencies from 200 - $400 \mathrm{kHz}$ were used. Above $290 \mathrm{kHz}$ responses were inconsistent. The authors reported responses to frequencies as high as $320 \mathrm{kHz}$. They concluded that the auditory perception of Delphinus delphis ranges from $18 \mathrm{~Hz}-280 \mathrm{kHz}$. These tests were repeated on another animal with the same results.

In 1970 auditory threshold research on Orcinus orca was conducted by Hall and Johnson (1972) at Sea World of San Diego. The young male test subject responded from $500 \mathrm{~Hz}$, the lowest frequency presented, to $31 \mathrm{kHz}$. 
Maximum sensitivity was at $15 \mathrm{kHz} ; 30 \mathrm{~dB}$. High sensitivity was noted from 10 - $20 \mathrm{kHz}$. Below $15 \mathrm{kHz}$ thresholds decreased by approximately $10 \mathrm{~dB} /$ octave. Above $30 \mathrm{kHz}$ sensitivity decreased in an almost vertical manner.

Also in 1970, Jacobs and Hall (1972) obtained auditory thresholds for the Amazon River dolphin, Inia geoffrensis, using a test subject at Sea World. The animal responded to frequencies ranging from 1 , the minimum presented, to $105 \mathrm{kHz}$. According to the authors, the maximum sensitivity was between 75 and $90 \mathrm{kHz}$ at approximately $50 \mathrm{~dB}$; however, their graph indicates maximum sensitivity between $30-50 \mathrm{kHz}$ at $50 \mathrm{~dB}$. Below $30 \mathrm{kHz}$ the sensitivity decreased by approximately $10-15 \mathrm{~dB} /$ octave, from $60-100 \mathrm{kHz}$ sensitivity decreased by $55 \mathrm{~dB} /$ octave and above $100 \mathrm{kHz}$ by approximately $300 \mathrm{~dB} /$ octave.

A male and female Delphinapterus leucas were used to determine the auditory thresholds of the Beluga whale (White, Norris, Ljungblad, Baron, di Sciara, manuscript). The upper frequency threshold for the female was 123 $\mathrm{kHz}$, and for the male $120 \mathrm{kHz}$. Maximum sensitivity for both test subjects was at $30 \mathrm{kHz}, 36 \mathrm{~dB}$ for the female and $41 \mathrm{~dB}$ for the male. High sensitivity began at $20 \mathrm{kHz}$ for both animals, ending at $75 \mathrm{kHz}$ for the male and $85 \mathrm{kHz}$ for the female. The increase in sensitivity from $1 \mathrm{kHz}$ to $20 \mathrm{kHz}$ was $12-15$ $\mathrm{dB} /$ octave in both animals. The decrease in sensitivity at the upper threshold was $370 \mathrm{~dB} /$ octave for both whales. In the audiogram for the female there were three notches where sensitivity was $15-20 \mathrm{~dB}$ less than the adjoining frequencies. Thresholds at these notches were 57 to $54 \mathrm{~dB}$ at $25 \mathrm{kHz}, 50 \mathrm{kHz}$ and $100 \mathrm{kHz}$. The cause for these harmonically related notches is unknown.

\section{Behavioral Tests - Pinnipedia}

Audiograms for three phocid and one otariid seal have been determined behavioral7y. The common seal (Phoca vitulina) has a hearing range in water of $1-180 \mathrm{kHz}$ (Moh 1, 1968). These frequencies represent the undistorted range of the testing equipment. Maximum sensitivity occurred at $63 \mathrm{~dB}$ at 32 $\mathrm{kHz}$. Thresholds above $32 \mathrm{kHz}$ decreased by $60 \mathrm{~dB} /$ octave to $64 \mathrm{kHz}$ and by only $12 \mathrm{~dB} /$ octave from $90-180 \mathrm{kHz}$. Frequency thresholds with the test subject in air were from $1-22.5 \mathrm{kHz}$ with maximum sensitivity at $12 \mathrm{kHz}$ at $-85 \mathrm{~dB}$ (re 1 $u W / \mathrm{cm}$ ). 
For the harp seal (Pagophilus groenlandicus) (Terhune and Ronald, 1971; 1972) the aquatic audiogram was from $760 \mathrm{~Hz}-100 \mathrm{kHz}$. Maximum sensitivities were at $68 \mathrm{~dB}$ at $2 \mathrm{kHz}$ and $63 \mathrm{~dB}$ zt $22.9 \mathrm{kHz}$. Frequencies were tested in $1 / 2$ octave steps. In-air responses were obtained from 1 - $50 \mathrm{kHz}$. Maximum sensitivity was at $5 \mathrm{kHz}$ at $-57 \mathrm{~dB}(\mathrm{re} 1 \mathrm{uW} / \mathrm{cm})$. If expressed as power units (rather than intensity units) the water audiograms are comparable to sensitivities noted for terrestrial mammals. The intensity threshold of air audiograms was generally 10 - $30 \mathrm{~dB}$ less than the water audiograms when comparing like dB units.

Male and female test subjects were used to determine the auditory threshold of Pusa hispida (Terhune and Ronald, 1975). Test frequencies from 1-90 kHz were used with the upper and lower frequency limits fixed by the equipment. Both test subjects responded throughout the test band. The female test subject had slightly more acute hearing than the male. However, the male had relatively better hearing at higher frequencies than the female. Maximum sensitivity for the female was at 11 and $16 \mathrm{kHz}$ at $68 \mathrm{~dB}$ with a high sensitivity from $8-22.9 \mathrm{kHz}$. Maximum sensitivity for the male was at $44.9 \mathrm{kHz}$ with high sensitivity from $4-44.9 \mathrm{kHz}$.

Schusterman, Balliet and Nixon (1972) tested Zalophus californianus at frequencies from $250 \mathrm{~Hz}-64 \mathrm{kHz}$. The upper frequency threshold was considered to be between 36 and $48 \mathrm{kHz}$. Maximum sensitivity was approximately $79 \mathrm{~dB}$ at $16 \mathrm{kHz}$. Above $18 \mathrm{kHz}$ sensitivity decreased at $60 \mathrm{~dB} /$ octave to $36 \mathrm{kHz}$ and by $14 \mathrm{~dB} /$ octave to $64 \mathrm{kHz}$. Responses were noted to frequencies as high as $192 \mathrm{kHz}$ with intensities at approximately $138 \mathrm{~dB}$. The authors maintain that at levels above $48 \mathrm{kHz}$ the animals were responding to pressure conducted through the skul1, whereas at lower frequency conventional (ossicular chain conduction) hearing was used.

\section{Electrophysiological Tests}

Electrophysiological audiograms have been obtained in two ways: a) evoked potentials from deep cortical probes (Bullock, Grinnel, Ikezono, Kameda, Katsuki, Nomoto, Seto, Suga and Yanagisawa, 1968; Bullock and Ridgway, 1972; Bullock, Ridgway and Suga, 1971; and Ridgway and Joyce, 1975); or from electrodes mounted to the sku11, with an artifact inhibiting system to monitor EEG (Seeley, Ridgway and Flanigan, 1976); b) and cochlear microphonics (McCormick, 1968). 


\section{Cetacea}

Bullock et al. (1968) played frequencies from $5-150 \mathrm{kHz}$ to 29 anesthesized test animals, including Stenella coeruleoalba, $\underline{\text { s. attenuata, }}$ Steno bredanensis and Tursiops gilli. Interspecific sensitivities were not significantly different and were in close agreement with the behavioral audiograms for Tursiops of Johnson (1966) and Ljungblad (Pers. comm.). Auditory evoked potentials were noted from $5 \mathrm{kHz}$ to $120-140 \mathrm{kHz}$. Maximum sensitivities were $35 \mathrm{~dB}$ at $60 \mathrm{kHz}$. High sensitivities were noted from 20 $80 \mathrm{kHz}$. Sensitivity decreased by approximately $100 \mathrm{~dB} /$ octave above $100 \mathrm{kHz}$. In 1972 these tests were repeated on alert Tursiops truncatus (Bullock and Ridgway, 1972). Responses to $120 \mathrm{kHz}$ were noted. Maximum sensitivities were from $40-60 \mathrm{kHz}$. The intensity at maximum sensitivities was approximately 60 $\mathrm{dB}$ greater than at $10 \mathrm{kHz}$ where the evoked potentials were barely determinable.

Seeley, Ridgway and Flanigan (1976) tested seven alert Tursiops truncatus at frequencies between $5-200 \mathrm{kHz}$. Probes were mounted to the skulls of alert animals and using a special artifact inhibiting system an audiogram was obtained. Thresholds were obtained throughout the test frequencies. Maximum sensitivities were around $70 \mathrm{kHz}$ at $54 \mathrm{~dB}$ for the most sensitive animal.

An electrophysiological audiogram was completed at the Naval Ocean Systems Center on the same Tursiops truncatus gi1li used by Ljungblad for a behavioral audiogram. The results of the two auditory threshold measurement techniques for this cetacean were within $10 \mathrm{kHz}$.

Using a cochlear microphonics technique on Lagenorhynchus obliquidens and Tursiops truncatus, McCormick (1968) obtained several audiograms. In this measurement technique an electrode mounted to the round window of the cochlea monitors electrical potentials produced by firings of the hair cells. By changing the frequency and intensity of tones played to the test subject audiograms are obtained. McCormick tested auditory thresholds for signals transmitted to the cochlea by bone and ossicular chain conduction. Tests were done with the test subject in air and underwater. Five audiograms were produced. The air audiograms using bone conduction were more variable than those taken underwater where marked notches were noted, particularly at 10 
$\mathrm{kHz}$. In the test, tones up to $250 \mathrm{kHz}$ were played to a Tursiops truncatus; results above $100 \mathrm{kHz}$ were not given by the author. With LC-10 hydrophone used as a sound source, underwater responses were noted as high as $200 \mathrm{kHz}$ in a Tursiops truncatus. In a similar test the upper threshold was $100 \mathrm{kHz}$ with another Tursiops. Since the $d B$ intensity reference was in terms of the $d B$ loss relative to the highest cochlear potential measured with each animal, absolute $d B$ intensity thresholds were not obtained. Thus, only the upper frequency thresholds and the comparative slope of the intensity thresholds are available. This last term refers to a comparison of their audiogram with that of Johnson's (1.966) Tursiops behavioral audiogram (Figure 12). A comparison of the relative intensity thresholds can be made, and in this case the increase in sensitivity of the cochlear microphonics audiogram is similar to that of the behavioral tests.

\section{Pinnipedia}

Using deep cortical probes on both alert and anesthetized animals, Bullock, Ridgway and Suga (1971) obtained audiograms from two Zalophus californianus and one Phoca vitulina. All results were from subjects tested in the air; the results from both species were similar. Evoked potentials were recorded in the harbor seal from $400 \mathrm{~Hz}-20 \mathrm{kHz}$, with maximum sensitivity of $54 \mathrm{~dB}$ at $4 \mathrm{kHz}$. In one sea lion potentials were recorded from $500 \mathrm{~Hz}-35 \mathrm{kHz}$ and in the other from $500 \mathrm{~Hz}-20 \mathrm{kHz}$. Maximum sensitivity for both was from $4-8 \mathrm{kHz}$, with a maximum sensitivity threshold of $52 \mathrm{~dB}$. The results for $Z$ alophus were in close agreement with those of Schusterman (1972); however, results for Phoca differed significantly from those of Mohl (1968) and Terhune $(1972 ; 1975)$.

Using deep cortical probes on six gray seals (Halichoerchus grypus) audiograms were obtained for hearing both in and out of the water (Ridgway and Joyce, 1975). The animals were not restrained and the EEG signals were transmitted by radio from the animals. Responses were noted from the lowest used frequency of $1 \mathrm{kHz}$ to $150 \mathrm{kHz}$ in water and from $200 \mathrm{~Hz}-30 \mathrm{kHz}$ in air. Maximum sensitivity in water was $60 \mathrm{~dB}$ at $30 \mathrm{kHz}$ and in air $70 \mathrm{~dB}$ at $5 \mathrm{kHz}$. 
The cetaceans appear to have a 20-30 dB superiority over the pinnipeds in their respective regions of greatest sensitivity, and except for the killer whale, their audition extends one to two octaves beyond that of the pinnipeds.

\section{Sound Production of Marine Mammals}

Although little information is currently available on the sounds perceived by large whales, it is generally assumed that most animals can hear sounds similar to those that they produce. A major portion of the regions of peak sensitivity fits well the animals' own signal characteristics (Diercks, Trochta and Evans, 1973). These similarities correlate with those noted for some species of fish and other animals for which similar data are available. Marine mammals have a broad repertoire of sounds, the echolocation pulses of the dolphin being the best documented. The high-frequency character of the echolocation clicks is reflected in the high-frequency sensitivity of these animals.

Caution should be exercised in limiting the received bandwidth of sounds based solely on those that a large whale produces. Tables 4 and 5 summarize source level data for cetaceans with corresponding peak frequency bands or sound characters. These values are typically based on peak energy levels in relatively narrow bandwidths.

Broadband ( $1 \mathrm{kHz}-40 \mathrm{kHz}$ ) recordings for four species of toothed whales were presented by Fish and Tur 1 (1976). These included the northern right whale dolphin, Lissodelphis borealis; the Pacific bottlenose dolphin, Tursiops truncatus; the Pacific pilot whale, Globicephala macrorhynchus; and the common dolphin, Delphinus delphis. The data for these species showed that source levels were not confined to narrow bandwidths, as presented in Tables 4 and 5 , but can cover a broad frequency range.

Thompson, Winn and Perkins (1979) classified mysticete sounds into four groups. Group I includes low frequency moans from 0.4 to 36 seconds long, with the fundamental frequencies from 12 to $500 \mathrm{~Hz}$. Moans may contain strong harmonic structures or pure tones. All but the sei whale, Balaenoptera borealis, and the minke whale, Balaenoptera acutorostrata, are known to make these sounds. Group II includes grunt-1ike thumps and knocks of short 
duration. The humpback whale, Megaptera novaeangliae, the southern right whale, Eubalaena glacialis australis, the northern right whale, Eubalaena glacialis glacialis, the bowhead whale, Balaena mysticetus, the gray whale, Eschrichtius robustus, the fin whale, Balaenoptera physalus, and the minke whale, Balaenoptera acutorostrata, are known to produce these sounds, which range in duration from 50 to $500 \mathrm{msec}$ with major energy between 40 and 200 $\mathrm{Hz}$. Group III contains chirps, cries and whistles at frequencies above 1.0 $\mathrm{kHz}$. Chirps are generally pulses producing short (50 to $100 \mathrm{msec}$ ) discrete tones which change frequency rapidly and are not harmonically related, whereas cries and whistles are pure tones with or without harmonics. Group IV sounds are clicks or pulses which generally last from 0.5 to $5 \mathrm{msec}$ with peak energy between 20 to $30 \mathrm{~Hz}$.

Ljungblad, Leatherwood and Dahlheim (1979) recorded two types of sounds from bowhead whales (Balaena mysticetus): a short $(0.35-0.85 \mathrm{sec}$ ) sound and a longer $(0.65-2.56 \mathrm{sec})$ sound, with fundamental frequencies of $50-580 \mathrm{~Hz}$ and 100-195 Hz, respectively. 
Noise from offshore oil and gas drilling activities cover a broad frequency range ( $10 \mathrm{~Hz}$ to $10 \mathrm{kHz}$ ), and average source levels range from 130 to $180 \mathrm{~dB}$ re $1 \mathrm{~m} \mathrm{PA}$ a $1 \mathrm{~m}$. Depending on the frequency band where these levels appear in the spectrum, signal-to-noise ratios may approach 80 to $100 \mathrm{~dB}$. The ambient noise level would be 80 to $100 \mathrm{~dB}$ higher than that measured in an area if the source were not operating. For example, a signal-to-noise ratio of 100 $\mathrm{dB}$ would not be completely attentuated until it reaches a point of almost 50 NM from the source.

Underwater hearing thresholds for marine mammals of "pure tones" in low background noise environments show that the lower and upper limits are comparable. The areas of maximum sensitivity, however, are quite variable possibly due to the acoustic environment in which they were sampled and due to individual species sensitivity.

It should be noted that the lower limits do not extend below $1.0 \mathrm{kHz}$, but in most cases sounds below $1 \mathrm{kHz}$ were not used. This is possibly due to the difficulty of projecting low frequency pure tones at levels above ambient noise without distortion, the effects of standing waves, or interference due to near field effects. The upper hearing limits for the recorded cetaceans are between 75 and $150 \mathrm{kHz}$ with the exception of the killer whale, whose upper hearing limit was measured around $30 \mathrm{kHz}$. The upper limit of aquatic hearing for the recorded pinnipeds are between 30 and $50 \mathrm{kHz}$. 


\section{ACKNOWLEDGEMENT:}

Parts of this literature review were based on a report by Norris and White (1978) of Hubbs/Sea World Research Institute prepared for and submitted to the Naval Ocean Systems Center, San Diego, California. 
Andersen, S. (1970). Auditory sensitivity of the harbour porpoise, Phocoena phocoena. In: G. Pillerie (ed.) Invest. on Cetacea. Berne, Switzerland. Vol. 2, 255-258.

Au, W.W.L., R.W. Floyd, R.H.Penner, and A.E. Murchison (1974). Measurements of echolocation signals of the bottlenose dolphin, Tursiops truncatus, in open waters. J. Acous. Soc. Amer. 56: 1280-1290.

Beamish, P. and E. Mitchel1 (1971). U1trasonic sounds recorded in the presence of a blue wha7e, Balaenoptera musculus, Deep-Sea. Res., 18: 803-809.

Beamish, P. and E. Mitchel1 (1973). Short pulse length audio sounds recorded in the presence of a minke whale, Balaenoptera acutorostrata. Deep-Sea Res. and Ocean. Abst. 20: 375-386.

Bel'kovich, U.M. and G.N. Solntseva (1970). Anatomy and function of the ear in dolphins. Zoolog. Zh. (Russian) No. 2, 275-282. (J.P.R.S. 50253, 7 Apri1 1970, 9 pp.

Bullock, T.H., A.D. Grinnel, E. Ikezono, K. Kameda, Y. Katsuki, M. Nomoto, 0. Seto, N. Suga, and K. Yanagisawa (1968). Electrophysiological studies of central auditory mechanisms in cetaceans. Z. Verg7. Physiol. 59: 117-156.

Bullock, T.H., S. H. Ridgway and N. Suga (1971). Acoustically evoked potentials in midbrain auditory structures in sea lions (Pinnipedia). Z. Verg1. Physiol. 74: 372-387.

Bullock, T.H. and S.H. Ridgway (1972). Evoked potentials in the central auditory system of alert porpoises to their own and artificial sounds. J. Neurobiology 3 : 79-99.

Busnel, R.G. (1978). Introduction. In: Effects of Noise on Wildlife, J.L. Fletcher and R.G. Busnel (eds)., Academic Press: 1-5.

Corcel1a, A.T. and M. Green (1968). Investigations of impulsive deep-sea noise resembling sounds produced by a whale. J. Acous. Soc. Amer. 44: 483-487.

Cummings, W.C. and P.0. Thompson (1971). Underwater sounds from the Blue Whale, Balaenoptera musculus. J. Acous. Soc. Amer. 50: 1193-1198.

Cummings, W.C. and J.F. Fish and P.0. Thompson (1972). Sound production and other behavior of southern Right Whales, Eubalaena glacialis. Trans. San Diego Soc. Nat?. His. 17: 1-13. 
Cummings, W.C., P.O. Thompson and R. Cook (1968). Underwater sounds of migrating gray whales, Eschrichtius glaucus (Cope). J. Acous. Soc. Amer. 44: 1278-1281.

Diercks, K. J., T. Trochta, and W. E. Evans (1973). Delphinid sonar: measurements and analysis. J. Acous. Soc. Amer. 54: 200-204.

Drouin, A.H. (1974). Design and field operations of an underwater acoustic telemetry system. 6th Ann. Offshore Tech. Conf. OTC 1965: 9 pp.

Dudok van Hee1, W.H. (1962). Sound and cetacea, Neth. J. Sea Res., $\underline{1}(4)$ : 407-507.

Dunn, J. L. (1969). Airborne measurements of the acoustic characteristics of a sperm whale. J. Acous. Soc. Amer. 46: 1052-1054.

Evans, W.E. (1976). Personal communications.

Fish, J.F. and C.W. Turl (1976). Acoustic source levels of four species of small whales. Naval Undersea Center, NUC TP 547: $1.4 \mathrm{pp}$.

Fleischer, G. (1976). Hearing in extinct cetaceans as determined by cochlear structure. J. Paleontal. 50(1): 133-152.

Ford, J. (1977). White whale offshore exploration acoustic study. Report submitted to Imperial 0 il Co., F. F. Glaney \& Co., Ltd. Vancouver, Canada: $21 \mathrm{pp}$.

Francis, R.L. (1975). Behavioral audiometry in mammals: Review and evaluation of techniques. Symp. Zool. Soc. Lond. 37: 237-239.

Fraser, F.C. and P.E. Purves (1960). Hearing in cetaceans. Bull. of the Brit. Mus. 7: 1-140.

Golubkov, A.G., I.V. Ershova and A.P. Zhezherin (1969). Methods and equipment processing dolphin sounds. Proceedings of Leningrad Institute of Aircraft Gear Construction, [eningrad (Russian) 64: 133-140.

Hall, J.D. and C.S. Johnson (1971). Auditory threshold of a killer whale, Orcinus orca. J. Acous. Soc. Amer. 41(1): 515-517.

Hal1, J.D. and C.S. Johnson (1972). Auditory thresholds of a killer whale Orcinus orca Linnaeus. J. Acoust. Soc. Amer. 51: 2 (Part 2).

Jacobs, D.W. and J.D. Hal1 (1972). Auditory thresholds of a freshwater dolphin, Inia geoffrensis Blainville. J. Acoust. Soc. Amer. 51: 2 (Part 2).

Johnson, C.S. (1966). Auditory thresholds in the bottlenose porpoise Tursiops truncatus Montagu, U.S.N. Ordnance Test Station (NOTS) TP 4178, 22 p. 
Kellog, W.N. (1953). Ultrasonic hearing in the porpoise. J. Comp. Physiol. Psychol. 44: 445-450.

Kellogg, W.N. and R. Kohler (1952). Reactions of the porpoise to ultrasonic frequencies. Science 116: 250-252.

Kramer, S.A. and T.E. Wing (1976). APEX Final Report (U). Bell Laboratories.

Levenson, C. (1972). Characteristics of sounds produced by humpback whales (Megaptera novaeangliae). NAVOCEAN TECH. NOTE NO. 7700-6-72: 1-10.

Levenson, C. (1074). Source level and bistatic target strength of the sperm whale (Physeter catodon) measured from an oceanographic aircraft. Acous. Soc. Amer. 55: 1100-1103.

Licklider, J.C.R. (1951). Basic correlates of the auditory stimulus. In: Steven, S.S. (ed.) Handbook of Experimental Psychology. New York, wiley, $985-1039$.

Ljungblad, D.K., S. Leatherwood, and M.E. Dahlheim (1979). Sounds recorded in the presence of an adult and calf bowhead whale, Balaena mysticetus. Naval Ocean Systems Center, NOSC TR 420, 1-7.

Malme, C.I. and R.M. Lawski (1979). Measurements of underwater acoustic noise in the Prudhoe Bay area. Bolt, Beranek \& Newman, Inc., Tech. Memo. No. 513: $16 \mathrm{pp}$.

McBride, A. F. (1956). Evidence for echolocation by cetaceans. Deep-Sea Research 3: $153-154$.

McCormick, J.G. (1968). Theory of hearing for delphinids. Doctoral Dissertation, Princeton University.

McCormic, J.G., E.g. Wever, J. Palin, and S.H. Ridgway (1970). Sound conduction in the do?phin ear. J. Acous. Soc. Amer. 48(6): 1418-1428.

Moh 1, B. (1968). Auditory sensitivity of the common seal in air and water. J. Auditory Res. 8: 27-38.

Moh1, B. and S. Andersen (1973). Echolocation: High-frequency components in the click of the harbour porpoise (Phocoena ph. L). J. Acous. Soc. Amer. 54: 1368-1372.

Morgane, J.P. and N.S. Jacobs (1972). Comparative anatomy of the cetacean nervous system. In Functional Anatomy of Marine Mammals, Vol. I. R. J. Harrison (ed). Academic Press: 117-244.

Morozov, V.P., A.I. Akopian, V.I. Burdin, A.A. Donskov, K.A. Zaitseva and Yu. A. Sokovykh (1971). Audiogram of the dolphin Tursiops truncatus (Russian). Sechenov Physiological Journal of USSR 6: 843-848.

Myrberg, A.A. (1978). Ocean noise and the behavior of marine animals: Relationships and implications. In : Effects of Noise on Wi?dlife. J.L. Fletcher and R.G. Busnel (eds). Academic Press: 168-208. 
Norris, K.S. (1969). The echolocation of marine mammals. In The Biology of Marine Mammals, H.T. Harrison (ed). Acad. Press: 391-4 $\overline{23}$.

Norris, K.S. and R.R. Reeves (eds) (1978). Report on a workshop on problems related to humpback whales (Megaptera novaeangliae) in Hawaii. U.S. Dept. Comm., NTIS PB-280-794: $90 \mathrm{pp}$.

Norris, J. and M.J. White (1978). Review of marine mammal auditory threshold literature. Submitted to the Naval Ocean Systems Center by Hubbs/Sea World Research Iristitute, H/SWRJ TR 78-112.

Patterson, B. and G.R. Hamilton (1964). Repetitive 20 cycle per second biological hydrostatic signals at Bermuda. In: Marine Bio-Acoustics, W.N. Tavolga (ed). Pergamon Press: 125-145.

Purves, P.E. (1966). Anatomy and physiology of the outer and middle ear in cetacean. In: Whales, dolphins and porpoise, K.S. Norris (ed). Univ. Calif. Press.: $320-380$.

Reppening, C.A. (1972). Underwater hearing in seals. In Functional anatomy of marine mammals. R. J. Harrison (ed). Acad. Press: 307-331.

Reysenbach de Haan, F.W. (1957). Hearing in whales. Acta Otolaryngol 134: 1-114.

Ridgway, S.H. and P.L. Joyce (1975). Studies on seal brain by radio-telemetry. Rapp. P.-v. Re'un. cons. int. Exp T. Mer. 169: 81-91.

Schevi11, W.E. and B. Lawrence (1953). Auditory response of a bottlenose porpoise, Tursiops truncatus, to frequencies above $100 \mathrm{Kc}$. J. Expl. Z001. 124: 147-165.

Schevill, W.E. and W.A. Watkins (1966). Sound structure and directionality in Orcinus (Killer whale). Zoologica 51: 71-76.

Schevi11, W.E. and W.A. Watkins (1971). Pulsed sounds of the porpoise, Lagenorhynchus australis, Brevoria 366: 1-10.

Schevill, W.E., W.A. Watkins and R.H. Backus (1964). The 20-cycle signals and Balaenoptera (fin whales). In: Marine Bio-Acoustics, W.N. Tavloga (ed)., Pergamon Press: 147-157.

Schevil1, W.E., W.A. Watkins and C. Ray (1969). Click structure in the porpoise, Phocoena phocoena. J. Mamm. 50: 721-728.

Schusterman, R.J., R.F. Balliet and J. Nixon (1972). Underwater audiogram of the California sea lion by the conditioned vocalization technique. J. Experimental Analysis of Behavior 17: 339-350.

Seeley, R.L., W.F. Flanigan, Jr., and S.H. Ridgway (1976). A technique for rapidly assessing the hearing of the bottlenose porpoise, Tursiops truncatus. Naval Undersea Center, NUC TP 552. 
Stevens, E.E. (1951). Mathematics, measurement and psychophysics. In: Handbook of Experimental Psychology, Stevens, S.S. (ed.), New York, Wiley, 1-49.

Sukhoruchenko, M.N. (1973). Frequency discrimination in dolphins (Phocoena phocoena) (Russian). Sechenov Physiological Journal of USSR 9(8): 1205-1210.

Terhune, J.M. and K. Ronald (1971). The Harp Seal, Pagophilus groenlandicus (Erxleben, 1777). X. The Air Audiogram. Canadian J. of Zool. 49: 385-390.

Terhune, J.M. and K. Ronald (1072). The Harp Seal, Pagophilus groenlandicus (Erxieben, 1777). III. The Underwater Audiogram. Canadian J. of Z001. 50: $565-569$.

Terhune, J.M. and K. Ronald (1975). Underwater hearing sensitivity of two Ringed Seals (Pusa hispida). Can. J. Zool. 53: 227-231.

Thompson, T.J., H.E. Winn and P.J. Perkins (1979). Mysticete sounds. In: Behavior of marine animals. Vol. 3. Cetaceans. H.E. Winn and B.L. 0ाTa (eds). Plenum Press: 403-43I.

Underwater Systems, Inc. (1073). Noise measurements from offshore oil rigs. Under. Sys. Inc. Note 312-5: $15 \mathrm{pp}$.

Urick, R.J. (1967). Principles of Underwater Sounds. McGraw-Hill Book Co., $384 \mathrm{pp}$.

Watkins, W.A. and W.E. Schevill (1974). Listening to Hawaiian spinner porpoises, Stenella cf. longirostris, with a three-dimensional hydrophone array. J. Mamm. 55: 319-328.

Wever, E.G., J.G. McCormick, J. Palin, and S.H. Ridgway (1971). The cochlea of the dolphin, Tursiops truncatus: general morphology. Proc. Nat. Acad. Sci., $68(10): 2382-2385$.

White, M.J., J.C. Norris, D.K. Ljungblad, K.S. Baron, and G.N. DeSciara. 1078. Auditory thresholds of two beluga whales (Delphinapterus leucas). Manuscript. 


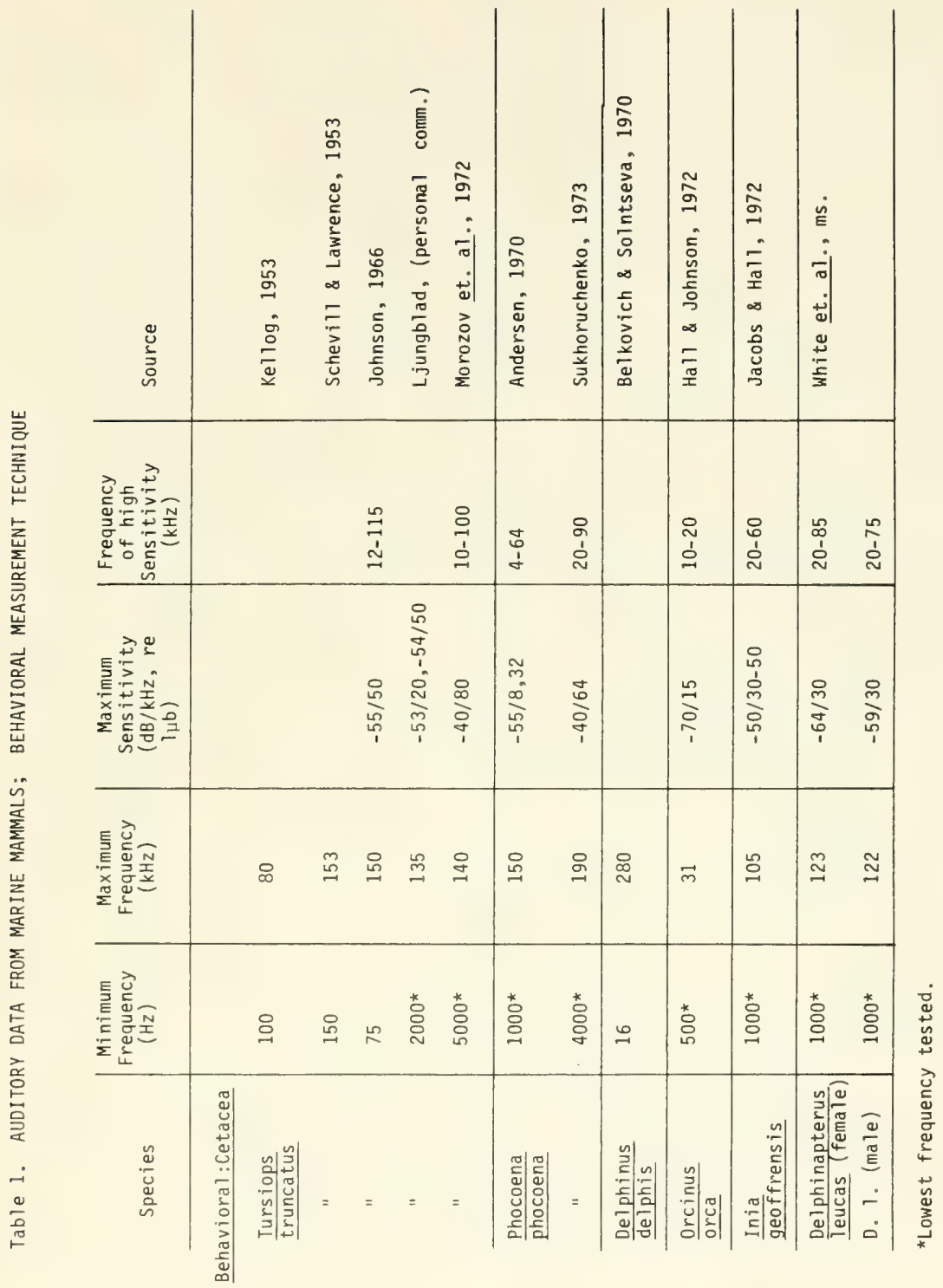




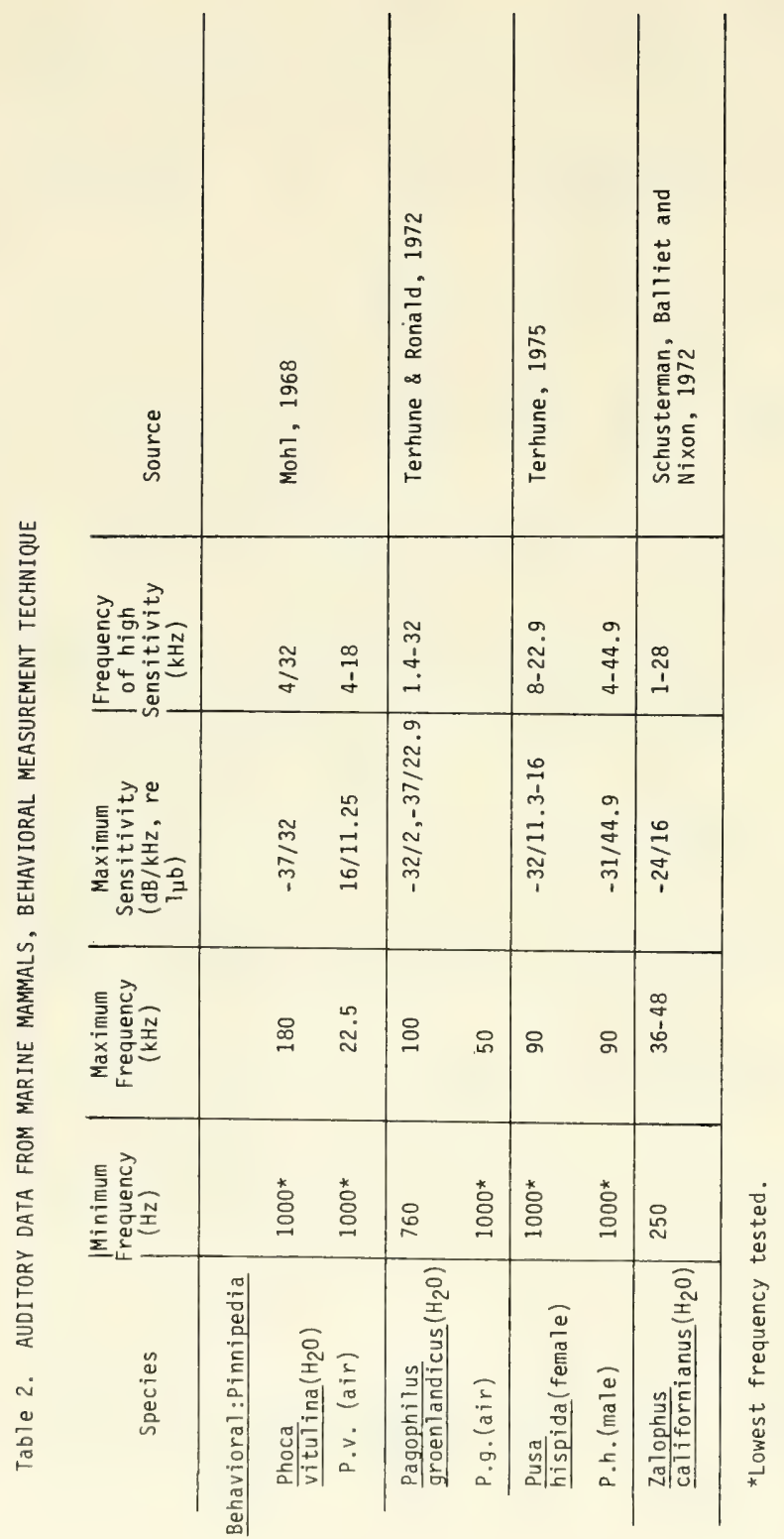




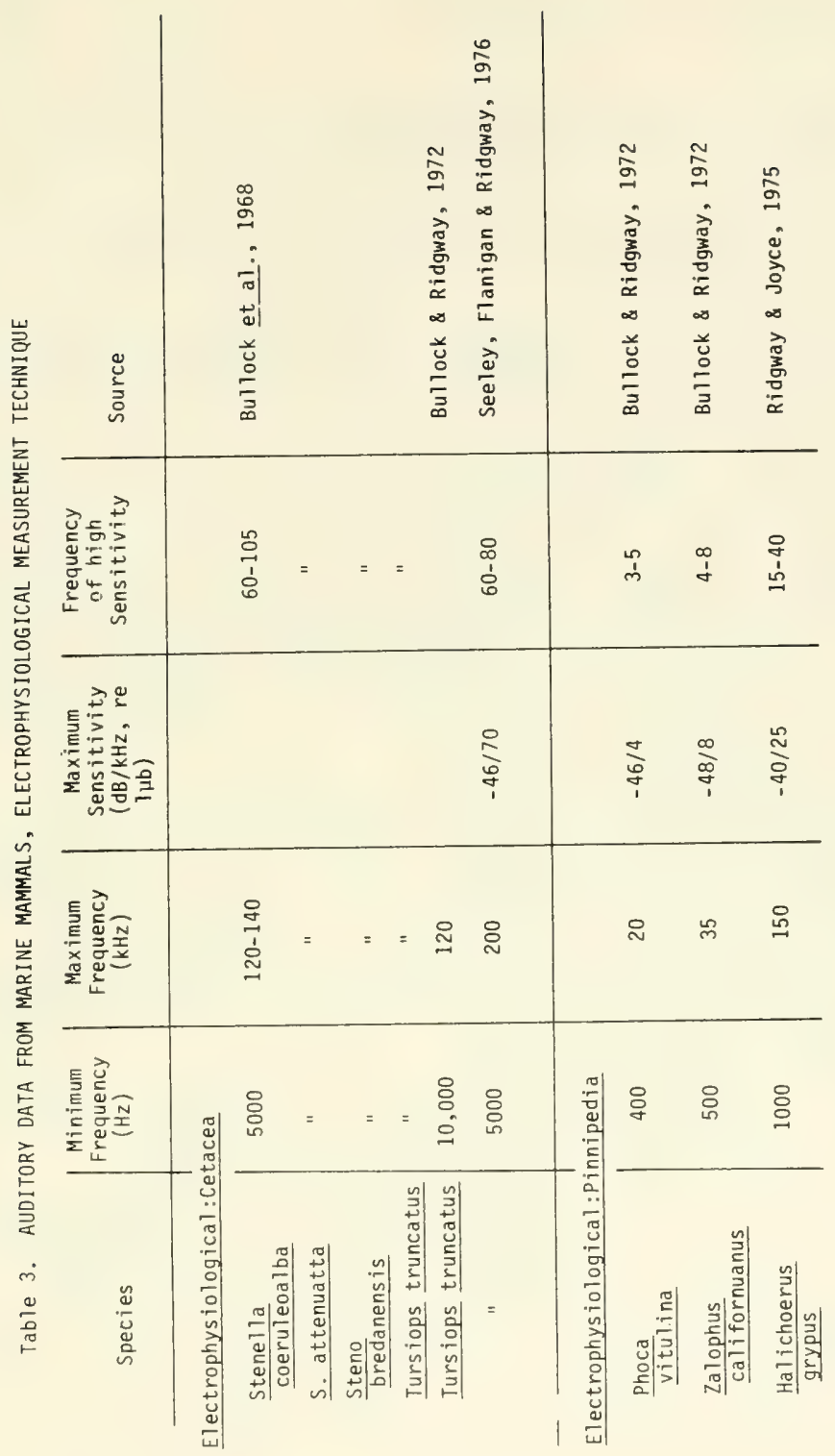


Table 4. Summary of source level data for odontocete

(From Fish and Turl, 1976)

\begin{tabular}{|c|c|c|c|}
\hline Species & $\begin{array}{l}\text { Source Level } \\
\text { (dB, re } 1 \text { upa at } 1\end{array}$ & Comments & Reference \\
\hline Tursiops truncatus & $\begin{array}{c}217-228 \\
175\end{array}$ & $\begin{array}{l}\text { Broadband peak-to-peak } \\
\text { of clicks. }\end{array}$ & $\begin{array}{l}\text { Au, Floyd, Penner } \\
\text { and Murchison (1979) } \\
\text { Evans (1976) }\end{array}$ \\
\hline$\frac{\text { Lagenorhynchus }}{\text { australis }}$ & 80 & $\begin{array}{l}\text { Broadband RMS level of } \\
\text { clicks. }\end{array}$ & $\begin{array}{l}\text { Schevill and Watkins } \\
\text { (1976) }\end{array}$ \\
\hline Orcinus orca & 160 & $\begin{array}{l}\text { Broadband RMS levels of } \\
\text { screams (click trains) }\end{array}$ & $\begin{array}{l}\text { Watkins and Schevill } \\
(1966)\end{array}$ \\
\hline$\frac{\text { Stenella }}{\text { longirostris }}$ & $\begin{array}{c}108-115 \\
109-125 \\
85-95\end{array}$ & $\begin{array}{l}\text { Broadband RMS levels of } \\
\text { pulse bursts } \\
\text { "squeals" } \\
\text { clicks }\end{array}$ & $\begin{array}{l}\text { Watkins and Schevill } \\
\text { (1974) }\end{array}$ \\
\hline Inia geoffrensis & 165 & $\begin{array}{l}\text { Broadb and peak-to-peak } \\
\text { levels of clicks. }\end{array}$ & Evans (1976) \\
\hline Phocoena phocoena & $\begin{array}{l}100 \\
140 \\
(132-149)\end{array}$ & $\begin{array}{l}\text { Broadband RMS level of } \\
\text { clicks. } \\
\text { Mean and range of peak } \\
\text { broadband level of } \\
\text { clicks. }\end{array}$ & $\begin{array}{l}\text { Schevil1, Watkins } \\
\text { and Ray (1969) } \\
\text { Mohl and Anderson } \\
(1973)\end{array}$ \\
\hline Physeter catodon & $\begin{array}{c}135 \\
173.5 \\
171.2 \\
(165.5-175.3)\end{array}$ & $\begin{array}{l}\text { Peak broadband level } \\
\text { of pulses. Thought to } \\
\text { be P. catodon. } \\
\text { Mean } 1 \frac{13-\text { octave leve }}{13} \\
\text { of cl icks at } 1 \mathrm{kHz} \text {. } \\
\text { Mean and range of } \\
\text { broadband level of } \\
\text { clicks. }\end{array}$ & $\begin{array}{l}\text { Corcella and Green } \\
\text { (1968) } \\
\text { Dunn (1969) } \\
\text { Levenson (1974) }\end{array}$ \\
\hline
\end{tabular}


Table 5. Sumary of source level data for mysticetes

(From Fish and Turl, 1976)

\begin{tabular}{|c|c|c|c|}
\hline Species & $\begin{array}{l}\text { Source Level } \\
\text { re } 1 \text { uPa at } 1\end{array}$ & Comments & Ref erence \\
\hline Megaptera novaeangliae & \begin{tabular}{c|}
138.6 \\
148.6 \\
155.4 \\
$(144.3-174.4)$
\end{tabular} & $\begin{array}{l}\text { Mean } 1 / 3 \text {-octave level } \\
\text { at } 5 \mathrm{kHz} \text {. } \\
\text { Mean } 1 / 3 \text {-octave level } \\
\text { at } 1 \mathrm{kHz} \\
\text { Mean and range of } \\
\text { broadband levels of } \\
\text { various types of signals }\end{array}$ & Levenson (1972) \\
\hline$\frac{\text { Eubalaena }}{\text { glacialis }}$ & $172-187$ & $\begin{array}{l}\text { Levels in the } 25-2500 \\
\mathrm{~Hz} \text { band for "belch-like" } \\
\text { sounds. }\end{array}$ & $\begin{array}{l}\text { Curmings, Fish and } \\
\text { Thompson (1972) }\end{array}$ \\
\hline Eschrichtius glaucus & $138-152$ & $\begin{array}{l}\text { Mean broadband levels } \\
\text { for several different } \\
\text { types of low-frequency } \\
\text { signals. } \\
\text { Highest level measured. }\end{array}$ & $\begin{array}{l}\text { Cummings, Thompson } \\
\text { and Cook (1968) }\end{array}$ \\
\hline$\frac{\text { Balaenoptera }}{\underline{\text { musculus }}}$ & $\begin{array}{l}159.2 \\
188\end{array}$ & $\begin{array}{l}\text { Maximum broadband level } \\
\text { of clicks. } \\
\text { Mean level of moans in } \\
\text { a } 14-222 \mathrm{~Hz} \text { band }\end{array}$ & $\begin{array}{l}\text { Beamish and Mitchel1 } \\
\text { (1971) } \\
\text { Cummings and } \\
\text { Thompson (1971) }\end{array}$ \\
\hline$\frac{\text { Balaenoptera }}{\text { physalus }}$ & $173-181$ & $\begin{array}{l}\text { Source level for } 20 \mathrm{~Hz} \\
\text { pulses. } \\
\text { Source level of } 20 \mathrm{~Hz} \\
\text { pulses thought to be } \\
\text { from } \mathrm{B} \text {. Physalus, based } \\
\text { on source level calcu- } \\
\text { lations as cited by } \\
\text { Norris and Reeves (1978). }\end{array}$ & $\begin{array}{l}\text { Patterson and } \\
\text { Hamilton (1964) } \\
\text { Schevill, Watkins, } \\
\text { and Backus (1964) }\end{array}$ \\
\hline$\frac{\text { Bal aenoptera }}{\text { acutorostrata }}$ & 152.6 & $\begin{array}{l}\text { Maximum broadband level } \\
\text { clicks. }\end{array}$ & $\begin{array}{l}\text { Beamish and Mitchell } \\
\text { (1973) }\end{array}$ \\
\hline
\end{tabular}



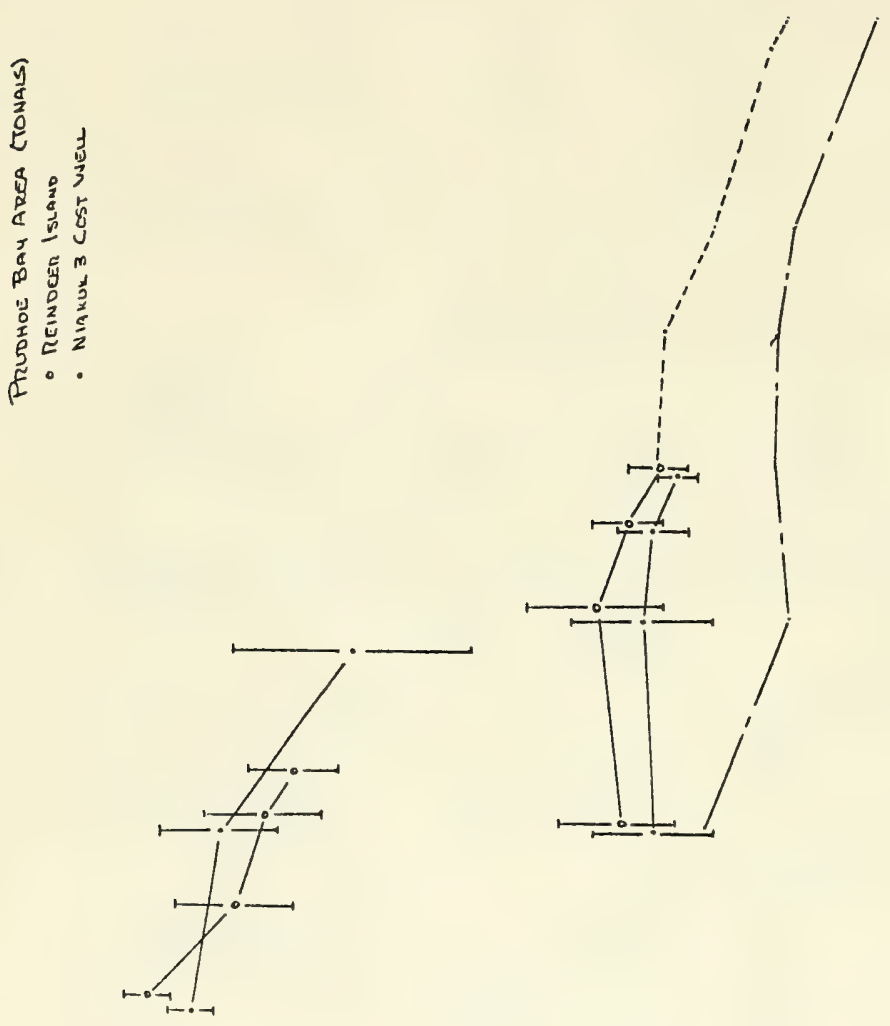

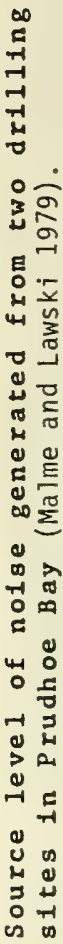

$+$

0
5
0
0
1
1

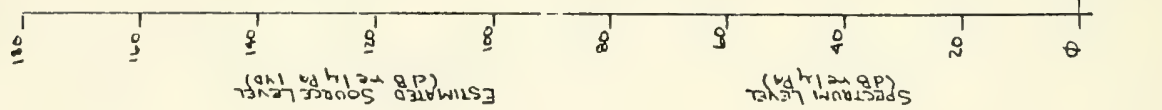



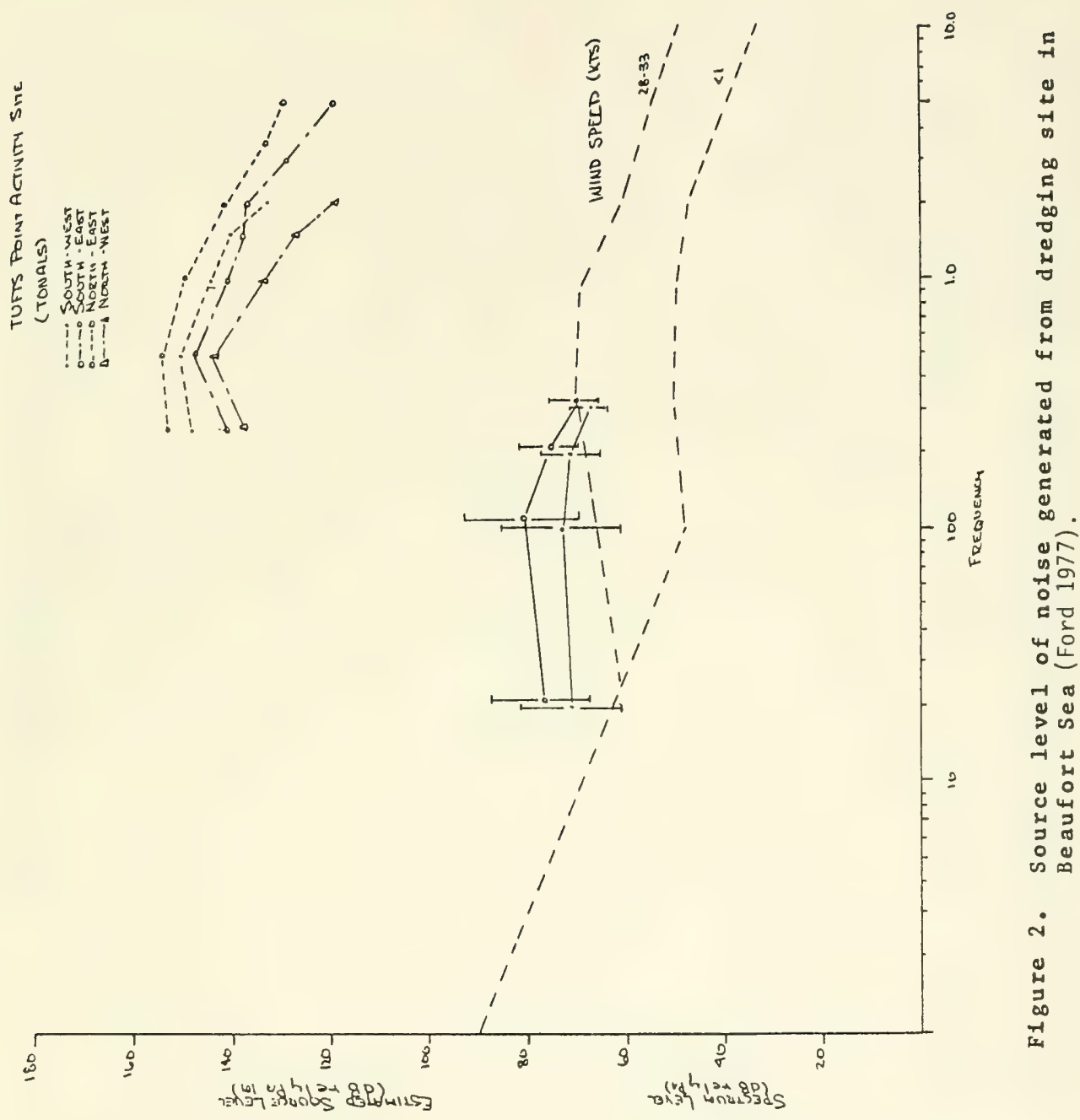

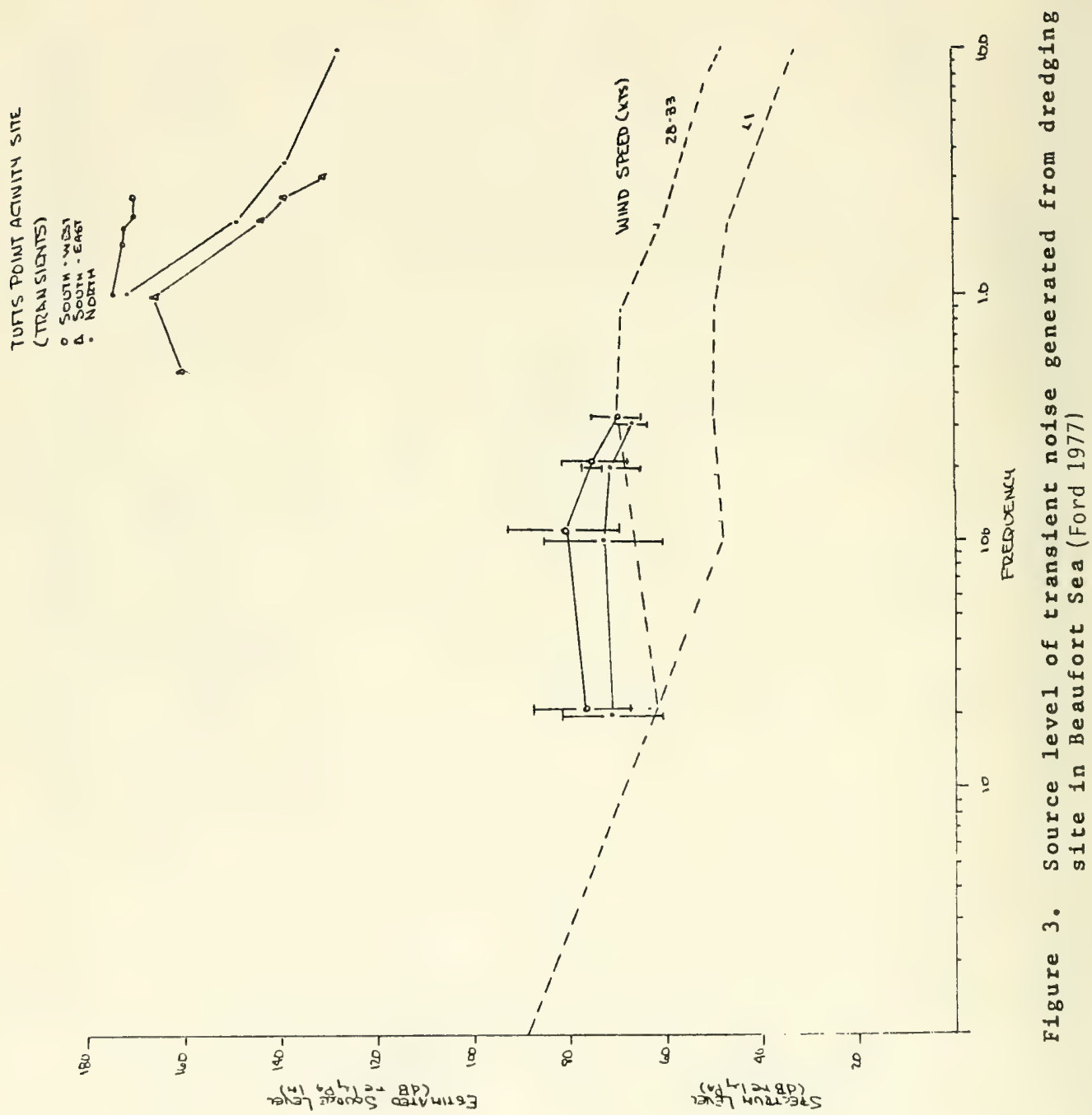

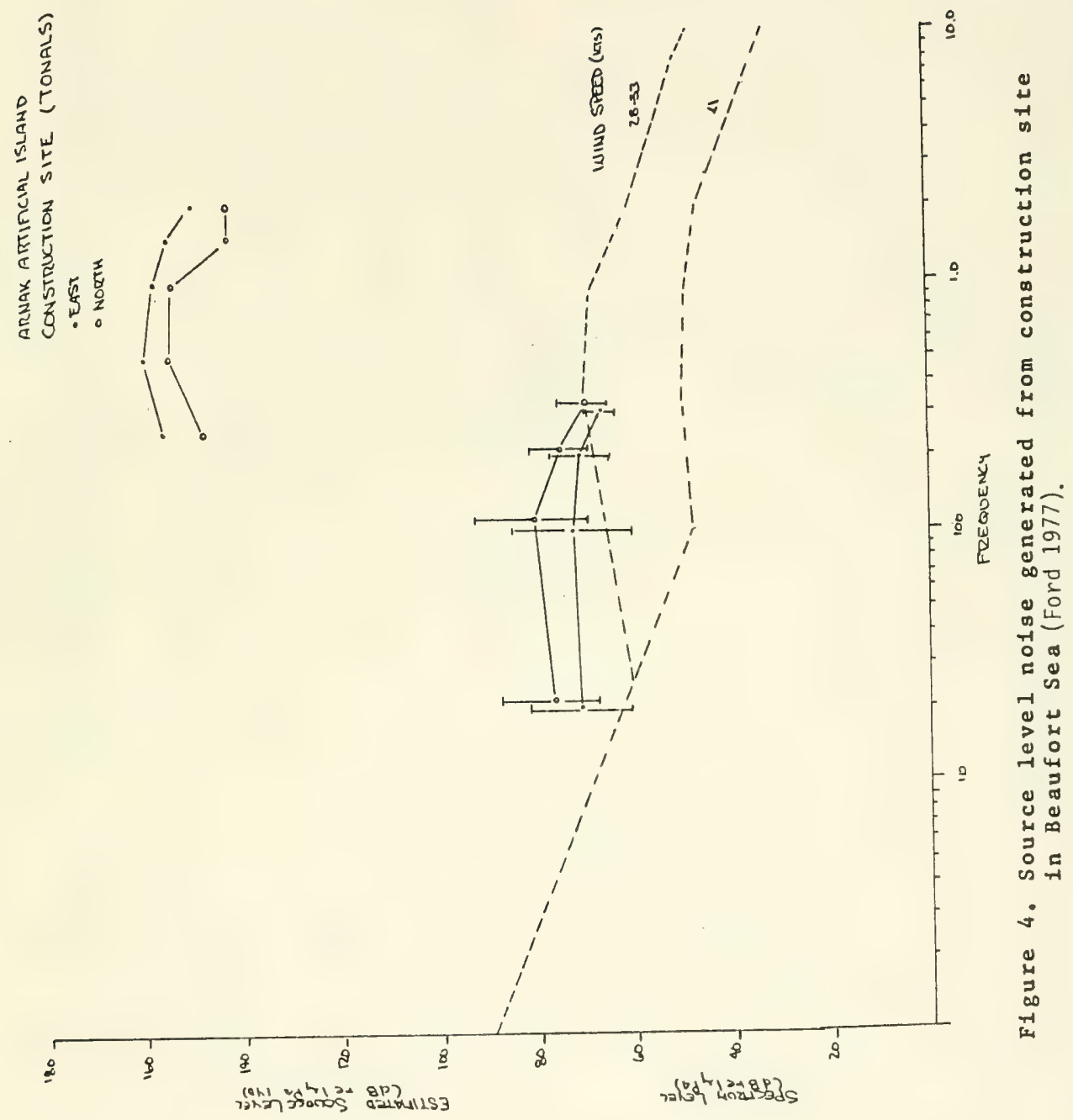

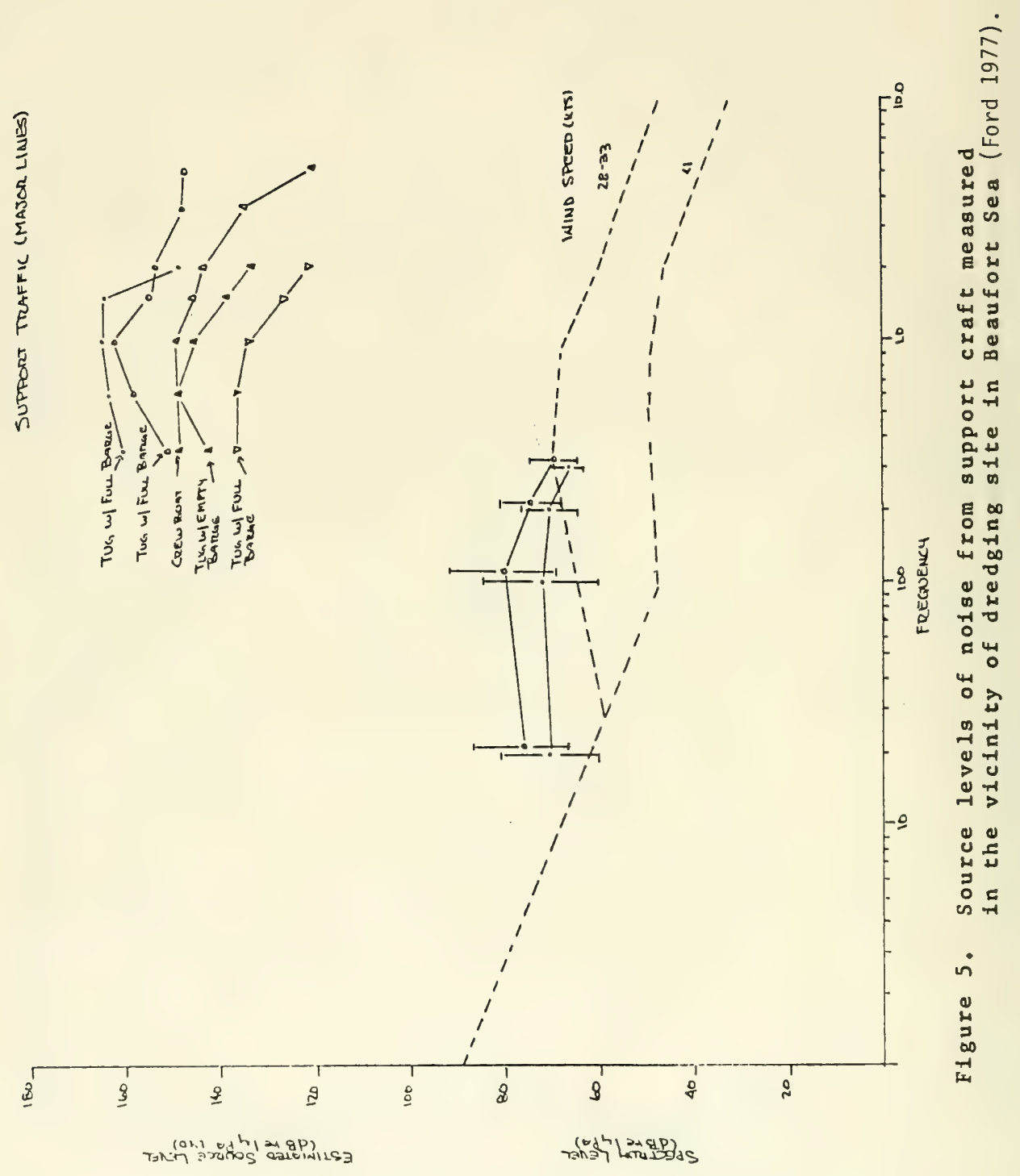

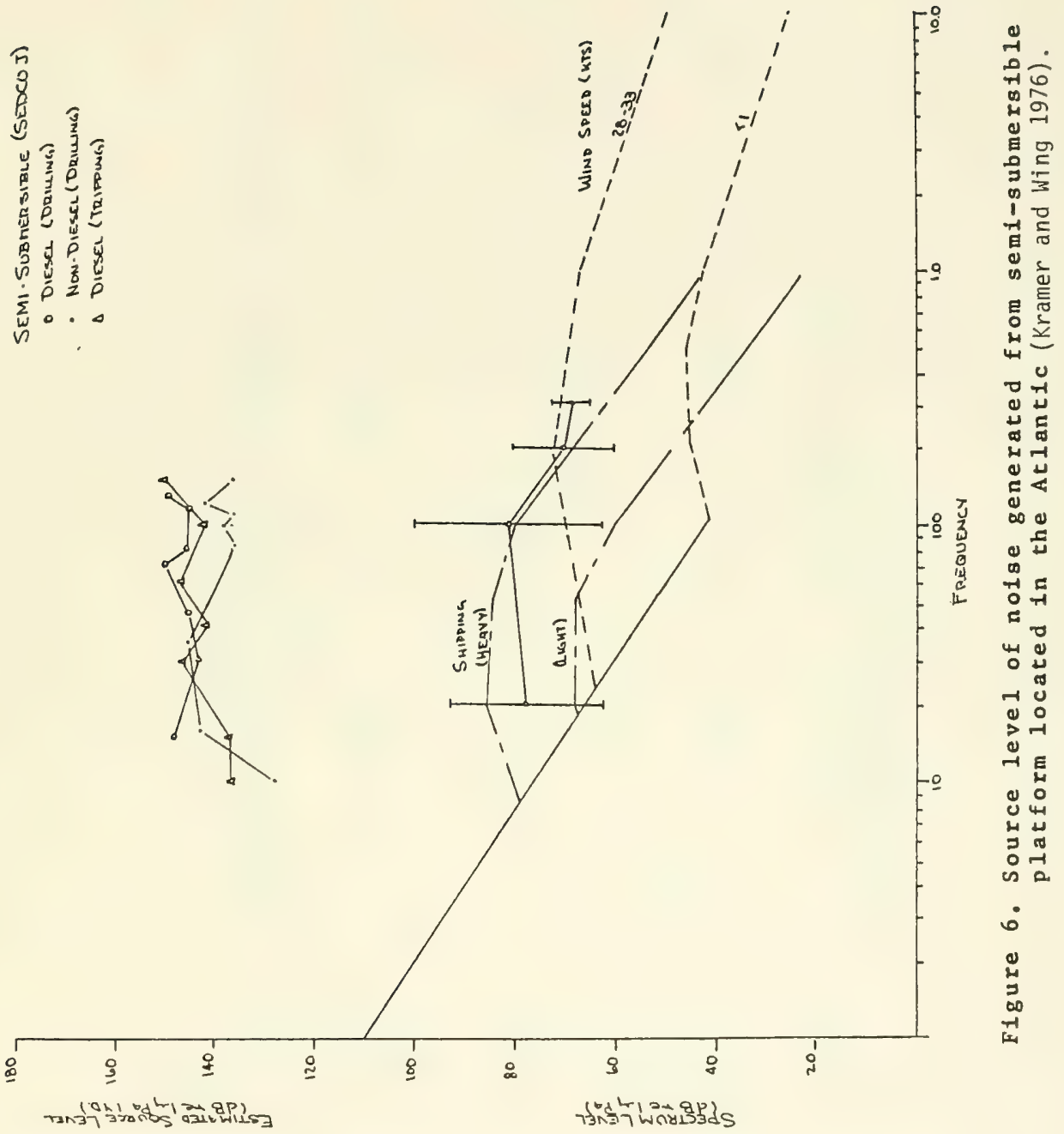


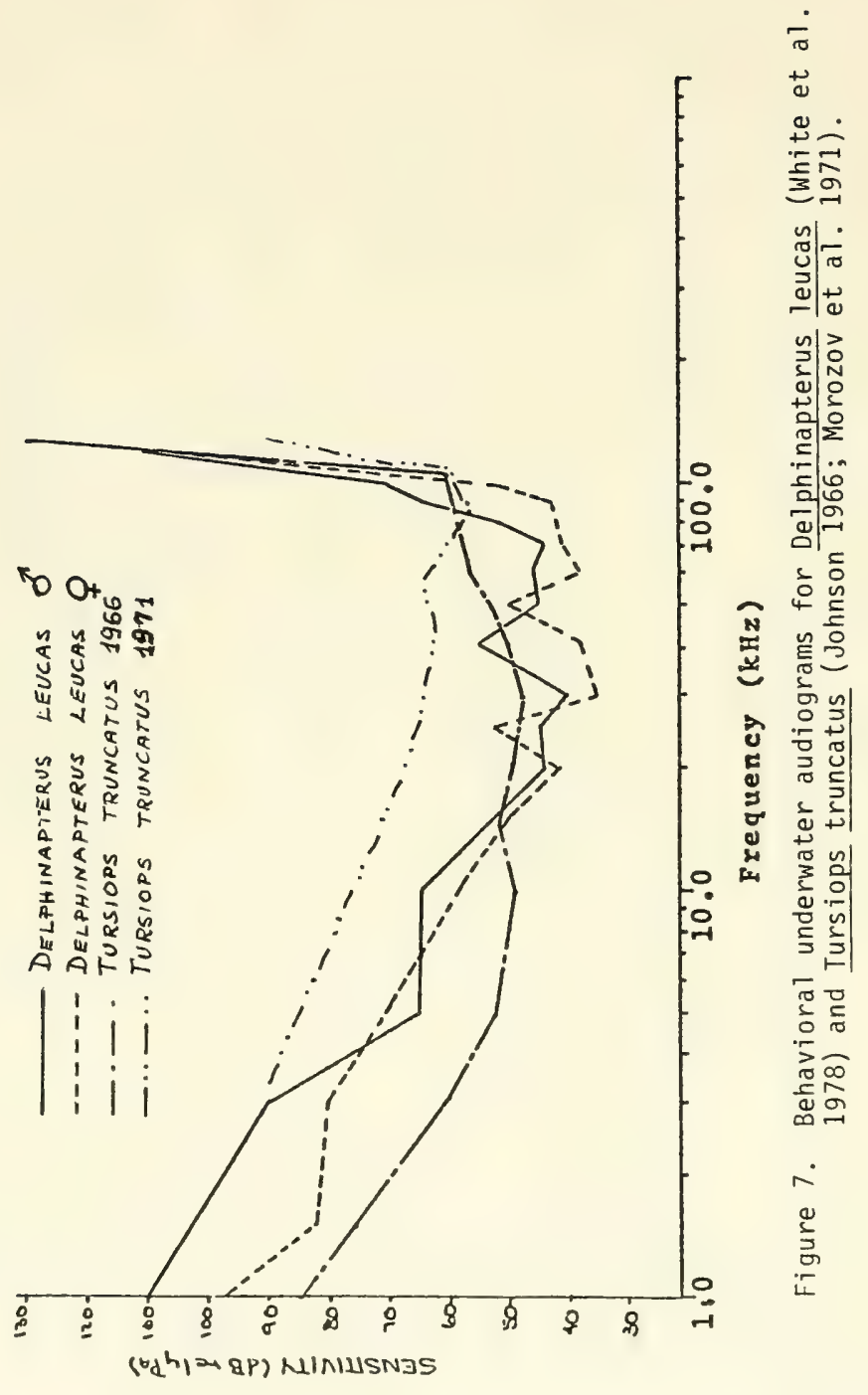




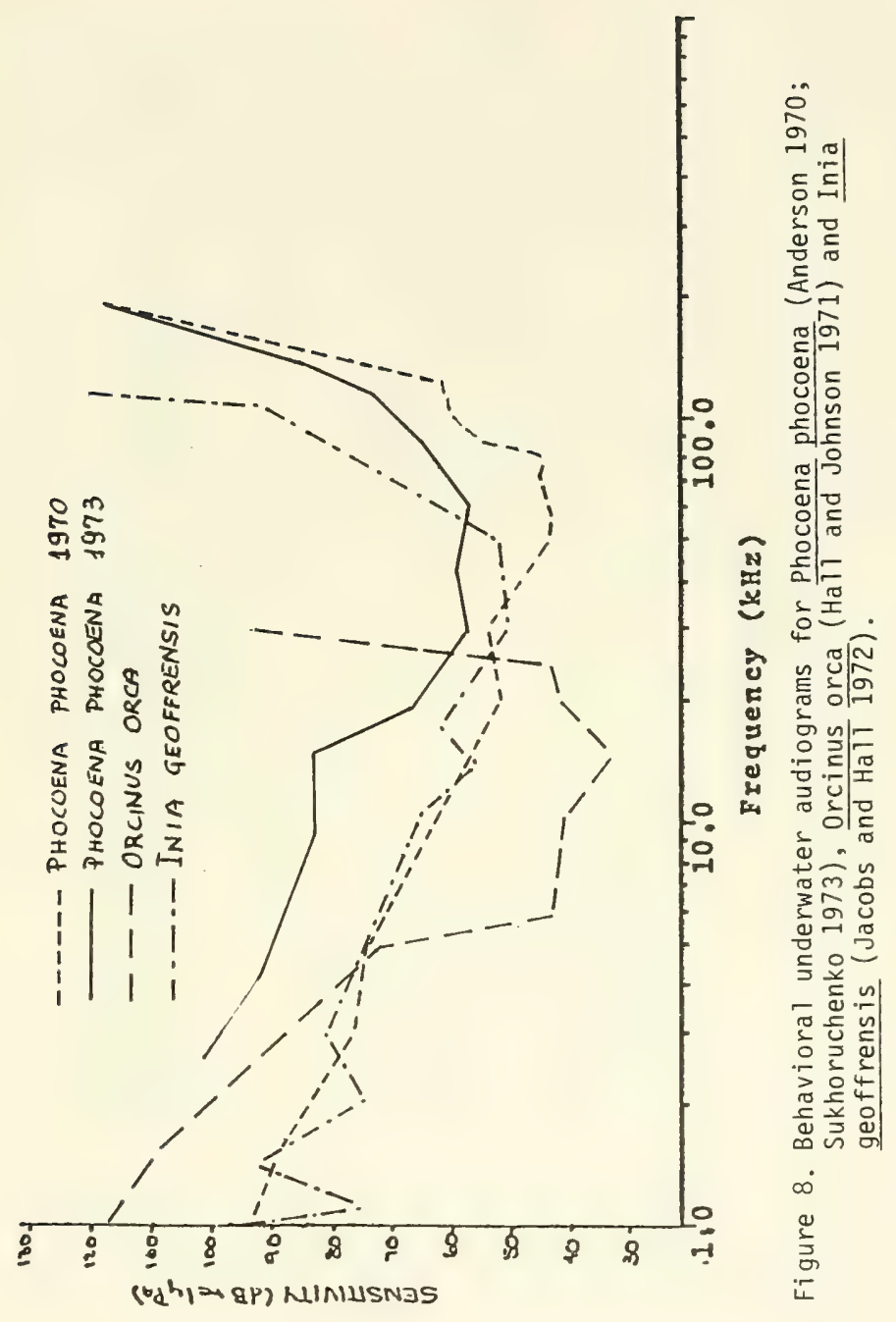




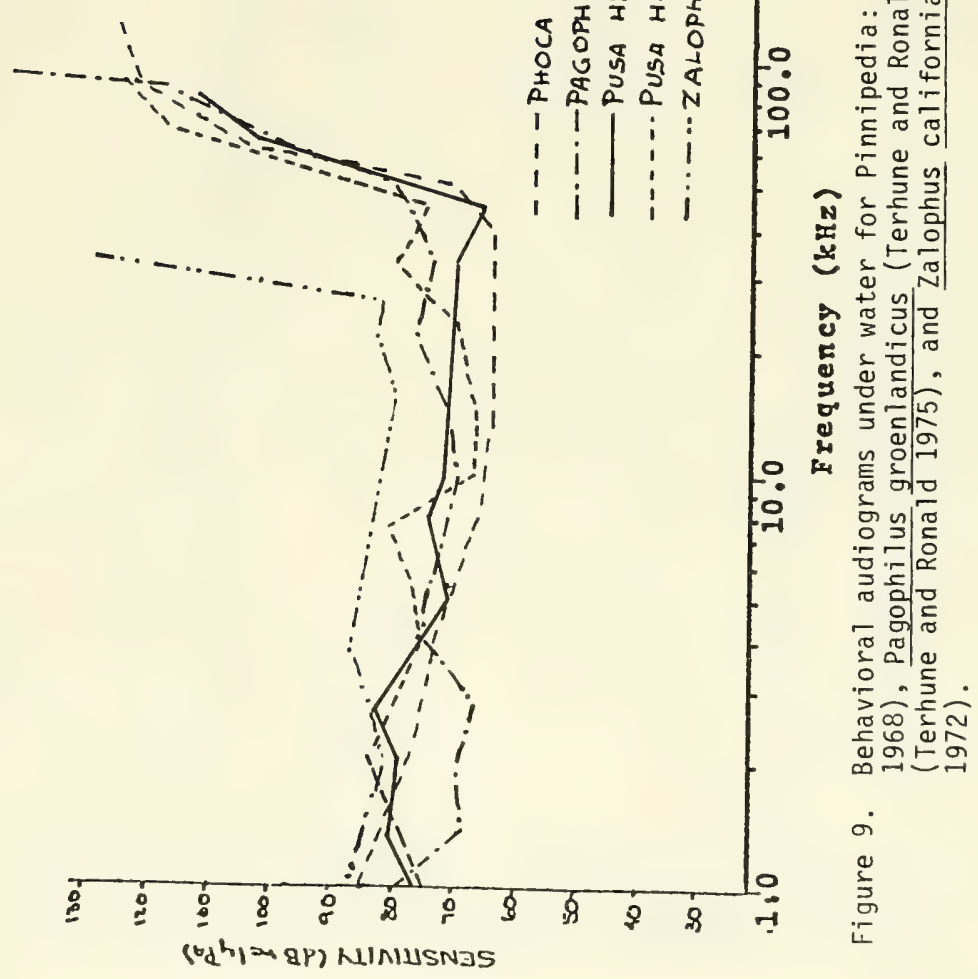




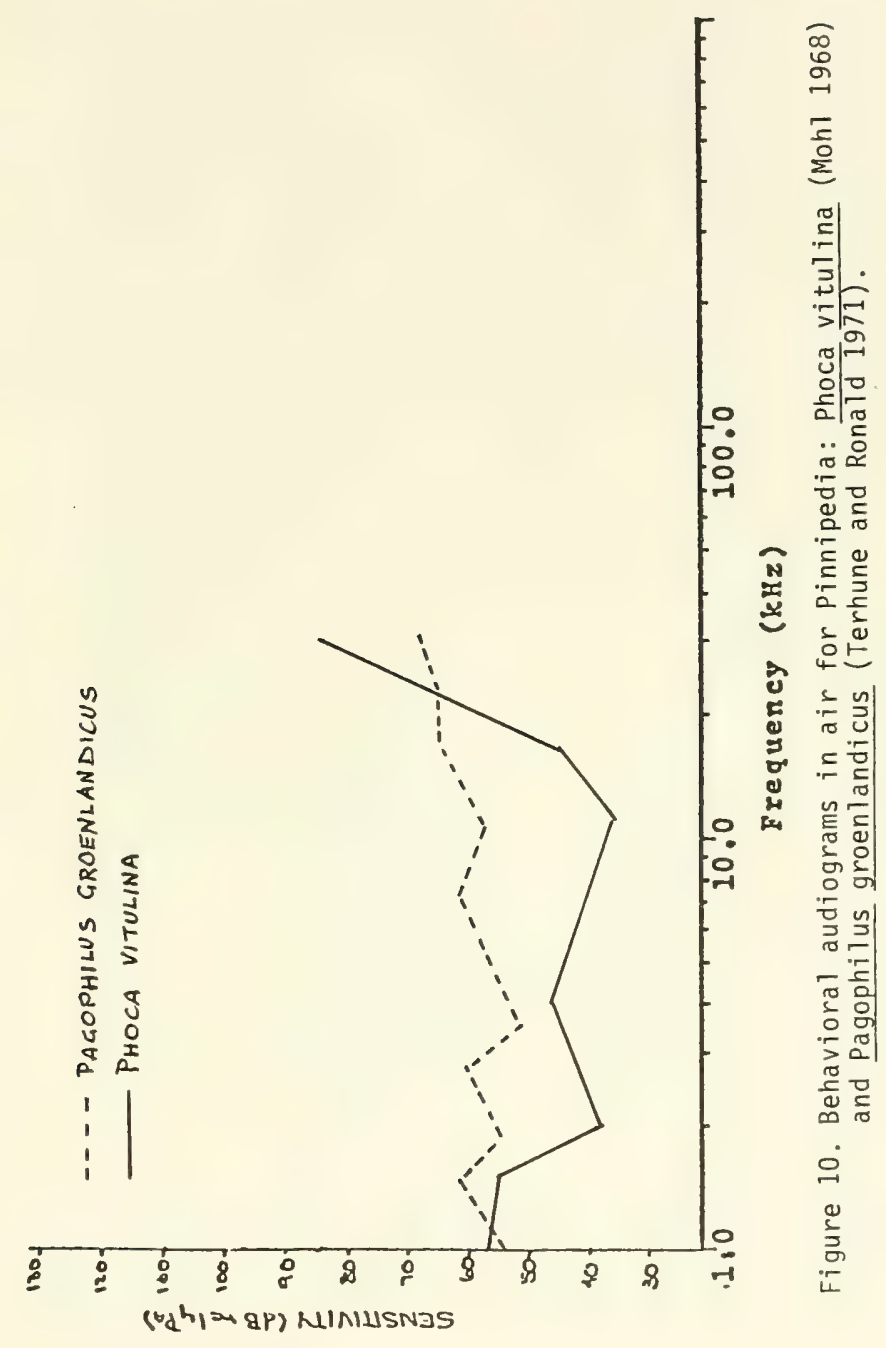




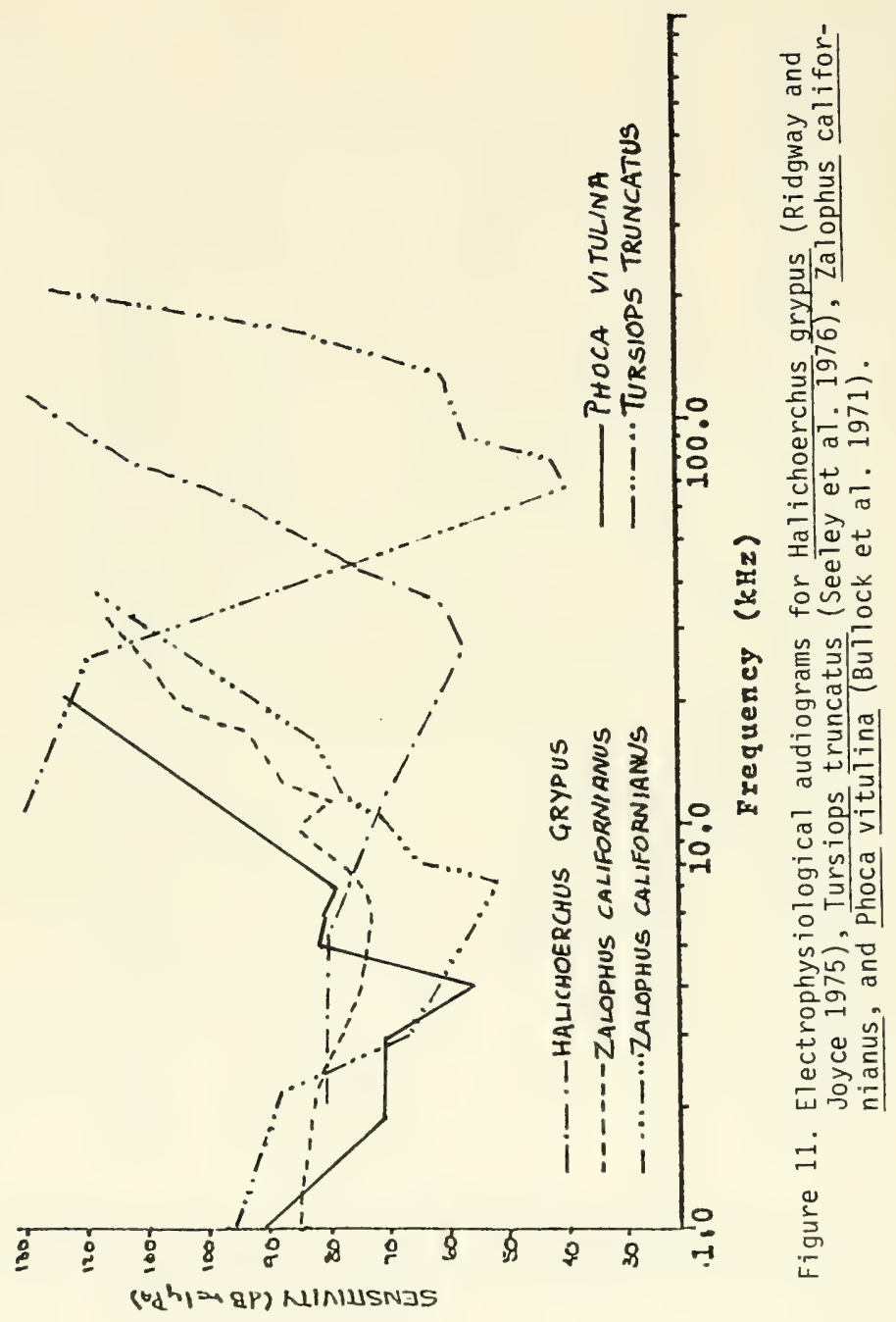




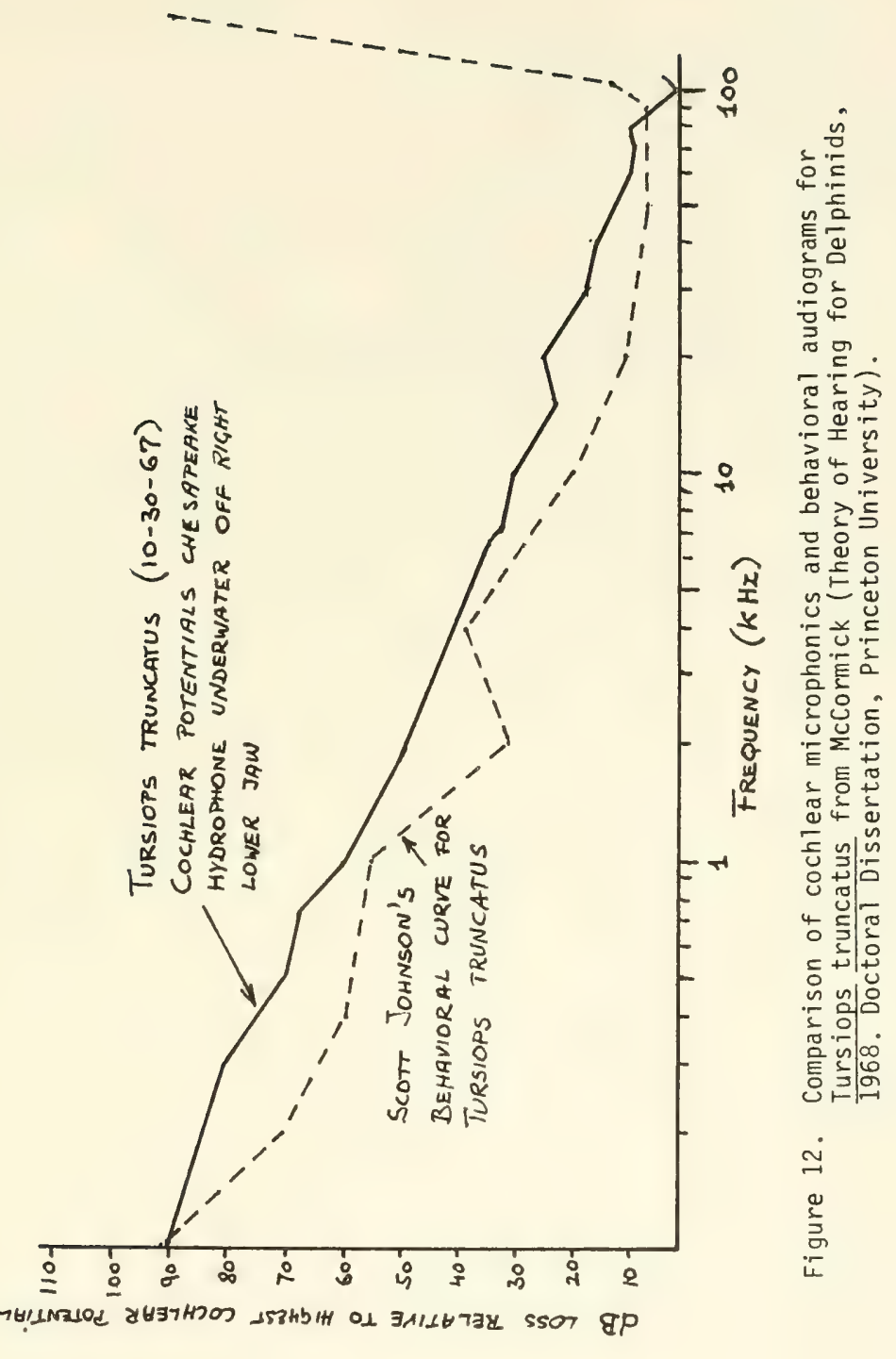



APPENDIX B 
INTERVIEW PROGRAM TO DETERMINE PROXIMITY OF LARGE

MARINE MAMMALS TO OIL/GAS PLATFORMS

Prepared for:

NAVAL OCEAN SYSTEMS CENTER

San Diego, California

\author{
Prepared by: \\ CHAMBERS CONSULTANTS AND PLANNERS \\ 10557 Beach Boulevard \\ P. 0. Box 356 \\ Stanton, California 90680
}

March 1981

E-1

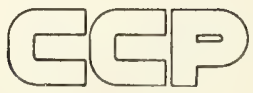




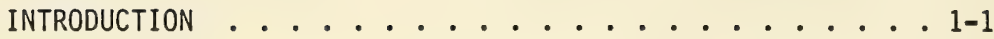

QUESTIONNAIRE DEVELOPMENT .............. 2-1

2.1

The Concept of the Program ............ 2-1

2.2

The In-Person Historical Interview Questionnaire . . . . 2-2

2.3

The Sighting Card ............. 2-3

INSTRUCTIONAL METHODS AND MATERIALS ......... . . 3-1

4

COLLECTION OF RELEVANT BASELINE DATA FOR COMPARISON WITH RESULTS OF INTERVIEW PROGRAM ........... 4-1

THE COMPUTER PROGRAM ................. . 5-1

Sighting Card Program ........ 5-32

How the BLM Data is Read into the Program . . . . . 5-47

How the BLM Data was Derived. . . . . . . . 5-47

Sample Runs with Imaginary Data ........ . . 5-57

6

6.1

6.1 .1

6.1 .2

6.2

6.2 .1

6.2 .2

6.3

6.3 .1

6.3 .2

THE PILOT PROGRAM

Contacts and Communications with 0 il companies. . . . .6-1 Introduction ............. 6-1 Detailed Account of Communications with 0il Companies. . 6-2 Implementation of the Pilot Program . . . . . 6-6 Aminoil Platform Emmy (Huntington Beach) . . . . 6-6 Shell Beta Platforms (Huntington Beach). . . . . 6-7 Results ................. 6-8 Results of In-Person Historical Interviews . . . . 6-8 Results from Sighting Cards. ........ 6- 6-14

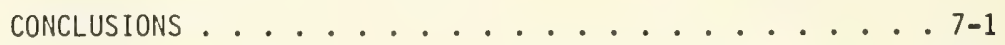

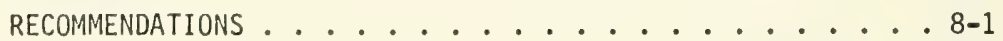

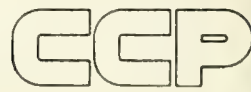




\section{Section 1}

\section{INTRODUCTION}

This interview program to determine the proximity of large marine mammals to oil and gas platforms was designed to support the Bureau of Land Management (BLM) Program at the Naval Ocean Systems Center (NOSC). The Targer NOSC study is directed at investigating the effects of noise of offshore oil and gas operations on the behavior of marine mammals. The objective of the interview program was to design a method to find out from workers aboard oil platforms and ships and aircraft servicing those platforms whether or not large whales and other marine mammals occur in any substantial numbers in areas where oil resource development is underway. The interview program was also planned to obtain as much useful data as possible on the behavior of those marine mammals observed by the oil platform workers. In an effort to ascertain whether the marine mammal density around a platform was the same as the density without the platform, a method was developed to compare the observations of the oil platform workers with baseline data on marine mammal distributions in the Southern California Bight. 
Section 2

QUESTIONNAIRE DEVELOPMENT

\subsection{THE CONCEPT OF THE PROGRAM}

It was determined that the goals of the program could best be met by two separate types of questionnaires:

1) an in-person interview questionnaire to extract data on previous (historical) observations, and

2) a sighting card to be filled out by the worker as soon as possible after he sees a marine mammal.

Previous experience with training scientific observers has indicated that if observations are not written down within a few hours most of the details are lost. Therefore, it seemed that the most realistic way to obtain valid data would be to develop a sighting card which could be left on the platform for the worker to fill out the same day that he saw a marine mammal. The sighting cards would provide the most reliable and quantitative data for this program.

However, it was also decided that there would be considerable value in administering an in-person interview to question workers about marine mammals that they had seen during the whole length of time they had been working on the platform. Although the reliability of observations made as much as months or years in the past is open to doubt, it seemed as though the goals of this program would best be met by extracting all possible information from the workers. In addition, it was likely that many workers who would not take the time to fill out a sighting card would answer questions if contacted directly. 
The informal, conversational format of the in-person interview would invite anecdotes on observed marine mammal behavior. It was felt that even though the reliability of the data from historical observations was marginal, if enough workers were questioned patterns might become apparent in the distribution and behavior of marine mammals around offshore platforms. Anecdotes about unusual behavior might also provide important clues on how the offshore activities are affecting marine mammals. In addition, the contact with the workers during the in-person interviews would provide an opportunity to explain the sighting card program and personally elicit their coopration.

It was originaliy envisioned that the interview program would proceed in the following way. Scientists would go to each platform and put up the posters, the sighting cards, and a box for completed sighting cards. The scientists would then administer the historical questionnaire to as many workers as possible. While talking to the workers, they would explain the program, ask for cooperation, and ask for any suggestions that would make the program easier for the workers. Two weeks later, the scientists would return to each platform, collect the completed sighting cards and interview as many workers as possible again. For those workers who were previously interviewed, the second in-person interview would focus on the marine mammal observations during the 2 weeks between interviews. The workers would be asked if they had any difficulties filling out the sighting cards, and if they had any suggestions for improving the program.

\subsection{THE IN-PERSON HISTORICAL INTERVIEW QUESTIONNAIRE}

The in-person historical interview questionnaire consists of 37 questions (Table 2-1, at end of section). If all questions are asked, the questionnaire takes approximately 10 minutes to administer. If the worker being questioned has seen only one or two categories of marine mammals, the time is considerably shorter.

Since the questionnaire elicits information about observations made over an extended period of time (months and sometimes years), questions are only asked about details that could reasonably be remembered. No attempt is made to ask

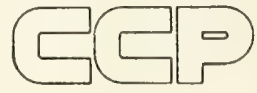


questions about such fine points as the shape of the dorsal fin or the position of the spout. The questionnaire was also designed in such a way that it did not suggest details which the worker may not really have remembered. The questions were phrased so that the answers could be readily analyzed by computer.

There are two spaces at the end of the questionnaire (Questions 38 and 39) which are to be filled out by the interviewer. These questions allow the interviewer to put down his own impressions of how the interview went and what he thought the reliability and knowledge of the subject was. Such information may be important to the later evaluation of the data.

The most effective way to administer the in-person interview is for the interviewer to use a tape recorder. In many cases, the worker being interviewed will tell anecdotes about the marine mammals he saw. These anecdotes constitute some of the potentially most valuable information which can be elicited from the in-person interview. If the interviewer has to write these incidents down, he will have to stop the flow of the story. The tape recorder captures these anecdotes which can then be transcribed later.

\subsection{THE SIGHTING CARD}

The purpose of the sighting card is to record detailed information on recent marine mammal observations. The sighting card is designed to identify marine mammals to species, to determine densities of these species around the oil platforms, and to determine the relationship, if any, between the densities of marine mammals around the platforms and various oil drilling activities.

The sighting cards are to be placed on the platforms alongside the posters which not only demonstrate how to identify marine mammals but have the following explanation of the sighting cards: 
A T T ENT I ON N W WE NEED YOUR HELP

HAVE YOU SEEN ANY WHALES, PORPOISES, SEALS, OR SEA LIONS FROM THIS PLATFORM? WE ARE TAKING A SURVEY OF MARINE MAMMALS IN SOUTHERN CALIFORNIA WATERS, AND WOULD APPRECIATE ANY INFORMATION ON MARINE MAMMALS (WHALES, PORPOISES, AND SEALS) WHICH YOU HAVE OBSERVED OFF THE PLATFORM. IF YOU SEE A WHALE, PORPOISE, OR SEAL PLEASE FILL OUT A CARD AS SOON AS POSSIBLE AFTER SEEING THE ANIMAL AND PLACE THE CARD IN THE BOX. THESE POSTERS DEMONSTRATE HOW TO IDENTIFY THE COMMON MARINE MAMMALS. YOUR INFORMATION WILL HELP US TO UNDERSTAND THE POPULATIONS, DISTRIBUTIONS AND BEHAVIOR OF THESE ANIMALS. WE HOPE TO SHOW THAT OIL PLATFORMS ARE A GOOD SOURCE OF INFORMATION.

In addition, the sighting card program will be explained to the workers during the in-person interviews.

The sighting card consists of a total of 47 questions (Table 2-2) but the worker does not fill them all out. He completes 16 initial questions and then goes to the category of animal he saw and fills out an additional 7 to 12 questions. Most questions are answered by simply checking the appropriate box, and the entire card takes only a couple of minutes to fill out.

The sighting card was designed not only to extract information pertinent to the NOSC program, but to act as a learning tool for the worker. As he fills out the set of questions for the category of marine mammal that he saw, he will learn the important characteristics in identifying these animals. Hopefully, the next time he sees a marine mammal, he will look for those characteristics.

The sighting card is designed to be readily analyzed by computer. The computer can identify to species the marine mammal observed if the worker can fill out most of the characteristics even if he is unable to name the species. The card is also designed to double-check false identifications since the worker is asked not only to put down the species he thinks he saw, but to check the characteristics.

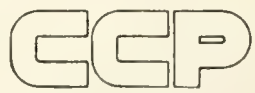


The sighting card is somewhat formidable in appearance but is easy to fill out. Once the worker has become familiar with the card he should be able to complete it rapidly. The difficulty is to get workers into the habit of using cards. 
What is your occupation and shift?

1. How long have you been working on this platform?

2. Are your interested in the marine life around you out here?

3. How often do you see marine mammals from this platform?

1) Never

2) Seldom (less than once a month)

3) Often (at least once a month)

4. How many large whales have you seen? (Ask for number if he can give one)

1) None

2) One

3) A few (less than ten)

4) Many (ten or greater)

5. Do you know what kind? (Name)

Do you remember what they looked like? If so, describe.

6. How close to the platform were they? In yards or miles.

7. Do you remember what time of day it was?

1) No

2) Dawn or dusk

3) Midday

4) Throughout the day

5) Night

8. Do you remember what time of year it was?

1) No

2) Winter

3) Summer

4) Spring

5) Fal1

6) Throughout the year 
9. When you saw the anima1s were they alone or in groups?
1) Single
2) Group
3) Both

10. Do you remember what direction they were moving in?
1) No
2) Most7y upcoast
3) Mostly downcoast
4) Mostly out to sea
5) Mostly towards shore
6) Changed direction while watching. Explain:
7) Al1 directions

11. Did you notice any behavior? Explain:

12. Did this behavior seem related to any work on the platform?

13. When you saw the whales do you remember what the activity yas on the platform?

14. How many dolphins or porpoises have you seen from this platform? (Ask for number if he can give on)
1) None
2) One
3) A few (less than ten)
4) Many (ten or more)

15. Do you know what kind? (Name)

Do you remember what they looked like? If so, describe

16. How close to the platform were they? In yards or miles.

17. Do you remember what time of day it was?

1) No

2) Dawn or dusk

3) Midday

4) Throughout the day

5) Night 
18. Do you remember what time of year it was?
1) No
2) Winter
3) Summer
4) Spring
5) $\mathrm{Fall}$
6) Throughout the year

19. When you saw the dolphins or porpoises were they alone or in groups?
1) Single
2) Group
3) Both

20. Do you remember what direction they were moving in?
1) No
2) Mostly upcoast
3) Mostly downcoast
4). Mostly out to sea
5) Mostly toward shore
6) Changed direction while watching. Explain:
7) All directions

21. Did you notice any behavior? Explain:

22. Did this behavior seem related to any work on the platform?

23. When you saw the dolphins or porpoises do you remember what the activity was on the platform?

24. How many seals or sea lions have you seen from this platform? (Ask for number if he can give one)
1) None
2) One
3) A few (less than ten)
4) Many (ten or more)

25. Do you know what kind? (Name)

Do you remember what they looked like? If so, describe: 
26. How close to the platform were they? In yards or miles.

27. Do you remember what time of day it was?
1) No
2) Dawn or dusk
3) Midday
4) Throughout the day
5) Night

28. Do you remember what time of year it was?

1) No

2) Winter

3) Summer

4) Spring

5) $\mathrm{Fall}$

6) Throughout the year

29. When you saw the seals or sea lions were they alone or in groups?
1) Single
2) Group
3) Both

30. Do you remember what direction they were moving in?

1) No

2) Mostly upcoast

3) Mostly downcoast

4) Mostly out to sea

5) Mostly inshore

6) Changed direction while watching. Explain:

7) All directions

31. Did you notice any behavior? Explain:

32. Did this behavior correspond to any work on the platform? Explain:

33. When you saw the seals or sea lions do you remember what the activity was on the platform? 
Any comments:

Interviewers impression of reliability and scientific knowledge of subject: 


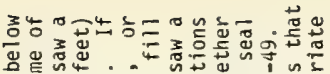

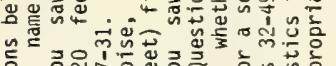

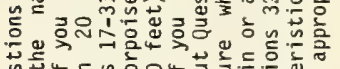

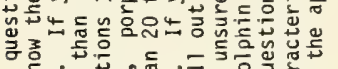

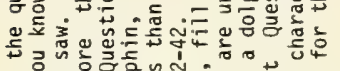

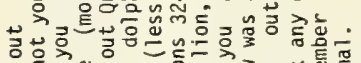

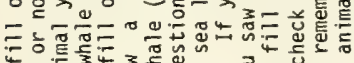

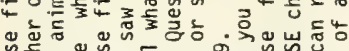

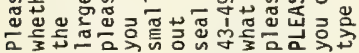
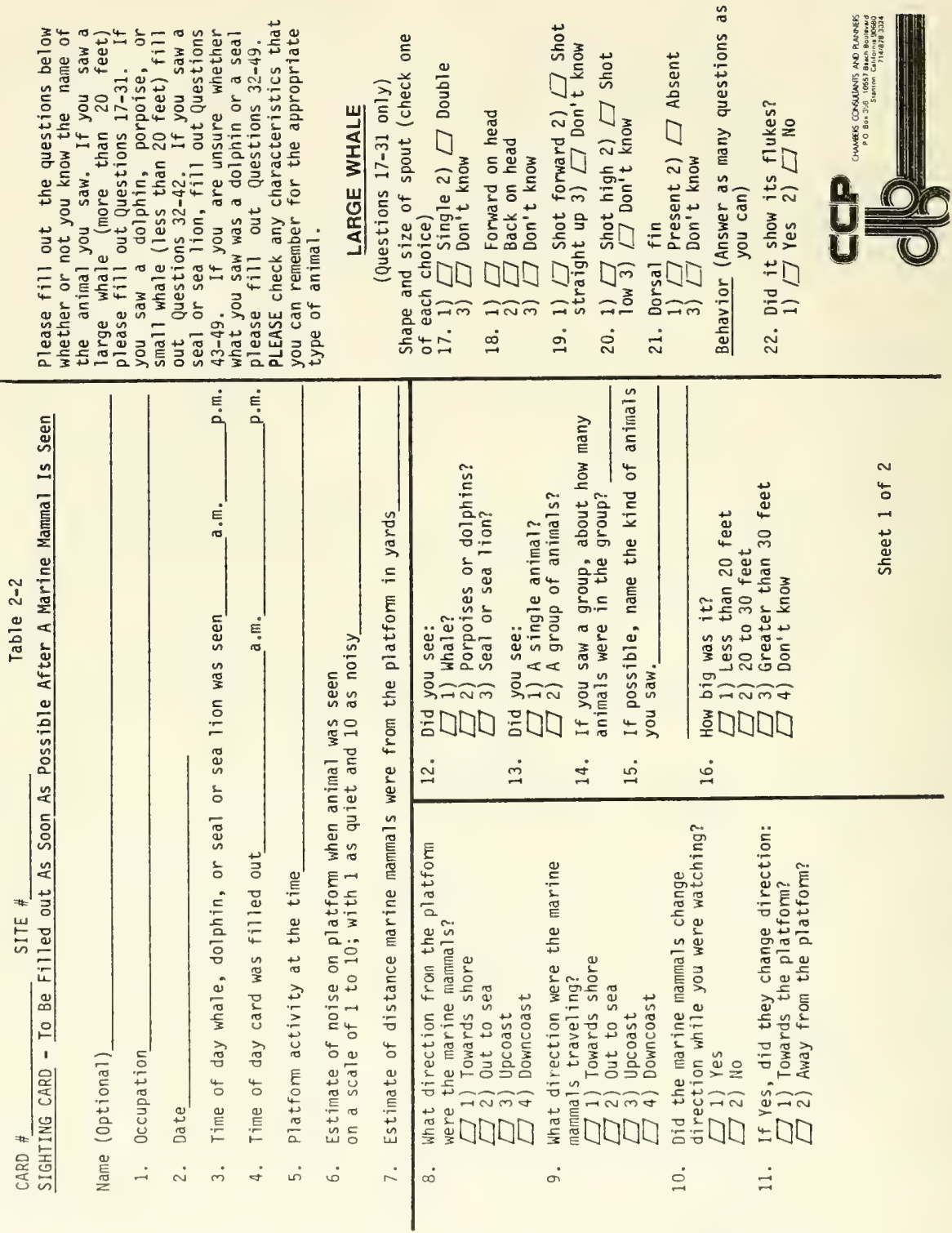


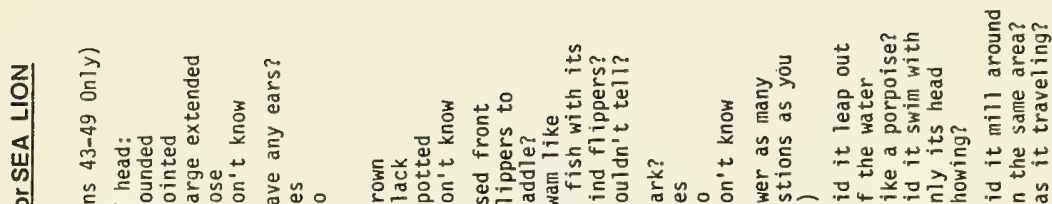

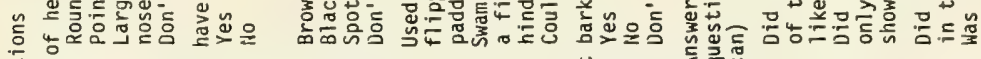

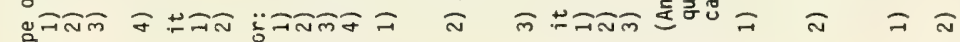

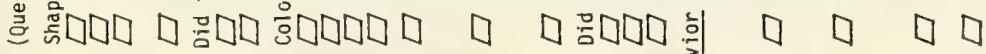

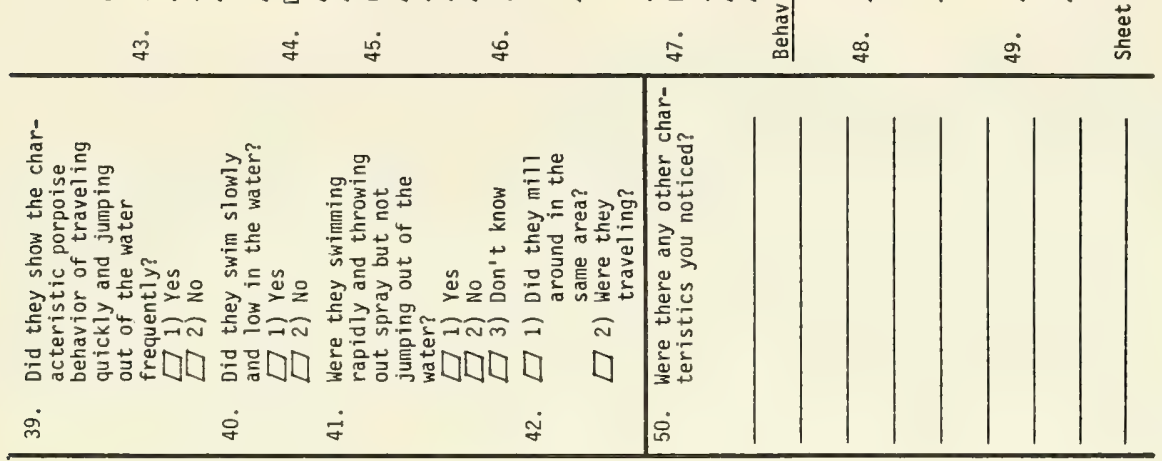

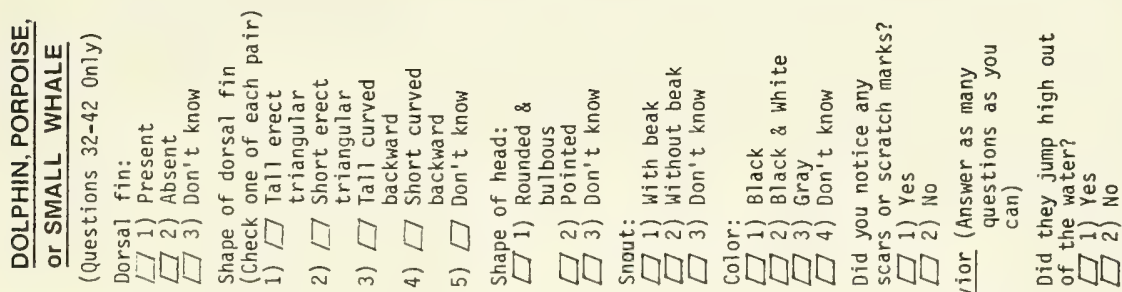

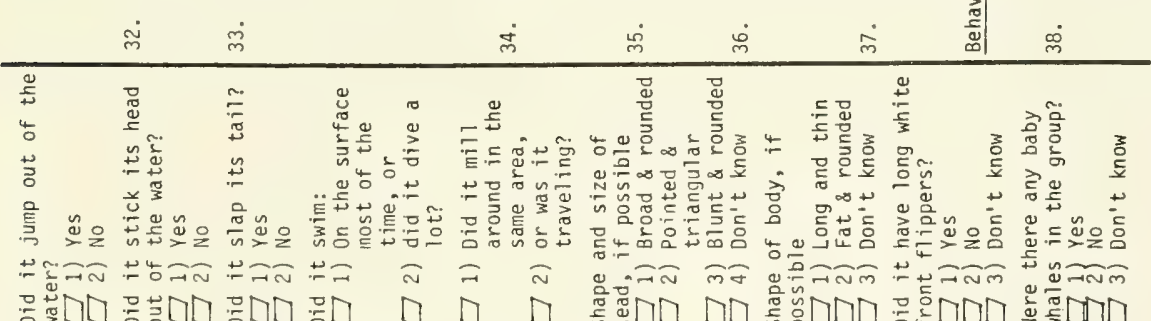

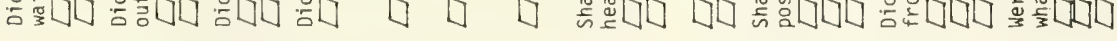

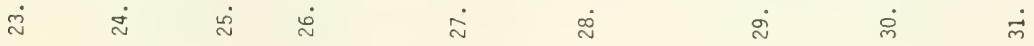


Section 3

INSTRUCTIONAL METHODS AND MATERIALS

The training program is designed to be as straightforward, simple, and relevant as possible. Three posters have been designed: one for large whales, one for dolphins and porpoises, and one for seals and sea lions. These posters focus on the species the workers are most likely to see, and they emphasize the most relevant characteristics for identification. No attempt is made to get workers to differentiate between species that are very difficult to tell apart, such as the large rorqual whales, as even trained marine mammalogists have difficulty identifying these animals in the field.

Field guides were not developed as part of the instructional program, because communications with oil company personnel suggested that the fewer separate materials we supplied the less confusing the program would be for the workers. It might be a good idea to supply a small guidebook such as that put out by the California Department of Fish and Game. The guidebook would serve not so much as an instructional material but as a source of information for workers who become interested in the marine mammals. However, we have found that it is quite difficult to locate space for the siting cards and posters and would recommend that field guides be put out only if there is a convenient place for them.

In addition to the posters, the sighting cards were designed to be not only a source of data, but part of the instructional program. As the worker fills out a sighting card he will learn what characteristics are important for the identification of marine mammals. 


\section{Section 4}

\section{COLLECTION OF RELEVANT BASELINE DATA FOR COMPARISION \\ WITH RESULTS OF INTERVIEW PROGRAM}

In order to determine whether or not offshore oil activities are affecting the distribution of marine mammals, it is necessary to know what density of marine mammals would be expected in the area if no oil activities were present.

A literature search rapidly determined that by far the most complete and quantitative data available on marine mammals in the Southern California Bight are from the Bureau of Land Management's (BLM's) 3-year marine mammal program. These data have not yet been published, but BLM will allow the report to be examined in their offices, and they will permit the relevant portions to be photocopied.

The BLM report gives seasonal sightings for each species of marine mammal on a grid pattern of the Southern California Bight. From these sighting data, the BLM investigators has regressions of densities of each species versus various environmental parameters. From those regressions which were statistically significant an overall density pattern, which correlated a species' abundance to the distribution of the significant environmental parameters, was projected for each marine mammal species in the Bight. Densities of each species of marine mammal around the oil platforms as estimated by the sighting cards can then be compared to the density of the marine mammal species in the appropriate quadrat as estimated by BLM. The sighting card program determines whether the density calculated by the sighting cards is within the range of density estimates calculated by BLM for that quadrat during the same season.

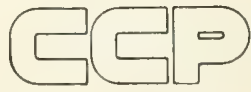


The portion of the BLM document which explains how their data were derived is reproduced in Section 5.4.2 of this report. The BLM investigators had to make a number of assumptions in their data calculations, and there are obvious limitations to the data collected from the sighting cards by this program. Furthermore, one can question whether or not it is even valid to compare data collected by such different methods. Still, it is felt that if enough data can be gathered from the oil platforms the overall results derived from the comparison will help to answer the question of whether the oil activities are affecting marine mammal distributions. If densities around the platforms do not fall within the range calculated by BLM, it will be necessary to question whether the differences are simply due to a dissimilarity in methods. However, the differences in marine mammal densities between the oil platform and the quadrat as a whole will also alert NOSC scientists to a possible real effect of the platforms on marine mammals. 
Section 5

THE COMPUTER PROGRAM

\section{$5.1 \quad$ INTRODUCTION}

The following is a description of programs written to analyze anecdotal data gathered from oil platform workers. Two programs were written, one to analyze data generated by in-person interviews and the other to analyze data gathered from questionnaires left on oil platforms. The questionnaires are to be filled out by workers upon sighting marine mammals.

The two methods of data gathering were employed for different ends. The inperson interviews were meant to gather "historical" data on marine marimal occurrence and behavior around oil platforms while the sighting cards were to be used as a method of determining present marine mammal distribution and densities and possibly detemining the effects, if any, of oil platform operation on marine mammal distribution and density.

The programs, for both the in-person interview and the sighting card analysis, were written in SAS, the statistical analysis system, version 79.3. The SAS program can be used as a data management system, report writing system, data analysis system and a programming language. For these reasons, it was used in the applications to be described. 
5.2.1 Description of the Program to Analyze the In-Person Historical Interviews

The analysis of the in-person interviews is very basic. The program merely reads in the raw data derived from the interview forms and reports on the frequencies of responses to the individual questions. The reports are divided into three sections. One section corresponding to question concerning whales, one corresponding to questions about porpoises and dolphins and, lastly, one corresponding to questions about seals and sea lions.

\subsubsection{Creating the Raw Data to be Read Into the Program}

This section presents information necessary to correctly create data cards for input into the in-person interview analysis program.

Data will be input in standard 80-column record format. Each interview will result in one 80-column record. The data will be column dependent.

The "code book" presents the data format variable, with column specifications, all possible values for each variable, a definition of each value and, where appropriate, notes on converting multiple responses or incorrect responses to a codeable form. 
Variable

QUEST_NO

Questionnaire Identification Number

NOTE: Right justify value

DATE Date of Interview

$6-13$

OCCUP Occupation of Interviewee

NOTE: Code only one value in columns 14-15. Right justify the value

$14-15$
Column Value

1-5 1 Thru 99999

Shift which interviewee works NOTE: Right justify coded value

$16-17$

Q1 Months working this platform NOTE: Convert all units to months (i.e., $1 \frac{1}{2}$ years should be 18 months). Right justify coded values
$18-19$

20$$
\text { vatues }
$$

life?

\section{Value Label}

NOTE: Each sighting card should have a unique number. The highest number that can be assigned is 99999 , since only five columns have been defined for this variable.

The format of this variable is MPI/DD/YY with the slashes (/) in columns 8 and 11 and where: $M M=$ Month

$\mathrm{DD}=$ Day

$Y Y=$ Year (i.e., 01/02/31)

\section{Production Foreman}

Platform (Prod.) Operator

Head Well Puller

Derrickman

Floorman

Roustabout

Mechanic

Electrician

Chemical Tech/Cathodic

Protection

Drilling Foreman

Driller

Roughneck

Helper

Hel icopter Pilot

Boat operator

Divers

Other

Code blank if no response

Day Shift

Night Shift

Swing Shift

Code blank if no response

NOTE: If value of months is greater than 99 code 99

$b \quad$ Code blank if no response 
Variable

Q3 How often do you see marine mammals from this platform?

Q4 How many large whales have you seen?

NOTE: Ignore any values other than those coded here (i.e. $1,2,3,4$ or $b$ )

Q5 What kind of whale?

NOTE: If no positive ID try to key using the verbal description recorded on interviewed coded sheet. Right justify values.
Q6 How close to platform were whales? (in yard)

NOTE: Convert all units to the nearest yard and right justify all numbers

Q7 Time of day whales were sighted?

Q8 Time of year whales were sighted?
Column Value

Value Label

21

$\begin{array}{ll}1 & \text { Never } \\ 2 & \text { Seldon (less than 1/Mo) } \\ 3 & \text { Often (at least 1/Mo) }\end{array}$

22

1
2
3
4
$b$

None

One

A few (less than ten)

4 Many (ten or greater)

$\rightarrow \quad$ Code blank if no response

23-24

1
2
3
4
5
6
7
8
9
10
11
12
13
14
15
16
17
18
19
20
$b$

Gray whale

Sei, fin, or blue

Right whale

Sperm whale

Humpback whale

killer whale

Minke whale

Pilot whale

Rissos dolphin (Grampus)

10 Bottlenosed dolphin (Tursiops)

11 Common dolphin

12 Right whale dolphin

13 Harbor porpoise

14 Dall's porpoise

15 Pacific white-sided dolphin

16 Elephant seal

17 Harbor seal

18 Stellar sea lion

19 Northern fur seal

20 California sea lion

$\rightarrow \quad$ Code blank if respondant answered other than above or did not respond

25-28 1 Thru If the respondant answers a 9999 value of greater than 9,999 yards Code 9999

$\rightarrow$ Code blank if no response

29

\begin{tabular}{ll}
1 & Unknown \\
2 & Dawn or dusk \\
3 & Midday \\
4 & Through the day \\
5 & Night \\
\hline$b$ & Code blank if no response
\end{tabular}

30

$\begin{array}{ll}1 & \text { Unknown } \\ 2 & \text { Winter } \\ 3 & \text { Summer } \\ 4 & \text { Spring }\end{array}$

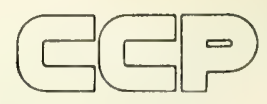


Q8 Time of year whales were sighted? (Cont'd)

Q9 Were whales alone or in groups? 31
Q10 What direction were whales
$\begin{aligned} & \text { traveling? }\end{aligned}$

$5 \quad$ Fall

6 Throughout the year

b Code blank if no response

Q11 Did you notice any whale behavior?

NOTE: Right justify questionnaire number

Q12 Did behavior relate to platform activity?

$\begin{array}{ll}1 & \text { Single } \\ 2 & \text { Group } \\ 3 & \text { Both } \\ + & \text { Code b }\end{array}$

32

1
2
3
4
5
6
7
6

Unknown

Mostly upcoast

Mostly downcoast

Mostly out to sea

Mostly towards shore

Changed direction while watching

All directions

* Code blank if no response or different than above

QUEST NO NO

$\mathrm{B}^{-}$

If

If yes code questionnaire number

Code blank if no response

38

1 Yes

2 No

$\rightarrow$ Code blank if no response

Q13 Type of platform activity

NOTE: Right justify activity codes.

$39-40$

1 Drilling

2 Production

3 Dormant

$4 \quad$ Testing

$\rightarrow \quad$ Code blank if no response

Q14 Number of dolphins or porpoises seen.

NOTE: Ignore any actual counts and code only

values given here.

Q15 What kind of dolphin or porpoise did you see?

NOTE: If no positive ID try using the verbal description recorded on interview coding sheet.
411 None

2 One

3 A few (less than ten)

4 Many (ten or greater

$\rightarrow \quad$ Code blank if no response

$42-43$

* * $\quad$ See 05 for codes and value labels

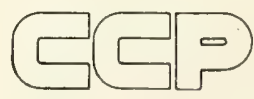


Q16 How close to platform were dolphins or porpoises?

NOTE: Convert all other units to nearest yard and right justify numbers

Q17 Time of day porpoises or dolphins were sighted.

48

44-47 Yards

$\rightarrow$ dolphins were sighted.

Q18 Time of year porpoises or

Q19 Were dolphins or porpoises along or in groups?

Q20 What direction were porpoises/ dolphins going?
1
2
3
4
5
6
49

51

50

$\begin{array}{ll}1 & \text { Unknown } \\ 2 & \text { Winter } \\ 3 & \text { Summer } \\ 4 & \text { Spring } \\ 5 & \text { Fal1 } \\ 6 & \text { Throughout the year } \\ 6 & \text { Code blank if no response }\end{array}$

1 single

2 In groups

3 Both

$\rightarrow \quad$ Code blank if no response

Unknown
NOTE: If respondant answers a value greater than 9,999 yards code 9999

Code blank if no response

1 Unknown

2 Dawn or dusk

3 Midday

4 Throughout the day

5 Night

b Code blank if no response

1
2
3
4
5
6
7
6

Mostly upcoast

Mostly downcoast

Mostly out to sea

Mostly toward shore

Changed direction while watching

All directins

Code blank if no response or different than above

Q21 Did you notice any porpoise/ dolphin behavior?

NOTE: Right justify questionnaire number

$52-56$

0 No

QUEST_NO If yes, code questionnaire number

$\rightarrow \quad$ Code blank if no response

Q22 Did behavior relate to platform activity?

1 Yes

2 No

$\rightarrow \quad$ Code blank if no response

Q23 Type of work on platform when 58-59 dolphin/porpoise sighted. NOTE: Right justify activity values. $\begin{array}{ll}1 & \text { Drilling } \\ 2 & \text { Production } \\ 3 & \text { Dormant } \\ 4 & \text { Testing } \\ \text { b } & \text { Code blank if no repsonse }\end{array}$

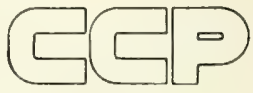


$\underline{\text { Variable }}$

Q24

Number of seals or sea lions seen.

NOTE: Ignore any actual counts. Only code values given here.

Q25 What kind of seal or sea lion did you see?

NOTE: If no positive ID try using the verbal description recorded on interview sheet. Right justify codes.

Q26 How close to platform were seals or sea lions?

NOTE: Convert all other units to nearest yard and right justify numbers.

Q27 Time of day seals or sea lions observed.

Q28

Time of year seals or sea lions sighted.

Q29 Were seals/sea lions alone or in groups?

Q30 What direction were seals/ sea lions going when seen?

Column value

60

1 None

3 A few (less than ten)

4 Many (ten or more)

b Code blank if no response

$61-62$

*See Q5 for codes and value labels

63-66 Yards NOTE: If respondant answers a value greater than 9,999 yards code 9999

$\rightarrow \quad$ Code blank if no response

67

1 Unknown

2 Dawn or dust

3 Midday

4 Throughout the day

5 Night

$\rightarrow \quad$ Code blank if no response

68

\begin{tabular}{ll}
1 & Unknown \\
2 & Winter \\
3 & Summer \\
4 & Spring \\
5 & Fall \\
6 & Throughout the year \\
\hline 6 & Code bTank if no response \\
1 & Single \\
2 & Group \\
3 & Both \\
6 & Code blank if no repsonse
\end{tabular}

70

$\begin{array}{ll}1 & \text { Unknown } \\ 2 & \text { Mostly upcoast } \\ 3 & \text { Mostly downcoast } \\ 4 & \text { Mostly out to sea } \\ 5 & \text { Mostly inshore } \\ 6 & \text { Changed direction while watching } \\ 7 & \text { All directions } \\ 7 & \text { Code blank if no response or } \\ & \text { different than above }\end{array}$

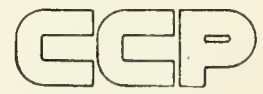


Variable

Q31

Did you notice any seals/ sea lions behavior?

NOTE: Right justify questionnaire number

Q32 Did behavior relate to platform activity?

Q33 Type of activity on platform when seals/sea lions sighted.

NOTE: Right justify activity codes.

SECOND CARD

SITE Name of platform surveyed
Column Value

71-75

QUEST_NO

No

If yes, code questionnaire number

Code blank if no response

76

1 Yes

2 No

$\rightarrow \quad$ Code blank if no response

$77-78$

1 Drilling

2 Production

3 Dornant

4 Testing

$\rightarrow \quad$ Code blank if no response

$1-10$

Value Label

Write name of platform
$\rightarrow \quad$ Code blank if missing 


\subsubsection{The In-Person Historical Interview Program}

The following is an annotated version of the SAS program to analyze the inperson historical interview data. The annotation will point out changes necessary to the program depending on whether data will be input as cards or input from tape or disk. The annotation also describes what each section of code does and where necessary program logic is.

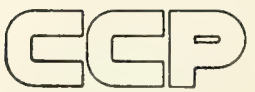




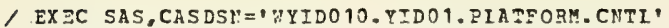

* DATA DESCRIPEION, TARIAEIE I.ABELS, AND VALOE LABELS*:

TIIONS RLRSIZE $=10040$

A:A MASTER;

UFILE CAS CLOSE=FRES;

"PO?

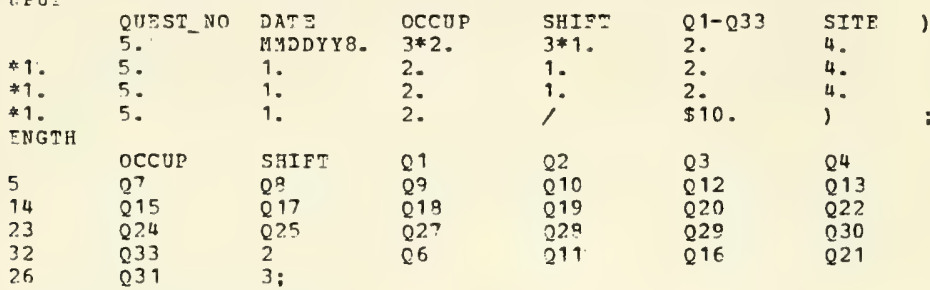

ABEL

QUES: NO=QUESTIOHAIRE NUMBER

SIME= NAME OF PLATFOP:I

OCCUP= NCCOPATION OF INTEOVIEHEF

SHIFT=SHIFT OF INEFEVIEKEE

Q $1=$ LENGTH OF TIME WORKING TEIS PLATFORM

Q2=IUTERESTED IN MARINE I.IFE?

Q3 =ARE MAMMALS SIGHTED FROM PLATFCRM OFTEN?

QU = NTNBEP. OF LARGE FHALES SEEN?

Q5= SPECIES OF WHALE SEEN?

Q6=DISTANCE FROH PIAIFOR: (IN YDS.)?

Q7=FHAT TIME OF DAY?

C8= IME OF YEAR OF WHALE SIGHEINGS?

Q9=NEPE FHALES AIONE OR IN G3OUPS?

Q10=LIRECTION WHAIES WESE UNVING?

Q 11=NOTICE ANY WHATE IEHA IOR?

C12=BEHAVIOR RELATED TO ELATFORH ACTIVITY?

$013=$ "rHAT WAS FLATFORY ACEIVTMY?

Q14=HUMBEP. CF DOLPHINS OF PORPOISES SEEN?

$215=$ SPECIES OE PORPOISE CP DOLPHIN SEEN

Q16=DISTAYCE FROM DLAZFOPY(IN YDS.)?

Q $1^{7}=$ NHAT TIME OF DAY?

Q18=-IME OF YERR OF PORECISE SIGHEIMGS?

Q19=KERE DOLPHINS AINNE OR IN GEOTPS?

Q20=DIRECTION POPP/DOLPHINS WERE MOサIษG?

$221=$ NOTICE ANY POQPOISE/DOI?HIN BEHAVINP?

Q22=3EHA"IOR RELATED IO PLATFORM ACMIVITY?

$223=$ WHAI WAS PLATFOPY ACTIVITY?

Q2.4=NIHBER OF SENLS OR SEA I.IONS SEEN?

22.5=SDECIES NF SEAL OR SEA IICY SEEN

Q2.6=DISTA शCE FEOH PI.AFFCFA (IN YDS.)?

$227=$ WHAT TIME OE D.Y?

Q2 $8=$ 'TILE OF YEAP OF SEAI/SEA ITON STGHTING'

229=WTRE SEALS/SEA IITCNS ALNHE OR IN GROURS?

Q $30=D I E E C$ ION SIAJS/SEA LIONS NEEF IOTING?

Q31= UOTICE ANY SEALS/S DA LIOUS TIHATIOR?

Q32=BEIAVIOF, RELATED TO PIATFOR: ACIIVITV?

233=NHAT WAS PIATFORM ACMIVITY?:

CDEATE YARIARLES AIMID, PNOPOIEF, ANO SEAL. THESE VAPIABLES WILI BE USED IN CREAMING REPORTS TO ANALYZE THE INTERVIEN DAMA IF THE RESZONDENT HAS IINETE TO ZDEYTTTY THE HAPENE MAMMAL TO SDECTES. 


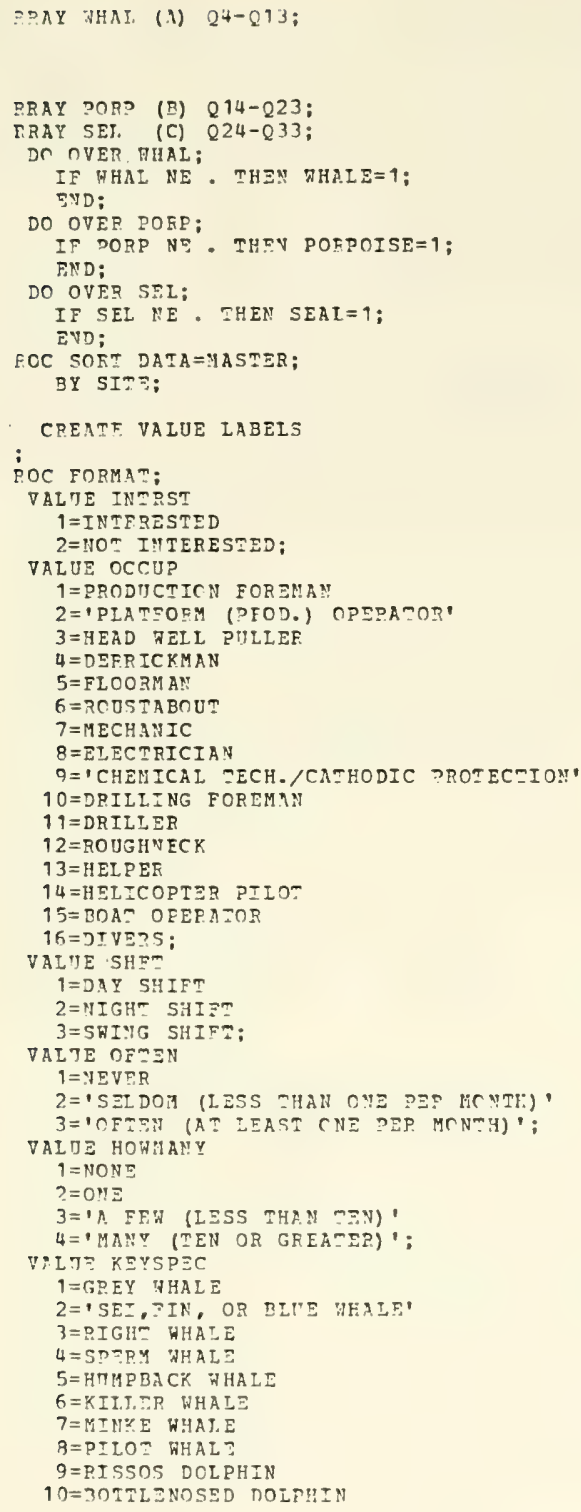




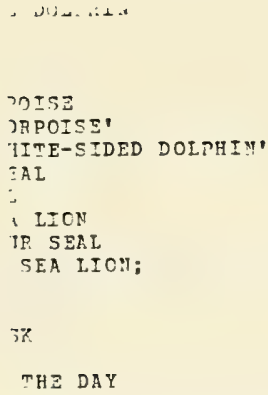




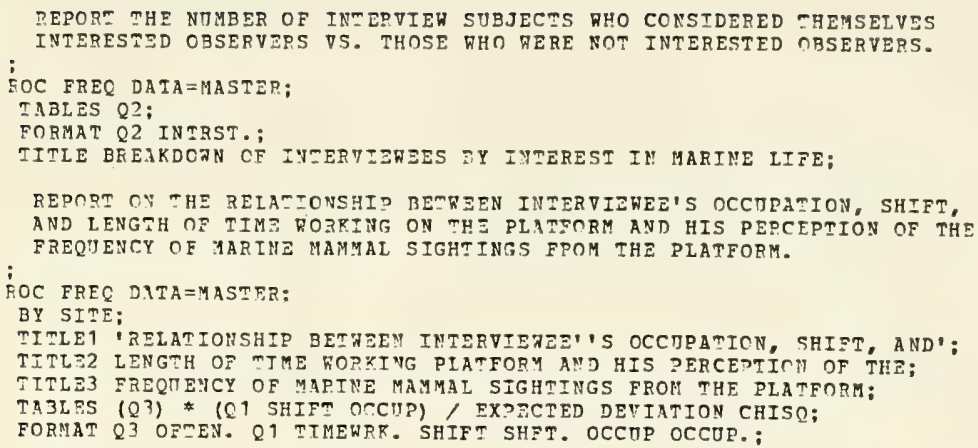

CREATE M HRE DATA SETS, CNE CONTAIIING RESPONSES CCNCERNIYG HHALSS, ONE CONCERNING PORDOISES OP DCIEYINS, AND ONE CCNCERIING SEALS OP SEI LIONS. 


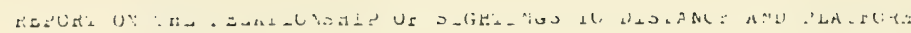

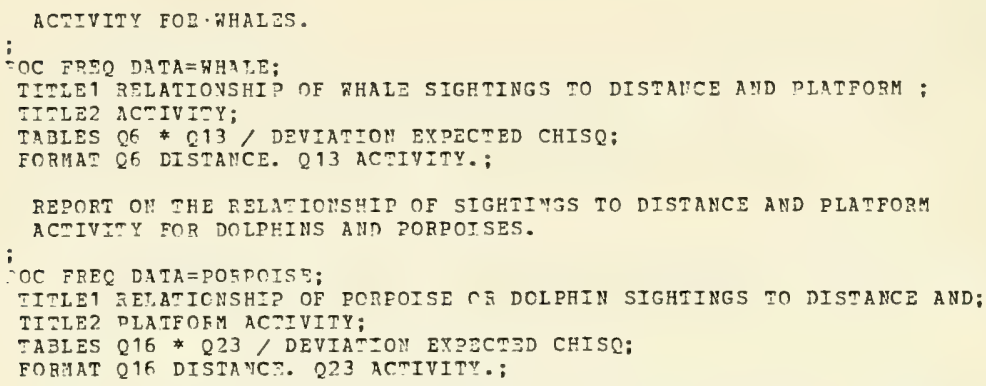


5.2.4 The Job Control Language Necessary to Run the In-Person Historical Interview Program

The following is the catalogued procedure used to execute this program. 


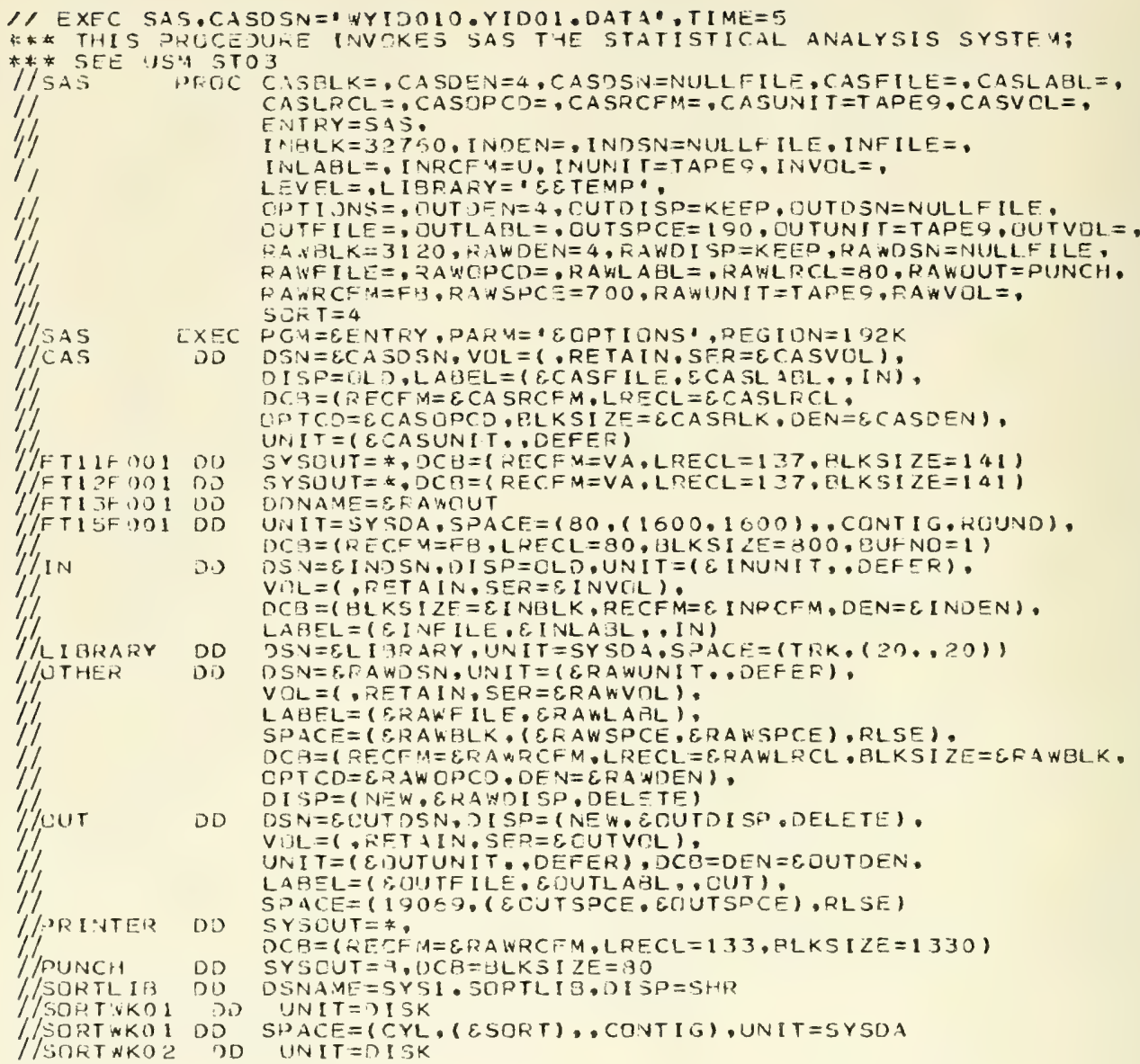

/ SURT NKOE: DO

/ SORTRKO 3 Do

$/ /$ SORT RKO 3 DO

$1 \%$

1/5TEPI I:S UU

1,1

/ / S Y snut

IFUKK

/ MLMADATA

/ /SYSIN

no

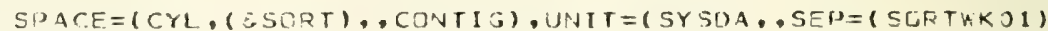
UNIT $=$ DISK

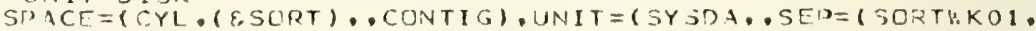
SURTWIKO?)

DSN $=$ SYS4.SAS.LDADELEVEL, DI SP=SHR

DSN $=$. LI RRRARY, DISJ- (LLD, PASS). UNIT =SYSDA.

VUL $=$ REF $=\$$. L IPRARY

SYSDUT $=$,DC $\mathrm{B}=$ SUUF $N \mathrm{NO}=1$

(INIT = SYSI)A. JPACE $=(T H K,(240,80))$

DD DSN=WYIOOIO.YIDOI. MUADATA.CNTL.DISD=OLD $\mathrm{DD}$ ‡ 


\subsubsection{Description of the Program}

The purpose of this program is to use the results of a simple questionnaire to identify marine mammals to species, to determine densities of these species, to determine the relationship, if any, between densities and oil drilling activities, and to compare the results of chance data gathered from sighting cards to data from more conventional methods of estimating marine mammal population densities.

Figure 5-1 represents the flow of the overall program which accomplishes the above goals. Raw data is read in, new variables are generated, questionnaires are evaluated to determine species of marine mammal observed, counts are tallied, densities calculated, data from an unpublished BLM report are read in, densities from both sources are compared and reports are written.

\subsubsection{Creating the Raw Data to be Read Into the Program}

This section presents information necessary to correctly create data cards for input into the sighting card analysis program.

Data will be input in standard 80-column record format. Each sighting card will result in two 80 -column records. The data will be column dependent.

This "code book" presents the data fomat, variable by variable, with column specifications, all possible values for each variable, a definition of each variable, a definition of each value, and, where appropriate, notes on convertiny multiple responses or incorrect responses to a codeable form.

The two cards which represent the information from one sighting card must be in sequence. In other words, the final data deck (or data set if on tape or disk) must have the following sequence, card one, card two, card one, card two...etc. 


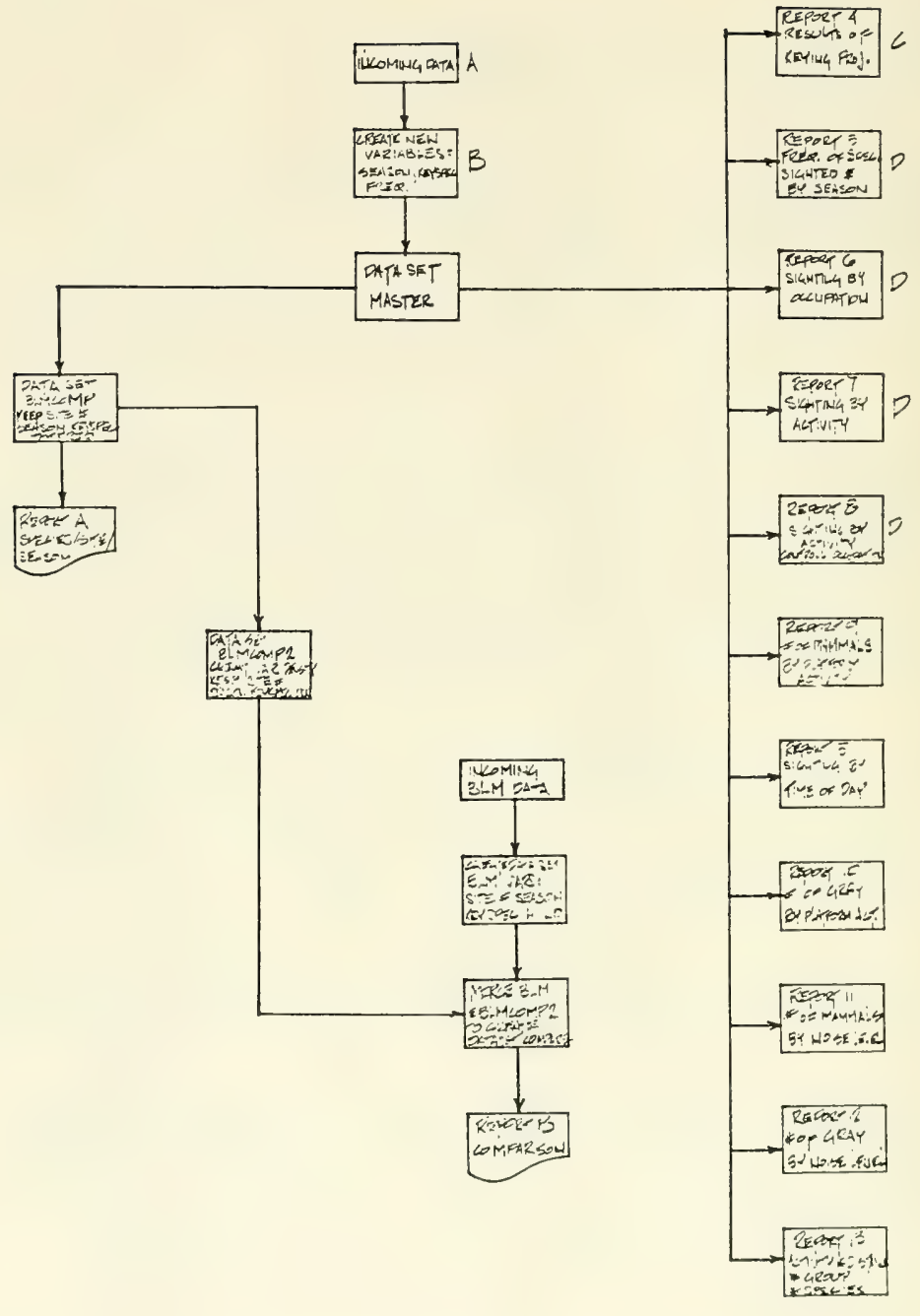

Figure 5-1 


\subsubsection{The Sighting Card Program}

Figures $5-2,5-3,5-4,5-5,5-6$ represent the logic of the section of the program which evaluates the data to determine the species of marine mammal sighted by the respondent. Note that many of the branches lead to intermediate results. if certain key questions were not answered or were answered ambiguously the results of the key to the point of ambiguity will be printed and the next sighting card analyzed.

An annotated version of the entire program is as follows. 


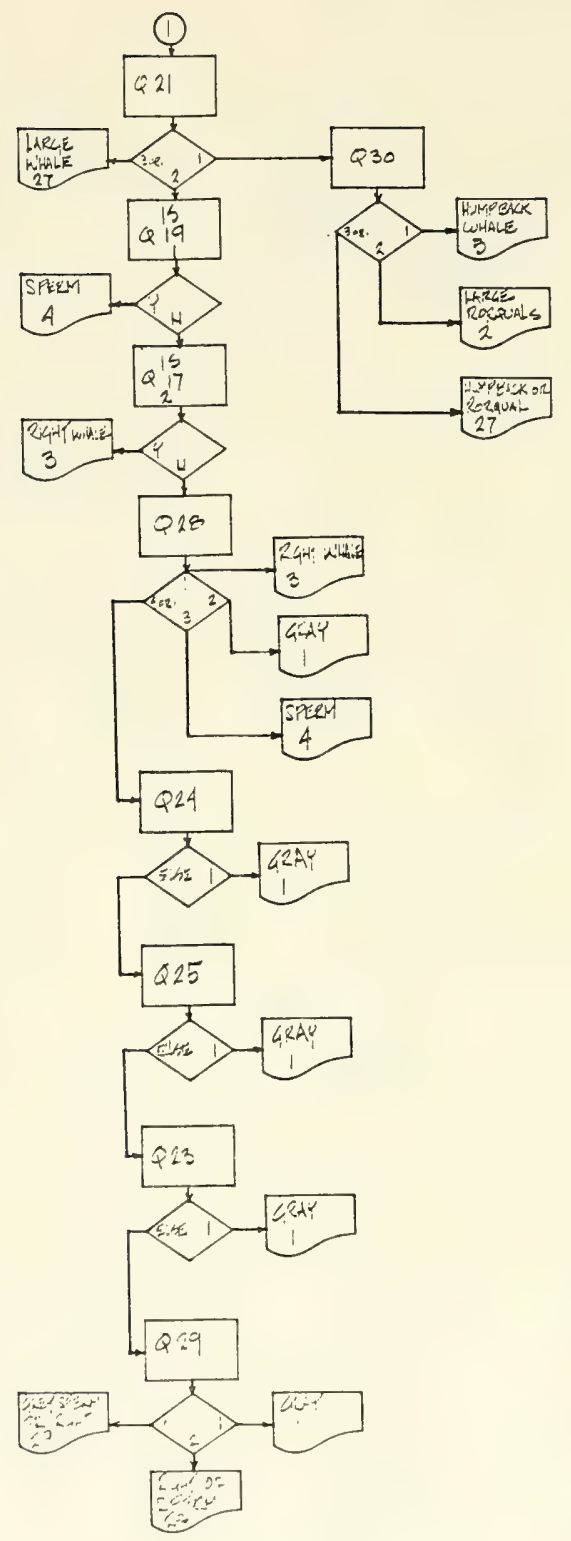

Figure 5-2 


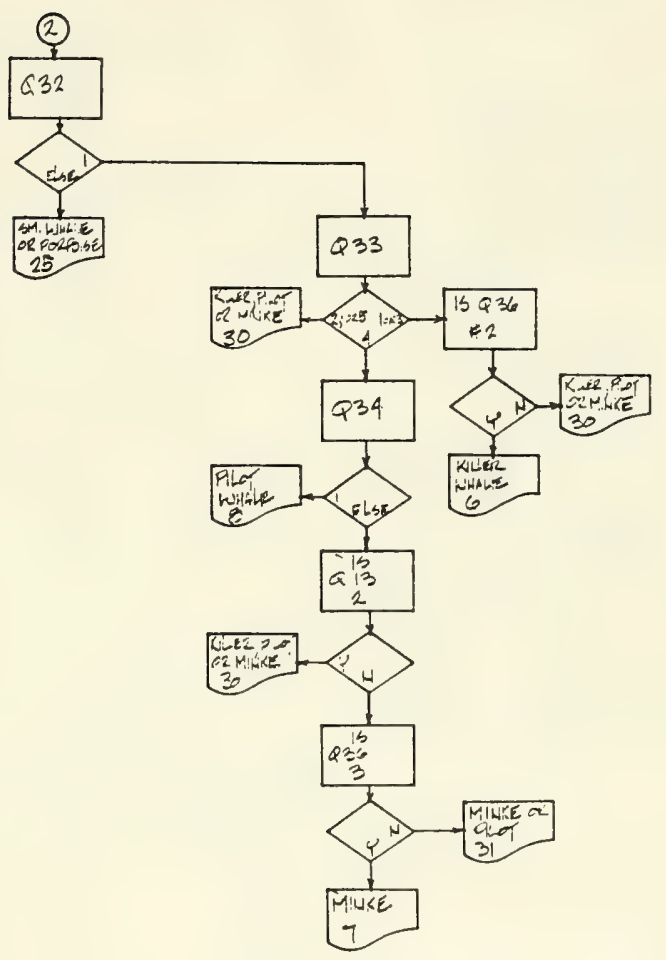

Figure 5-3 


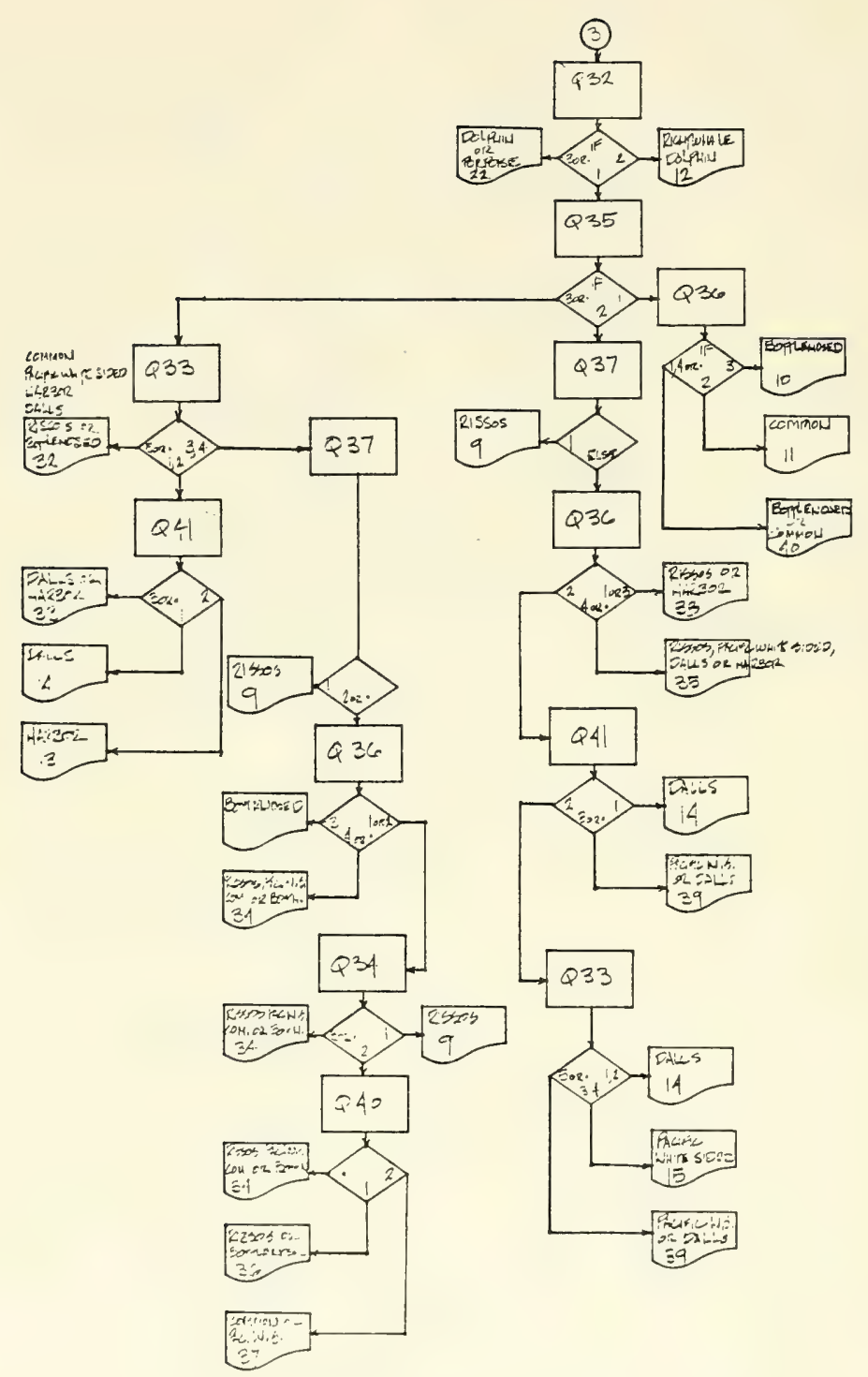

Figure 5-4 


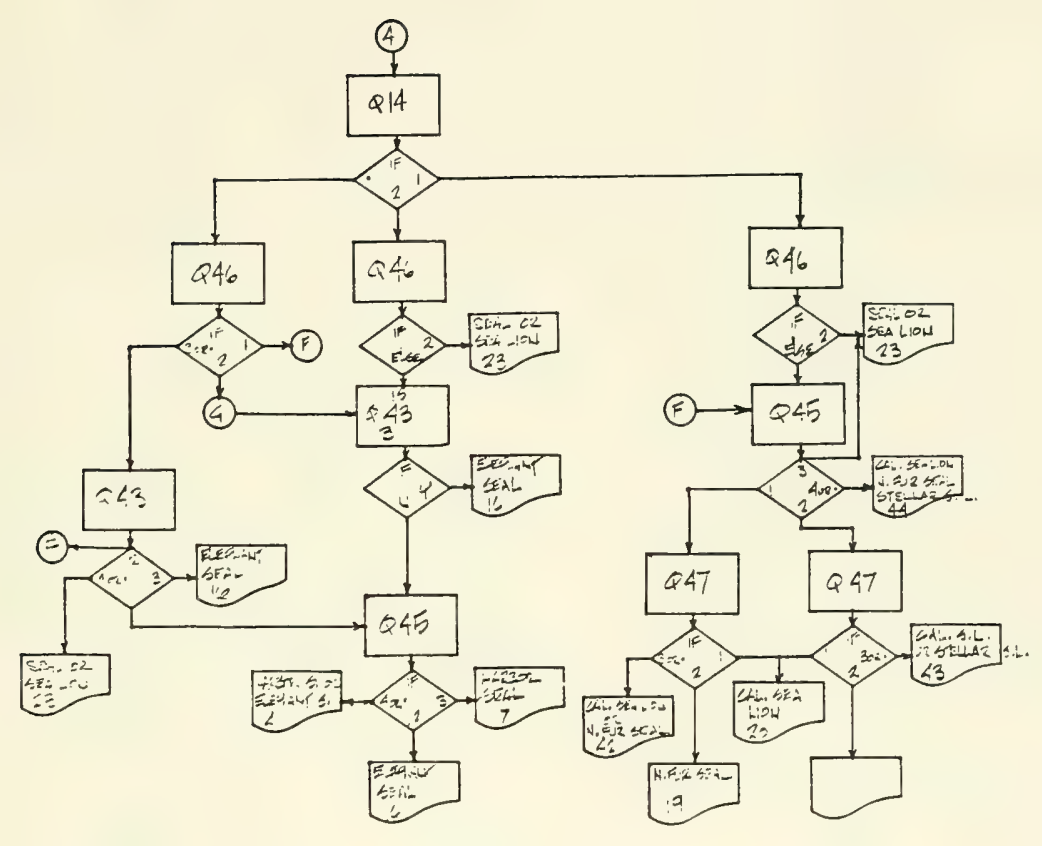

Figure 5-5 


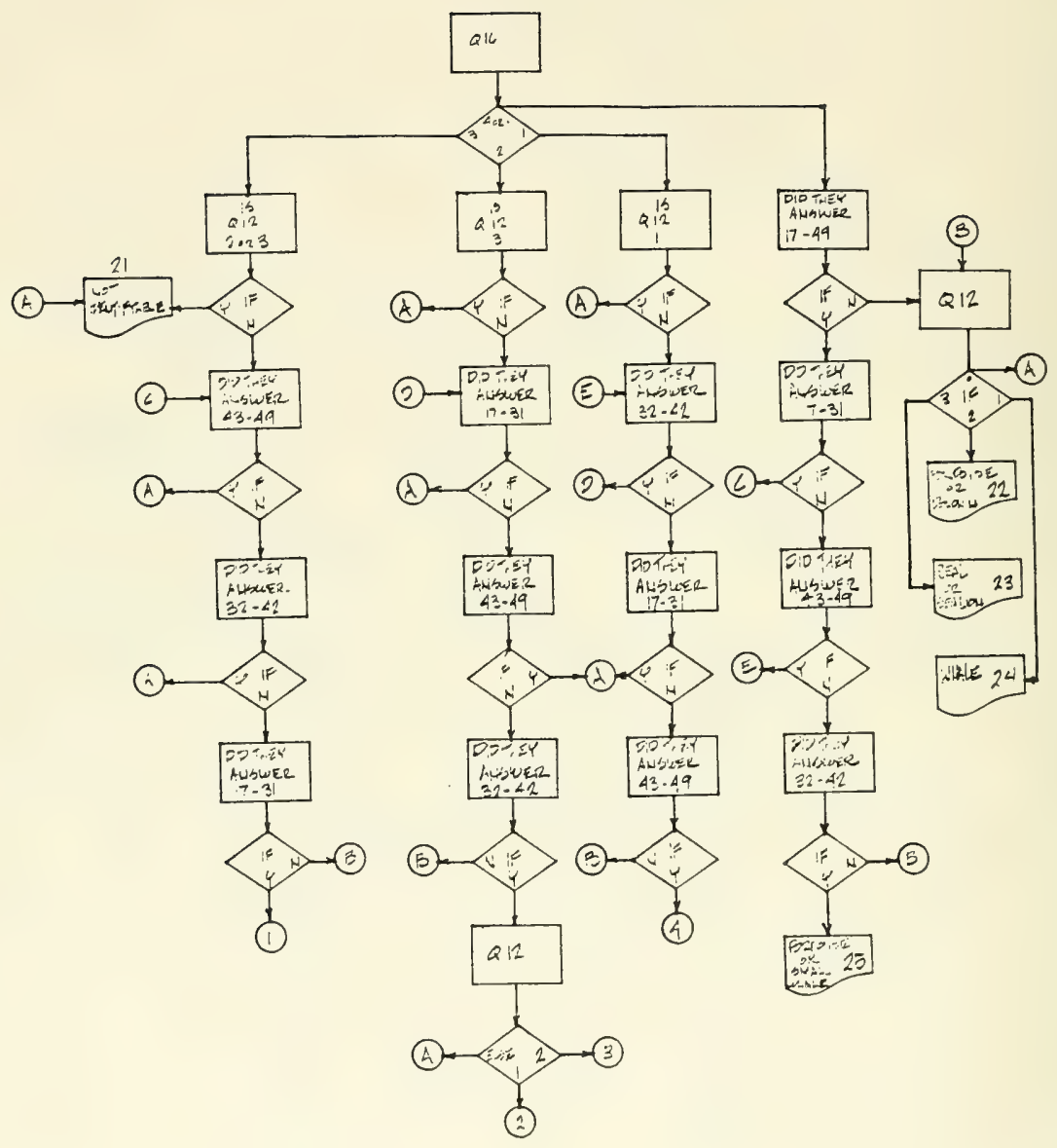

Figure 5-6 
Variable

QUEST_NO

Questionnaire Identification

Number

NOTE: Right justify value

OCCUP Occupation of Interviewee

NOTE: Code only one value in columns 6-7. Right justify the value

SITE NO Quadrat number wi thin which the oil platform is located. NOTE: Code only one quadrat per sighting card.

Right justify value of this variable.

DATE

Date this sighting card was filled out.

$11-18$

TIME SITE The time marine mammal was sighted.

NOTE: Code in military time

(i.e. $1 P M=13: 00$ ).

$19-23$
Column Value

1-5 1 Thru 99999

$6-7$

1
2
3
4
5
6
7
8
9

10

11

12

13

14

15

16

17

b

8-10 1 Thru 195
Value Label

NOTE: Each sighting card should have a unique number. The highest number that can be assigned is 99999 , since only five columns have been defined for this variable.

\section{Production Foreman}

Platform (Prod.) Operator Head Well Puller

Derrickman

Floorman

Roustabout

Mechanic

Electrician

Chemical Tech/Cathodic

Protection

Drilling Foreman

Driller

Roughneck

Helper

Hel icopter Pilot

Boat Operator

Divers

other

Code blank if no response

To determine value of this variable consult the quadrat map (Fig. 5-7). Choose the quadrat within which the oil platforin of concern is located.

NOTE: This variable is of extreme importance for comparing BLM data and the results of the sighting card data.

The format of this variable is $M M / D D / Y Y$ with the slashes (/) in columns 13 and 16 and where: MM = Month

$\mathrm{DD}=$ Day

$Y Y=$ Year

The format of this variable is $\mathrm{hh}: \mathrm{mm}$ with the colon (:) in column 21, and where:

$h h=$ hour

$\mathrm{mm}=$ minute

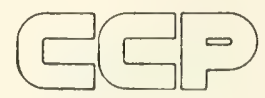


TIME FILL The time of day this sighting 24-28 card was filled out.

NOTE: Code in military time

(i.e. $2: 35 P M=14: 35$ )

ACTIVITY Activity on platform when marine mammal was sighted. NOTE: Code only one activity per sighting card. Right justify the values.

NOISE Estimate of platform noise. NOTE: Code only one noise estimate for each sighting card. Right justify the values.

Q7 Distance of mammal from platform (in yards)

NOTE: Right justify value.

$29-30$

The format of this variable is $\mathrm{hh}: \mathrm{mm}$ with the colon (:) in column 26 and where:

$\mathrm{hh}=$ hour

$\mathrm{mm}=$ minute

\section{Drilling \\ Production \\ Dormant \\ Testing \\ Blank if no response}

$31-32$

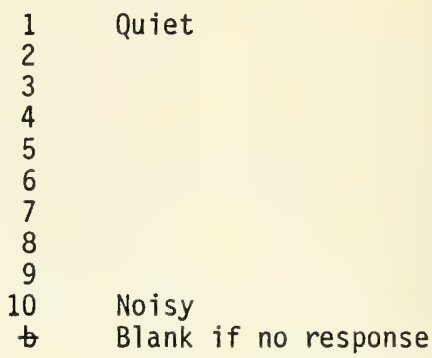

33-36 1 Thru 9999

The value of this variable should be in the units yards. Any other units should be converted. If the respondant answers a value of greater than 9,999 yards, code 9999

Q8 Direction from platform to mammal $(s)$.

1 Towards shore

2 Out to sea

3 Upcoast

4 Downcoast

$\rightarrow \quad$ Code blank if no response

Q9 Direction marine mammal traveled

38

Towards shore

Out to sea

Upcoast

Downcoast

Code blank if no response

Q10 Did mammal(s) change direction?

39 
Variable

Q11

If yes, towards or away from platform?

Q12 Kind of marine mammal sighted.

Q13

Were mammals along or in a group?

Q14 If group, how many?

Q15 Name of mammal sighted.

Q16 Size of mammal
Column Value Value Label

40

$\begin{array}{ll}1 & \text { Towards } \\ 2 & \text { Away } \\ \text { - Code blank if no response }\end{array}$

41

1 Whate

2 Porpoise or dolphin

3 Seal or sea lion

$\rightarrow \quad$ Code blank if no response

$42 \quad 1 \quad$ Single animal

2 Group of animals

$\rightarrow \quad$ Code blank if no response

43-45 1 Thru Number of animals respondant 999 sighted. If value is greater than 999, code 999

$\rightarrow \quad$ Code blank if missing

46-47 1 Gray whale

2 Sei, fin, or blue

3 Right whale

4 Sperm whale

5 Humpback whale

$6 \quad$ Killer whale

7 Minke whale

8 Pilot whale

9 Rissos dolphin (Grampus)

10 Bottlenosed dolphin (Tursiops)

11 Common dolphin

12 Right whale dolphin

13 Harbor porpoise

14 Dall's porpoise

15 Pacific white-sided dolphin

16 Elephant seal

17 Harbor seal

18 Stellar sea lion

19 Northern fur seal

20 California sea lion

- Code blank if respondant answered other than above or did not respond

481 Less than 20 feet

210 to 30 feet

3 Greater than 30 feet

4 Don't know

- Code blank if no response 


\section{Variable}

Q17

Shape and size of spout.

Q18 Shape and size of spout.

Q19 Shape and size of spout.

Q20 Shape and size of spout.

Q21 Dorsal Fin.

Q22 Did whale show flukes?

Q23 Did whale jump out of water?

Q24 Did whale stick head out of water?

Q25 Did whale slap tail?

Q26 Swimming behavior.

Q27 Was whale traveling or milling about?
Column Value

49

1 Single

2 Double

3 Don't know

$\rightarrow \quad$ Code blank if no response

50

1 Forward on head

2 Back on head

3 Don't know

b Code blank if no response

51

1 Shot forward

2 Shot straight up

3 Don't know

- Code blank if no response

52

1 Shot high

2 Shot low

3 Don't know

$\rightarrow \quad$ Code blank if no response

53

1 Present

2 Absent

3 Don't know

$\rightarrow \quad$ Code blank if no response

54

1 Yes

2 No

$\rightarrow \quad$ Code blank if no response 55

1 Yes

2 No

b Code blank if no response

56

1 Yes

2 No

b Code blank if no response

57

1 Yes

2 No

$\rightarrow \quad$ Code Blank if no response

58

1 Swam on surface

2 Dove often

* Code blank if no response

59

1 Milling about

2 Traveling

b Code blank if no response 
$\underline{\text { Variable }}$

Q28

Shape of head.

Q29 Shape of body.

Q30 Did whale have long white flippers?

Q31 Were there any young?

Q32 Occurrence of dorsal fin

Q33 Shape of dorsal fin.

Q34 Shape of head.

Q35 Description of snout.

Q36 Color of porpoise/dolphin

Q 37 Did you see scars?
61

66

67

Column value

Value Label

60

1 Broad and rounded

2 Pointed and triangular

$3 \quad$ Blunt and rounded

4 Don't know

$\rightarrow \quad$ Code blank if no response

1 Long and thin

2 Fat and rounded

3 Don't know

$b$ Code blank if no response

62

1 Yes

2 No

3 Don't know

b Code blank if no response

63

1 Yes

2 No

3 Don't know

$\rightarrow$ Code blank if no response

64

1 Present

2 Absent

3 Don't know

$\rightarrow \quad$ Code blank if no response

1 Tall, erect, triangular

2 Short, erect, triangular

3 Tall, curved backward

4 Short, curved backward

5 Don't know

$\rightarrow \quad$ Code blank if no response

1 Rounded and bulbous

2 Pointed

3 Don't know

b Code blank if no response

1 With beak

2 Without beak

3 Don't know

$\rightarrow$ Code blank if no response

68

1 Black

2 Black and white

3 Gray

4 Don't know

$\rightarrow \quad$ Code blank if no response

69

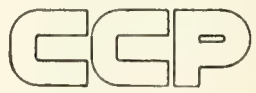


Q38 Did propoise/dolphin jump high out of water?

70

71

Q39 Was the animal porpoising?

Q40 Did mammals swim slowly and low in water?

72

73 Did mammals swim
throwing spray?

Q42 Were dolphins traveling or milling about?

Q43 Shape of head of seal/sea lion

Q44 Did you notice any ears?

Q45 Color of seal or sea lion.

Q46 Swimming behavior.

78

Q47 Did the seal/sea lion bark?

Q48 Other swimining behavior.

74

75

77

79

80 $\begin{array}{ll}1 & \text { Yes } \\ 2 & \text { No } \\ \rightarrow & \text { Code blank if no response }\end{array}$

1 Yes

2 No

b Code blank if no response

1 Yes

2 No

$\quad$ Code blank if no response

1 Yes

2 No

* Code blank if no response

1 Milling about

2 Traveling

$\rightarrow$ Code blank if no response

1 Rounded

2 Pointed

3 Large extneded nose

4 Don't know

$\rightarrow \quad$ Code blank if no response

$76 \quad 1 \quad$ Yes

2 No

$\rightarrow \quad$ Code blank if no response

1 Brown

2 Black

3 Spotted

4 Don't know

b Code blank if no response

1 Used front flippers to paddle

2 Swam iike fish with hind flipper

3 Could not tell

$\rightarrow \quad$ Code blank if no response

1 Yes

2 No

3 Don't know

b Code blank if no response
1 Leapt out of water like porpoise
2 Swam with only head showing
$\rightarrow$ Code blank if no response

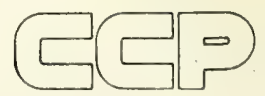


SECOND CAR.D

Q49 Were seals/sea lions traveling or milling about? NOTE: This variable will be coded in column one of card \#2.

Q50 0ther characteristics noted on sighting card \# NOTE: This variabi wiTi be coded in columns 2-6 of card \#2.
$1 \quad 1 \quad$ Milling about

2 Traveling

$\rightarrow \quad$ Code blank if no response

2-6 $\quad 0 \quad$ Code 0 if no comments

\# Code same value as variable SITE_NO if additional comments. 
5.3.4 The Job Control Language Necessary to Run the Sighting Card Program

The following is the catalogued procedure used to run SAS programs. 


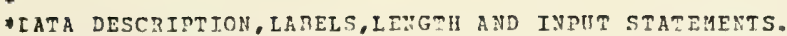

;

CPTIONS ELKSIZE $=1906$ ?

CATA YASTER;

INPUT

IENGT:

CCCUP_NO

C 11 Q 12

S19 Q20

CARL No

ACTI

$6 * 1$.

1.

C26

Q27

Q34

633

640

647

Q41

Q48

C14

Q50

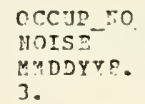

5.

$\begin{array}{ll}\text { ACFIVITY } & \text { NOTSE } \\ 813 & 814 \\ 221 & 222 \\ 829 & 820 \\ 035 & 036 \\ 842 & 243 \\ 249 & 2 \\ 3 & ;\end{array}$

IABEL

CARD NO= STGMTING CAEA NHIRER

CCCU $\bar{P}$ NO=OCCOPATICN OT RESTOUDENT

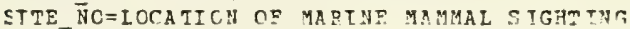

I ATE $=$ CATE OF SIGHTIR

TIMESTTE=TTME OF MARTNE MAMMAI SITHTING

TIMEPILL=TIME SIGHTINA CARJ EILLED OUT

ACTIVITY=ACTIVITY CN ELATFORM NHEN AHIMAL SIGATED

NOISE=ESTIMATE OI PLATFOPY NOISE

C7=DISTANCF. CF MAMMAL FECM DLAFFOEN

Ç $8=$ DIPECTICN FRO: PLATFORM TO MAMMAI (S)

C9=DIRECTICH MAMMAL (S) TPAVELED

C $10=$ DID MARINE MAYMALS CAANGE DIRECTIOH?

Q19=IF YES, TCVATES OR AVAY FEOM ELATFCRM?

\$ $12=K I N D(S)$ OF MARIUI MAYMAL(S) SIGHTED?

Q13=HERE MAMMALS ALCNE OR IN A GACTE?

C $14=$ IF GROUP, HOW MANY?

C $75=$ WAME OF MARMAL (S) STGEM DO

\$ $16=$ SIZE OF MAMMAL (S)

C17=STAPE AND SIZE OF BION (УणMREP)?

(18=SHAPE ANE SIZE OP BIOH (LCCATTCM)?

C 19=SHAPE ANC SIZE OF RLOW(DIRECTICN)?

C $20=$ SHAPE AHD SIZE OF EICF (IETGHT)?

C21=DORSAL FIN, PRESTNT OP ABSENT?

Q22=DTD WHALE SHOH FLURES?

C23=DIE WHALE JUMP OUT OF WATER?

C24=DID HHALE STICK VEAT CIT OF KATER?

C25=DID WHALE SLAP FLUKES?

C26=TRPE OF SHIMMTNG REYAVIDR?

Cุ27=WAS NHALE TRAVELTIG ON YILLINC ABOTI?

C $28=S Y A D E$ OF HEAD?

C29=SHARE OF PODY?

C $30=D I D$ WUALE FAVE LCUG VIITE FIIPRERS?

C31= HERE THERE AN? YOJYG?

C32=PRESENCE CF DCLPYIN TCESAL PIN?

C $33=S H A P E$ OF CORSAL FIN?

Q $34=5$ TAPE OF HEAD?

\section{TIMESITE TIYEFILI}

1 ( 5.

4.

210

Q 18

225

Q 32

239

Q 46
IYEFIIL

0
8
5
2
9
6


$535=$ SHADE OE SHOUT?

C $36=$ COLOF OF RORPOISE/LOLIIIX?

C37=DID YO'J SEE AHY SCARS?

C $38=$ DID POEROISE JUM? HIGH OJ OF TATER?

C39=DTD IHP ANTMAS YOJ SAH POIPOISE?

$40=D I D$ MAMMALS SKIY SLOWLY AND LOII IN GATER

C4 1=DID MAMMALS SYTM EADICLY THROETIS S?RAY?

C42=WERE MAMMALS TRAVELING OR MILLING ABODT?

C43= S4ADE OF SEAL/SEA LICN READ?

C44=DID YOU NOTICE AIIY EAPS?

C45=COLOR OF SEAL/SEP. LICN?

¿46=TYPE OF SWIMMING DEHAVIOR?

Q $47=$ ANY BARRI WIG BEAAVIOT?

C4B=TYPE OF SWIMMING BFHAVIOR?

C4 $3=$ HERE MAYMALS TEAVELING OR MILITNG ABOUT?

C50=OTHER COMMENES (SEE FORM * ...)?

$$
\text { : }
$$

* if data ts CN carts the asterisk fReceEjing the cards stamement shodld

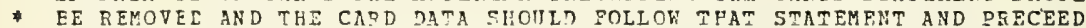

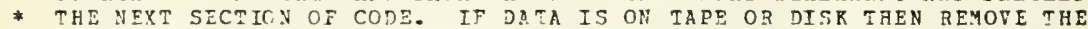

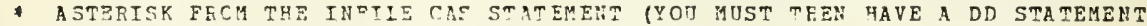

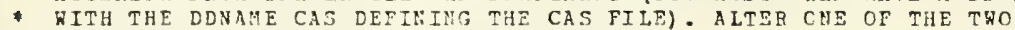

* follontyi statements as descriter abote:

\section{$\rightarrow C A R D S$ :}

- INFILE CAS:

$*$

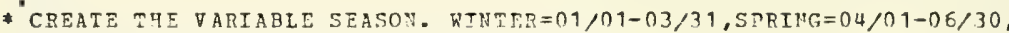

- SUMMER=07/01-09/30,FAII=10/01-12/31.

:

LAT = PJT (LATE, MMDDYYS.):

IF DAT GE $01 / 21$ ' AUD EAT LE $03 / 31$, THEN SFISON=1;

IF DAT RE $04 / 01$ ' AND EAT LE $06 / 30$ ' TEEN SEASON=?;

IF [AT GE '07/01' AND DR ? IE $103 / 30$ ' THEH SEASON=3;

IF DAT TE '10/01' AND EAT LE'12/31' MPEN SFASON=4:

* create mhe vartabie etec. preg is tqe number of animais sighted

- EY The RESPCNDENT OF EACH OIISTICNATRE.

*;

IP Q14 NE. THEN FSEC=? 14

ELSE FEEQ $=1$ :

$+$

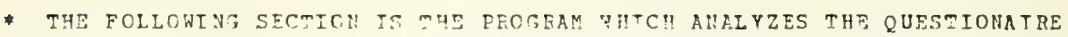

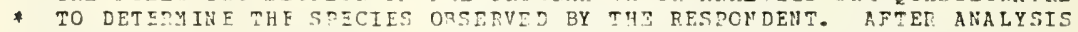

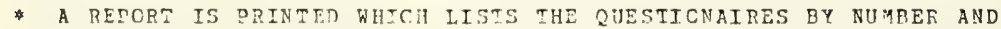

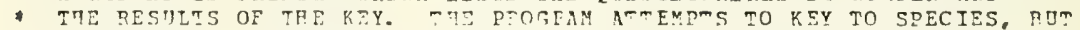

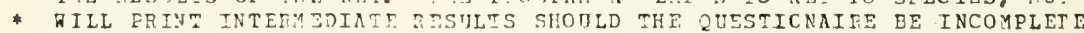

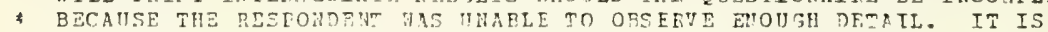

* RECOMENDED OHAT THOSE JUTCTIONLIFES THA LEAD TO INTERMEDIATE RESULT

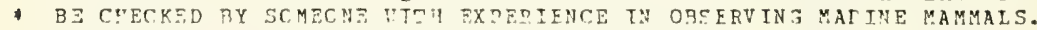

* theq may be able to mate an edicated gijess as to specifs. This

- protiar caniot mäz enticamej tussses.

*:

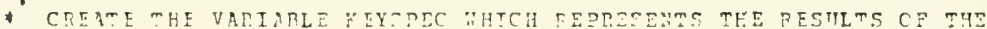

* follontang section.

:

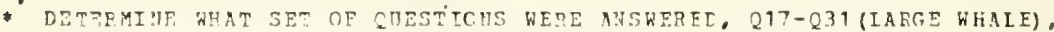

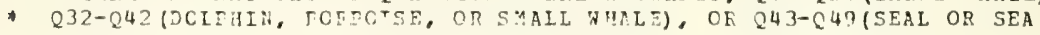




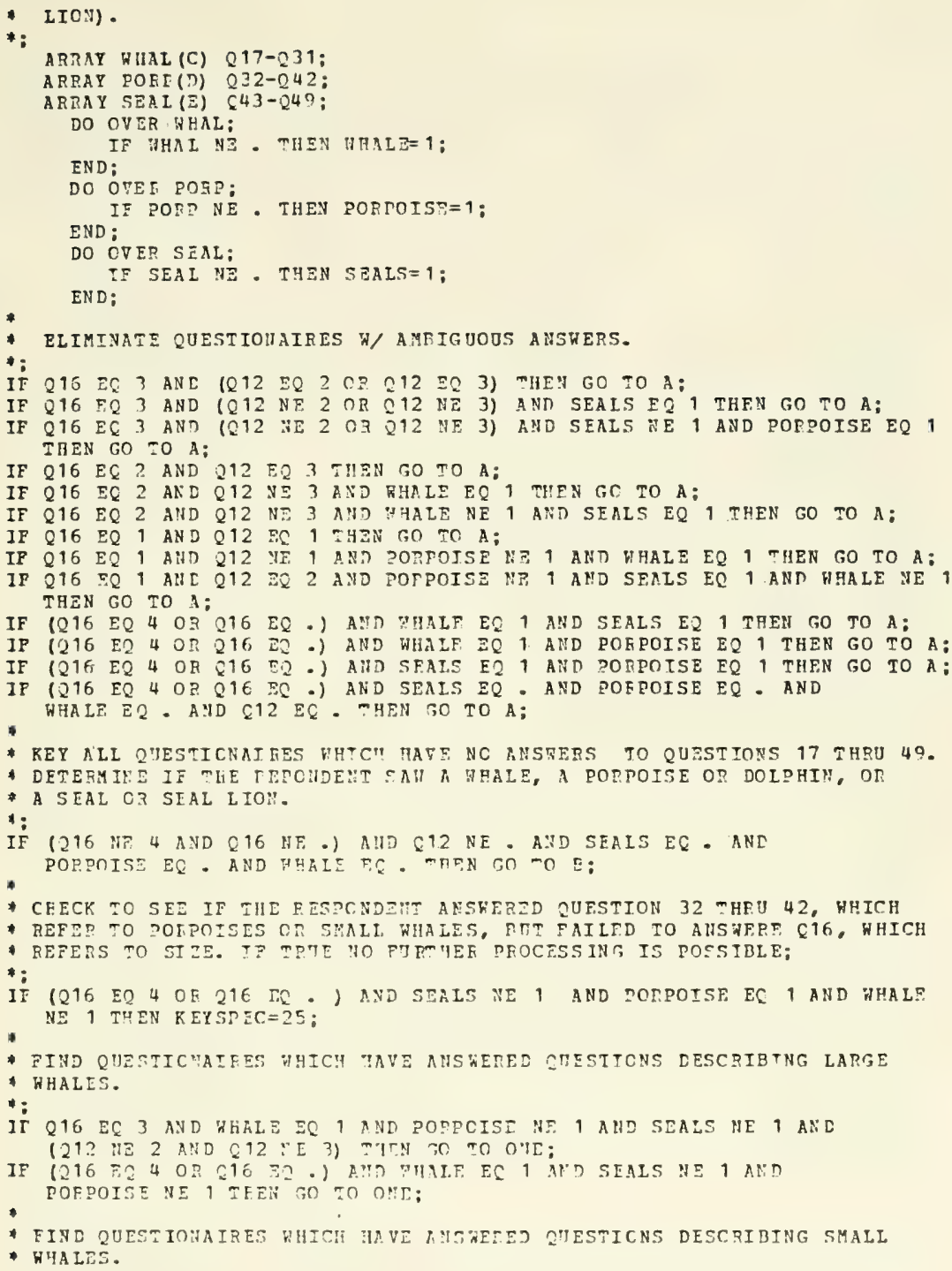


T:

216 EQ 2 ANC (Q12 $\because E$ OP. 212 VE 3) AYD VHALE NE 1 AND SEALS NE 1 AND POFDOISE $\mathrm{EQ} 1$ MHEN $\mathrm{SO}$ TO THO;

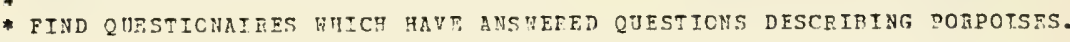

i:

IF $Q 16$ EQ 2 AUก 212 :2 2 AHD YHAL NE 1 AND POFPOISE EQ 1 AND SEALS NE 1 TI! EN KEYSPEC $=25$;

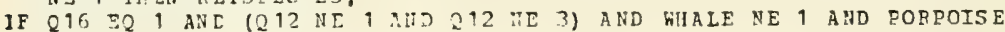
E2 1 AND SEALS NE 1 THIN GO TO TEREZ:

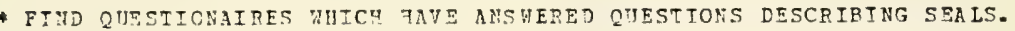
4 :

IF Q16 EQ 1 AND (Q12 NE 1 AND 212 NE 2) AND KHALE NE 1 AND PORFOISE VE 1 AND SEALS EQ 1 THEN GO TO FCUR;

IF 1216 EQ 4 OR Q $16 \mathrm{EQ}$.$) AND WHALE NE, A N D$ PORDOISE NE 1 AND SEALS EQ 1 THEN TO TO FOTIF;

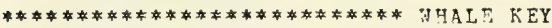

$\$$;

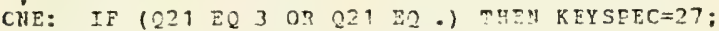

IF 221 EC 1 AN L 230 EQ 1 THEN REYS IEC=5;

IF 221 EQ 1 AND Q $3 \cap$ ES 2 THEN KEYSEEC=2:

IF Q21 EQ 1 AWD ( 830 FE 3 O? 230 EQ -) TITE KEYSEEC=27;

IE 221 EQ 2 AN $Q 19$ EC 1 HEN KEYSPEC 4 ;

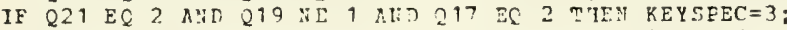

IF 221 EQ 2 AND 219 IE 1 A 37 C17 $\mathrm{NE} 2$ AUD 228 EQ 1 THEN KEYSPFC=3;

IF $Q 21 \mathrm{EC} 2$ AN $219 \mathrm{NE} 1 \mathrm{NND}$ C $17 \mathrm{NE} 2 \mathrm{AND} 228$ FQ 2 THEN REYSPEC=1:

IF Q21 FQ 2 AND Q19 $\mathrm{NE} 1$ AND 217 IE 2 A ID 228 EQ 3 THFN KEVSPFC=4:

IF $221 \mathrm{EC} 2$ ANE 219 VE 1 AND Q 17 Nล 2 AND (228 F2 4 OR 228 EQ .) AND Q24 EQ 1 TI! ZY KEYS

IF Q21 EQ 2 ANC 219 NE 1 AND 217 NE 2 AMD (Q2B EQ 4 OE Q28 EQ A) AND Q24 NE 1 AND 225 HE 1 AND $Q 23$ EQ 1 THEN KEYSEEC=1:

IF $221 \mathrm{EQ}$ ? तNE Q19 UE 1 ANS $217 \mathrm{NE} 2$ AND (Q28 EQ 4 OF 228 EQ .) AID 024 ME 1 AND $225 \mathrm{NE} 1 \mathrm{AND} 223 \mathrm{NE} 1$ A YD $229 \mathrm{EQ} 1$ THEN KEYSPEC=1;

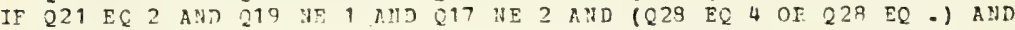
$024 \mathrm{NE} 1 \mathrm{AND} 225 \mathrm{NF} 1 \mathrm{AND} 023 \mathrm{NE} 1$ AND 29 EQ 2 THEN KFYSPEC=28:

IF Q21 EC 2 AND Q19 IE 1 ANJ 217 ï 2 A AD (228 EQ 4 OP Q28 EQ .) AllD

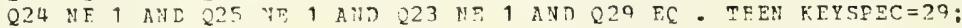
LET RA :

: :

TWO: IF Q32 NP T TUEN KEYSEEC $=25$

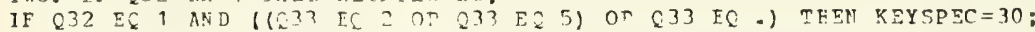

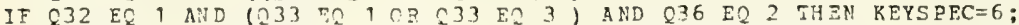

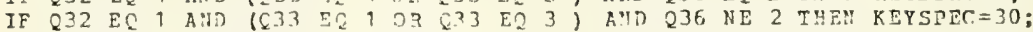

$1 F \quad 832 \mathrm{EQ} 1$ AND 233 EC 4 AID $234 \mathrm{EC}$ I THEN KETSEEC=R:

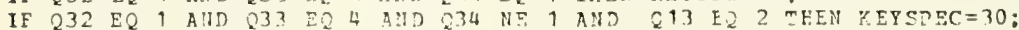

IF 232 EQ 1 ALD 233 ER 4 AID 234 YE 1 AND C 13 NE 2 AND Q36 EQ 3 THEN $K$ P Y $\mathrm{YSEC}=$ ? :

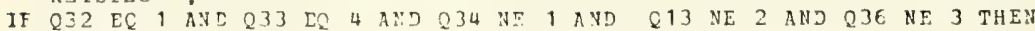
KEYSEEC $=31$; EETUEN:

$\rightarrow$

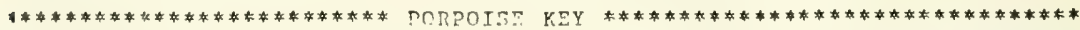
$\because$

IHREE: IF 032 EQ 2 THEN KEYSPEC=12; 
IF $232 \mathrm{EC}$. OE $Q 32$ EQ 3 THER KRTSPEC $=22$ :

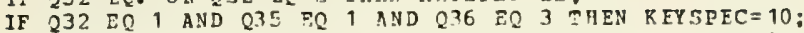

IF Q32 EQ 1 ANC 35 EQ 1 AND 236 ES 2 THEN KEYSEEC=11:

IF $Q 32$ F.Q 1 AND $235 \mathrm{EQ} 1$ AND (236 NE 2 AND 236 NE 3) THEN KEYSPEC=40:

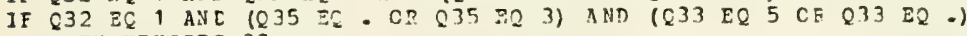
THEN KEYSPEC $=32$ :

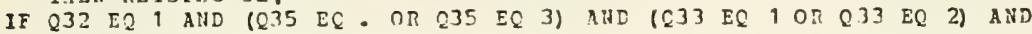
Q41 EQ 1 THEN KEY SREC $=14$;

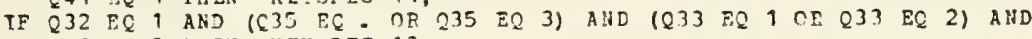
C 41 EC 2 THEN KEYSPEC=13;

IF Q32 EQ 1 AND ( $835 \mathrm{EQ}$. O? $235 \mathrm{EQ} 3) \mathrm{AND}(033 \mathrm{EQ} 1$ OR Q33 EQ 2) AND (Q4 1 FQ 3 OI 241 EQ.) FHEA REYSEZC=33;

IF $Q 32 \mathrm{EQ}, \mathrm{AHC}$ (C $35 \mathrm{ZQ}$. OP $235 \mathrm{EC} \mathrm{3)} \mathrm{AND} \mathrm{(Q33} \mathrm{EQ} 3$ OR C33 EQ 4) AND Q37 EQ 1 THEN KEYSFEC=?

IF $Q 32 \mathrm{EQ} 1 \mathrm{AND}(\mathrm{Q} 35 \mathrm{EQ}$. OR $Q 35 \mathrm{EQ} 3)$ AHD (Q33 EQ 3 OE Q33 $\mathrm{EQ}$ 4) AND Q37 NE 1 AND Q36 FQ 3 IMEN REYSTEC=10:

IF C32 EQ 1 AND (235 EQ. OR Q35 EQ 3) AND (Q33 EQ 3 OR Q 33 EQ 4) AND $Q 37$ NE 1 AND ( 236 324 OR $Q 36$ EQ •) THEN KEYSFEC $=34$ :

IF $Q 32 \mathrm{EC} 1$ AND ( $35 \mathrm{FE}$. OR $635 \mathrm{EQ} 3$ ) AND (C33 EQ $3 \mathrm{CR} Q 33$ EQ 4) AND Q37 NE 1 ANC ( Q3E E2 1 OR 236 E2 2) AND 234 EQ 1 THEN KEY S PEC $=9$;

IF $Q 32 \mathrm{EQ} 1$ ANר (Q35 $\mathrm{EQ}$. OR Q35 $\mathrm{EQ}$ 3) ANC (Q33 EQ 3 OE Q 33 EQ 4)

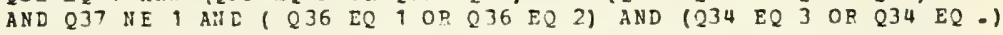
THEN KE TSEEC $=34$;

IF $232 \mathrm{EQ} 1$ AND $(035 \mathrm{EQ}$. OR $235 \mathrm{EQ} 3) \mathrm{AND}(\mathrm{Q33}$ E2 3 OR 233 EQ 4) AND Q37 VE 1 AND ( Q $36 \mathrm{EQ} 1$ OR 236 EQ 2) AND Q34 EQ 2 AND Q40 EQ. THEN REYSEEC $=34$;

$1 F \quad 032 \mathrm{EQ} 1 \mathrm{AND}(\mathrm{Q} 35 \mathrm{EQ}$. DF $235 \mathrm{EQ} 3)$ NND (Q33 EQ 3 OF Q33 EQ 4) AND Q3? NE 1 KND ( 236 त2 9 OR $Q 36$ EQ 2) AND Q34 EQ 2 AND Q4O EQ 1 THEN KEYSPEC $=36$ :

IF Q32 EQ 1 AND (Q35 EQ. OR $235 \mathrm{EQ}$ 3) AND (Q33 EQ 3 OF Q33 EQ 4) AND Q37 NE 1 AND ( 236 E2 1 OB Q 36 E2 2) AND Q34 EQ 2 AND Q4O EQ 2 THEN KEYSPEC $=37$;

IF Q32 EQ 1 AND $Q 35$ EQ ? AHD Q37 EQ I THEY REYSDEC=9:

IF Q32 EQ 1 AND $Q 35$ EC 2 NND 237 NE 1 AND (Q36 EQ 1 OE Q36 EQ 3) THEN KEYSEEC=38;

IF Q32 EQ 1 AND Q35 ER 2 AND Q 37 NE 1 AND (Q36 EQ 4 OE Q36 EQ .) THEN KEYSEEC $=35$ :

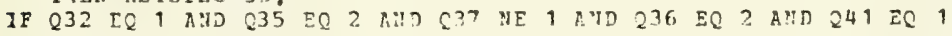
IHEN KEYSPEC $=14$;

IF $Q 32$ EQ 1 AND 235 EQ 2 AND Q37 NE 1 AND 236 EC 2 AND 1 (Q4 1 EQ 3 OF. Q41 EQ.) THEN KEYSPEC $=33$;

IF 232 EQ 1 AliD $Q 35$ ZQ 2 IN 237 NE 1 AND 236 EQ 2 AND Q4 1 EQ 2 AND 1033 EQ 1 OR Q33 EO 2) MIEY KEYC EEC=14;

IF Q32. EQ 1 AV 235 EC 2 AND $237 \mathrm{NE} 1$ AND 236 EE 2 AND C4T EQ 2 AND (Q33 EQ 3 OR 233 EQ 4 ) THEVI KEYSFEC= 15:

IF $Q 32 \mathrm{EC} 1$ AID 235 Zू 2 तND $237 \mathrm{NE} 1$ AND 236 FC 2 AND 241 EQ 2 AND (Q33 EQ 5 O 233 BQ -) TYE. REYSEEC=39;

\section{EET EIV:}

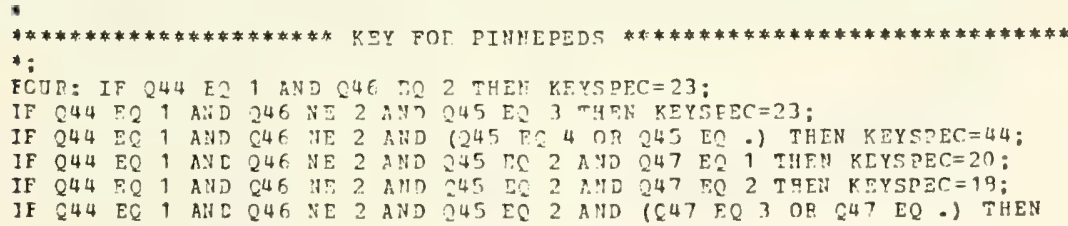


KEYSPEC $=43$;

IF 044 EC 1 AND 246 NE 2 AMD 245 F2 1 AND 247 EQ 1 THEN KFYSPEC=20;

IF Q44 EQ 1 ANI 246 NE 2 AND 245 ES 1 AND 247 Fू 2 THEN KEYSPEC=19:

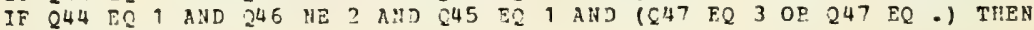
KEYSEEC $=42$ :

IF 244 EQ 2 AND 246 E2 2 TYIII KFYSPEC=23;

IF 244 EQ ? AAC 246 NE 2 AND 243 E. 3 THEN KEYSPEC $=16$;

IF Q44 EC 2 ANI 246 UE 2 AND 243 WE 3 A ND Q 45 EQ 3 THEN KEYSDEC=1?:

IF Q44 EQ 2 AND 246 IE 2 NND 243 NE 3 AND (E45 FQ 1 OE 245 EQ 2) THEN KETS DEC $=16$;

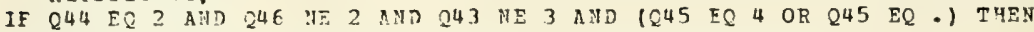
KEYS DEC $=41$

IF Q44 EQ . AND Q46 ER 1 AND 245 TQ 3 THEN KEYSEEC=23;

IF $Q 44 \mathrm{EQ}$. AID 246 E 1 AND $Q 45$ EQ 2 AMD 247 EQ 1 TAEN KFYSPEC=20;

$1 \mathrm{~F} Q 44$ EQ . Air 246 ER 1 AND 245 EQ 2 AND Q47 EQ 2 THEN KEYSPEC=18;

IF Q44 EQ . AND Q46 EQ 1 AND Q45 F.Q 2 AND (847 EQ 3 OR Q 47 EQ -) THEN KIYSPEC $=43$;

IF $Q 44 \mathrm{EQ}$. AND 246 EQ 1 AND (Q45 EQ 4 OR 245 B2 -) TFEN KEYSPEC=44:

IF Q44 EC: AND Q46 FQ 1 AND 245 EQ 1 AND 247 EQ 1 THEN KEYSPEC $=20$;

IF Q44 EQ . AND Q $4 E$ ES 1 AND 245 EC 1 AND $Q 47$ EQ 2 THEN KLYSPEC=19:

IF Q44 EQ. AND Q46 E2 1 ANT C45 FQ 1 AND (Q47 EQ 3 OR Q47 EQ .) THEN KEYSPEC $=42$;

IF Q44 EQ. AND 246 EQ 2 ANI C4 3 EQ 3 FHEN KEYSPEC=23:

IF Q44 E2 - AND Q46 E2 ? AND 43 NE 3 AND 245 EQ 3 THEN KEYSDEC $=17$;

IF Q44 EQ. AND 246 FQ 2 AHD Q43 $\because: 5.3$ AND (Q45 EQ 1 OR 245 EQ 2) THEN K.: Y SPEC $=16$;

IF Q44 EQ . AND 246 E2 2 AND $243 \mathrm{nT} 3 \mathrm{~N} N \mathrm{D}$ (Q45 EQ 4 OR C45 EQ -) THEN REYS PEC $=41$;

IF 244 EQ . AND (Q46 EQ 3 OR 246 EQ .) AND Q43 521 AND Q45 EQ 3 THEN $K E Y S P F,=17$;

IF Q44 EQ. AND (CUE EQ $303246 \mathrm{EQ}$.) AND Q43 EQ 1 AND (Q45 EQ T OP. Q45 EQ 2) THEN KEYSPIC=16;

IF $244 \mathrm{EQ}$. AND $(846 \mathrm{EC} 3$ OR $246 \mathrm{EQ}$.) AND 243 EQ 1 ANA $(245 \mathrm{EQ} 4 \mathrm{OR}$ Q45 EQ .) THEY KEYSPEC $=41$;

IF Q44 EQ - AND $(846$ EQ 3 O? 246 EQ .) AND Q43 FQ 2 AND 245 EQ 3 THEN $\mathrm{K}$ IY SPEC $=23$;

IF Q44 EQ AND ( 246 EQ 3 กE Q 46 EQ -) AND 243 EQ 2 AND Q45 EQ 1 AND Q47 EQ 1 TAEN KEYSP ZC $=20$ :

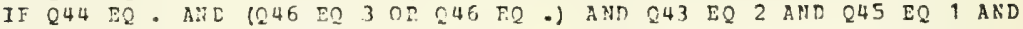
Q 47 EQ 2 TIEN KEYSPEC=1?:

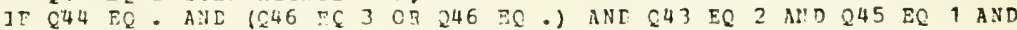
$(247$ EQ 300247 E2, T TAE KRYSPEC $=42$;

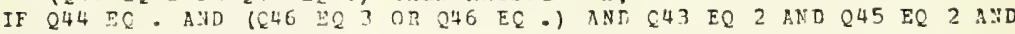
C47 EQ 1 THEN KETSDEC $=20$;

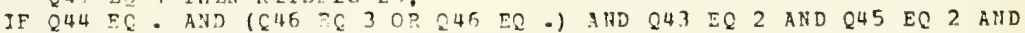
Q47 EC 2 TIIEN KEYTDEC=18;

IF Q44 EC. ATD $(246$ EQ 3 ก 246 BE.) AND Q43 EQ 2 AND C 45 EQ 2 AND (247 EQ 3 OF 247 EQ.) TपEM P.EYSEEC $=43$;

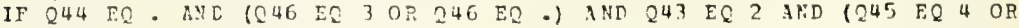
C45 EQ.) THEN KEYS DEC $=44$;

IF 244 EQ . AHD $(246$ EQ 3 OR 246 ER -) AND C43 FQ 3 THEN KEYSERC=16:

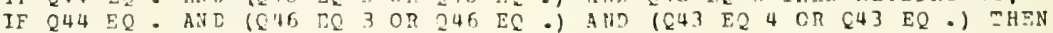
KEYSPEC $=23$;

EFTUR: :

A: KBYSPFC $=21$;

IETUEN:

B:IP 212 ED . THEN KBYSEEC=?1;

IF Q12 ES 1 TKE! KEYS?EC=?4; 


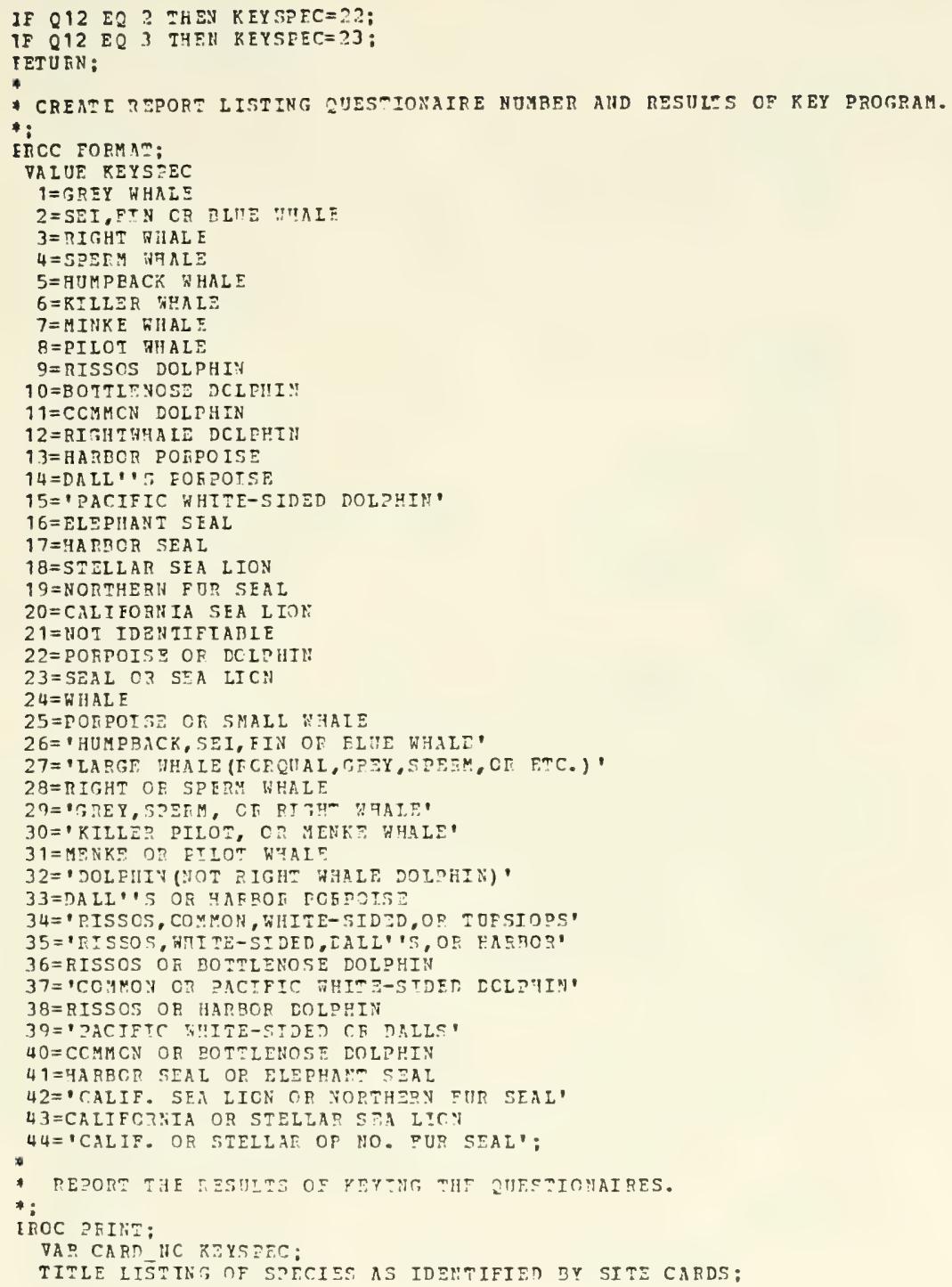




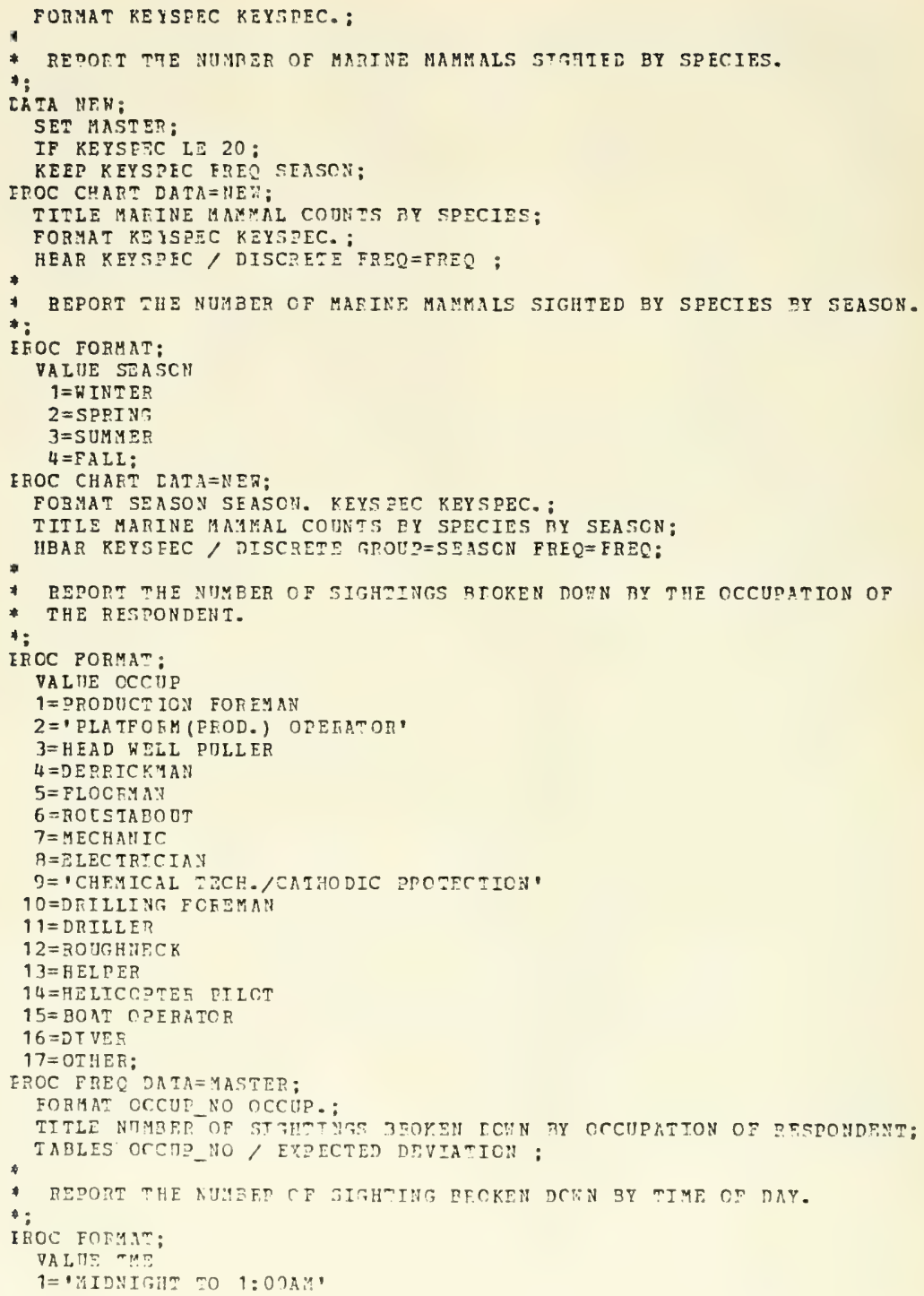




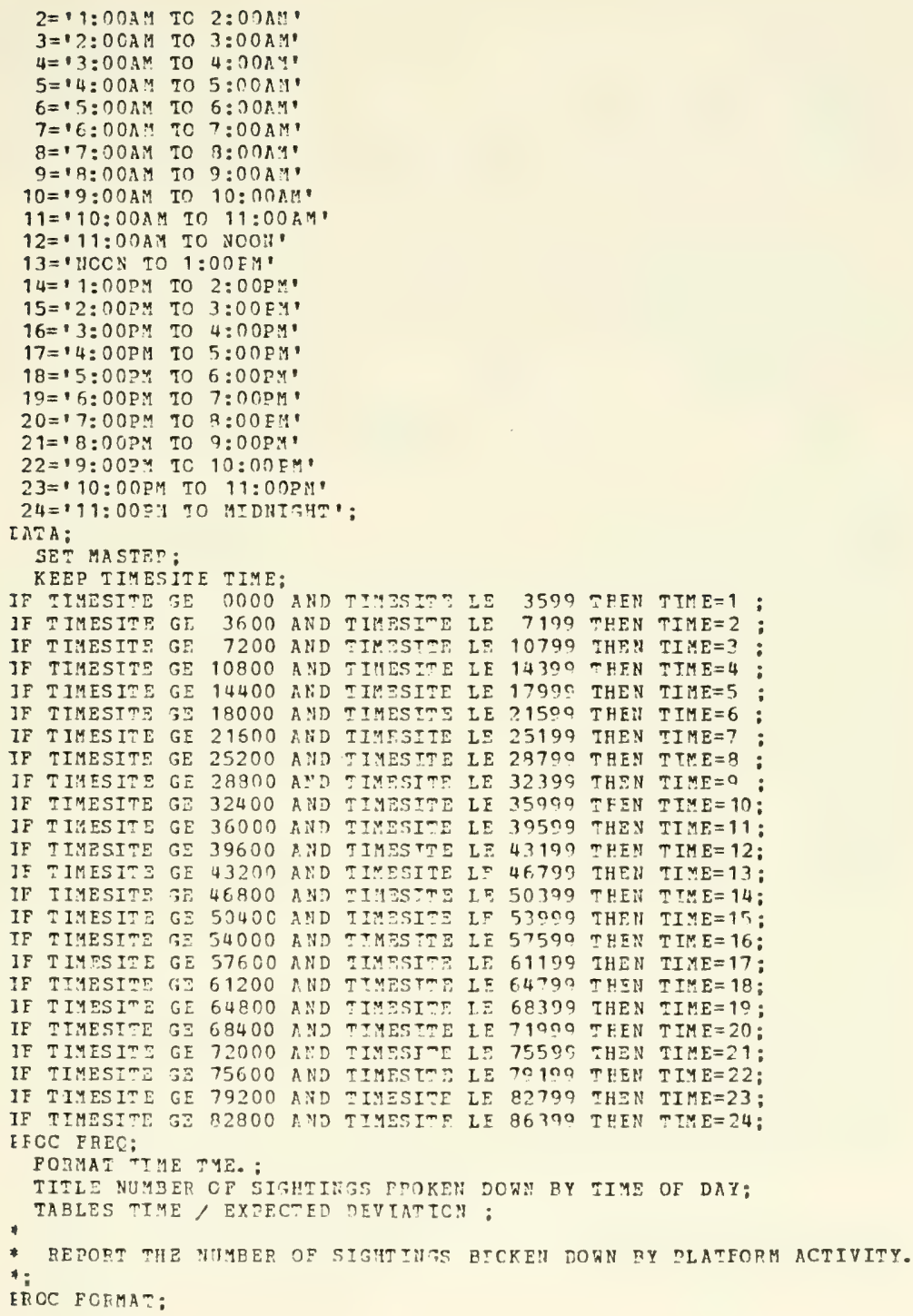




\section{VALUE ACTIVITY}

$1=$ DP.ILIING

$2=$ PROD LC - IC

$3=D C B M A N T$

$4=\operatorname{TrSTIST}$;

EEOC FRTO CATA=1ASTER:

FORMAT ACTIVITY RCIVITY.:

TITLE NU:BER OF SIGHTIFGS BROKEN DOHN BY PLATFORM ACTIVITY;

TABLES ACIIVITY / EXPECTED DEVIATION;

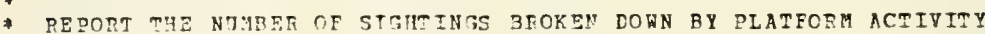

* CONTROLLING FOR OCCUPATION OF RFSECNDET. ;

$*$

FIOC FREC DATA=MASTEP;

FORMAT ACTIVITY ACTIVIMY. OCCIN NC OCCUT.;

IITLE 1 NUMBER OF SIGHTINGS BROREN DCWN BY PLATFCFM ACTIVITY CONZFOLLING;

TITLE2 FOR CCCTPAIIOU OE RESEOUDENT.;

TABLES RCTIVITY*OCCII NO / ALL;

* report the ntyser of mamals sighted bfoken don bi platform

* ACTIVITY.

$1:$

PROC FREC DATA=MASTER;

FOBIAT ACTIVITY AC PIVIIY.;

TITLE NUY3ER OF MAMYALS SIGHTZD EFOKEN DOFN BY PIATFORM ACTIVIMY.:

TABLES ACIIVITY, EYPECTED JEVIATION;

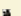

WEIGHT FREQ:

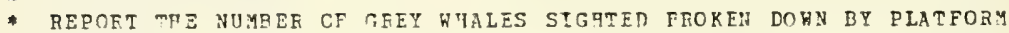

$*$; ACTIVITY.

I AT A ;

SET MASTER:

IF REYSPEC $=1$;

KEE? REYSEEC ACIIVIFY FEEQ ;

IFOC FFEQ;

FORMAT ACTIVITY ACIIVITY. ;

TITLE1 NUYBER OF GEEY WIALES SIGHTFD BRCKEN DOWN BY ELATFORM:

TITIE2 ACIIVTTY. :

TABLES NCTIVITT; EXPTCTED DEVIATION ;

A ศEIGHT FREC;

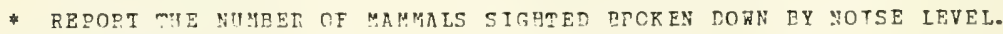

4 ;

ER̃CC FOTMAT:

VALUE NOIJE

$1=$ QUTE T

$10=V$ ERY "OIST;

EPOC FREQ DATA= $1 A S T E R$ :

FORIAT NOISE NOISE.;

TITLE NUKRED OF MAMMALS SEBITED FFCKEN DONN BY NOISE LEVEL;

TABLES YOIJE / EXPECTED DEVIA:ION ;

WEITHT FREC:

4

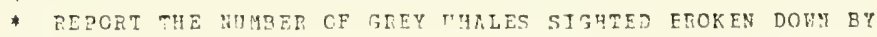

* VOISE LEVEL.

*:

I AT A: 


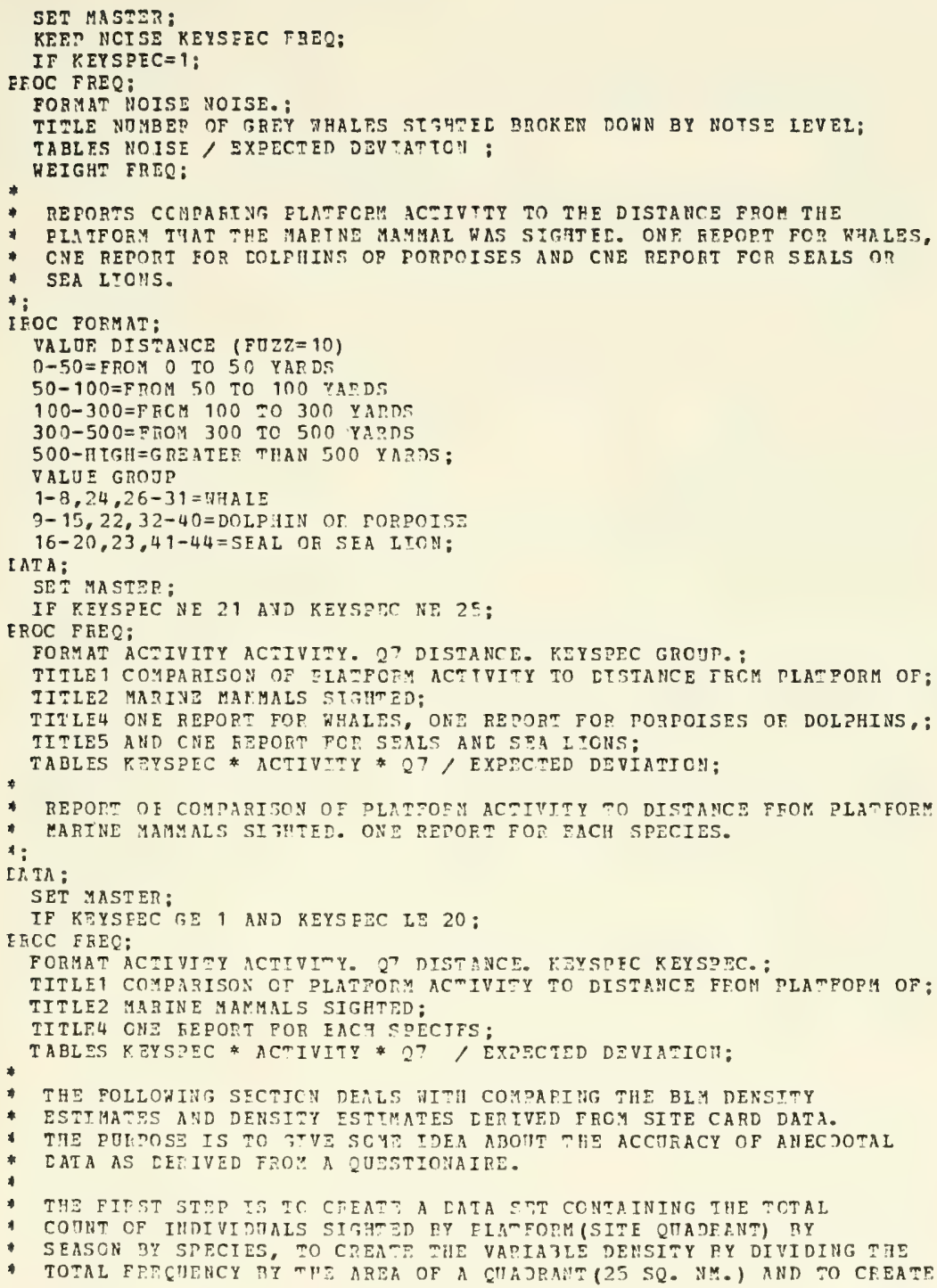




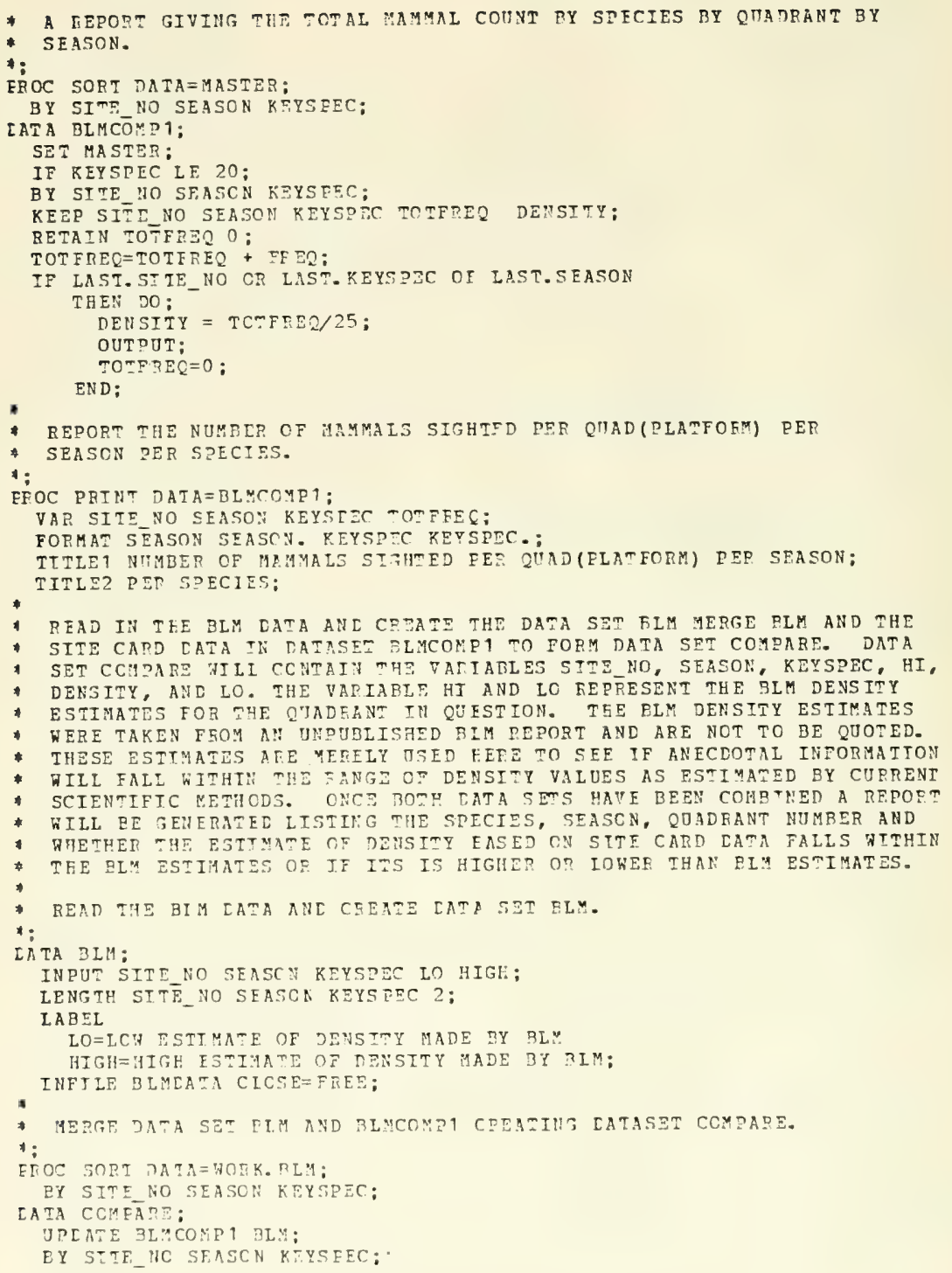


IF DENSITY NE : :

1

* compape site cafd density estimate uith biy high and lop densimy * estrmate fCR each! quajent.

$*$;

DAIA CCMEARE:

SET CCMPAKE:

IF LO EQ . DI भIGH RQ. THEN RESULT $=4$;

IF DENSITY GE IO AND DENSITY LF HIGH TFEN RFSOLT=1;

IF DENSTTY LT LO TIEN RESULT=2;

IF DENSITY GT HIGH THEN RESULT=3;

$+$

* report on the restuts of dznstty comparischs

*:

ERCC FORMAF;

VALUE FESUIT

1=DENSITY WITHIN RAHGE OF BLM FSTIMATES

2=DENSTTY LOUER THAN PLM ESTIMATES

3=DENSITY HIGHEF THAN BLM ESTIMATES

$4=$ NO ESTIMATES MADE RY BLY;

EFOC PRINT CAT $\Lambda=$ CONPARE;

FORMAT SEASCN SEASON. KEYS PEC KEYSPEC. PESULT RESULT.;

TIMLE1 RESULTS OF COMPARING SITE CARD DENSITY ESTIMATES AND BLM: TITLE2. DENSTTY ESTIUATES:

FFOC FREQ LATA=COMPARE;

TITLE BREAKDCHN CF DENSITY CCYEARISONS;

FOKMAT RESULT RESULT.;

TABLES FESCLT:

* report on stght cafds hitch hate addttonal comments describing

- marine mamMals

4

IAT A:

SE $\rightarrow$ MASTEE;

IF Q50 NE O;

KEEP Q50:

EEOC PRINT;

TTTLE1 DLEASE NOME: TRE FOLLONIHG STGUT CAROS HAVE ADDITIOHAL;

TILLE COMMENTS DESCRIEING MARINA MAMMALS; 


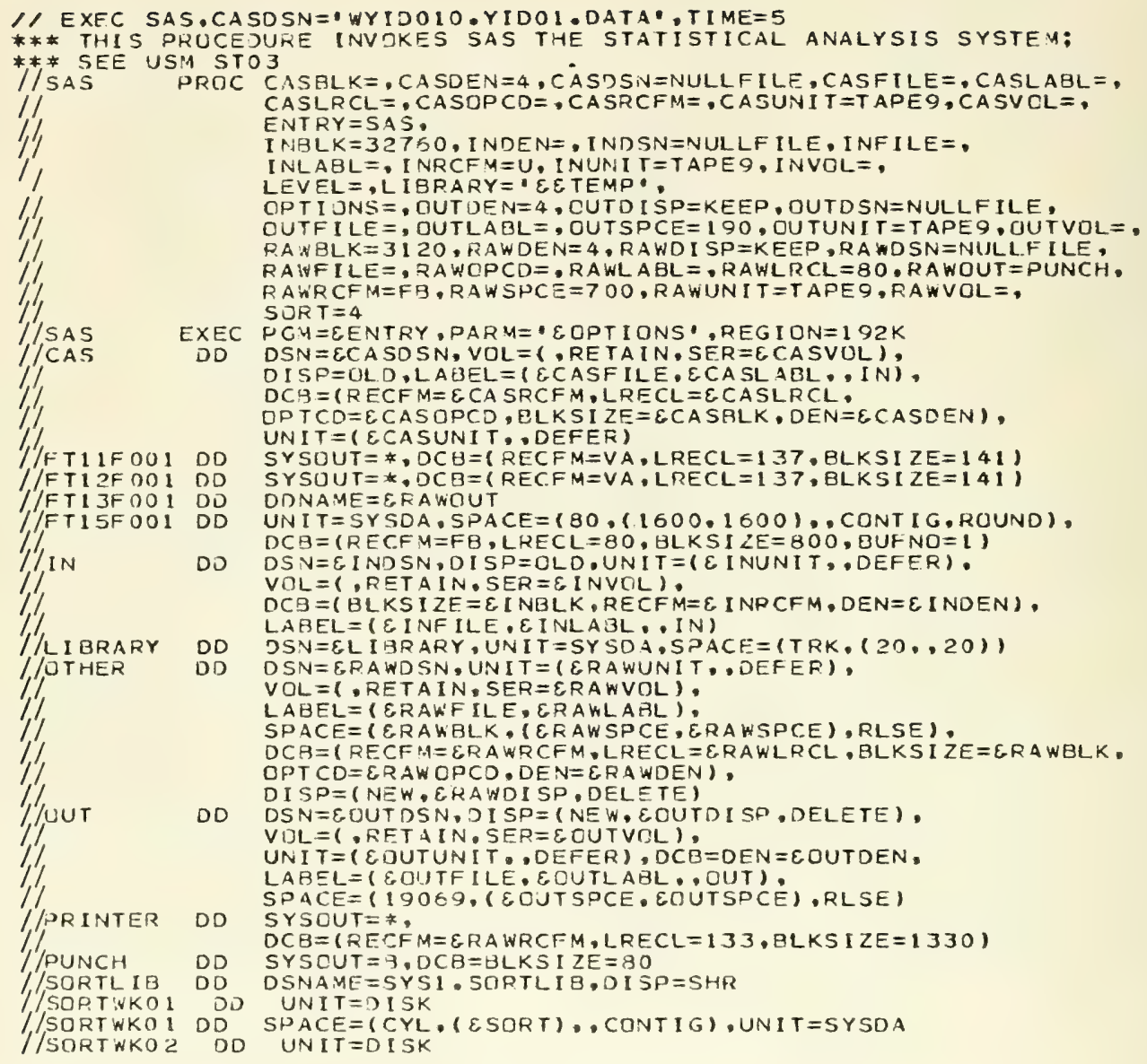

//SURTWKOL //SORTWKO 3 $1 / 1$ SORTWKO3 OD $1 /$ TEPL I 3 1,1 / S Y SOUT /NURK //PLMDATA /FYSIN

DD

DD

OD

DO

DD
SPACE $=(C Y L,(E S C R T)$, CONTIG), UNIT $=($ SYSOA . SEP $=($ SORTWKOI $)$ ) UN IT $=D$ I SK SPACE $=(C Y L,($, SORT) , ,CONTIG), UNIT = (SYSDA, .SED = (SORTWKOI, SORTWKO? ) )

DSN $=$ SYS4.SAS. LDADELEVEL, DI SP=SHR

DSN $=$ * L I BRARY, DI SP = (OLD, PASS ), UNIT $=$ SYSDA,

$V U L=R E F=*$. L IBRARY

SYSOUT $=$ * DCB $=$ HUFNO $=1$

UNIT $=$ SYSDA, SPACE $=(T R K,(240,80))$

DSN=WYIDOIO.YIOOI. QUADATA. CNTL. DISP $=O L D$ * 


\subsection{THE BLM DATA}

5.4.1 How the BLM Data is Read into the Program

The BLM data is read into the program from tape. The program as written requires that a JCL card with DONAME BLMDATA be supplied pointing to the tape containing the raw data. The data is on File One of the IBM Standard Label Tape with Volumn Serial Number: NOSC. The data set name is BLMDATA. The tape is written at 6,250 BPI with a logical record length of 80 characters, and a block size of 3120 . There are 15,599 card image records. Each record contains five variables. They are: Site number (see Figure 5-7), season, species (see Q15 in Section 5.3.2), low-density estimate, and high-density estimate.

The codes are as follows:

Winter $=1$, Spring $=2$, Summer $=3$, and Fall $=4$.

The data is not column dependent and can be read with SPSS using freefield input or SAS using list input.

\subsubsection{How the BLM Data Was Derived}

The following is a direct quotation from the BLM report explaining the derivation of their data:

"5. Data Analysis

From the onset of this study we have intended to correlate cetacean abundance, distribution, and movement with measurable features of the physical environment. Some of these features such as bottom topography, bottom slope, water depth, and distance from mainland are fixed in time and space and are constants. Others, such as sea surface temperature, wind direction and velocity are seasonal and variable.

We divided the Southern California Bight (SCB) into nine zones or subunits of similar ecogeographic types. We further divided the study area into 1,000 quadrat blocks of five minutes latitude by five minutes longitude for which water depth, bottom slope, and distance factors were determined and entered into the computer file. 


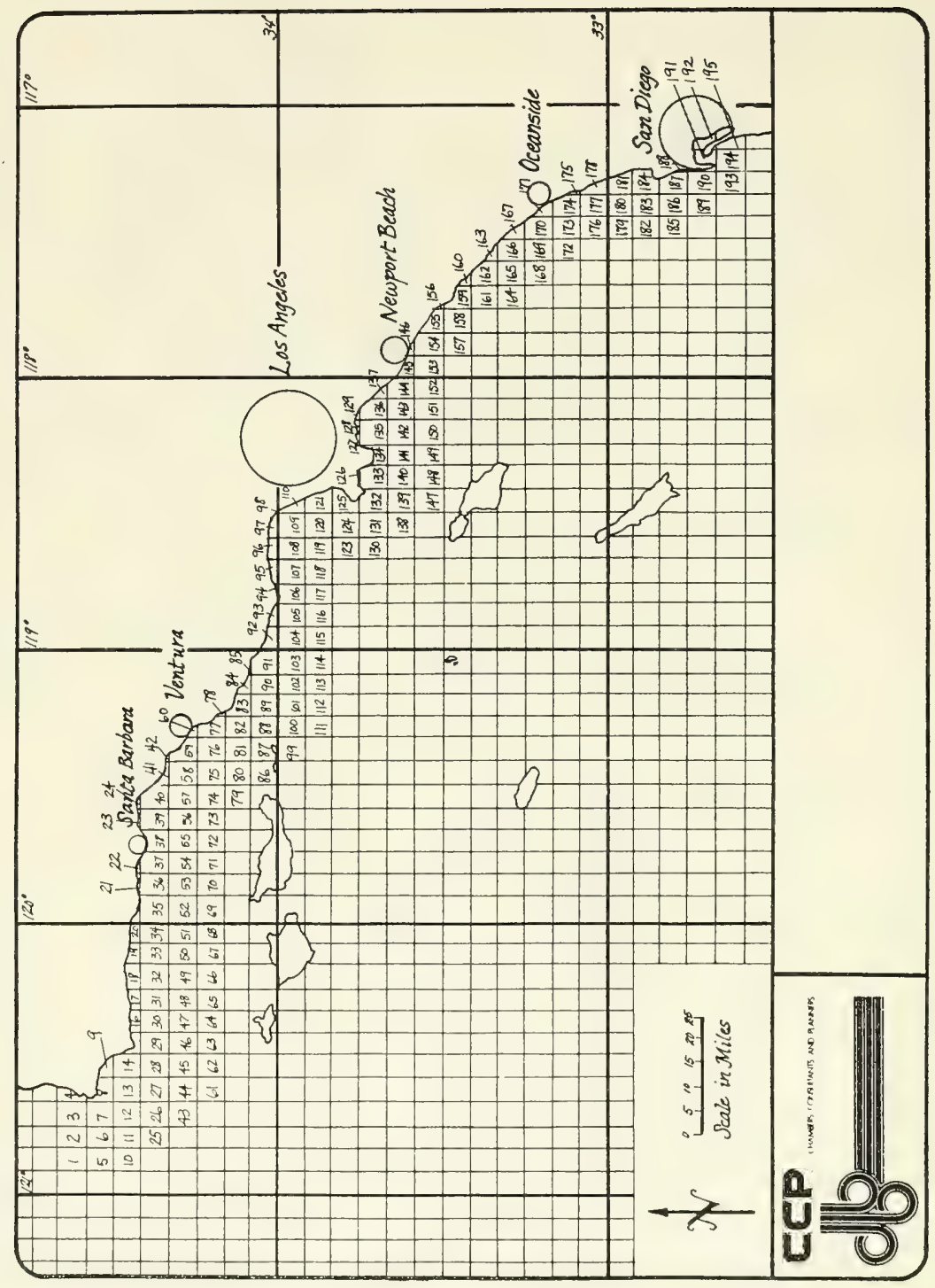


To determine whether our shipboard and aerial transect coverage adequately sampled the SCB and the full range of environmental gradients found within the study area, we determined the frequency distribution of these variable characteristics for all 1,000 quadrats and compared these statistically with the same parameters represented by, for example, transect lines. Chi-square analysis showed no statistical difference between the range of environmental parameters sampled in our transects and that of all the quadrats in the SCB. We therefore conclude that our shipboard and aerial transects adquately sampled the environmental variables with no significant bias.

Since seasonal and geographical variations and sea surface temperatures affect the potential availability of cetacean prey, and therefore cetacean distribution, we mapped water temperatures along our survey tracks for each period and each trip. Surface temperatures were measured hourly from the ship with a through-hull thermometer calibrated with a bucket thermometer. For offshore or coastal areas or quadrats not visited on a particular trip, we referred to maps generated by the U.S. Coast Guard aerial surveys and the biweekly temperature projections published by the National Marine Fisheries Service. Temperatures to $.5^{\circ} \mathrm{C}$ were assigned to each quadrat for a given survey period and entered into the permanent computer files. The resultant computer-generated maps were used to obtain mean sea surface temperature profiles throughout the Bight and in each zone for comparison of cetacean densities with the above stated environmental factors.

For each cruise or flight series a battery of computer data output was produced: 1) a chronological listing of a 11 cetacean sightings including species, number of individuals, and locations, 2) a listing by specific location (quadrat) of all cetacean sightings, density and numbers, 3) a generated cetacean density map of the entire Bight, 4) a computer-generated graphic display Bight-wide of cetacean density in relation to environmental factors, 5) a computer-generated level of effort map indicating quadrats visited and number of visitations.

Stepwise multiple linear regression programs were designed to detect and rank those environmental features which related significantly to variation in cetacean density. The output of the regression program, carried out on an IBM 360 computer, determined which environmental features best predicted geographic variation in density. Independent variables entered into the regression analysis included water depth, sea surface temperature, bottom slope, distance to nearest land, distance to mainland, as well as the inverse of these variables. If density along the transect 7 ine was functionally related to some variables, for instance, water depth, its measured value would be expected to increase or decrease with an increase or decrease in the value of the independent variable. This analysis calculated a sequence of equations beginning with regression of density against that single variable that made the greatest reduction in the error sums of squares and continuing to rank and include variables until no additional variation in density could be explained.

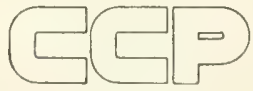


The validity of the completed equation was then measured by an $F$ test of the significance of each regression coefficient. The use of the regression equation as a predictive tool was determined from the multiple $R$ valug or the coefficient of determination value, $R^{2}$. When the multiple $R$ or $R^{2}$ value was large enough to indicate a substantial portion of the density variation from quadrat to quadrat was accounted for by the regression relationship, the equation was then used to interpolate from our sample to the entire study area. This step consisted of sequentially substituting the value found at the quadrat midpoint for each statistically significant variable into the regression equation in order to calculate an expected density in this specific location. This interpolation procedure was carried out for each of the 1,000 quadrats following each ship or aerial transect survey and resulted in a picture of how and in what numbers animals were distributed within the study area at the time of the survey. Interpolations, however, did not extend into waters that were insufficiently sampled (Fig. III-41).

Comments on population enumerators

It is generally agreed that aerial surveys of terrestrial wildlife yield underestimates of total populations. The reliability of aerial surveys, when utilized in the marine environment, becomes even more difficult to assess.

Cetacea generate their own set of handicaps to the investigator engaged in population surveys. First, to be counted, the animal must be at or near the surface; the smaller species of cetacea surface every 3-4 minutes or so, while the large ones may not surface for 10-12 minutes or considerably longer. Secondly, when cetacea are disturbed or "flushed" they, unlike birds, move downward in the water and become unavailable for enumeration. Finally, it is well known that schooling cetacea are stacked or layered in the water column so that only some portion of the school are at the surface at any one time. Each of these phenomena indeed add to the probability that population numbers are underestimated, and/or that entire schools pass uncounted.

Although aware of these conditions which lead to probable underestimation, no attempt was made to establish a "fudge" factor for those animals flushing away from the line of sight or those below the surface at the time of the count. The rationale for this is twofold: we are more comfortable with "hard" numbers (those representing actually observed animals), and any arrived at "fudge" factor would only fit one of many sets of conditions, leading to a series of such factors, each more suspect than the 1ast. Secondiy, since any future surveys or monitoring attempts will be faced with the same vexing conditions of flushing, layering, and surface time, it seems reasonable for the sake of comparability to utilize only observed numbers and relative indices of abundance, rather than lean too heavily upon absolute population estimates arrived at in a questionable or non-reproducible manner.

A usual assumption made during a census of this type is that the transect lines or search areas are randomly selected. Such was not the case in this survey; our transect lines were fixed and we considered 


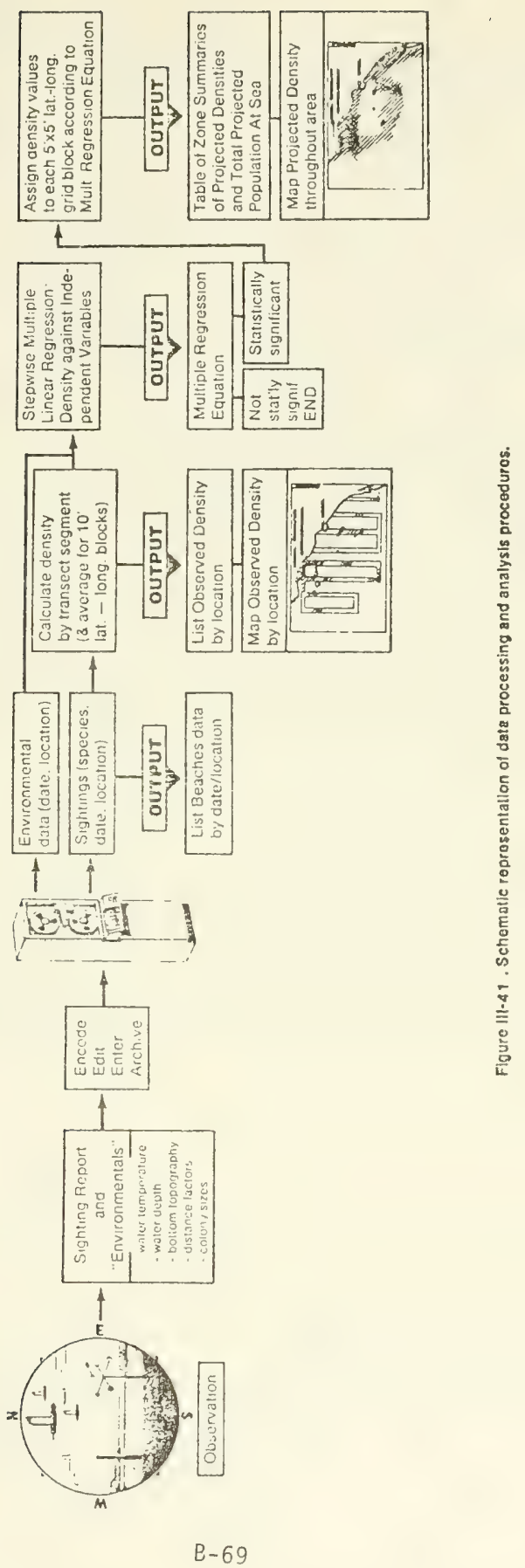


that the highly mobile animals were the random element. We know that we violate this premise, since these animals are not randomly distributed but as social animals are found in aggregations, and this very patchiness of sightings leads to additional problems with statistical analyses.

Another assumption that must be made in a survey of this nature is that the estimate of distance from transect line to target is accurate. Estimation of distances over open water with no landmarks for guidance is extremely difficult and the precision of estimations of distance must be in doubt. However, whatever error or bias that might exist in our distance estimation should be consistent, since the method of the distance estimation was the same from observer to observer.

For an enumerator to be effective and consistent, the probability of detection of each target must be the same and the detection of one target should not lead to the detection of additional targets. For cetacea this is not the case; small schools may be detected by the behavior (e.g. aerial behavior) of a single animals, while large schools may be located from the actions of only a small proportion of the group.

Other variables which may aid or hinder the "see-ability" of cetacea are the animal's size, color, or type of movement. In addition, environmental factors such as sun angle, light levels, glare, sea state, and visibility all contribute to the probability of detection. And we have yet to consider observer bias. Does he see more when fresh at the start of a day's survey; does the sighting of one school "perk" him up so that he is more likely to see subsequent groups?

We know that on many, if not all, occasions we have violated from three to five of the assumptions necessary to maintain the statistical accuracy for any line transect theory, and realize we probably grossly underestimate or "undersee" the number of cetacea on any survey. In spite of these errors in methodology, common to all current survey techniques, we present five common methods of computation for determining the relative abundance of cetacea. Animal densities $/ \mathrm{nm}^{2}$ from each of the five formulae are then extrapolated to arrive at Bight-wide estimtes of populations. Each of the formulae is outline in turn below, followed by consideration of the most useful and reasonable method to assess realistic population numbers.

Formula \#1. Index of Abundance:

$$
\frac{\mathrm{N}}{\text { transect Tength } \mathrm{x} \text { path width }}=\text { Index }
$$

where $\mathrm{N}=$ number of animals observed;

where $L$ (transect length) = linear distance flown in $\mathrm{nm}$;

Where $W($ path width $)=$ right angle distance off flight line which observer scanned. If each side of aircraft was manned by observers, right angle distance is doubled. In this formula right angle distance was considered to be $1 \mathrm{~nm}$ and, since both sides 
of the aircraft were manned, the path width distance was called $2 \mathrm{~nm}$.

Example: Let $\mathrm{N}=350$

$$
\begin{aligned}
& L=2,034 \mathrm{~nm} \\
& W=W \mathrm{~nm} \\
& \therefore \frac{350}{2,034 \times 2}=0.086 \text { anima } 7 \mathrm{~s} / \mathrm{nm}^{2}
\end{aligned}
$$

This density of 0.086 animals $/ \mathrm{nm}^{2}$, when extrapolated to the area surveyed $\left(25,000 \mathrm{~nm}^{2}\right)$, yields an estimated abundance of 2,150 animals in the SCB.

Formula \#1 is fundamentally the same as Eberhardt 1968, the estimator used by U.S. Fish and Wildlife Service in their Alaskan bird surveys, and the uncorrected or raw estimator referred to by Wiens et al. 1977. The only difference between these estimators is in path width utilized by each investigator. It is also the estimator we initially utilized until sufficient data were assembled for us to question the validity of a $2 \mathrm{~nm}$ wide observed path width.

Other investigators have utilized an inverted form of this formula, mistakenly believing that the resultant computations yielded animal density per unit, area squared, when in actuality their formula yielded the number of $\mathrm{nm}^{2}$ traveled to locate one animal.

Formula \#2. Animals observed/linear nm:

$$
\frac{\mathrm{N}}{\text { transect length }}=\text { animals/linear } \mathrm{nm}
$$

where $\mathrm{N}=$ number of animals observed;

where $L$ (transect length) = linear distance flown in $\mathrm{nm}$.

$$
\begin{aligned}
& \text { Example: } \text { Let } N=350 \\
& L=2,034 \mathrm{~nm} \\
& \therefore \frac{350}{2,034}=0.172 / 1 \text { inear } \mathrm{nm}
\end{aligned}
$$

This formula is useful only as a relative index of abundance and may be used under circumstances where the path width is unbounded or when observational conditions very substantially during a transect or from transect to transect. However, the denisty figure obtained should not be extrapolated to area-wide population estimates, since path width is not available. This method of computation has extremely limited applications, but is presented for comparison's sake and since it has been utilized by investigators in the past.

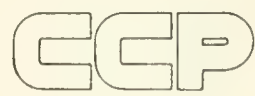


Formula \#3. $90 \%$ sighting distance:

$\frac{\mathrm{N}}{\text { transect length } \times 90 \% \text { sighting distance }}=$ density

where $N=$ number of animals observed;

where $L$ (transect length) = linear distance flown in $\mathrm{nm}$;

where $90 \%$ sighting distance $=$ right angle distance within which $90 \%$ of sightings occur. This $90 \%$ distance is obtained from records kept of right angle distance to sighting. If both sides of aircarft are manned, the distance is doubled. In this study the $90 \%$ right angle distance was determined to be $0.48 \mathrm{~nm}$. Therefore in this formula $0.96 \mathrm{~nm}$ was used since both sides of the aircraft were manned.

Example: Let $N=350$

$$
\begin{aligned}
& L=2,034 \mathrm{~nm} \\
& 90 \% \text { distance }=0.96 \mathrm{~nm} \\
& \therefore \quad \frac{350}{2,034 \times 0.96}=0.179 / \mathrm{nm}^{2} \\
& \text { This density figure of } 0.179 \text { animals } / \mathrm{nm}^{2} \text {, when extrapolated to } \\
& \text { the area surveyed }\left(25,000 \mathrm{~nm}^{2}\right) \text {, yields an estimated abundance } \\
& \text { of } 4,475 \text { animals in the Bight. Note that the density figure in } \\
& \text { this formula does not differ greatly from that derived from } \\
& \text { formula } \# 2 \text {. }
\end{aligned}
$$

Formula \#3 is an inhouse modification of Formula \#1, adjusting the path width downward, as a result of our review of the initial sighting data.

Formula \#4. Percent of area surveyed ratio:

$$
\text { Ratio }=\% \text { of Bight surveyed : } N \quad:: \quad 100 \% \text { of Bight : X }
$$

where $\%$ of Bight surveyed $=\mathrm{nm}$ flown $\times 0.96 \mathrm{~nm}$ (path width when both sides of aircraft are manned) divided by area of the Bight;

where $\mathrm{N}=$ number of animals observed. 
Example: Let $\mathrm{L}$ (transect length) $=2,034 \mathrm{~nm}$

$$
\begin{aligned}
\text { Bight area } & =25,000 \mathrm{~nm}^{2} \\
\% \text { surveyed } & =7.8 \\
N & =350 \\
X & =\text { Bight-wide population }
\end{aligned}
$$

$\therefore 7.8: 350:: 100: x$

$$
\begin{aligned}
7.8 x & =35,000 \\
x & =4,487
\end{aligned}
$$

This simplistic ratio yields population estimates that are in significant agreement with figures obtained using either formula \#2 or \#3. Its usefulness may al so be extended to smaller geographic zones where the assumed range of a species may be less than the entire study area.

Formula \#5. Gates I;

$$
\frac{N-1}{2 L \cdot \bar{X}}=\text { density }
$$

where $\mathrm{N}=$ number of animals observed;

where $L=$ linear distance flown in nm, multipled by 2 if both sides of the aircraft are manned.

where $x=$ the mean of right angle sightings distances, obtained from records kept at the right angle distance to each sighting from transect line.

Example: Let $\mathrm{N}=350$

$$
\begin{aligned}
& L=2,034 \mathrm{~nm} \\
& x=0.25 \mathrm{~nm} \\
& \therefore \frac{350-1}{2 \cdot \frac{2,034 \cdot 0.25}{2}}=0.34 \text { animals } / \mathrm{nm}^{2}
\end{aligned}
$$

The above $g=0.34$, when extrapolated to the area of the SCB $\left(25,000 \mathrm{~nm}^{2}\right)$, yields an estimated abundance of 8,500 animals. These figures for $d$ and Bight-wide abundance are approximately double those obtained in formulae \#2, \#3, or \#4.

Formula \#5, utilizing the mean right-angle sighting distance, appears to artifically inflate the animal density number by drawing all sightings into a very narrow corridor, in this case $0.25 \mathrm{~nm}$ wide.

General remarks on data analysis

Throughout the remainder of this report and within the individual species accounts, animal density and area-wide population estimates are

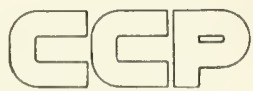


computed using Formula \#3. This formula seems to combine the advantages of a line transect estimator with that of a strip survey. It gave these investigators some degree of confidence that computed estimates generally agreed with our feel for the numbers and densities of the animals seen.

There remains a basic schism between choosing a conservative but realistic formula for computation of density and area-wide population estimates on one hand, and, on the other, the sure knowledge that we are underestimating actual population numbers with existent survey methods. There is no reason to believe that new improved or more precise survey methodologies will become available in the foreseeable future. Therefore, we prefer to maintain a more conservative reproducible data analysis technique that will allow subsequent investigators to reasonably compare their data base and those data collected during this three-year study.

Total population numbers would be of considerable interest, but we believe they are unobtainable at this time. To monitor the health of the cetacean community and to look at future population trends, seasonal sampling will probably be the method of choice. Given that actual population numbers are unknowable, a rigorous and reproducible sampling technique would appear to be the method of choice."

\subsection{THE TAPE}

The tape supplied with this report is an IBM Standard Label Tape. It is written at 6,250 BPI. It contains three files whose DCBs are;

$$
\begin{aligned}
& \text { LRECL }=80 \\
& \text { BLKSIZE }=3120 \\
& \text { RECFM }=F B
\end{aligned}
$$

File One contains BLM data described in the previous section. The data set name is BLMDATA. It is 400 blocks in length.

File Two contains the SAS program to analyze data from sighting cards. The data set name is SIGHT.CARD.PGM. The data set is 19 blocks long.

File Three contains the SAS program to analyze data from in-person interviews. The data set name is INTER.VIEW.PGM. The data set is 8 blocks long. 
Both the in-person historical interview program and the sighting card program were tested by running them with imaginary data. The output from these sample runs are shown on the computer printout sheets. 
Section 6

THE PILOT PROGRAM

\subsection{CONTACTS AND COMMUNICATIONS WITH OIL COMPANIES}

\subsubsection{Introduction}

Obtaining the cooperation of the oil companies turned out to be the single most serious difficulty encountered in conducting this program. Lack of oil company support was not anticipated, because initial contact with oil company biologists and executives was positive. The difficulty seems to come at the level of the immediate supervisors in charge of platform work. The problem obtaining support from oil company employees at that level seems to be related to several factors:

1. They are busy people, and it is easier to say no than yes.

2. They are afraid that the men under their supervision will turn into whale watchers and their output will decrease.

3. They have anti-envrionmentalist sentiments.

The lack of cooperation from the oil company supervisors caused several difficulties in implementing the Pilot Interview Program:

1. It took us much longer than anticipated to arrange permission to use the platforms. 
2. We had to modify our program to meet the restrictions of the oil companies. 0il companies were willing to cooperate in different ways and, consequently, the program was implemented differentiy at different platforms.

3. Lack of enthusiastic support from the oil companies made it more difficult for us to elicit cooperation from the workers than we had anticipated. We were generally tolerated rather than supported, and the men usually were not encouraged by their supervisors to fill out the cards. In the one case where we did have enthusiastic support from the immediate supervisor (Aminoil) we got an encouraging number of sighting cards filled out.

The lack of support from the oil companies may make this method of obtaining information on marine mammals around platforms unfeasible. On the other hand, it is hoped that this difficulty may evaporate as the program proceeds. When the oil company supervisors discover that the program does not interfere with work, they may become more willing to cooperate. In addition, the oil companies which initially refused to support the program may change their minds when they are shown that the program has worked on other platforms.

\subsubsection{Detailed Account of Communications with 0il Companies}

Appendix A contains copies of a11 written correspondence between Chambers Consultants and Planners (CCP) and oil companies.

\subsubsection{Aminoil (Platform Emmy)}

\section{Contacts:}

Steve Stephens - Construction Supervisor (714) 540-8787 Ext. 265

Louis Kastroff - Crew Foreman (714) 540-8787 Ext. 272

R.L. Goggins - Head of Production (714) $540-8787$ 
Aminoil USA, Inc.

Golden West and Ocean Avenue

P.0. Box 191

Huntington Beach, California 92648

Initial contact with Aminoil was made through Steve Stephens whom we had worked with on a previous job. CCP met with Stephens and Crew Foreman, Louis Kastroff, and they reviewed the questionnaire and sighting cards. They said they thought the platform workers would have no problems with either format. Stephens informed Head of Production, R.C. Goggins, of our program, and we sent Goggins a formal letter. Mr. Goggins approved the program on the condition that we did not interrupt workers' schedules.

The interviews were initially conducted at the Aminoil heliport on December 23, 1980. Mr. Kastroff was on vacation and Ed Taylor was acting as foreman. $\mathrm{Mr}$. Taylor permitted us to conduct our program but was negative about it and seemed wary of "environmental ists."

Further interviews were conducted at the Aminoil heliport on January 15, 1981. $\mathrm{Mr}$. Kastroff had returned from vacation. He was very supportive and told us that he had actively been encouraging his workers to fill out the sighting cards.

\subsubsection{Shell 0il (Shell Beta Unit)}

\section{Contacts:}

Claude F. Martin - Staff Engineer of Pacific Division (715) $879-2466$

Entex Building

1200 Milan

P.0. Box 527

Houston, Texas 77001

Tom Hartnet - Construction Supervisor (213) 435-3783 
Chet J. Frazier - Production Superintendent

(805) 648-2751

P.0. Box 92047

Worldway Center

Los Angeles, California 90009

Initial contact was with $\mathrm{Cl}$ aude Martin whom CCP had worked with on another job. Mr. Martin contacted Tom Hartnet who agreed to let us conduct the program. CCP then got in touch with Hartnet who said he had no problems with the proposed program but he had to check with Chet Frazier. Mr. Frazier called CCP and said he did not want to conduct the program until the end of January because the workers at the platforn were too busy. СCP discussed the matter with Mr. Martin who instructed Frazier to find a way to accommodate the program.

CCP met with Mr. Frazier and discussed the interview program. Mr. Frazier said that he thought he could help us best by emphasizing the sighting cards rather than trying to accommodate both sighting cards and interviews. He provided sighting cards to the workers on the Beta platforms and they have sent these completed cards to СCP. So far we have received two completed cards.

\subsubsection{ARCO (Platform Holly)}

\section{Contacts:}

June Lindstedt Siva - Senior Science Advisor

(213) 486-0741

515 Flower Street

Los Angeles, California 90071

Bob Carlson

P.0. Box 2540

Goleta, California 93010

Initial contact was with June Lindstedt Siva. Dr. Siva was supportive of the interview program, and said that she had previously initiated a program to 
collect scientific data from workers on oil platforms. Her program had also involved filling out observaiton sheets. She said her program had worked fine until the workers got very busy. At that point they ceased to take the time to fill out her sheets. Dr. Siva put us in touch with Bob Carlson who is in charge of operations. He suggested that we make a formal written request. He responded to our letter by saying he felt that they were too busy at the time to accommodate the interview program.

\subsubsection{Union 0il (Platforms $A, B$, and C)}

\section{Contacts:}

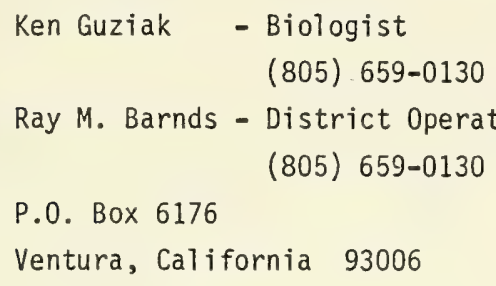

Initial contact was with Ken Guziak who supported the program. He put us in touch with Ray Barnds. Subsequent communications were with both Mr. Barnds and Mr. Guziak. Mr. Barnds kept saying that he had to have more information about the program before he could make a decision. These communications extended over a period of approximately 3 months. Finally, Mr. Barnds turned down our request on the basis that use of the posters and questionnaires would require extensive training of Union platform workers.

One useful suggestion that Mr. Barnds made was that we prepare a written handout to explain the program to workers before beginning the interviews. We prepared such a handout, and it is included in Appendix A.

\subsubsection{Chevron (Platforins Hilda, Hazel, Hope, and Heidi)}

\section{Contacts:}

Beth P. Johnke - Engineering Assistant

$$
\text { (415) 894-6105 }
$$


575 Market Street

San Francisco, California 94105

John Herring - Operation Foreman

1253 Coast Village Road

Santa Barbara, California 93108

W.D. Edman - Division Manager

P.0. Box 605

La Habra, California 90631

Initial contact was with Beth Johnke whom CCP had worked for on another job. She was supportive of the program and put us in touch with John Herring. John Herring did not want us on the platforms but he was willing to let us conduct interviews and put out posters on Chevron Pier. CCP wrote a formal letter to Division Manager, W.D. Edman, to confirm Mr. Herring's position.

\subsection{IMPLEMENTATION OF THE PILOT PROGRAM}

\subsubsection{Aminoil Platform Emmy (Huntington Beach)}

The pilot program was begun on December 23, 1980, at 0700 at the Aminoil heliport. Workers on Platform Emmy take the helicopter out to the platform at this time. On December 23, it was too foggy for the helicopter to fly, and the workers were preparing to drive to the harbor to take a boat to the platform.

Two scientists from CCP and a scientist from NOSC interviewed the workers before they left for the boat dock. The workers had not been alerted that the interview program was going to take place, and the interviewers had to explain it to them. A few of the workers did not want to talk, but most were cooperative. A few of the workers, especially the older ones who had been working on the platform a long time, had good whale stories to tell. The tape recorders proved to be very useful in these instances. Posters and sighting cards were

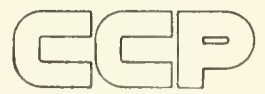


put up in the room where the men wait for the helicopter. One of the workers offered to put the posters and boxes on the platform itself and acting foreman, Ed Taylor, said that he would prefer if the interviewers did not go out to the platform.

The interviewers returned at 1430 on the same day to catch the swing shift which goes out to the platform at this time. It was still too foggy to fly and, apparently, the men had gone directly to the boat dock. There were only a couple of people around to interview.

Two scientists from CCP returned to the Aminoil heliport at 1430 in the afternoon of January 15, 1981. The posters were still up in the room but the sighting card box had apparently fallen down and was set on a bench. There was one completed sighting card in it. Workers coming in and going out for the shift change were interviewed, but there were fewer of them than there had been for the morning shift. Apparently, less men work the swing shift. At the time of the second interview, the men were aware of the program because they had seen the boxes and posters and had heard about the program from crew foreman, Louis Kastroff, as well as other workers.

One CCP scientist returned to the Aminoil heliport on February 3, 1981 and collected six completed sighting cards from the sighting card box. The program seems to be working relatively well at Platform Emmy.

\subsubsection{Shel1 Beta Platforms (Huntington Beach)}

The pilot program at the Shell Beta Platforms was implemented by putting out sighting cards only. No interviews were administered, because Production Superintendent, Chet Frazier, felt that it was better to concentrate on only one method. He made the sighting cards available to the workers on the Shell Beta Platfoms. Two completed sighting cards were sent to CCP. Shell did not provide any input as to how the program was received by the workers. 

6.3
RESULTS

\section{3 .1}

Results of In-Person Historical Interviews

\subsubsection{Analysis of Questionnaires}

The analysis of the data from the Historical Interview Questionnaires is shown on a computer printout sheet. The pilot program analyzed questionnaires from the interviews at Platfonn Emmy, as well as questionnaires from interviews conducted by NOSC personnel at Platforms Holly and Hondo in the Santa Barbara Channel. A total of 30 questionnaires were analyzed.

There was too little data for valid statistical analysis of most of the infomation. Not only were there a small number of questionnaires filled out from each platform ( 1 for Holly, 12 from Hondo, 17 from Emmy). but in many cases the interviewer did not answer all the questions.

The interviews did clearly show that oil platform workers see all three categories of marine mammals from the platforms, and that in many cases these marine mammals come close to the platforms. 75 percent of the workers said that they were interested in the marine life around the platforms. From these data, no relationship could be detected between the distance the marine mammals occurred from the platform and the activity on the platform.

For Platform Emmy, there was a significant relationship (chi square test) between the length of time a worker had been employed on the platform and his frequency of marine mammal sightings. Those who had been working on Emmy longer stated that they saw marine mammals more frequently. No significant relationship could be detected between a worker's job and his frequency of sightings. For large whales, 31.2 percent of the Emmy workers said that they had seen many, 37.5 percent said that they had seen a few, 6.2 percent said that they had seen one, and 25 percent said that they had seen none. Of those who could name the kind of whale they thought they had seen 87.5 percent said they had seen gray whales, and one worker (12.5 percent) said he had seen a humpback. Since humpback whales are unusual in the San Pedro area (the BLM

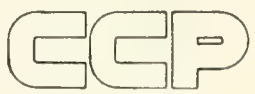


recorded none on the San Pedro quadrats), this was probably a misidentification. 12.5 percent of the workers who had seen a whale (s) said that it was within 10 yards of Platform Emmy, 62.5 percent said it was about 100 yards away from the platform, 12.5 percent said 200 yards away, and 12.5 percent said it was 1,760 yards away. 45.5 percent of the Platform Emmy workers said that they saw whales throughout the day, 36.4 percent said they saw them at midday, 9.1 percent said they saw them at dawn or dusk, and 9.1 percent said they did not remember when they had seen them. 80 percent of the workers said they saw whales in the winter, 10 percent said they saw them in the fall, and 10 percent said they could not remember. 36.4 percent of the workers said the whales they saw were alone, 36.4 percent said the whales they saw were in groups, and 27.3 percent said they had seen both solitary whales and groups of whales. For the direction the whales were traveling, 57.1 percent of the workers said mostly upcoast, and 42.9 percent said mostly downcoast. None of the workers noticed any relationship between activity on the platform and whale behavior. 85.7 percent said the platform was drilling when they saw the whales and 14.3 percent said the platform was in production.

Of the Platform Emmy workers. 14.3 percent had seen no dolphins or porpoises from the platforms, 14.3 percent had seen one dolphin or porpoise, 35.7 percent had seen a few, and 35.7 percent had seen many. Only one worker could name a species. That worker thought he had seen a Pacific white-sided dolphin. 16.7 percent of the Emmy workers said the dolphons or porpoises were within 20 yards of the platform, 33.3 percent said they were 50 yards away, 16.7 percent said they were 100 yards away, 16.7 percent said they were 440 yards away, and 16.7 percent said they were 1,760 yards away. 33.3 percent of the workers saw porpoises at dawn or dusk, 41.7 percent saw them at midday, and 25 percent said they saw dolphins or porpoises throughout the day. For time of year of porpoise sightings, 33.3 percent of the workers could not remember, 25 percent saw porpoises in winter, 25 percent saw propoises in summer, 8.3 percent saw dolphins or porpoises in fall, and 8.3 percent saw dolphins or porpoises throughout the year. 70 percent of the workers reported that the dolphins or porpoises they saw were moving upcoast, and 30 percent reported the ones they saw were moving downcoast. All dolphins or porpoises sighted from Platform Emmy had been in groups. No worker had noticed any relationship between 
behavior and platform activity. 62.5 percent of the workers said the platform was drilling when they saw the dolphins, and 37.5 percent said the platform was in production.

15.4 percent of the workers interviewed had seen no seals or sea 1ions from Platform Emmy, 46.1 percent had seen a few, and 53.8 percent had seen many. 75 percent of the workers who had seen seals or sea lions said the seal or sea lion was within 3 yards of the platform and 25 percent said the seal or sea lion was within 50 yards. 11.1 percent of the workers could not remember what time of day they saw seals or sea lions, 22.2 percent said they saw them at midday, 55.6 percent said they saw them throughout the day, and 11.1 percent said they saw them at night. 77.8 percent of the workers saw seals or sea lions throughout the year, while 11.1 percent said summer, and 11.1 percent could not remember. 55.6 percent of the workers reported seeing a single seal or sea lion, 11.1 percent had seen a group, and 33.3 percent had seen seals and sea lions both alone and in groups. None of the workers could recall seeing seals or sea lions moving in any particular direction. 80 percent of the workers said seal or sea lion behavior was unrelated to work on the platform and one worker (20 percent) said he had noted a relationship. All of the workers who had seen seals or sea lions reported that the platform was drilling at the time.

The one worker interviewed from Platform Holly was a crewboat skipper who said he often saw marine mammals. He had seen a few large whales, mostly grays, at varying distances from the platform. He reported that he saw whales throughout the day. The whales were usually moving downcoast alone or in pairs. He had not noted any relationship between whale behavior and work on the platform. He had seen many dolphins or porpoises at varying distances from the platform. He usually saw the dolphins or porpoises at dawn or dusk. They were always in groups. He could not remember the time of year he had seen them or the direction they were moving in. He had seen many seals and sea lions near Holly. He had seen both California sea lions and harbor seals. They had been close to the platform and he saw them throughout the day and throughout the year. The seals and sea lions occurred both singly and in groups and moved in all directions. He had not noticed any relationship between seal and sea lion behavior and work on the platform. 
For Platform Hondo, there was not a significant relationship between length of employment on the platform and frequency of marine mammal sightings, although, workers who had been employed longer did see marine mammals more frequently. of the Platform Hondo workers interviewed, 22.2 percent had seen no large whales, 11.1 percent had seen one, 55.6 percent had seen a few, and 11.1 percent had seen many. All those who could name a species said they had seen gray whales. 40 percent of the liorkers had seen the whales within 880 yards of Hondo while 60 percent said the whales had been 2,640 yaras away. 66.7 percent of the workers reported seeing whales throughout the day, 22.2 percent saw whales at dawn or dusk, and 11.1 percent could not remember what time of day they had seen whales. For time of year of whale sightings, 45.5 percent of the workers could not remember, 45.5 percent said winter, and 9.1 percent said throughout the year. All of the workers who had seen whales said the whales were alone and none of the workers could remember what direction the whales were moving in. None of the workers had noticed any relationship between the whales and platform activity. In all cases in which whales were seen, Hondo was drilling.

58.3 percent of the Hondo workers had seen a few dolphins or porpoises, 8.3 percent had seen one, and 33.3 percent had seen none. 62.5 percent of the workers had seen the dolphins or porpoises at dawn or dusk, while 37.5 percent had seen them throughout the day. None of the workers could remember the time of year of the dolphin or porpoise sighting or what direction the animals had been moving in. 62.5 percent of the workers said the dolphins or porpoises were in groups, while 37.5 percent had seen solitary animals. None of the workers had noticed any relationship between dolphin or porpoise behavior and platform activity.

All of the workers interviewed on Platforn Hondo reported seeing many seals or sea lions. All the workers said they saw the seals or sea lions throughout the day and throughout the year. 88.9 percent of the workers reported seeing both single animals and groups while 11.1 percent said the seals or sea lions were in groups. 33.3 percent of the workers thought there was a relationship between seal or sea lion behavior and platform activity. 


\subsubsection{Additional Anecdotes and Observaitons from Interviews}

Direct quotations of comments, observations, and anecdotes which were volunteered by the workers during the in-person historical interviews follow. All these quotations were from workers on 0 il Platform Emmy.

"I've seen California gray whales carrying their young on their back."

"I'd say I'd seen more gray whales when they were coming back home."

"I haven't seen the dolphins and propoises as close to the platform as the whales."

"There's a lot of sea lions."

"There was a whale washed in from the beach last week."

"I see porpoises all the time going through the waves going out on the hel icopter."

"Don't forget our pet seal."

"There was a whale about a half mile out, just blowing steam, gasping for air."

"I see seals out there all the time. They're always trying to get the mackerals. They're just right next to the platform swimming around - big brown ones. They go swimming around those pylons - in between 'em - they just play around out there. You see a lot of them when we take the boat like right now from Long Beach. You see them sitting on those rocks. They try to get fish around the platform. There's a lot of fish around there. I saw one dead on the beach about 8 or 10 months ago - just right over there."

"There used to be more marine mammal sightings than there have been the last few years."

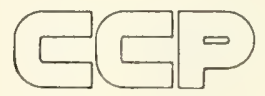


"This time of year the whales are moving and we see them."

"The whales kind of hung by out there at certain times of the year."

"There is this one place the gray whales hang around. I've seen seven or eight at a time out there. These migrating whales do some unusual stunts out there. They dive and jump. It seems as if when they go away they come right back to this one place. There must be something out there. The area is about half a mile due south of the platform."

"Whales come right up to the platform. This baby whale was laying on the back of its mother."

"This whale dived underneath the buoy. We could see its tail near the chain. He might have been rubbing up against the chain."

"I saw three whales go right underneath the heliport. They were gray whales for sure."

"I very seldom see porpoises near the rig."

"Seven or 8 years ago, seals would come in quite regularly and climb on the buoys and boat landings. In the last year or so you hardly see any anymore. I don't know why."

"I've seen little bitty harbor seals get upon the sportfishing boats tied to the buoys and the fishermen feed them."

"I saw a seal once on our boat landing that had a puncture in his side that looked like a bullet hole. A guy stepped down onto the boat landing and scared the seal which made a big noise and dived into the water."

"As far as seeing seals or sea lions, I haven't seen that many."

"I haven't seen anything since you started this program." 
"We see the whales migrate once in a while, but you have to catch them. They are at a distance."

The following comment comes from Platform Hondo:

"When the big boats come up to the platform the sea lions leave for awhile, but they come back soon"

\subsubsection{Results from Sighting Cards}

The computer output from the analysis of the sighting cards from the pilot program is shown in one of the computer printout sheets. Only 10 sighting cards were returned in the pilot program. Unfortunately, in most of the cases there were not enough boxes checked for an identification of the marine mammal to be made. Consequentiy, the computer analysis did not yield much useful information.

The one identification the program did make was of a right whale. This is probably a misidentification since right whales are very rare in southern California. The problem is that some of the characteristics on the sighting card call for subjective deterninations on the part of the observer (i.e., broad and rounded versus blunt and rounded). If a large number of cards are collected, these problems should be overwhelmed by the sheer volume of data. When there are just a few cards, analysis by scientists, rather than computer, will probably yield more useful infomation.

Three of the seven workers who filled out cards from Platform Emmy saw gray whales. Two of the whales were seen at 1100 (on different days) and one worker did not specify the time of his observation. One whale was 150 yards from the platform, one was 300 yards, and one worker did not specify. Estimates of noise at the time of observation ranged from 3 to 5 on a scale of 10 . Two of the whales were shoreward of the platform and one was seaward. Two of the whales were traveling downcoast and one was going upcoast. In no case did the whales change direction while the worker was watching. Two of the workers saw single whales and one saw a pair. None of the whales showed their flukes. One whale dived a lot and milled around in the same area.

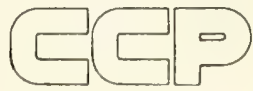


Two of the seven sighting cards filled out from Platform Emmy were for dolphin or porpoise sightings. One worker guessed he had seen Pacific dolphins and the other thought he had seen common dolphins. Neither checked enough characteristics to be sure of the identification. The worker who thought he saw common dolphons apparently made two sightings between 1600 and 1700 the same day. The platform was doing nomal well work and noise was estimated to be 4 to 6 on a scale of 10 . One group of dolphins were 50 yards from the platform and one group were 500 yards. One group was seaward of the platform and the other was upcoast. Both groups were traveling upcoast. The worker indicated that the dolphins changed direction towards the platform while he was watching. One group had about 20 animals in it and one had 100. They did not swim rapidly. They swam slowly and low in the water and milled around in the same area. They did not jump high out of the water but they did jump out of the water frequently.

The worker who thought he saw Pacific dolphins made his sighting at 1430 . The platform was coring and the worker esimated noise as 7 on a scale of 1 to 10. The dolphins were 20 yards shoreward of the platform. The animals were moving toward shore and did not change direction. The worker estimated that there were 75 dolphins in the herd. They swam rapidly and jumped high out of the water.

One sighting card from Emmy was for seals and sea lions. The worker said he saw one sea lion, about 12 feet long, and several gray seals. "The sea lion was on board for four straight days. The seals are on board regularly. The sea lion didn't look like an elephant seal but was huge and aggressive."

Two of the three sighting cards filled out for the Shell Beta Platforms were for gray whale sightings. One observation was made at 1300 . The whale was 400 yards shoreward from the platform and platform noise was estimated as 7 on a 1 to 10 scale. The whale was traveling downcoast and changed direction towards the platform while the worker was watching. The whale jumped out of the water and slapped its tail. It swam on the surface inost of the time. The other gray whale observation was made from a helicopter and the whales were 2 miles upcoast from the Beta Platforms. A group of six was seen at 1530 . 
They were traveling upcoast and did not change direction. They jumped out of the water, slapped their tails and swam on the surface most of the time. There were baby whales in the group.

The other sighting card from the Beta Platforms was for harbor seals and sea lions. Seals and sea lions are seen everyday of the week on the platform and the moorings, usually in the mornings. 


\section{Section 7}

CONCLUSIONS

The major unanticipated problem encountered in the pilot interview program was the difficulty in securing the cooperation of the oil companies. Lack of oil company support caused less data to be collected in the pilot program than had been anticipated. A great deal of time and effort was expended in trying to get permission to conduct "some sort of a program." In some cases pemission was refused. In other cases, interviews were only permitted "if they didn't interfere with schedules." It was thus necessary to conduct hurried interviews with men on their way to or from work. Most of the men interviewed were interested and cooperative, however.

Fewer sighting cards were returned than had been anticipated. Part of this lack of response may have been because men were not encouraged to cooperate. Response seemed to be picking up at Aminoil's Platform Emmy, however. Six cards were in the box the last time the platform was monitored. Because of the small amount of data, the computer program yielded little useful information.

It is likely that some of the difficulties encountered in the pilot program will disappear as the interview program proceeds. Once the oil companies have been shown that the interview program can be conducted without interrupting the men's work, the companies may become more helpful. As the men fill out the sighting cards they will find that the process can be done easily and rapidly. The sighting cards will teach them what characteristics of marine mammals are important to look for, so that in the future they may be able to check more boxes which will enable the computer program to make more positive identifications. 
It is apparent from this pilot program that workers on oil platforms do frequently sight marine mammals around the platforms. Whether enough information can be collected by this method to provide useful data to help meet the objectives of NOSC's larger mission remains to be determined. 
Section 8

\section{RECOMMENDATIONS}

Most of the difficulties encountered during the pilot interview program stem directly or indirectly from the lack of support of the oil companies. If the oil companies could be persuaded to actively cooperate, much more data could be collected. It might be possible to make participation in the interview program a mitigation measure for future offshore oil exploration programs.

Workers on 0 il Platform Emmy are beginning to fill out the sighting cards. These workers who have shown enough interest to fill out cards will probably continue to do so only if they are provided with some kind of encouragement and feedback. Otherwise, it might seem to them as if they are sending their cards out into a vacuum. One way to provide feedback would be to establish a whale watchers newsletter detailing some of the results of the program. The sighting cards could have a space for the observer to write his address if he were interested in receiving such information. 


\section{Appendix}

WRITTEN CORRESPONDENCE WITH OIL COMPANIES

P -95

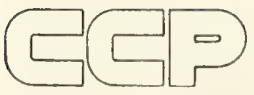




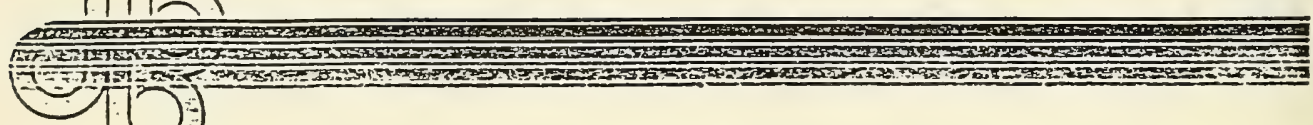

October 7, 1980

(3005)

Robert E. Carlson

P.0. Box 2540

Goleta, California 93018

Dear Mr. Carlson:

As 1 told you in our phone conversation on October 6 , our firm is acting as a consultant to the Naval Ocean Systems Center to develop a program to interview oil platform workers on their observations of marine mamnais around oil and gas platforms. We would like to use Platform Holly for this study.

The program would involve two scientists from our firm coming out for one day and interviewing as many workers as possible. We would hope that we could conduct these interviews without interfering with the men's work.

$\mathrm{Mr}$. Gealy of Arco's Environmental Sciences Division suggested that we might do the interviews during the boat ride to the platfrom. We would also like to put some posters on the platform, perhaps in the room where the men have their coffee. These posters would explain the program and give pointers on how to identify marine mamals. There will be a box with cards which we would request the men to fill out as soon as possible after seeing a marine mammal. We would then like to come back to Platform Holly two weeks after the initial visit and collect the filled out cards and interview as many workers as possible again.

We would like to begin this program as soon as it is convenient. Thank you so much for your assistance in this matter.

Sincerely,

CHAMBERS CONSULTANTS AND PLANNERS

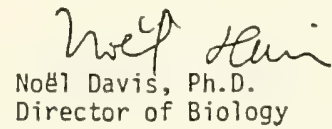




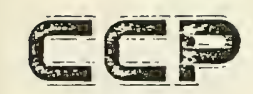

|llih

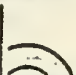

CHAMBERS CONSULTANTS AND PLANNERS

P.O. Box $356 \cdot 10557$ Beach Boulevard Stanton, California 90680 $714 / 828-3324$

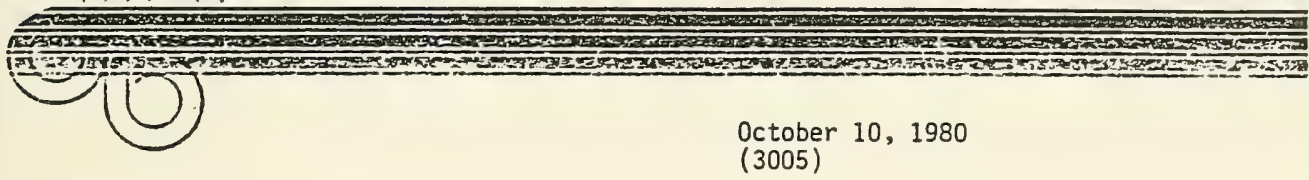

R.L. Goggins

Aminoil U.S.A.

Golden West and Ocean Avenue

P.0. Box 191

Huntington Beach, California 92648

Dear Mr. Goggins:

As Mr. Stephens has told you, our firm is acting as a consultant to the Naval Ocean Systems Center to develop a program to interview oil platform workers on their observations of marine mammals around oil and gas platforms. We would like to use Platform Emmy for this study.

The program would involve two scientists from our firm coming out for one day and interviewing as many workers as possible. We would hope that we could conduct these interviews without interfering with the men's work. We thought maybe we could try to catch them while they are waiting for the helicopter to take them to the platform. We would also like to put some posters on the platform, perhaps in the room where the men have their coffee. These posters would explain the program and give pointers on how to identify marine manmals. We would then like to come back two weeks after the initial visit and collect the filled out cards and interview as many workers as possible again.

We would like to begin this program as soon as it is convenient. Thank you so much for your assistance in this matter.

Sincerely,

CHAMBERS CONSULTANTS AND PLANNERS

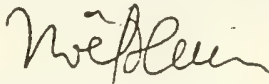

Noel Davis, Ph.D.

Director of Biology

ND:sg 


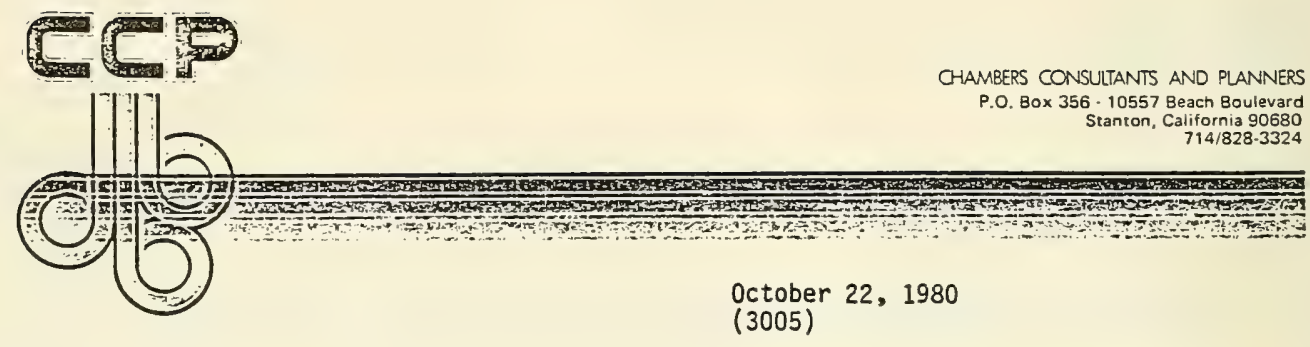

Union 0 il Company

P.0. Box 6176

Ventura, California 93006

Attention: Ken Guziak

Dear Mr. Guziak:

As Mel Chambers told you in your telephone conversation of October 21 , our firm is acting as a consultant to the Naval Ocean Systems Center to develop a program to interview oil platform workers in their observations of marine mammals around oil and gas platforms. We would like to use two of Union 0il's Santa Barbara Channel platforms for this study.

The program would involve two scientists from our firm coming out to each platform for one day and interviewing as many workers as possible. We would hope that we could conduct these interviews without interfering with the men's work. We would also like to put some posters in the platform, perhaps in the room were the men have their coffee. These posters would explain the program and give pointers as how to identify marine mammals. There will be a box with cards which we would request the men to fill out as soon as possible after seeing a marine mammal. We would then like to come back to each platform two weeks after the initial visit and collect the filled out cards and interview as many workers as possible again.

We would like to begin this program as soon as it is convenient. Thanks so much for helping us.

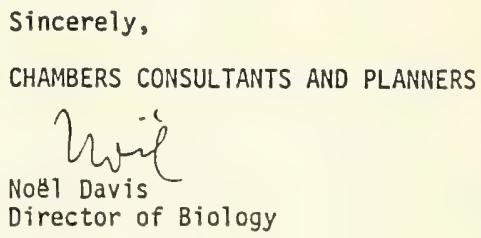

ND:sg 


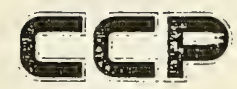

OHAMBERS CONSULTANTS AND PLANNERS

P.O. Box $356 \cdot 10557$ Beach Boulevard Stanton, California 90680

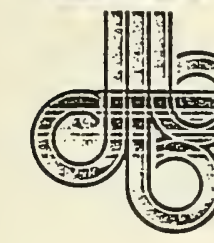

November 14, 1980

(3005)

Union 0 il Company

P.0. Box 6176

Ventura, California 93006

Attention: Ken Guziak

Dear Ken:

Per your conservation with Mel Chambers on November 12, 1980, we are enclosing several questionnaires and photocopies of the proof for the posters.

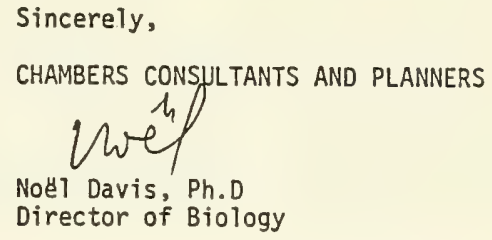

$N D: s g$ 


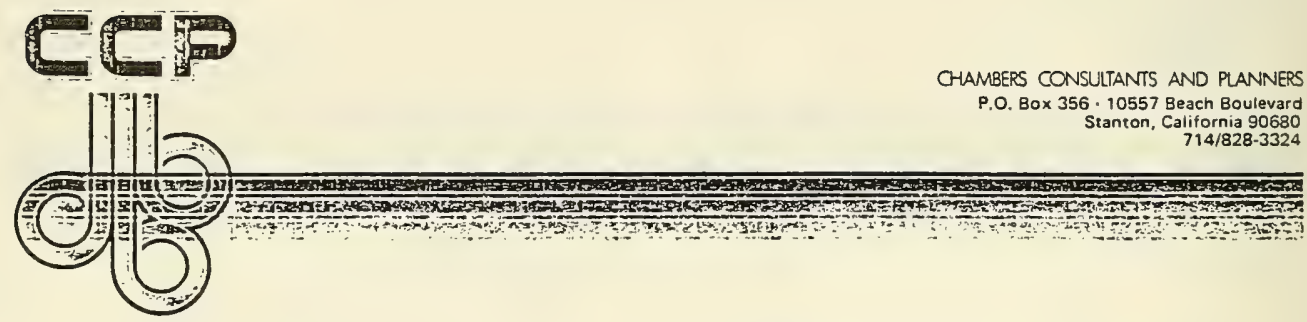

December 15, 1980

(3005)

Union 0 il Co.

P.0. Box 6176

Ventura, California' 93006

Attention: Ken Guziak

\section{Dear Ken:}

As you requested in your conversation with $\mathrm{Mel}$ on December 15, here is a description of our marine mammal program.

Chambers Consultants and Planners (CCP) is working as a contractor to the Naval Ocean Systems Center (NOSC) to develop a method to interview workers on oil and gas platforms to determine the proximity of large marine mammals to oil and gas platforms. This interview program is a small part of a large program in which NOSC is trying to find out if marine mammals are affected by noise from offshore oil operations.

We would like to have two people from CCP and an observer from NOSC interview workers from two platforms in the Santa Barbara Channel. We would be able to conduct all our interviews in the crew boats going out to the platforms. If possible, we would like to put the posters and sighting cards out on the platforms themselves. We would then like to come back two weeks after the initial interview and collect any cards which have been filled out and conduct some follow-up interviews. Each visit to each platform would take about one day, and we would be visiting each platform a total of two times. We enclose copies of the posters, the sighting cards, and the questionnaire. 
Union 0 il Co.

December 15, 1980

Page 2 of 2

CCP is most grateful for Union's help in this program, and we would be glad to meet any conditions and restrictions which you choose to impose.

Sincerely,

CHAMBERS CONSULTANTS AND PLANNERS

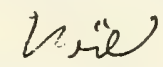

Noel Davis

Project Manager

ND:sg

Encl. 


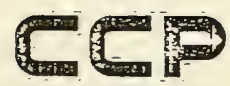

OHAMBERS CONSULTANTS AND PLANNERS

P.O. $80 \times 356$ - 10557 Beach Boulevard Stanton, California 90680 $714 / 828-3324$

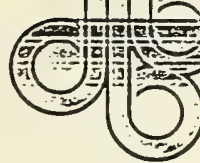

December 16, 1980

(3005)

Union 0 i1

P.0. Box 6176

Ventura, California 93006

Attention: Ken Guziak

Dear Ken:

Here is the handout for the platform workers. I hope it will meet Union's needs. If you want us to add or modify anything just let me know.

Thanks,

CHAMBERS CONSULTANTS AND PLANNERS

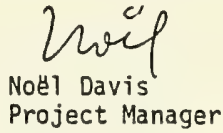

ND:sg

Encl. 
T0: Platform Workers

The Naval Ocean Systems Center is studying the distribution of whales, porpoises, and seals and sea lions around oil and gas platforms. We would appreciate any information on those animals which you have seen from the platforms. Your information will help us to understand the populations, distributions and behavior of these animals.

People from the Naval Ocean Systems Center will come on the crew boats and interview workers about their observations of whales, porpoises, and seals. These Naval Ocean Systems Center people will also put posters out which will show how to identify different types of these marine mammals. Beside the posters they will put a box of cards. If you see a whale, porpoise, or seal, we would very much appreciate it if you would fill out one of these cards. The Naval Ocean Systems Center people will come back in two weeks and collect these cards and ask some more questions about whether you saw any marine mammals in the past two weeks and if you had any trouble filling out the sighting cards.

We very much appreciate your cooperation in this program. 
Dear Ms. Davis:

I have reviewed the information you have provided Mr. Ken Guziak to support your marine mammal monitoring program in the Santa Barbara Channel.

In my judgment, the questionnaires, observation cards, and charts, while being excellently designed for a marine biologist or other skilled observer, are far too complicated to be effectively utilized during brief interview sessions on board the crew boat or at the Casitas Pier. To effectively carry out the apparent objectives of your program utilizing the materials provided Union Oil Company would require extensive training to develop observation skills clearly beyond the scope of casual sightings as they occur during normal daily production operations in the Dos Cuadras oil field.

In view of the obvious cost to Union Oil Company in terms of man-hours, operational efficiency and potential liability as a result of dividing the platform operators' attention from their assigned work, I must decline to cooperate with your program.

By copy of this letter, I am informing Mr. Michae1 F. Reitz, Acting District Supervisor of the U.S. Geological Survey, of this decision and suggest you contact his office for further suggestions as to appropriate methods to conduct the marine mamunal monitoring program.

Sincerely yours,

\section{RiB/bhs}

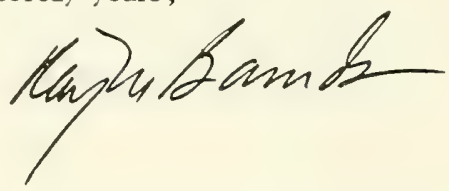

cc: Hichael F. Reitz

R. W. Yarbrough

R. C. Keller

R. A. Dombrowski

k. E. Guziak 


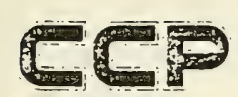

CHAMBERS CONSULTANTS AND PLANNERS

P.O. Box 356 - 10557 Beach Boulevard Stanton, California 90680

Mr. W.D. Edman, Division Manager

Chevron USA, Inc.

P.0. Box 605

La Habra, California 90631

\section{Dear Mr. Edman}

I spoke with Mr. John Herring in Santa Barbara about our.program with the Naval Ocean System Center. This program involves studying the distribution of whales, porpoises, and seals and sea lions around oil and gas platforms by interviewing offshore workers. Mr. Herring suggested that an interview program held at the Chevron pier would not inerfere with workers' operation. We have scheduled our interview on Chevron's pier for early February.

We would like to have two people from our company and an observer from NOSC interview workers coming and going on the crew boats. If possible, we would then like to come back 2 weeks after the initial interview and collect any cards which have been filled out and conduct some follow-up interviews. Each visit will take about 1 day.

We are most grateful for Chevron's help in this program, and we would be glad to meet any conditions and restrictions which you choose to impose.

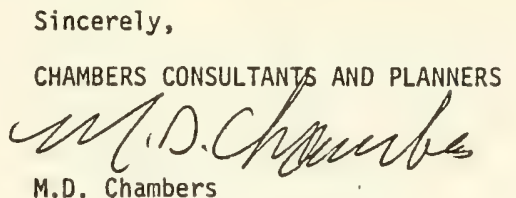

Vice President, Operations

$M D C: N D: d b$

cc: Mr. John Herring, Operation Foreman

1253 Coast Village Road

Santa Barbara, California 93108 

APPENDIX C 


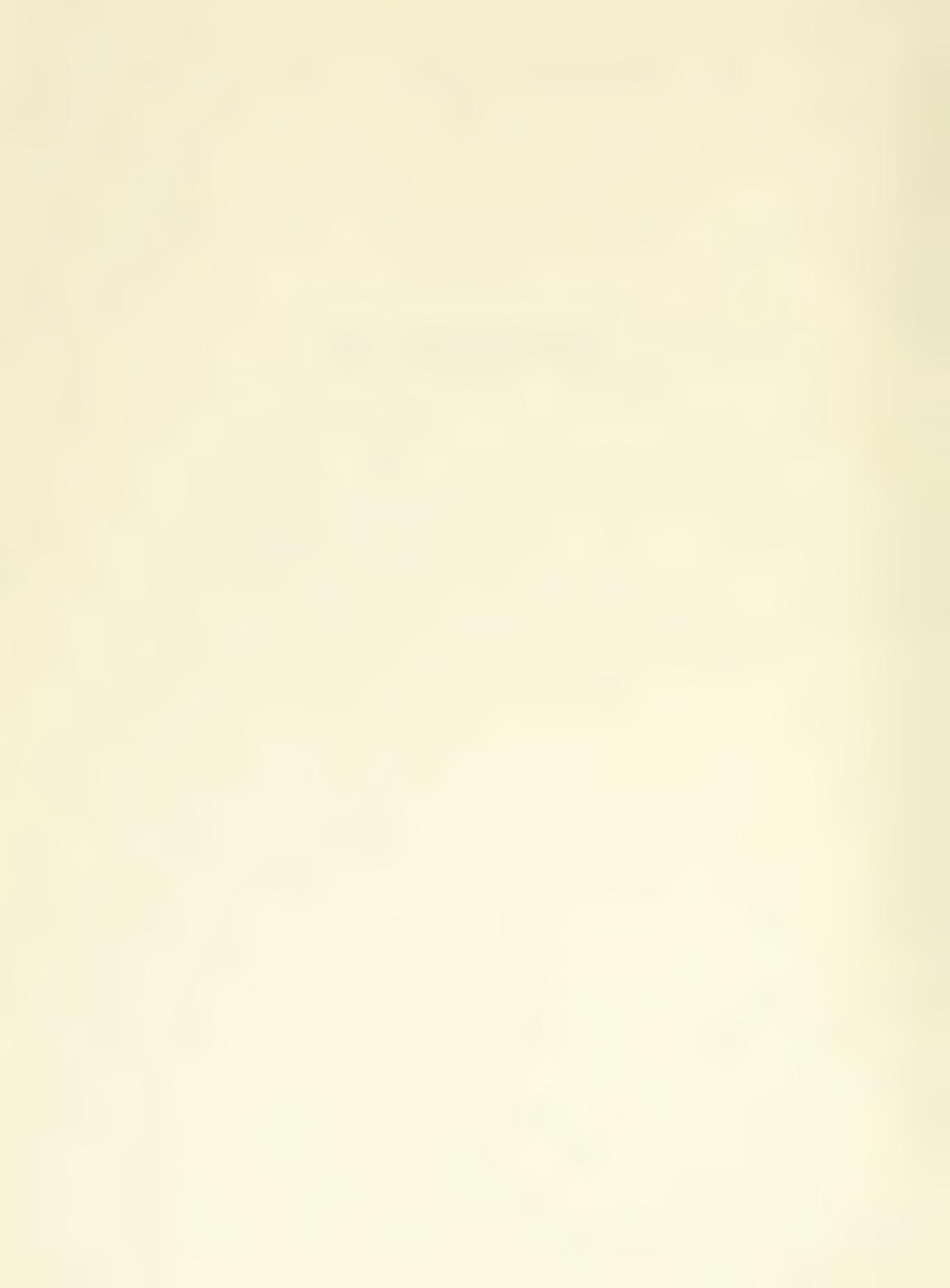


TECHNICAL REPORT

SURVEY OF THE EFFECTS OF OUTER CONTINENTAL

SHELF PLATFORMS ON CETACEAN BEHAVIOR

September, 1981

Prepared for:

Dr. Elek Lindner, Code 5131

Naval Ocean Systems Center

San Diego, California 92152

Prepared by:

Susan L. McCarty

Computer Sciences Corporation

4045 Hancock Street

San Diego, California 92110

Contract N00123-79-D-0272

Delivery Order 7 N69 


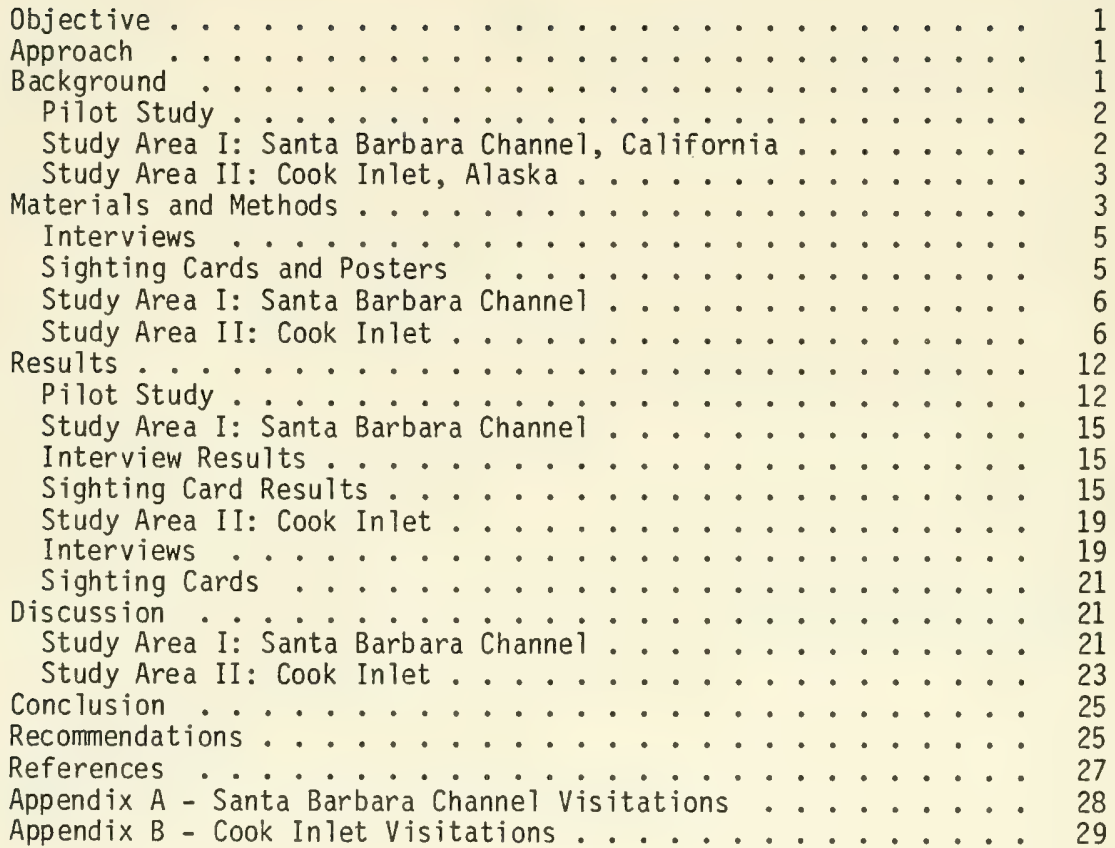

ILLUSTRATIONS

Figure

1 Study Area II: Cook Inlet, Alaska ......... 4

2 Santa Barbara Channel Identification Poster ...... 7

3 Santa Barbara Channel Identification Poster ...... 8

4 Santa Barbara Channel Identification Poster ....... 9

5 Original Sighting Card Used in Santa Barbara Channel . . 10

6 Revised Santa Barbara Channel Sighting Card ....... 11

7 Cook Inlet Identification Poster ........... 13

8 Cook Inlet Booklet Cover and Sighting Card ....... 14 


\section{SURVEY OF THE EFFECTS OF OUTER CONTINENTAL SHELF PLATFORMS ON CETACEAN BEHAVIOR}

\section{Objective}

The objective of this study was to evaluate the potential impact on marine mammals of outer continental shelf (OCS) oil and gas operations. This portion of the study deals with behavioral observations and subjective analys is by industry personnel of marine mammals in the areas of the OCS development. This program is to be used with the analys is of sound recordings of OCS platforms to try and determine a correlation between cetacean behavior and the noise from platform operations. Other possịble factors such as supply boat and helicopter movements and simple physical presence will be evaluated. The observed and suggested responses of marine mammals to offshore structures and associated activity is needed to develop policies regarding offshore development.

\section{Approach}

To collect the maximum amount of data two sampling methods were used:

1. Collection of historical and anecdotal data by interviews. Researchers were transported to offshore platforms via crewboat or helicopter. All industry personnel contacted were interviewed about the types of marine mammals they could remember seeing. This information yielded general trends in marine mammal occurrence.

2. Collection of direct observations by sighting cards. Personnel were provided with and asked to fill out a sighting card whenever they sighted marine mammals. This card recorded behavioral and general information related to the sighting. This information will be correlated with sound recordings of the platforms and evaluated for possible effects.

\section{Background}

The Bureau of Land Management (BLM) is designated as the administrative agency for leasing OCS lands. One of the BLM'S four priority goals for OCS leasing is "protection of the human, marine and coastal environments." To attain this goal much information must be added to the current data base of impacts from $0 i 1$ and gas exploration and production.

One of the major data gaps identified by previous studies and by the BLM is the lack of information on the effects of $0 i 1$ and gas operations on marine mammals, especially cetaceans. For example, no comprehensive studies have been undertaken to determine the effects of 
various sounds emitted from oil and gas operations on the behavior of cetaceans, or to evaluate the impacts resulting from offshore structures and human activity on cetacean populations. A number of cetacean species are listed as endangered or threatened and are protected under the Endangered Species Act of 1973. Therefore, a study on the effects of OCS activites on cetaceans is recommended for making effective management decisions and for developing mitigating measures if needed.

\section{Pilot Study}

Chambers Consultants and Planners (CCP) was responsible for a pilot study for this project. They developed identification posters and created the first sighting card and interview formats. The sighting cards and interviews were designed to permit computer analysis. An objective of the pilot study was to determine what job categories are expected to provide better results in the interview program because some jobs are better suited to make observations. Due to a low number of responses, this information was never attained. Essentially, the pilot study provided a basis to develop a full scale interview program. As many individuals as possible were interviewed and all data received was analyzed.

CCP wrote two computer programs. One analyzed the sighting card information, the other, the interview data. Although these programs proved to be useful with a sufficient number of theoretical data points, the collected actual information was not sufficient to yield any significant results.

Study Area I: Santa Barbara Channel, California

Perhaps the most significant aspect of this area is that it contains the transition point between two biogeographic coastal provinces. Stretching along the coast to the north from Point Conception to Alaska is a biologically rich cold-temperature province. To the south from Point Conception to the lower third of Baja California in Mexico is a warm-temperature area. The biota of this transition zone includes cold temperature species from the north and tropical species from the south, as well as a large number of endemic species. The importance of Point Conception as a major marine biogeographic boundary is well documented. Several investigators note that this California point Ties at a significant biogeographic boundary for many species of fish and invertebrates. In addition, the point is also a significant boundary area for several species of marine mammals and seabirds. The area marks a northern breeding limit for some warm-temperate species and a southern breeding limit for certain northern cold-temperate organisms.

In general, the large size, high mobility and wide pelagic range of the large whales, (gray, blue, humpback, and fin) have discouraged 
compilation of more complete ecological species accounts. It is clear, however, that toothed whales and dolphins, like most pinnipeds, represent a major link in the overall food chain. Furthermore, it is probable that cetaceans play a significant role in influencing relative species abundance levels of other marine biota. (FEIS Proposed Channel Is land Marine Sanctuary)

A recent study by the BLM of the Southern California Bight (1975-1977) covered a 3-year period of observations. Recordings were made of all marine mammals observed along aerial and nautical transects. Based on observed distribution, projected distributions and density were plotted for $5^{\prime}$ Tatitude by $5^{\prime}$ longitude squares created within the bight. The purpose was to be able to estimate at any given time and place, the number and type of marine mammals likely to be found.

The BLM study and studies documenting gray whale migration routes and population densities (Gilmore 1960a, 1976; Rice 1959/1960) were used to determine what types of animals in what numbers would be seen in the Santa Barbara Channel area.

Study Area II: Cook Inlet, Alaska

Cook Inlet is a tidal estuary. It measures 200 nautical miles long and 75 nautical miles wide at the mouth. Oriented northeast and southwest it joins the Gulf of Alaska east of the Alaska peninsula. Glaciers are common throughout the mountainous surroundings with many streams and several major rivers emptying their silt and sediment loads into the inlet (Figure 1). Due to strong and constant currents (5 to 6 knots) and an average tidal flow of 25-30 feet, the water in the Cook Inlet is very silty.

After the break-up of the ice in the Cook Inlet around March or early April "hooligan," a smelt-like fish, move up the Cook Inlet and into the river mouths in mid-April or early May. Following the hooligan are the beluga whales (Delphinapterus leucas). From the initial movement of the hooligan, throughout the salmon migration beginning in mid-June and until the inlet begins to freege, belugas are inhabitants of the Cook Inlet.

Materials and Methods

Data on the occurrence and behavior of marine mammals was collected by interviews for anecdotal data and by actual observation documented on sighting cards. Individuals working in areas or jobs associated with offshore platforms were interviewed to obtain their observations and opinions concerning the local marine life. In addition they were asked to fill out sighting cards during the study whenever they saw marine mammals. Educational posters were provided to assist them in making accurate recordings. Persons involved in this program were 


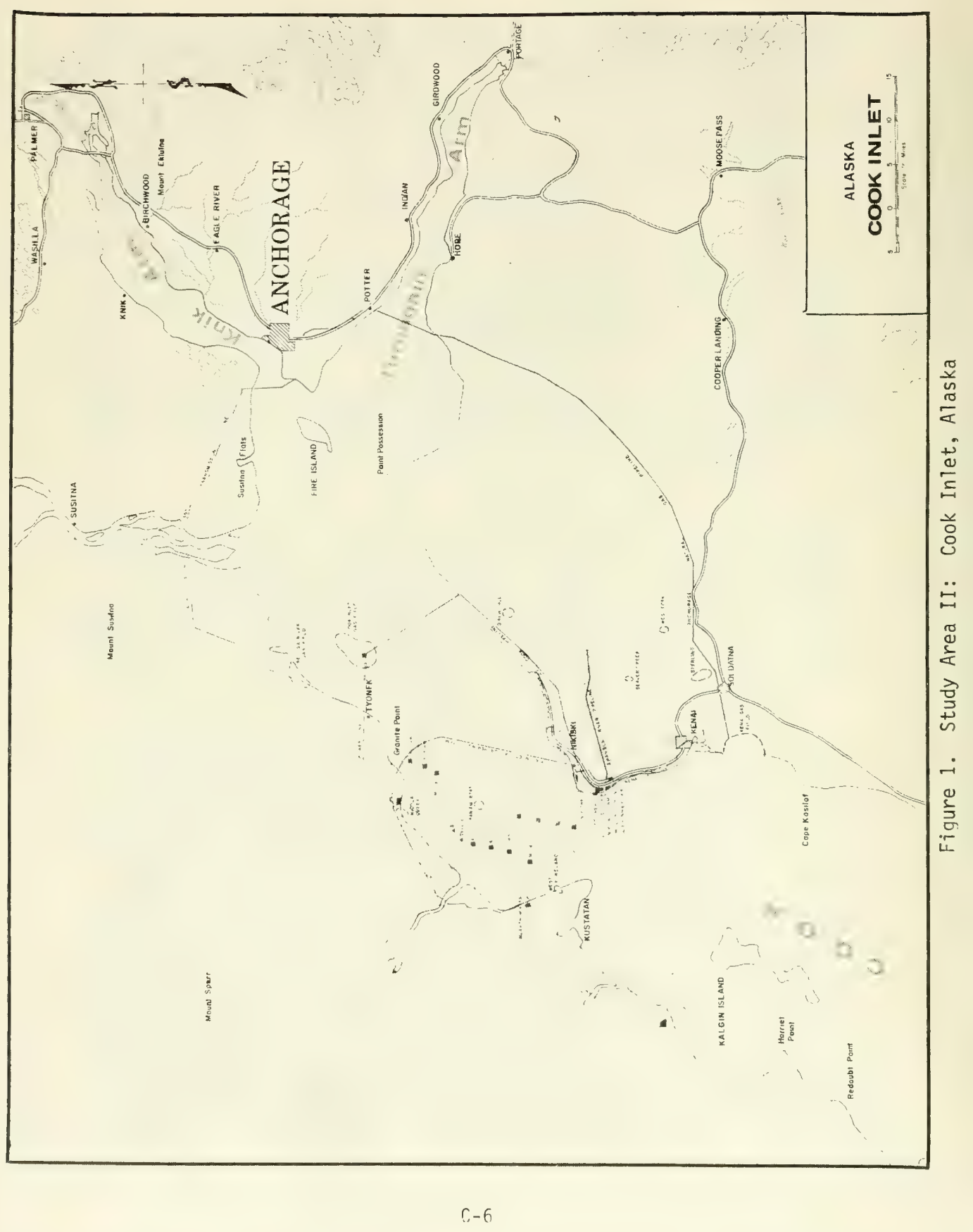


platform workers, supply boat crews and skippers, helicopter pilots, pier workers and a few others.

\section{Interviews}

The offshore oil and gas industry encompasses many various jobs and activites. A goal of the pilot study was to determine if some of these activities and therefore the individuals who performed them were better suited to sighting marine mammals. The interview was constructed to collect information about the workers, as well as their accounts of specific marine marnmal sightings. The questionnaire form of the interview was designed to allow easy information transfer to a computer program. The form was very structured and seemed to sometimes stifle spontaneous conversation.

During the project, the researchers found that if they allowed the conversation to flow freely, at least as much could be learned from each person as when the format was followed rigorously. The worker remained more relaxed and willing to talk. A more informal format allowed the interviewer to modify the questions to suit the worker's position, attitude and knowledge of marine life. Interviews were usually conducted on a one-to-one basis. Although some people were intimidated in that type of situation, it was generally quite successful. Sometimes interviews were conducted in small groups. Three or four workers would start talking and would no longer be talking specifically with the interviewer. At these times, the interviewer was aided by a hand-held tape recorder. The tape recorder made it easier to get everyone's additions and corrections to group discussions. The tape recorder was also useful when the interview was conducted in difficult locations, such as decks of crew boats, flights of stairs, etc.

\section{Sighting Cards and Posters}

The workers were provided with sighting cards to record actual observations. These cards asked for information about the animals sighted and related events. Distance of the animals from the platform and size of animals were the only estimations required. Most of the questions were yes or no, or multiple choice about some aspect of the observation. Time of day sighted and type of activity on the platform were also asked to permit correlation between marine mammal behavior and OCS activity.

The posters were designed to help with specific identification. They also suggested to the workers what identifying features to look for when observing the marine mammals. 


\section{Study Area I: Santa Barbara Channe1}

Visits to the platforms were made during the months of January and February. Interviews were conducted on the platforms, docks or at the heliport. The interview only requred 5 to 10 minutes to complete. Consequently many people could be interviewed in a short period of time. Usually, the researcher explained the purpose and method of the study before the interview. The interviews included questions designed to establish the interviewed persons background, experience and type of job as well as his recollection of marine mammal sightings. Often, specific questions were not necessary because as soon as "whales and dolphins" were mentioned the worker would eagerly recall past sightings. During the interviews the posters and cards were explained and left behind for future use.

For the Santa Barbara Channel area a set of three posters (Figures 2, 3, and 4) was designed. These posters described in words and pictures the species of marine mammals likely to be seen in the study area. The posters were displayed aboard supply boats, in platform galleys, and anywhere that seemed appropriate. Besides their instructional purpose, the posters constantly reminded the workers that a study was in progress, and inspired filling out sighting cards.

The $3^{\prime \prime} \times 5^{\prime \prime}$ sighting cards had questions printed on both sides pertaining to the appearance and behavior of the sighted animals. The sighting cards contained only a few personal questions regarding the worker's job and interest in marine life, putting the emphasis on recent marine mammal observations. Most questions on the card were presented in a "forced-choice" manner. Possible answers were provided and the worker allowed to choose the one that "fit the best." Some questions required filling in blanks, especially those pertaining to the size of the animal or distance from the platform. There was also room allotted for comments and any information not specifically asked for but what might have been considered important and relevant (Figures 5 and 6).

The workboat skippers and crews interviewed in Santa Barbara, are all employees of the "Tide Fleet," and were very cooperative. Industry personnel were associated with the platforms listed in Appendix A.

\section{Study Area II: Cook Inlet}

The Cook Inlet area was studied over a 3 -week period during the months of July and August. All interviews were conducted on board the platforms. Helicopters provided the transportation to and from the rigs. While helicopters are excellent vantage points for sightings, conducting interviews on them was not successful. Therefore, al1 interviews were conducted on the relatively stable and quiet platforms. 


\section{ATTENTION! WENEED YOUR HELP}

HAVE YOU SEEN ANY WHALES, PORPOISES, SEALS, OR SEA LIONS FROM THIS PLATFORM? WE ARE TAKING A SURVEY OF MARINE MAMMALS IN SOUTHERN CALIFORNIA WATERS, AND WOULD APPRECIATE ANY INFORMATION ON MARINE MAMMALS (WHALES, PORPOISES, AND SEALS) WHICH YOU HAVE OBSERVED OFF THE PLATFORM IF YOU SEE A WHALE, PORPOISE, OR SEAL PLEASE FILL OUT A CARD AS SOON AS POSSIBLE AFTER SEEING THE ANIMAL ANDPLACE THE CARD IN THE BOX. THESE POSTERS DEMONSTRATE HOW TO IDENTIFY THE COMMON MARINE MAMMALS. YOUR INFORMATION WILL HELP US TO UNDERSTAND THE POPULATIONS, DISTRIBUTIONS AND BEHAVIOR OF THESE ANIMALS. WE HOPE TO SHOW THAT OIL PLATFORMS ARE A GOOD SOURCE OF INFORMATION

\section{SEALS \& SEA LIONS}

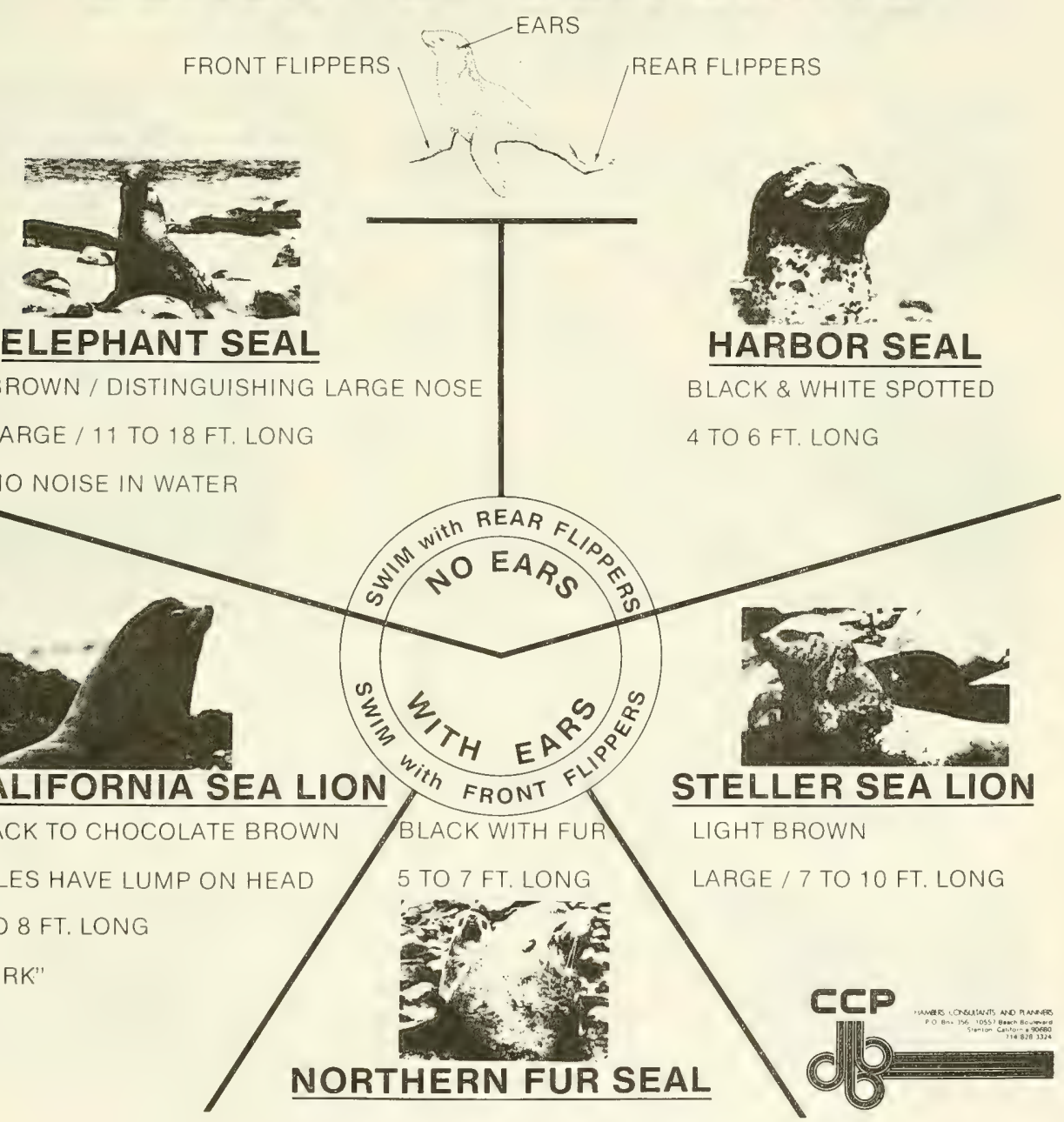

Figure 2. Santa Barbara Channel Identification Poster 


\section{DOLPHINS, \& SMALL WHALES \\ PORPOISES}

BLoHHOLE A. DORSAL IIN
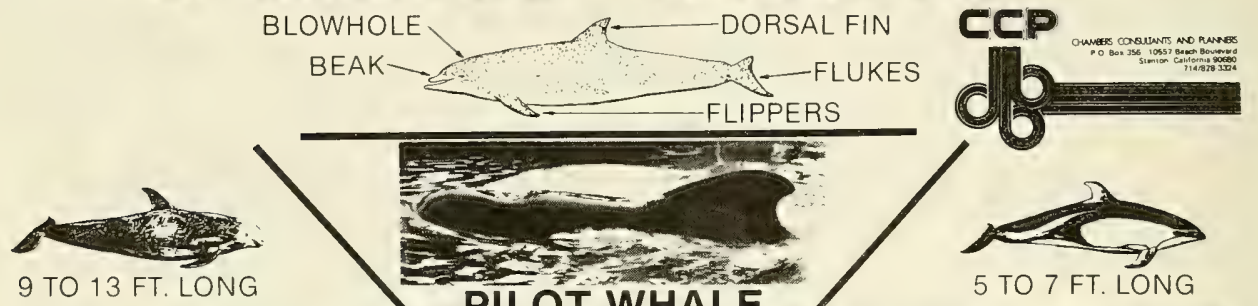

9 TO 13 FT. LONG

PILOT WHALE

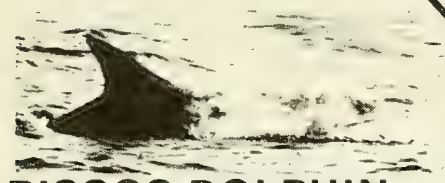

RISSOS DOLPHIN

TALL POINTED FIN ON BACK

BLUNT ROUNDED HEAD

DARK TO GRAY

W/ NUMEROUS SCARS ON BODY

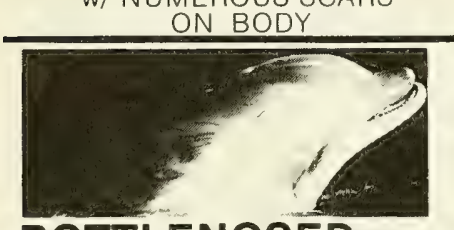

BOTTLENOSED DOLPHIN SLOW
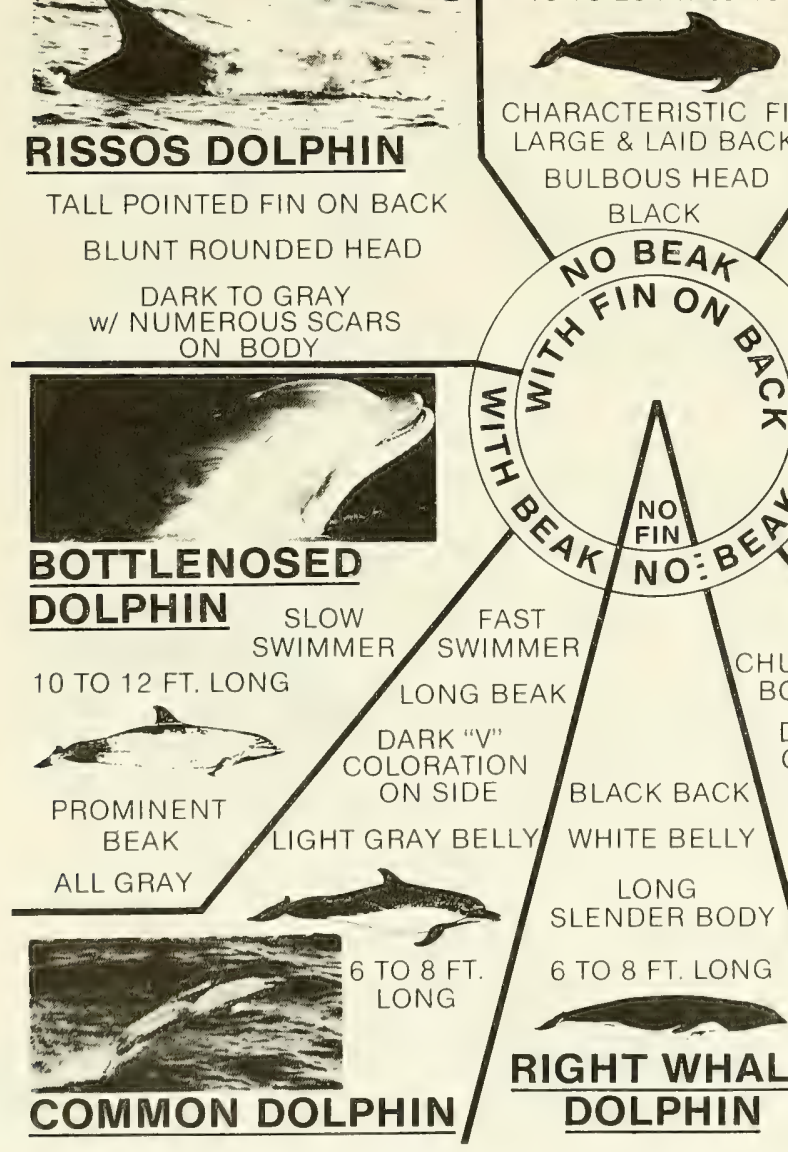

CHARACTERISTIC FIN LARGE \& LAID BACK

BULBOUS HEAD

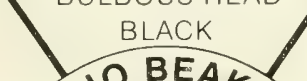

FAST SID
SWIMMER

PACIFIC WHITE

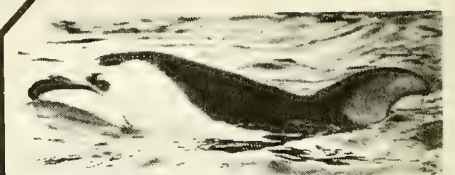

FAST SIDED DOLPHIN WO BEAK WHITE GRAY ON BACK OFFIN
THROAT GINON BLISH GRAY TO BLACK WO BEAF WHITE GRAY ON BACKOFFIN
FIN ON THRAT BLUISH GRAY TO BLACK $a^{2}$ ON BLUISH GRAY TO BLACK W/ WHITE PATCH ON SIDE

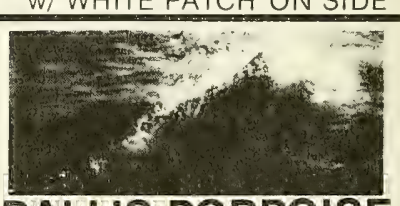

\section{DALL'S PORPOISE}

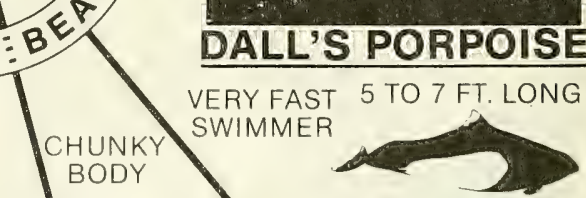

FAST
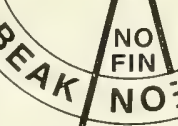

ON BACK

FIN TRIANGULAR W/ WHITE TIP

BLACK BACK FIN SMALL \& GRAYISH TO BLACK WHITE BELLY TRIANGULAR W/ WHITE PATCH ON SIDE
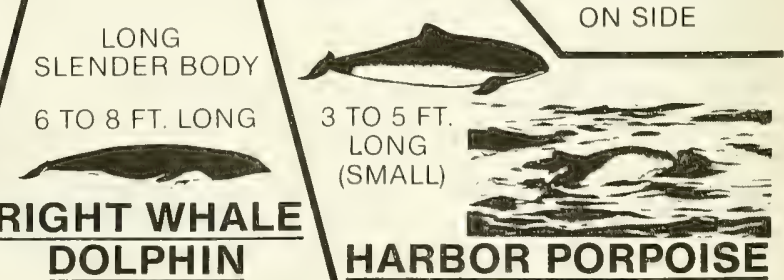

Figure 3. Santa Barbara Channel Identification Poster 


\section{LARGE \& MEDIUM WHALES}
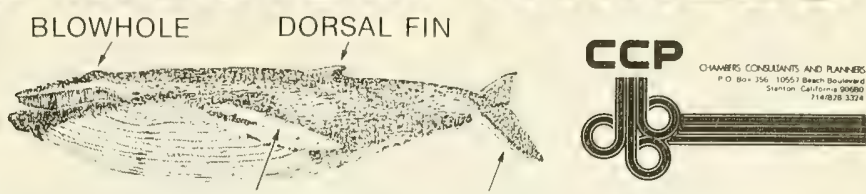

FLIPPERS

FLUKES

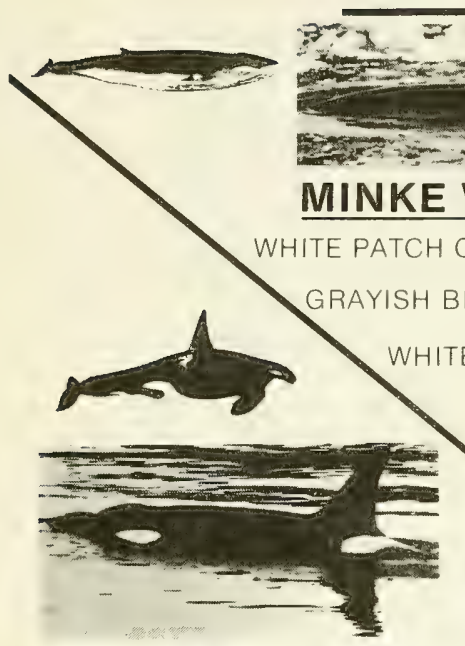

KILLER WHALE

OVAL WHITE PATCH BEHIND EYE

GRAY SADDLE ON BACK TALL ERECT FIN HUGE HEAD

W/ BLUNT SQUARISH SNOUT

BLOW HOLE WELL FORWARD WRINKLED SKIN

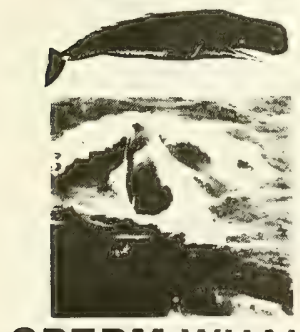

SPERM WHALE

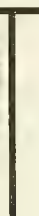

WHALE

ON FLIPPERS

CK ABOVE
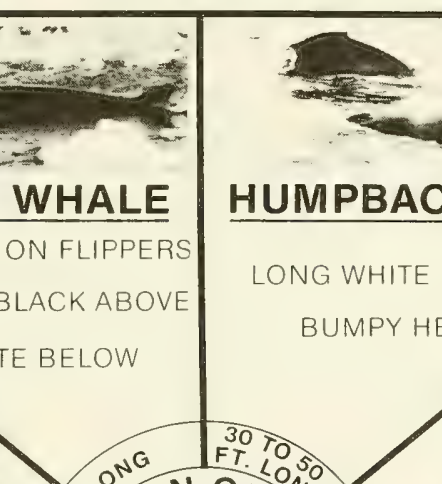

\section{HUMPBACK WHALE}

LONG WHITE FLIPPERS
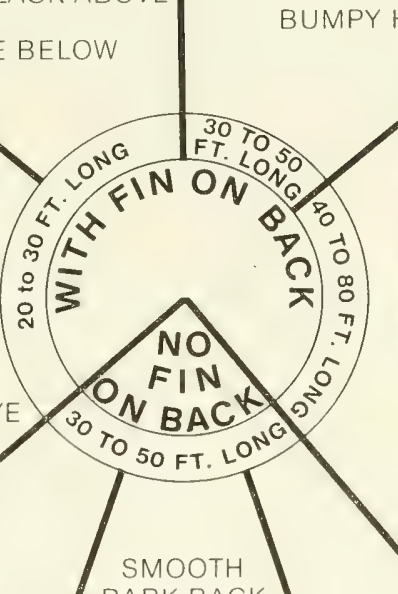

BUMPY HEAD

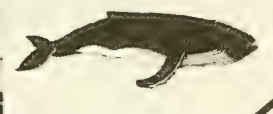

(SEI, FIN \& BLUE WHALE)

LARGE RORQUAL WHALE

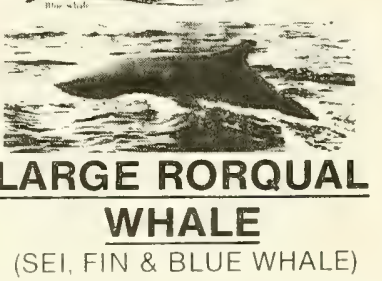

\section{TOWARDS REAR \\ FIN ON BACK LOCATED} SMOOTH
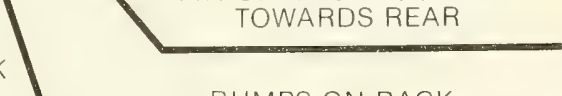

BUMPS ON BACK

GRAY MOTTLED BODY and

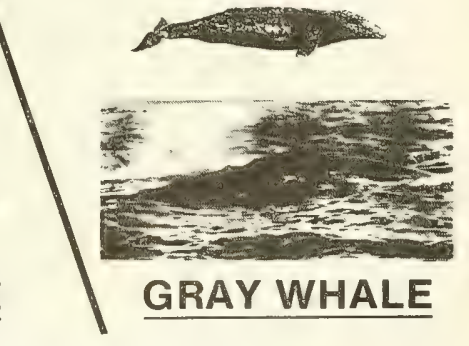

Figure 4. Santa Barbara Channel Identification Poster 
Please fill out the questions below whether or not you know the name of the animal you saw. If you saw large whale (more than 20 feet) please fill out Questions 17-29. If you saw a dolphin, porpoise, or snall whale (less than 20 feet) fill out Questions 30-40. If you saw a seal or sea lion, fill out Questions $41-47$. If you are unsure whether what you saw was a dolphin or a seal please fill out Questions 30-47.

Time of day whate, dolphin, or seal or sea lion was seen a.m $p, m$

4. Time of day card was filled ou

17. Please check any characteristics that you can remember for the appropriate type of animal.

6. Estimate of noise on platfom when aninal was seen on a scale of 1 to 10 ; with 1 as quiet and 10 as noisy

LARGE WHALE

7. Estimate of distance marine mammals were from the platform in yards

(Questions 17-29 only)

8. What direction from the platform were the marine mammals?

I 1) Towards shore

$\square$ 2) Out to sea

$\square$ 3) Upcoast

$\square$ 4) Downcoast

9. What direction were the marine mammals traveling?

7 1) Towards shore

$\square$ 2) Out to sea

3) Upcoast

$\square$ 4) Downcoast

10. Did the marine mamrals change direction while you were watching? $\square$ 1) Yes E. 2) No

11. If Yes, did they change direction: $\square$ 1) Towards the platform? $\square 2$ ) Away from the platfonm?

\section{Did you see:}

$\square$ 1) Whale?

2) Porpoises or dolphins?

$\square$ 3) Seal or sea lion?

13. Did you see:

$\square$ 1) A single animal?

L. 2) A group of aninals?

14. If you saw a group, about how many animals were in the group?

15. If possible, name the kind of animals you saw.

16. How big was it?

$\square$ 1) Less than 20 feet

$\square$ 2) 20 to 30 feet

3) Greater than 30 feet

4) Don't know

8. Shape and size of spout (check one of each choice)

1) $\square$ single $\square$ Doubl

2) $\square$ Forward on hea

3) Back on head

$\square$ Shot straight up

4) $\square$ Shot high $\square$ shot low

5) $\square$ Don't know

19. Dorsal fin

$\square$ 1) Present

$\square$ 2) Absent

$\square$ 3) Don't know

Behavior (Answer as many questions as you can)

20. Did it show its fiukes?

$\square$ 1) Yes

2) $\mathrm{NO}$

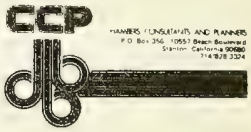

21. Did it jump out of the water?

$\square$ 1) Yes

$\square$ 2) No

22. Did it stick its nead out of the water? $\square 1$ ) Yes

ए 2) No

23. Did it slap its tail? $\square$ 1) Yes

$\square$ 2) No

24. Did it swim:

$\square$ 1) On the surface inost of the time, or

2) did it dive a lot?

25. $\square 1$ ) Did it inill around in the same area, $\square 2)$ or was it
traveling?

26. Shape and size of head, if possible $\square$ 1) Broad \& rounded $\square$ 2) Pointed \& trianguiar

$\square$ 3) Blunt \& rounded

$\square$ 4) Don't know

27. Shape of body, if possible

$\square$ 1) Long and thin

2) Fat \& rounded

(3) Don't know

28. Did it have long white front flippers?

$\square 1$ ) Yes

17 2) No

3) Dan't know

29. Were there any baby whales in the group? Q4, 1) Yes

3) Don't know

Figure 5.
DOLPHIN, PORPOISE, or SMALL WHALE

(Questions 30-40 Only)

30. Dorsal fin:

$\square$ 1) Present

$\square$ 3) Don't know

31. Shape of dorsal fin (Check one of each

pair)

1) $\square$ Tall $\square$ short

2) $\square$ Erect \& triangular $I$ Cirved backward

3) $\square$ Don't know

32. Shape of head:

$\square$ 1) Rounded \& bulbous

$\square$ 2) Pointed

$\square$ 3) Don't know

33. Snout:

$\square$ 1) With beak

$\square$ 2) Wi thout beak

[7 3) Don't know

34. Color:

$\square$ 1) Black

I 2) Black a white

(3) Gray

$\square$ 4) Don't know

35. Did you notice any

scars or scratcia inarks?

$\square$ 1) Yes

$\square 7$ 2) Wo

Behavior (Answer as inany

questions as you can)

36. Did they jump high out of the water?

$\square 21\}$ Yes
37. Did they show the characteristic porpoise behavior of traveling quickly and jumping out of the water frequenti $y$ ? DI 1) Yes

$\square$ 2) No

38. Did they swiln slowly and low in the water? $\square$ 1) Yes $\square$ 2) wo

39. Were they switnming rapidly and throwing out sipray but not out spray but not
jumping out of the water?

I) Yes

$\square$ 2) No

$\square$ 3) Don't know

40. $\square 1)$ oid they mill around in the same area?

$\square$ 2) were they traveling?

Were there any other
characteristics you noticed?

45. Did it bark?

$\square$ 1) Yes

$\square$ 2) 110

3) Uon't know

Behavior (Answer as many questions as you can)

46. $\square$ 1) Did it leap out of the water like a porpoise?

2) Did it swim with only its head showing?

47. $\square$ 1) Did it mill around in the saine area?

$\square$ 2) Was it traveling?

Original Sighting Card Used in Santa Barbara Channel 
Sighting Card

Date:
(Check correct box)

Time of sighting:

1. What did you see? Whale $\square$ Dolphin $\square$ seal/sea Lion $\square$ could you specifically identify it?

2. Was it ALONE $\square$ or in a GROUF $\square$ ?

3. Approximate length?

4. Direction of travel?

5. Direction from platform?

6. Distance fram platform?

7. Did their travel seem af $\overline{\text { fected by the platform? YES }}$

NO Did they move TOWARDS AWAY FROM the platfon?

Behavior: Did the animal..

1. Show its tail on dives?

2. Jump out of the water?

YES

YES

3. Stick its head out of the water?

4. Slap its tail on the water?

5. Swim on the surface

Dive a lot

NO

6. Stay in one area $\square$ Travel a lot

7. Swim slowly $\square$ swim fast

YES YES
No $\square$

\section{General Description}

1. Did it have a dorsal fin? YFS $\square$ No $\square$ Didn't see $\square$ If yes, what was the shape?

2. What shape was the head?

3. What shape was the body?

4. Did it have a "beak"? YES

5. Did it have scratches or scars on it? YES $\square$ NO $\square$

6. What color was it?

7. Did you notice any ears? YES $\square$ NO $L$

8. Did you notice the flippers? YES $\square$ NO $\square$ Can you describe them?

9. Did it swim with FRONT $\square$ BACK $\square$ flippers?

10. Did it make any sounds? YES $\square$ NO $\square$ What kinds?

Was there any activity on the platform that seemed to affect the behavior of the animal(s) that you saw?

Figure 6. Revised Santa Barbara Channel Sighting Card 
A less restricted, more free-flowing conversation interview format was used with great success. More emphasis was placed on past observations and less on personal, job-related questions. There are very few species of marine mammals in the cook Inlet. Therefore, questions did not need to cover as wide a range as at Santa Barbara Channel. As at Santa Barbara Channel, almost as soon as the project was explained, information on marine mammals was provided.

During the interviews, the instructional poster was displayed (Figure 7). Because of the few species in the Cook Inlet area all species of expected marine mammals were shown on one poster. The poster was placed in a prominent place on each platform and at the heliport offices.

The sighting card had been revised and simplified (Figure 8). The revised card had questions on only one side, and a postage paid return address on the other side. All of the personal questions were removed; only questions dealing strictly with sightings remained. A space was left for additional comments.

Five sighting cards were bound into a booklet, with a cover sheet explaining the project. This way, each person interviewed could have their own supply of sighting cards. The cards took less time to fill out and it was easier to collect them by mail than by a company representative.

The helicopter pilots interviewed worked either for ERA helicopters, or Kenai Air Alaska, and all were very helpful. Industry personnel were associated with the platforms listed in Appendix B.

\section{Results}

\section{Pilot Study}

The pilot study analyzed data from workers on four platforms. On Shell's platform Beta, only the sighting cards were used, because the platform management did not want the work to be disturbed by conducting interviews. Thirty interviews were analyzed in the pilot study: 1 from a crew boat skipper at Holly, 12 from workers on platform Hondo, and 17 from platform Emmy. Ten sighting cards were returned during the pilot study, seven from platform Emmy and three from platform Beta. The collected data were not sufficient for valid statistical analysis. However, the interviews did show that oil platform workers do see cetaceans and pinnipeds from the platforms. 

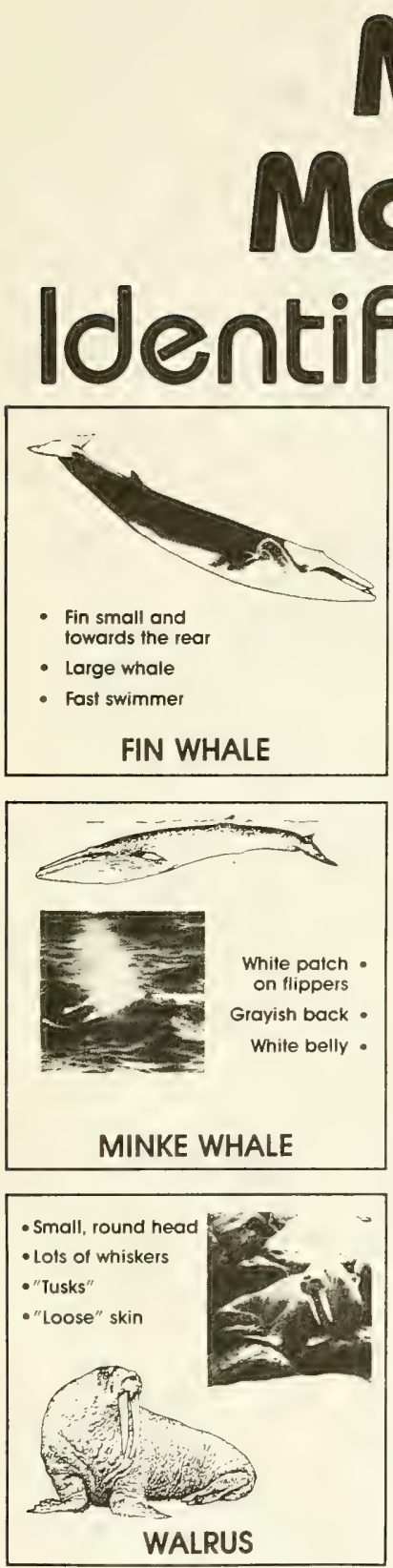
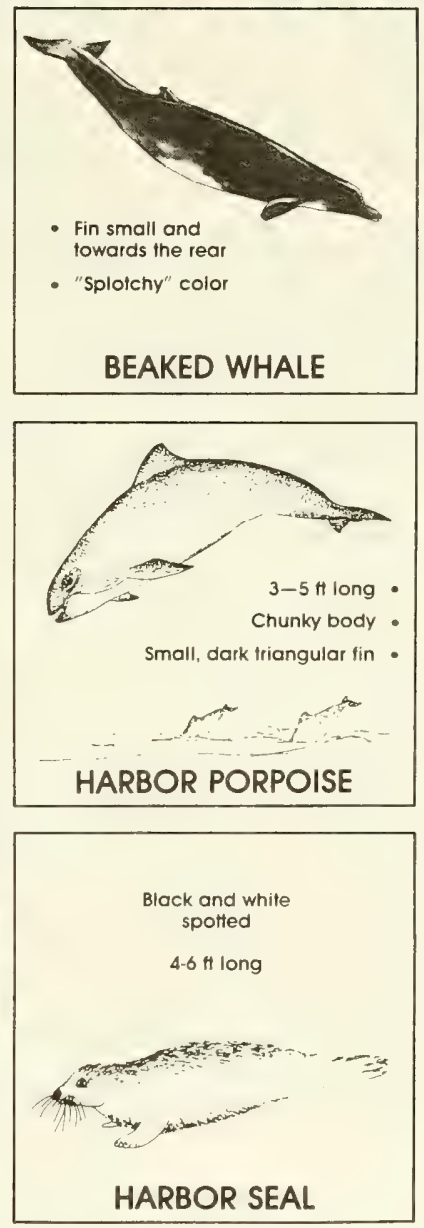
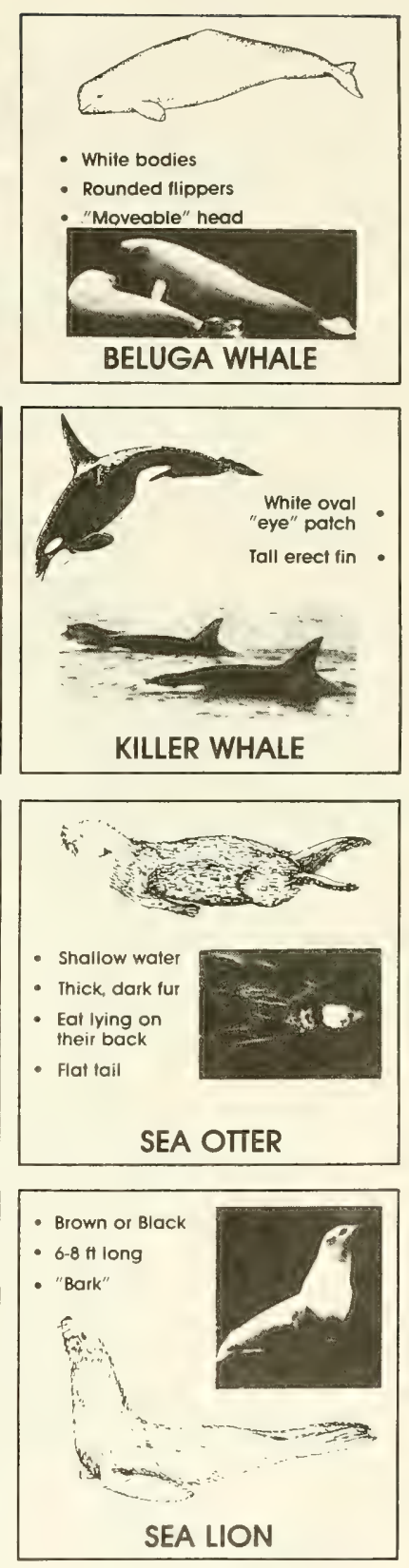

Fiqure 7. Cook Inlet Identification Poster 
The Naval Ocean Systems Center is conducting research on marine mammals in the Cook Inlet. Observations made by oil industry personnel provide very useful information about where and when these animais are present, and their patterns of movement and other behavors. We would be very grateful to you for completıng one of these postage paid business reply cards for each sighting you make.

Many species of marıne mammals occur in the Cook Inlet. Some of these are described by the poster accompanying these cards

Intormation of particular importance is species, number of animg is present, their direction of movement (indicate magnetic of true heading), the location of the sighting (latitude and longitude. if possible), and the water depth (some species appear to prefer certain depth ranges.) The type of vesse or aircratt you were in and how close the animal was to you is of interest, as is any reaction the animais may have had to your presence (did they dive or change course?) Record anything interesting you may have noticed.

Naval Ocean Systems Center, San Diego, CA 92152

COOK INLET MARINE MAMMAL SIGHTING CARD

$\begin{array}{lll}\square \text { WHALE } & \text { TYPE } & \text { SIZE } \\ \square \text { DOLPHIN } & \square \text { SEA OTTER } & \square \text { SEAL/SEA LION }\end{array}$

Number of animals

Direction of movement

(Indicate true or magnetic neading)

Location

Water depth

(Latitude and longitude. if possibie)

Date seen 1981

Time seen am $\square \quad p m \square$

Observation point

Name

Type

Closest distance of

$\square$ Plattorm

Vessel

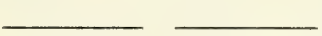
animal to observation

$\square$ Aircraft i point:

Activity around observation area

Other observations

Your name

Thank you tor laking the time 10 record youf observations.
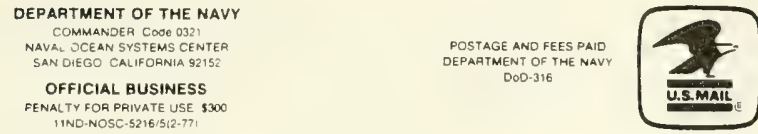

COMMANDER, CODE 0321

Naval Ocean Systems Center

San Diego. California 92152

Alln:

Code 5131, Seaside

Cook Inlet Sighting Program

Fiqure 8. Cook Inlet Booklet Cover and Siahtina Card 
Study Area I: Santa Barbara Channel

Interview Results

Thirty interviews were analyzed. Four interviews were conducted with work boat skippers, four with crew boat hands, twenty with platform workers, and two interviews with land-based office personnel.

Most people were helpful and cooperative when approached to be interviewed. Almost everyone seemed to be interested in marine life and they could recall seeing at least sea lions. The awareness of the workers toward marine life varied from disinterested to very aware and interested. Interviews conducted in a relaxed atmosphere rather than trying to strictly follow the prepared questionnaire format inspired cooperation, although some of the questions of lesser importance were omitted. Most people could not recall the direction that the sighted animals were traveling or their distance from the platform.

The results are shown in Table 1. Graphs 1 and 2 show that when more people were interviewed on a platform more animal sightings were reported. With the exception of platform Hogan, interest in marine life was found essentially the same at all study points. With a larger sample size the personnel at Hogan would probably fit the trend. There are all combinations of relative numbers of whales compared to relative numbers of dolphins. As in the pilot study these results show that many animals are seen from the platforms. Only four people interviewed could provide any information about platform activity influencing cetacea behavior. A third of those interviewed (10) stated that the mammals seemed to come in closer when there was less noise, but didn't seem to avoid or be driven away from the platforms when they were noisy.

Sighting Card Results

Only 11 sighting cards from five platforms were returned during the whole project. These cards were analyzed by hand because of insufficient numbers for computer evaluation.

Three cards were from workers on platform Grace, four were from Hondo, two from Houchin, one from Hogan, and one from a worker on Emmy.

One of the three sighting cards from Chevron's platform Grace reported only sharks. Therefore, this sighting had no relevance to this project. Another reported a school of dolphins moving south, 1/2 mile southeast of the platform. The platform didn't seem to affect their travel. The third sighting was of four whales, about 30 feet in length, moving northwest, about 500 yards west of the platform. Based on the reported behavior, and the date of the sighting, these were probably gray whales. 

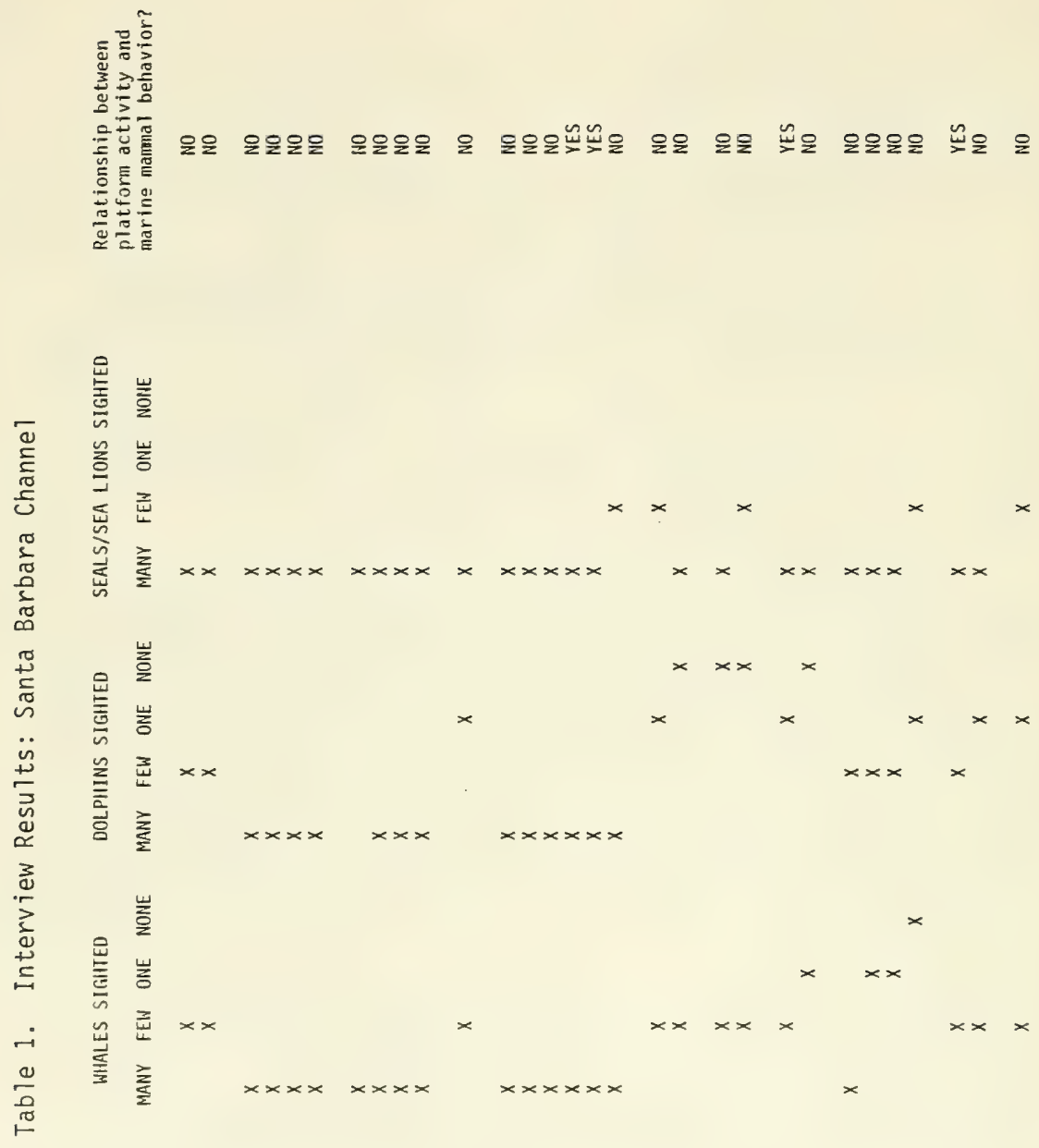

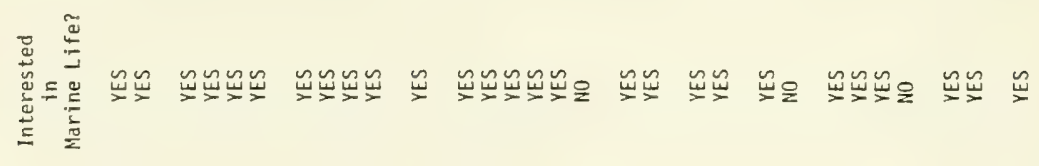

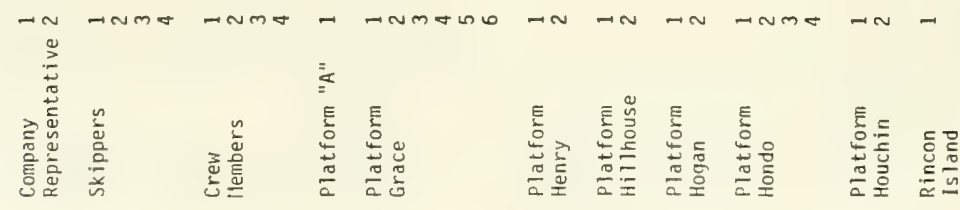




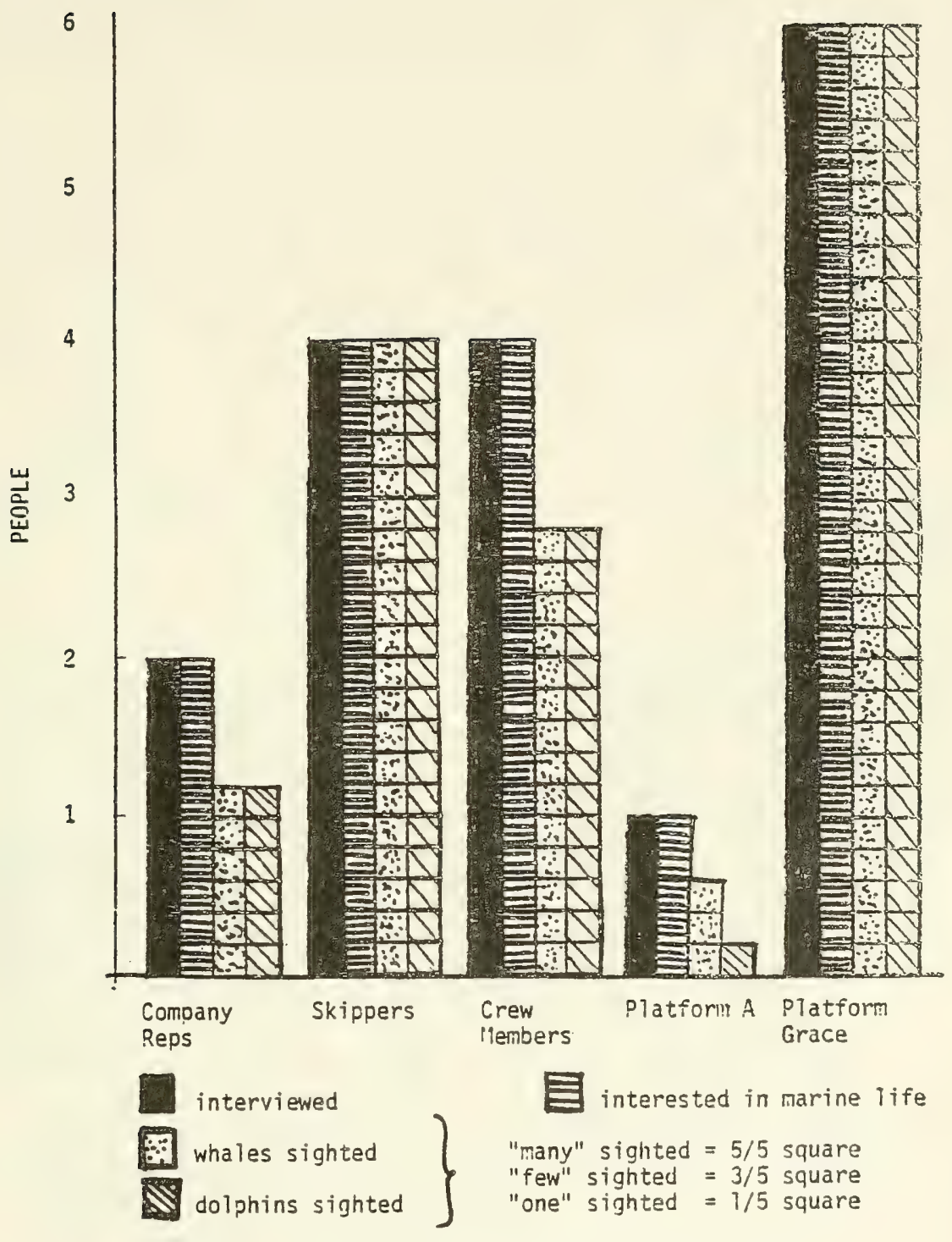

Graph 1. Interview Results: Santa Barbara Channel 


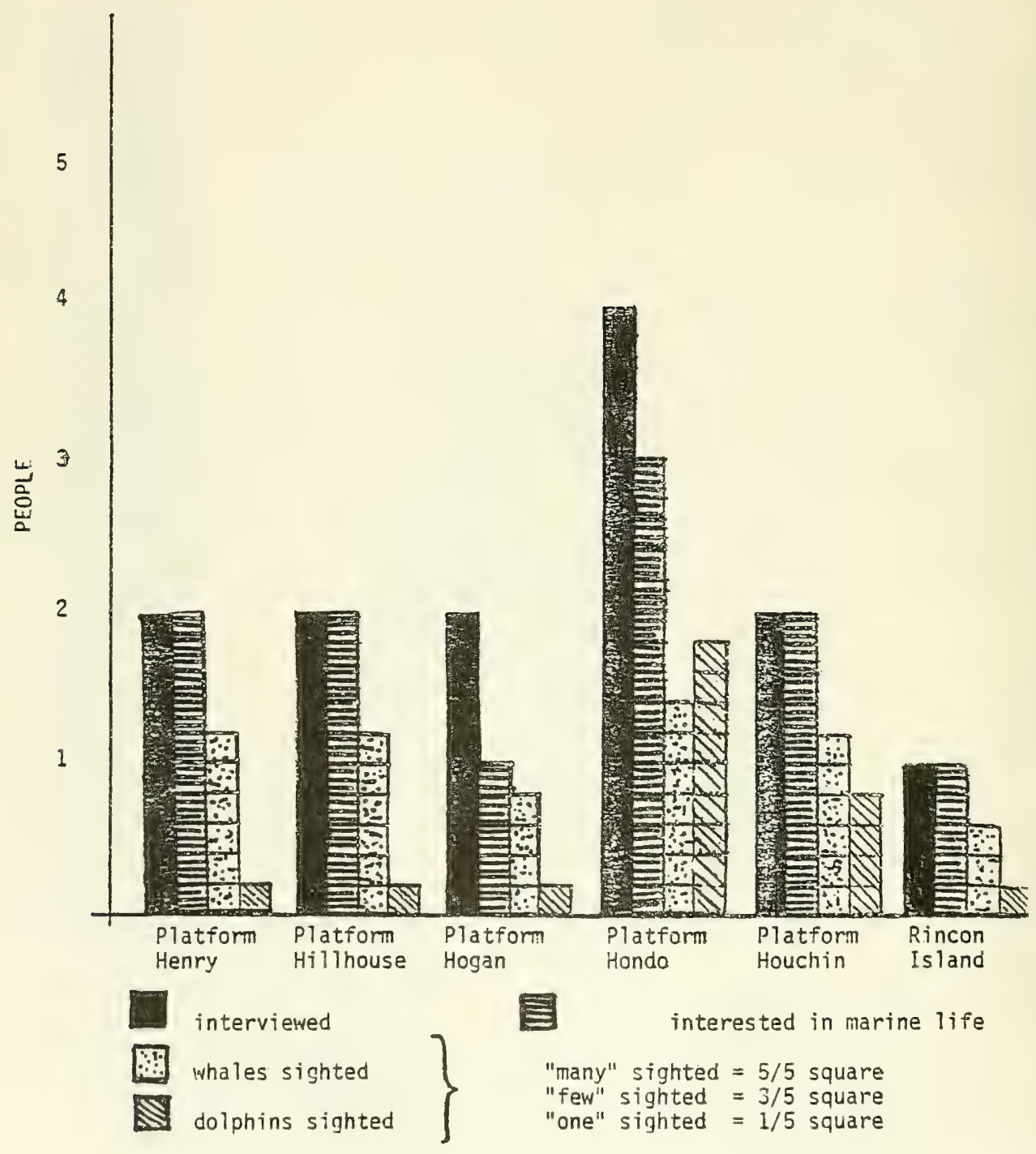

Graph 2. Interview Results: Santa Barbara Channel 
All four sighting cards from Exxon's platform Hondo reported gray whales in two groups of three, one of $8-10$, and one of 10-15. All animals were moving north at an estimated distance between 50 and 300 yards from the platform. Additional comments expressed surprise that the animals came in so close, especially since drilling was going on.

The sighting card from Phillip's platform Hogan reported sea lions. Since these animals are in abundance in this area this observation is expected and it reinforces the general belief that the platforms are beneficial to sea lion populations. The two sightings from platform Houchin were of whales. One was identified as a pilot whale, the other was not positively identified but according to the description could have been a pilot whale, too. Both animals were sighted at an estimated 50-100 yards from the platform. The only comment was a statement that the animals never seemed to avoid the platform, but did come in closer when there was less no ise.

The sighting card from a worker on Aminoil's platform Emmy reported a large school of about 100 dolphins and a group of six gray whales. The observations were made from a helicopter so few details were reported. These animals were seen about 2-3 miles from the platform which was reported as being noisy that day.

\section{Study Area II: Cook Inlet}

One hundred and forty-six interviews were conducted, five with helicopter pilots and the rest with platform workers. Twenty-seven interviews were conducted on Amoco's platform Bruce, 17 on Amoco's Dillon, 12 on ARCO's King Salmon, 8 on ARCO's Spark, 32 on Marathon's Dolly Varden, 5 on Phillip's Tyonek, 24 on Shell 0il Company's platform $A$ and 16 Shell platform $C$.

Most personnel working on the rigs work 7-day "hitches." Therefore, there is a new crew every 7 days. Each platform was visitied twice within a 2-week period in order to interview both crews.

Interviews

Almost everyone approached to be interviewed was helpful and talkative. They showed great interest in marine life. Many individuals had extensive training in biology and could volunteer very useful data. Often, the interview was turned around and the workers asked the researcher questions about the marine mammals.

Beluga whale sightings were recorded from all 146 people. To quote many of the workers, "you'd have to go around with your eyes closed to not see beluga whales." Belugas were reported as close as $30 \mathrm{ft}$. to the platform. Eighty three percent (122) of the reports included 
mother and calf pairs. The calves were estimated to be a minimum of 5-6 ft. long. Calves did not always surface when their mothers did, but when they did, the calves came up just after their mothers. Many calves were seen swimming just above the posterior half of their mother. There was much speculation about whether the Cook Inlet is a breeding ground for belugas.

Three incidences of spy-hopping were reported which occurred when there was a helicopter close. The usual behavior was the normal arched rolling of the whales as they swam through the water.

Responses to questions about the effect of the rigs on the whales were always negative. Whales are seen very close to the platform and there were many reports that the flare booms seem to attract whales. (It is more likely that the flares attract salmon, which in turn attract the belugas.) People who had been on rigs both actively drilling and not drilling could not report any change in the numbers of whales sighted. Their observations were that as long as the noise was consistent it didn't seem to effect the whales. Change in behavior such as a quick dive, an avoidance reaction, occurred when a helicopter flew over. All of the pilots and many workers reported this response from the belugas.

The direction of the tidal flow and the presence or absence of salmon seemed to be the major factors which determined the location of the beluga whales.

There is a suggested resident population of about $300-400$ belugas (Henning, 1978) in the Cook Inlet. Many (78 people, 55\%) reported several occasions when belugas could be seen from one side of the inlet to the other. Estimates of actual numbers range from 500-1000 animals, which may indicate that the Cook Inlet is on the beluga migration pathway. However, some kind of tagging or marker identification is needed to distinguish new groups of animals from those already counted.

Sightings of marine mammals other than belugas were few and far between. A minke whale was sighted by two people. It was about $1 / 2$ mile away from the platform. Pilot whales were reported by seven people, all from platform Dillon. There were three or four animals about a mile away from the platform. There were two reported incidents of killer whales in the Cook Inlet. Five people could recall a time three years ago when a pod of five animals were seen daily for about a week. The other sightings were this past spring. Seventeen people reported seeing a pod of eight killer whales swimming within the inlet.

There were two reports of dolphins, one from two workers on platform Bruce of a school of dolphin (50-100 members) about $1 / 2$ mile from the platform. The second report was of a pair of dolphins very close to the King Salmon. The three men who saw the pair estimated that the animals were about 50 yards away. 
Five people reported walrus, but all five probably saw the same animal since the reports were all from Shell platforms $A$ and C. Thirtyfive individuals reported seeing seals or sea lions. Usually these animals were alone although occasionally they appeared in pairs. The seals came in close to the platform but did not stay in the area for any length of time. Two individuals reported seeing a sea otter.

\section{Sighting Cards}

Twenty-three sighting cards were mailed in. One card was a sighting of a sea otter. It was seen around the Anchor Point area which is the lower Cook Inlet area, and therefore not directly usable in this study. Many species of animals were seen in the lower cook, around Anchor Point, but these animals don't usually move far enough up the Cook Inlet to be seen by the oil industry personnel on the rigs.

The twenty-two cards reported beluga whales in the range of two to a thousand animals. Two of these cards had pictures of beluga whales attached. Eleven people reported 20 or less belugas. Three cards reported between 20 and 50 whales, six cards recorded 50-200 and the last two cards estimated the animals to number around a thousand. The estimated distance of the whales from the platforms ranged from 30 feet to "the other side of the inlet" with most reports at 150-300 yards. No unusual behavior was reported.

Discussion

\section{Study Area I: Santa Barbara Channel}

One of the major difficulties encountered was the resistance of oil companys ' management and employees toward a project with implications of environmental protection involving their company and work. Although they are certainly in favor of protecting the environment, the primary objective of the oil companies is production and the major concern of their employees is job security. Extensive and detailed explanation of the purpose of the project was necessary to obtain permission from the oil company management to interview their employees. Similarly, at each interview some time had to be spent on reassuring the persons to be interviewed that this project would not jeopardize their company or their job in any way. Once the oil worker was convinced that his job was not threatened the interview could be conducted.

Most people involved with off-shore work have personal accounts of marine mammal sightings and are more than willing to share these anecdotes. However, because they were not trained observers, these people usually could not accurately recall important parameters, such as distance, direction, etc. Very few have had any training in identifying individual species of marine mammals. Therefore, usually reference to size presented the only identification clues. 
Generally, more useful information was obtained by the interview for anecdotal data than by the sighting card for data on actual observations. In most cases, the oil platform operators did not seem to have enough time, interest, or incentive to fill out the cards.

The original sighting cards, designed by CCP, were quite large, with a total of 50 questions to answer and gave the impression that a lot of work was required to fill them out. Even after the revision the smaller sized cards had 25 questions to answer, although most of them required only a check mark in an appropriate box.

On the platforms, the posters and cards were left in the galley or in the foreman's office, which was not always the most convenient place. If someone on the lower deck spotted an animal, it was too much effort to go get a card at the time and not important enough to worry about later. There was not much incentive for filling out a card, especially in the perspective that it may indicate that one's place of work could cause undesirable interference with some whales and may jeopardize one's job. Research for the sake of general knowledge didn't seem to have too high of a value with most of the workers, although the identification posters were received with great interest.

The presence of the researcher seemed to encourage awareness of the oil workers about the marine mammals and the study. Many cards were filled out just after the researcher's visit to the platform, but the rate tapered off quickly as normal patterns of work resumed and the novelty of the instructional posters wore off. The awareness increased again when the interviewer returned to the platform and received many apologies for not filling out the cards in spite of some sightings of whales around the platform. Thus, many direct sightings were reduced to anecdotal information.

Supervisors, obviously concerned with job performance and attention to duties, did not always insist that someone stop work to fill out a sighting card, and the animals did not always appear during lunch breaks or shift changes.

For these reasons, the actual number of animals passing within sight of a platform was probably larger than was recorded. The number of sightings seems to vary also with the location of the platform, which raises the question of whether the animals' natural pathways are through unexplored, undeveloped areas, or whether the animals have changed pathways to areas with little or no exploration or development. Without adequate baseline data it is difficult to tell whether the whales are actively avoiding the platforms, or if their natural migratory routes just pass through areas where no offshore production is occurring. To decide whether the presence of the rig caused a change in the pathway or if the animals would have shifted as a result of an evolutionary change would require many years of study, ideally on marked, tracked individuals. More knowledge about the 
feeding habits and navigational cues used during migration is needed before the effects of platforms on marine mammals can be assessed with appreciable certainty.

Besides physical presence of the platform in the migratory path of the whales, no ise and oil seepage could have effects on the behavior of the marine mammals.

Noise was recorded from every platform where the interview and sighting card program was conducted in Santa Barbara Channel and correlated to their concurrent activities. This information is being evaluated with respect to the cetacean hearing capability and the frequency of sightings around the platform. There is constant noise associated with the operation of offshore platforms although it varies in type, intensity, and frequency. While it is assumed that the marine mammals can hear the no ise, its effect and the response of the mammals are not known.

Natural gas and oil seepage may result from offshore production. However, marine mammals are present in many areas of natural seepage such as Coal $0 i 1$ Point, and animals have been observed swimming through areas of oily water.

Although the cetaceans were the primary subject of this study, pinnipeds were also included. California sea lions, Zalophus californianus, did not seem to be at all adversely affected by the various 0CS structures. They have been frequently reported resting on marker buoys, floating aids, and low deck platforms in the Santa Barbara Channel area. The reason for this is probably because the platforms create a very rich underwater environment. The submerged portions of the platforms support a diverse invertebrate community (Simpson, 1977) which attract higher organisms including fish which in turn attract sea lions. Usually, large numbers of sea lions can be seen around almost all of the platforms.

\section{Study Area II: Cook Inlet}

The program ran very smoothly in this area. There was a general acceptance of the study and lots of cooperation. Two companies, Union and Texaco, did not participate in the study. Union management felt that their employees were too busy to ever see any marine mammals and the Texaco representative felt that since only a few workers were ever out on their platform, it would not be a very useful study point. Nevertheless, this project was able to cover the main fields in the cook Inlet.

There are four major oil fields in the Cook Inlet. The Granite Point Field is the northernmost in the inlet and consists of AMOCO's platforms Bruce and Anna and Union's Granite Point Platform. Southwest from this point is the Trading Bay oil field which is being produced 
by ARCO's Spark platform, Union platform Monopod, and Texaco-Superior platform A. Further south is the MacArthur River field operated by ARCO's platform King Salmon, Marathon 0il Company's Dolly Varden platform, and Union's platform Grayling. The southernmost field is the Middle Ground Shoal where AMOCO's platforms Baker, and Dillon and Shell 0il Company's platforms $A$ and $C$ are operating. Phillip's Petroleum operates platform Tyonek, the northernmost platform in the Cook Inlet, which produces only natural gas.

Since all the platforms are grouped close to each other, much of the reported marine mammal activity is the same. The few reports of mammals other than beluga whales were from the same or neighboring platf orms .

It is clear that beluga whales are seen throughout the inlet. Their behavior does not seem to be affected by the presence of the platforms; their movement seems to be affected mostly by the tides and movements of the fish they are after. Many reports state that belugas were seen almost underneath the platforms. (Generally, when looking straight down and seeing an animal, the distance of the animal from the platform legs would be about 30 feet.) These whales are seen in the greatest number at slack tide, when movement within the area is the easiest.

The few reports of other animals are well substantiated. The novelty of seeing killer whales or sea lions was not blocked by the commonness of seeing beluga whales. One walrus was spotted and reported to Fish and Game, whose agent said that the walrus was "probably lost."

Due to the constant siltiness of the water it is difficult to locate animals, except the white whale which shows up very well against the murky water. This heavy silt could also discourage most other species from entering and inhabiting the inlet; only the belugas seem to adapt well to the poor visibility and tides. The general consensus seemed to be that the beluga whale population probably has increased considerably over the last 5 years.

The oil companys' record regarding oil spills in the Cook Inlet is very good. No major spills and very few minor ones have occurred. No natural areas of seepage are prominent, and with the tidal flow so strong, oil would dissipate almost totally before reaching shore. Nevertheless, the clean-up crews practice a couple of times a month and everyone is very aware of "cleanliness." The waste water discharged into the Cook Inlet from the platforms is filtered to the point that it is cleaner than when it was taken out.

The underwater environment of the Alaska platforms does not support as diverse flora and fauna as their Santa Barbara Channel counterparts. This could be due to the swift currents or to the high silt content in the water or to the cathodic protection system of the Alaska platforms. 
Cathodic protection uses sacrificial anodes placed on "sleds" at random intervals around the platform legs and resting on the bottom. A current is put through the connecting wires to the anodes from rectifiers which are on board the platforms. The current produces an ion flow with the result that the sacrificial anode material corrodes away instead of the platform leg. The amount of amperage through the system varies from $400-1800$ amps for 4 to 6 rectifiers. This could be enough current to affect marine mammals, at least to the point of alerting them of the presence of an electric field. There has not been much research done in this area.

The only noticeable effect of any OCS operation on marine mammals was that they would dive when a helicopter flew over. This occurs daily, but not constantly during the day. Therefore this effect may be minimal.

From all reports, OCS development in the Cook Inlet does not seem to be affecting the marine mamal populations.

\section{Conclusion}

At present, not enough information is available about the behavior, tolerance, and adaptability of individual species to evaluate the effect of OCS platforms on marine mammals conclusively. The present short study did not discover any adverse effects on large or small whales or dolphins. Anecdotal information tends to indicate that the whales either ignore the platforms or easily avoid them without appreciable change in behavior. Smaller cetaceans and pinnipeds may even find an attractive environment around the platforms. Some caution should be applied because without sufficient baseline information and adequate time for studying any long term effects these results cannot be interpreted in the proper perspectives.

\section{Recommendations}

The following changes in experimental design of this project are recommended in order to obtain more reliable data to study the effects of OCS platforms on marine mammals:

1. Pre-Development Studies. Conduct interview programs and observation studies, ideally aerially or nautically, to get baseline information in areas where OCS lease sales are proposed. Conduct studies prior to and during exploration and preliminary drilling, and at some time after drilling has been implemented.

2. Place Trained Observers on the Platforms. Individuals who are trained to identify various species of marine mammals should be placed on each platform to be used in the study with adequate instrumentation such as sextant, 
binoculars, log, and identification books. Their only job should be observing and making recordings of marine mammals.

3. Plan Sampling Periods.

Because of its predictable, seasonal migration, the gray whate (Eschrichtius robustus) would be an ideal subject for a model study in Santa Barbara Channel and could provide reliable yearly comparison. Studies could be conducted at peak migration times (northerly and southerly movements), as well as in-between migration periods. In the Cook Inlet studies should be conducted when the salmon run is in full swing and again when it is almost over, so this phenomena can be looked at in relation to the number of whales in the inlet. As information about migration, feeding, and calving is learned, it will become easier to determine optimum sampling time. 


\section{References}

1. Bureau of Land Management: Study of the Southern California Bight, 1975-1977, unpub 7 ished.

2. Gilmore, R.M. 1960a. A Census of the California Gray Whale. U.S. Fish and Wildlife Service. Special Scientific Report, Fisheries No. 342, 30pp.

3. Gilmore, R.M. 1976. Ecology of the Gray Whales. Environment Southwest, San Diego Natural History Museum, \#472: 3-7, illus.

4. Hayes, M.0. 1976. Coastal Morphology and Sedimentation, Lower Cook Inlet, Alaska, with Emphas is on Potential 0il Spill Impacts. TR No. 12-CRD. Alaska Dept. of Fish and Game by Coastal Research Div., Dept. of Geology, University of South Carolina.

5. Henning, R.A. (ed.) Alaska Whales and Whaling. Vor. 5 \#4. 1978.

6. Kinney, P.J., et.al. 1969. Kinetics of Dissipation and Biodegradation of Crude $0 i 1$ in Alaska's Cook Inlet. Contribution \#61. Institute of Marine Sciences, University of Alaska.

7. Rice, D.W. 1959/1960. Census of the California Gray Whale. U.S. Fish and Wildlife Service.

8. Simpson, R.A. 1977. The Biology of Two Offshore 0il Platforms, Institute of Marine Resources, University of California. IMR Reference 76-13. 


\section{APPENDIX A}

Companies and Platforms Visited for This Project
Santa Barbara Channel, California
Company

₹Indicates a platform visited during the pilot study. 


\begin{tabular}{|c|c|}
\hline \multicolumn{2}{|c|}{ Cook Inlet, Alaska } \\
\hline Company & Platf orms \\
\hline AMOCO & $\begin{array}{l}\text { Baker } \\
\text { Dillon } \\
\text { *Anna } \\
\star \text { Bruce }\end{array}$ \\
\hline ARCO & $\begin{array}{l}\text { Spark } \\
\text { King Salmon }\end{array}$ \\
\hline $\begin{array}{l}\text { Marathon Oil Co. } \\
\text { Phillip's Petroleum } \\
\text { Shell Oil Co. }\end{array}$ & $\begin{array}{l}\text { Dolly Varden } \\
\text { Tyonek } \\
\text { A } \\
\text { C }\end{array}$ \\
\hline
\end{tabular}

*No interviews or visits were made to these platforms, but posters and sighting cards were distributed. 


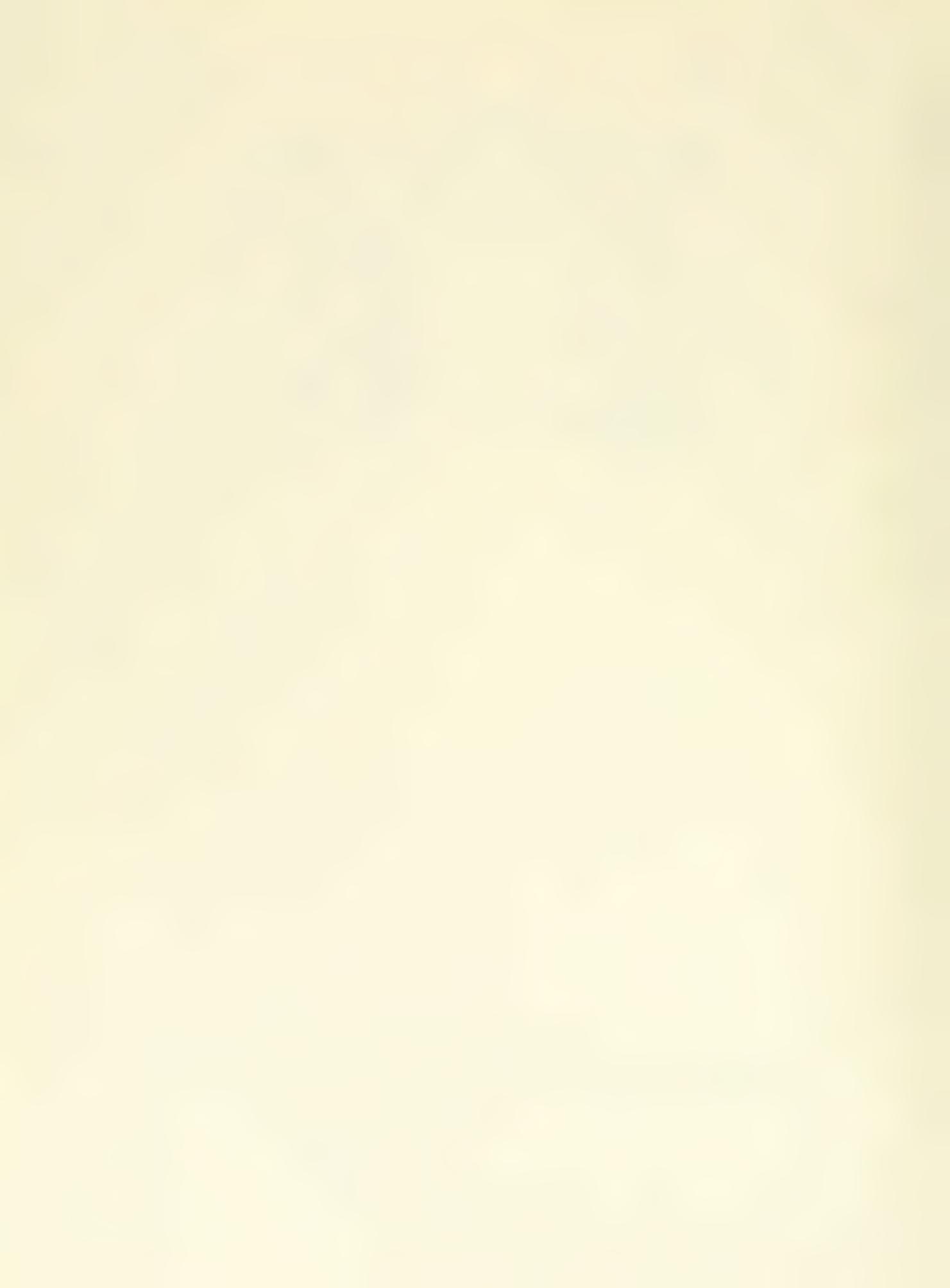


APPENDIX D 



\section{FIELD MEASURMENTS OF UNDERWATER NOISE}

FROM OFFSHORE OIL OPERATIONS

1 JANUARY TO 20 JUNE 1980

David R. Schmidt

Naval Ocean Systems Center

San Diego, CA 9215 ? 


\section{FIELD MEASUREMENTS OF UNDERWATER NOISE \\ FROM OFFSHORE OIL OPERATIONS \\ 1 JANUARY TO 20 JUNE 1980}

Waterborne noise measurements were taken in the vicinity of five continental shelf $0 i 1$ and gas rigs. Two were production platforms, one was a production platform also engaged in drilling, one was a man-made production island, and one was a semi-submersible drilling rig. Airborne noise measurements were taken in all major machinery spaces, and vibration measurements were taken at various points on the support structure. The waterborne, airborne, and vibration measures have not been compared as yet.

Initial project measurements were made around At lantic Richfield Company's (ARCO) Platform Holly and man-made Island Rincon located off the southern California coast. Platform Holly is $2 \frac{2}{2}$ miles offshore of Goleta, California, in 211 feet of water. Platform Holly is supported by eight legs in the form of two parallel sets of four legs. The legs are anchored into the ocean floor by pilings and filled with concrete. A view of Platform Holly is shown in figure 1. Island Rincon is about 3,000 feet from shore approximately 10 miles from Ventura, California, in 45 feet of water. It is connected to the mainland by a trestleway, which carries the oil piping and electrical supply lines.

The instrumentation used for measurements at these two sites was borrowed from Hubbs/Sea World Research. It consisted of a Bruel and Kjaer Type 8103 hydrophone, EG\&G Model 113 preamplifier, and a NAGRA Model IV SJ magnetic tape recorder. This instrumentation was limited by low hydrophone sensitivity and 
lack of DC recording capability. The hydrophone was capable of responding to $0.1 \mathrm{~Hz}$ signals, but the recorder limitation was $-3 \mathrm{~dB}$ at $15 \mathrm{~Hz}$.

The measurements around Platform Holly were taken throughout the day from a 65-foot work boat used to supply the platform. Sea state was 1 with a $5-k$ not wind. When the boat had moved to within 50 feet of the platform, the hydrophone was lowered, the boat engines were stopped, and a recording period started as the boat drifted away from the platform. Low frequency roll-off on the preamplifier was set to $1 \mathrm{~Hz}$. The platform was producing at a rate of about 6,000 barrels per day. During the morning drill pipe was being pulled. During the afternoon drilling commenced using the dynadrill technique at about 850-foot depth.

Island Rincon is essentially a sand core with protective outer rock. A dock is located on the north side from which a small boat was launched. Measurements were taken from the dock and trestleway and from the boat at various points along the northern and eastern edges of the island. The major airborne acoustic noise sources on the island are the Kobe Triplex pumps and the steam generators. The major waterborne noise source was a salt water pump located on the west of the dock area. A noticeable reduction in noise was observed when the pump was turned off.

The Cook Inlet, Alaska, measurements were made aboard ARCO platforms with the instrumentation system purchased by NOSC. This system consists of a Bruel and Kjaer Type 8101 hydrophone, I thaco Model 451 preamplifier and a NAGRA T instrumentation recorder. The 8101 hydrophone is about $25 \mathrm{~dB}$ more sensitive than the 8103 hydrophone used at Holly and Rincon. The lower frequency 
response of the 8101 hydrophone is $1 \mathrm{~Hz}(-3 \mathrm{~dB})$. The NAGRA T recorder allows this $1 \mathrm{~Hz}$ response to be used, since it has DC recording capability using frequency modulation (FM) recording amplifiers. The upper frequency recording limit using FM record at the $7 \frac{1}{2}$ ips recording speed is $2.5 \mathrm{KHz}$. The frequency range from $100 \mathrm{~Hz}$ to $30 \mathrm{KHz}$ is covered by the direct recording amplifier.

The first Cook Inlet platform measured was the Ocean Bounty, a semi-submersible drilling rig. 0cean Bounty was located about 40 miles off Homer, Alaska. It is supported by eight legs, each pair connected at the lower end by a 26-foot diameter hu11. The inboard hulls house the propulsion motors, and all hulls are floodable for submersion at the drilling site. The rig is anchored by chains at eight points on the ocean floor. Rig Ocean Bounty is shown in figure 2. The major airborne noise sources aboard were 4-2,000 HP diesel engines, two of which are running at a time. Their exhausts are unmuffled and point downward toward the water. Figure 3 shows the exhaust pipes under the rig. ARCO has plans for muffling the exhaust.

The 0cean Bounty was drilling during the period of measurement. NOSC personnel were not told the drilling depth due to company restrictions. Measurements were taken from the "Big Valley," a 50-foot fishing trawler (figure 4). The trawler was brought close to the 0cean Bounty, it's engines were shut down, the hydrophone was put in the water, and recording started while drifting away from the platform. Drift runs commenced about 50-100 feet from the platform and stopped at various distances ranging from 300-800 feet. Hydrophone depth was varied from 20-110 feet. The wind was 15-20 knots with a sea state of 2 to 3 . Water depth was 200 feet. 
The second and third platforms measured were production platforms of ARCO. They are located off Kenai, Alaska. Platform King Salmon is a quadripod type located in about 60 feet of water. The four legs are each 16 feet in diameter. The measuring equipment was set up in Leg Room 2 with the hydrophone in the water suspended from the east side of the platform. The wind was 30 knots with a sea state of 2 . The cable was streaming with the strong incoming tide and wind, causing FM recorder channel blockage due to the large signal level from the vertical hydrophone movement. Measurements were taken at slack high tide. The highest airborne noise level measured was outside the boiler room. This was thought to have been caused by the air intakes from the Worthington compressors on the deck above.

Platform Spark is about five miles to the north of King Salmon. It is a tripod platform with 16-foot diameter legs. This platform is mostly electric or turbine powered with only 1 reciprocating engine on board. Water depth at time of recording was approximately 75 feet. Equipment was set up on the north side on a catwalk on the lower deck between legs two and three. The equipment set-up is shown in figure 5. The hydrophone was estimated to be 24 feet from leg 2 and 21 feet from leg 3 . The hydrophone was streaming with the tide which was estimated to be flowing at three knots. The degree of cable streaming is illustrated in figure 6 . Recording was started when the hydrophone cable was vertical at slack tide. Wind was about 10 knots and sea state was estimated to be 1 . Recordings were made at hydrophone depths of 20 , 30 and 50 feet. The major airborne noise area on board was the turbine room. 
Calibrations were recorded on the magnetic tape at each Alaska site by means of a Bruel and Kjaer Type 4223 hydrophone calibrator. This method calibrates the entire system by applying a known pressure to the hydrophone, amplifying the signal, and recording it. A signal of $250 \mathrm{~Hz}$ is used, which is recorded on both the FM and direct-record channels. Voice commentary was put on one track of the recorder to record gain settings and general conditions as the measurement continued.

For this report, a preliminary analysis was done with a General Radio Model 1921 Real Time Analyzer. This instrument analyzes in one-third octave bands with band centers starting from $25 \mathrm{~Hz}$. The FM and direct channels were each analyzed at periods in the recording judged to be free of overload on the FM channel due to low frequency pressure changes. The tape speed was then doubled, and the FM channel analyzed again. This allowed analysis down to a 12.5 $\mathrm{Hz}$ cericered one-third octave band. A playback was also made of the 250 $\mathrm{Hz}$ calibrate signal on both FM and direct-record channels to allow absolute levels to be determined. Voice comments relative to gain settings, location, hydrophone depth, current conditions and other relevant information were noted.

The one-third octave band levels were then tabulated and plotted in figures 7 to 13 .

The data taken at Platform Holly showed that machinery noise in the water was not at a level above ambient water noise. The recordings were played back over a broad-band reproducing system, and experienced listeners could barely detect machinery noise in the predominant sea noise. The major machinery noise at Rincon was a submerged firewater pump, but this was largely masked by 
biological and sea noise. Data analysis is not presented of Rincon and Holly data. Recordings will be made with the NOSC more sensitive, lower frequency response system.

The data plots from Ocean Bounty show a general ups lope as the frequency increases with a peak at about $80 \mathrm{~Hz}$ and a rolloff above that. In figure 7, a plot of the measurements taken 50 feet from the rig, a rise of approximately 4 $\mathrm{dB}$ per octave is seen to the peak at $80 \mathrm{~Hz}$, with a falloff after the peak of about -6 dE per octave.

When the noise was measured at a distance of 350 feet from the ocean Bounty, figure 8, the $80 \mathrm{~Hz}$ peak is still evident, the overall level is lower, and the slopes have changed to +5 and about -4 , steeper on the lower end and less steep at the higher frequencies.

Figure 9 shows data taken 800 feet from the rig. The level has again dropped, the $80 \mathrm{~Hz}$ peak is still present although more rounded in shape, and the lower end slope is now indefinite due to a genera? valley which is present below $80 \mathrm{~Hz}$. The slope above $80 \mathrm{~Hz}$ is now about $-3 \mathrm{~dB}$ per octave.

The falloff in level with distance is within the range expected. The increase ir level at the lowest one-third octave band is evident only on the data from the Ocean Bounty and may indicate snergy from that rig is present at lower frequencies than were analyzed. 
The King Sa'mon data, one analysis of which is seen in figure 10 , shows a pronounced peak in signal level at $40 \mathrm{~Hz}$, one-half the frequency of the peak seen in 0cean Bounty data. A steep slope of about about $+17 \mathrm{~dB}$ per octave is seen at frequencies below this peak, with the falloff above the peak at about $-2 \mathrm{~dB}$ per octave. There is no suggestion of a rise in levels below the lowest one-third octave band analyzed.

Data from production Platform Spark (figures 11, 12, and 13) show a peak at a lower frequency than was evident in the previous figures. There is now a peak at $20 \mathrm{~Hz}$ and, as in the King Salmon data, no indication of energy present below the $12.5 \mathrm{~Hz}$ one-third octave band. The lower end slopes of the data in figures 11, 12, and 13 are in the order of $+40 \mathrm{~dB}$ per octave. The data above $31.5 \mathrm{~Hz}$ Inay be visually separated into two bands above and below $630 \mathrm{~Hz}$. There does not seem to be any pronounced change in analysis pattern with change in hydrophone depth.

As mentioned previously, these analyses are preliminary due to the short time available since the trip to Cook Inlet, Alaska. 


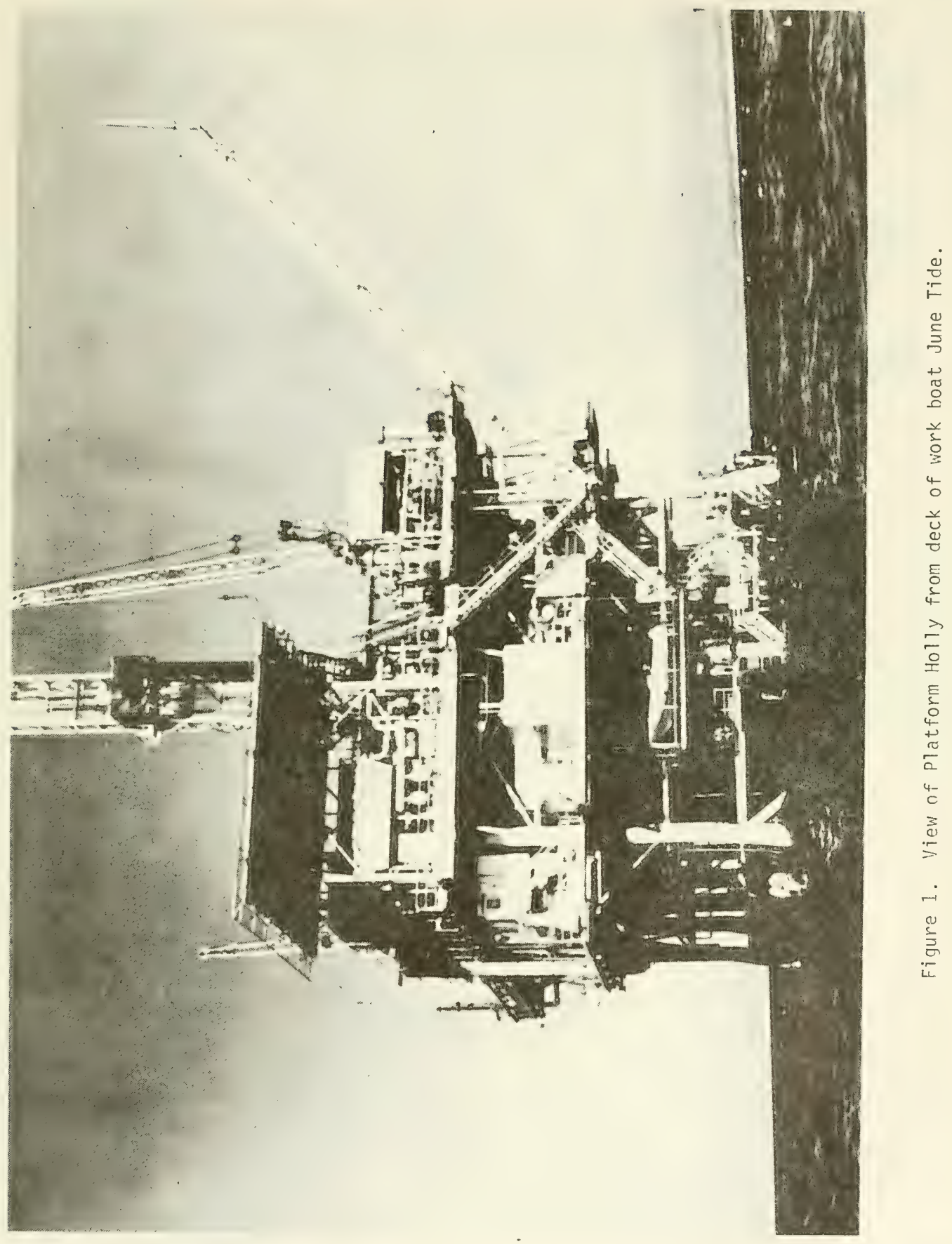




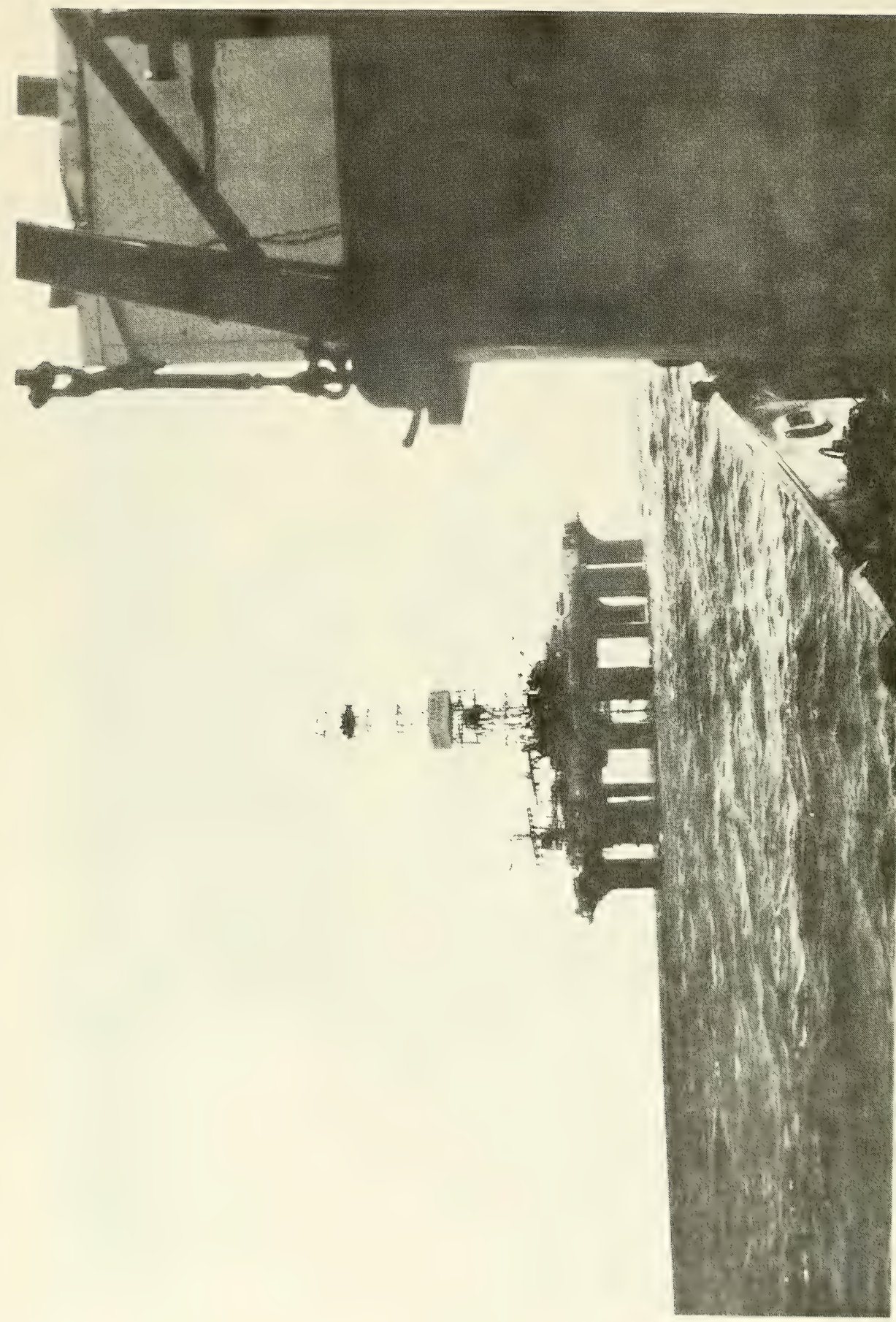

$\frac{7}{2}$

$\stackrel{0}{\circ}$

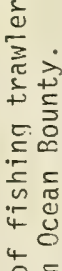

4 틀

ㄴ.

品

E $\frac{\pi}{0}$

4-

4-

후

응

ᄃ०

엉

o

단

달

ㅍำ

$=0$

ठ

$\frac{0}{5}$ 동

is

เ

吃

है

10

豈 皆

40

$=\$$

แิ

号官

ni

है

in 


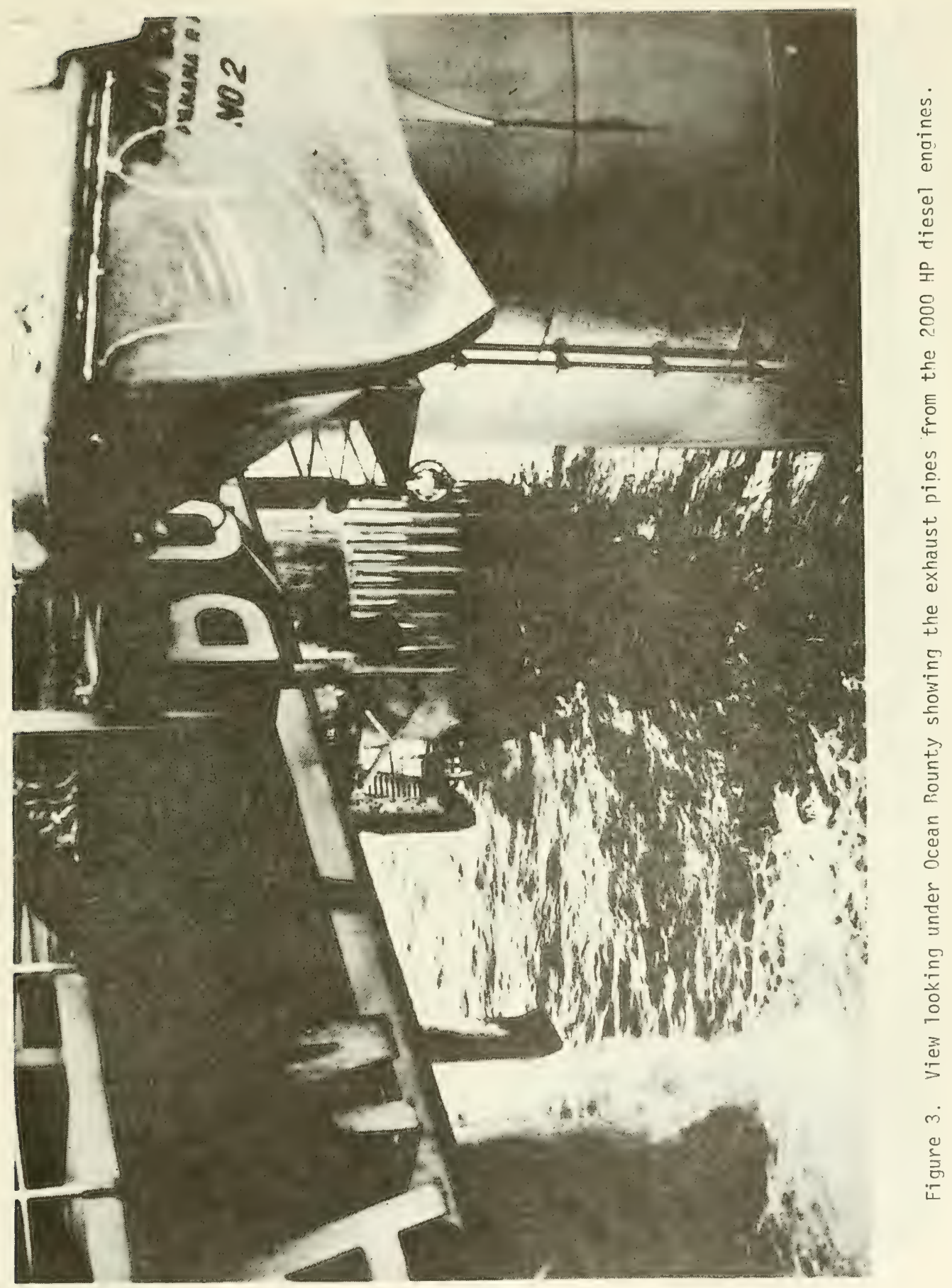




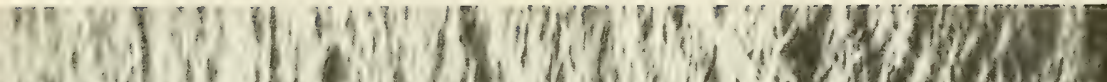

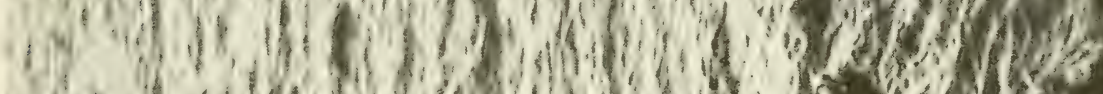

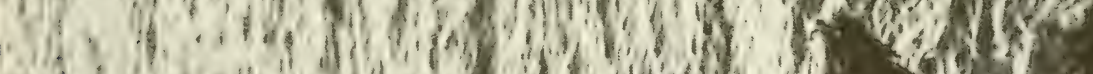

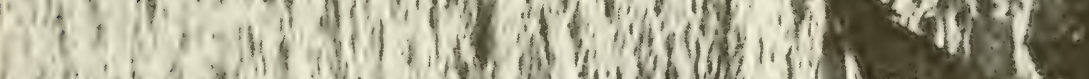

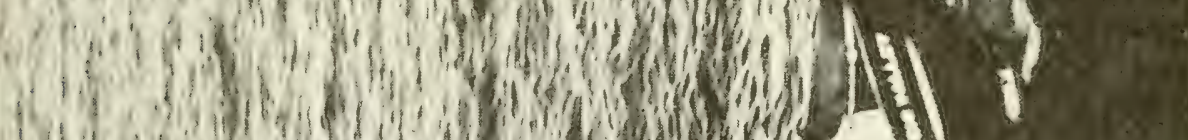

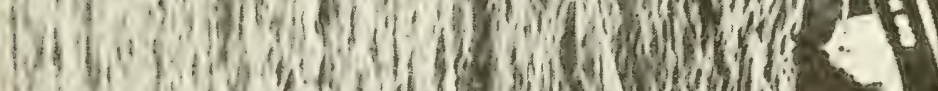

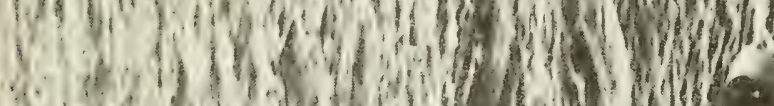

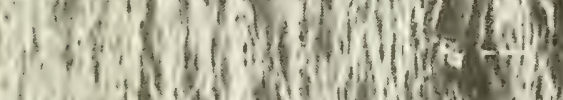

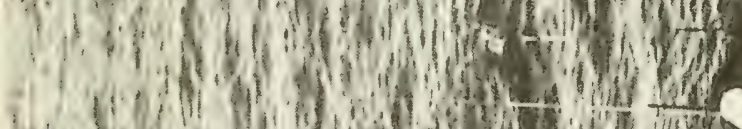

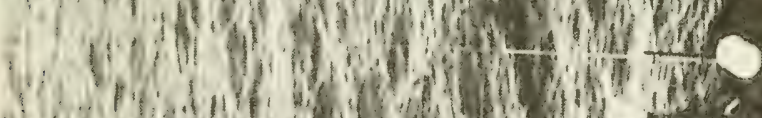

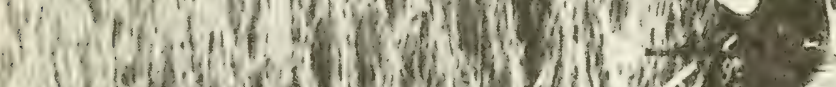

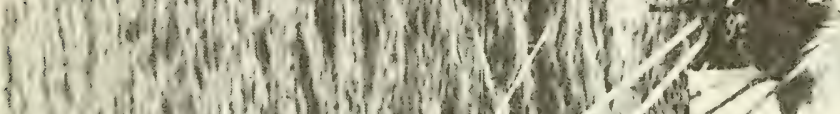

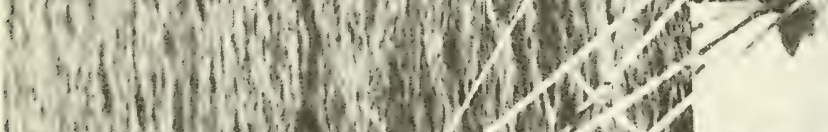
194 . W

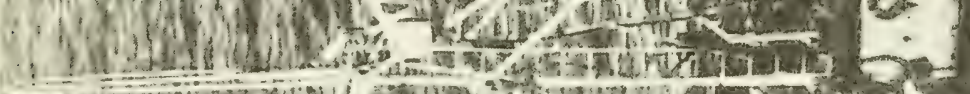

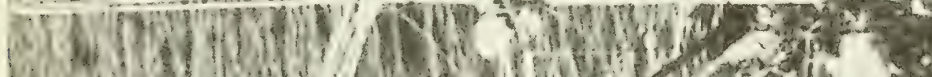

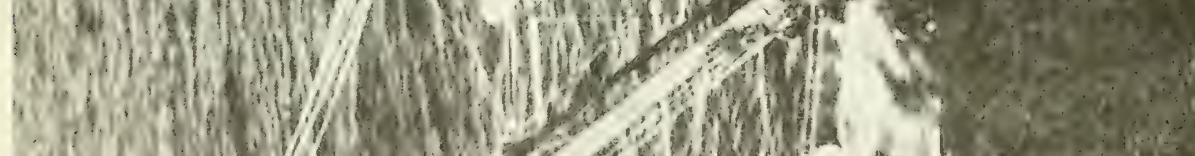

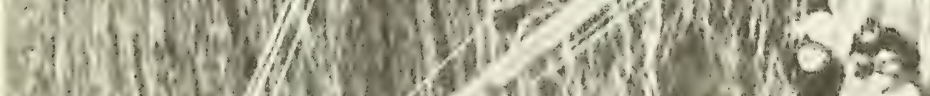

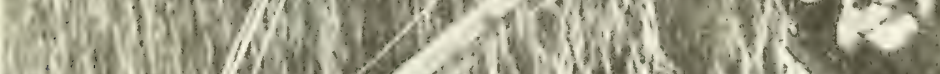

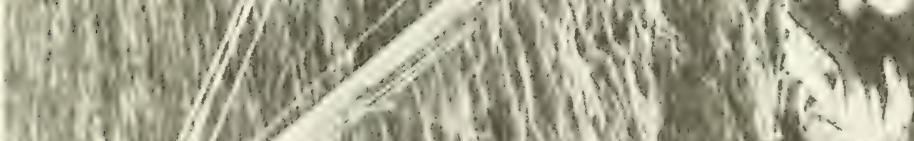
(12)

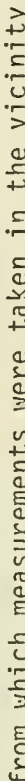

$\frac{1}{\frac{1}{0}}$

$\frac{c^{2}}{c}$

d)

$\frac{\pi}{3}$

के

밍

당

$\approx 5$

늘

15

4

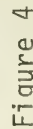




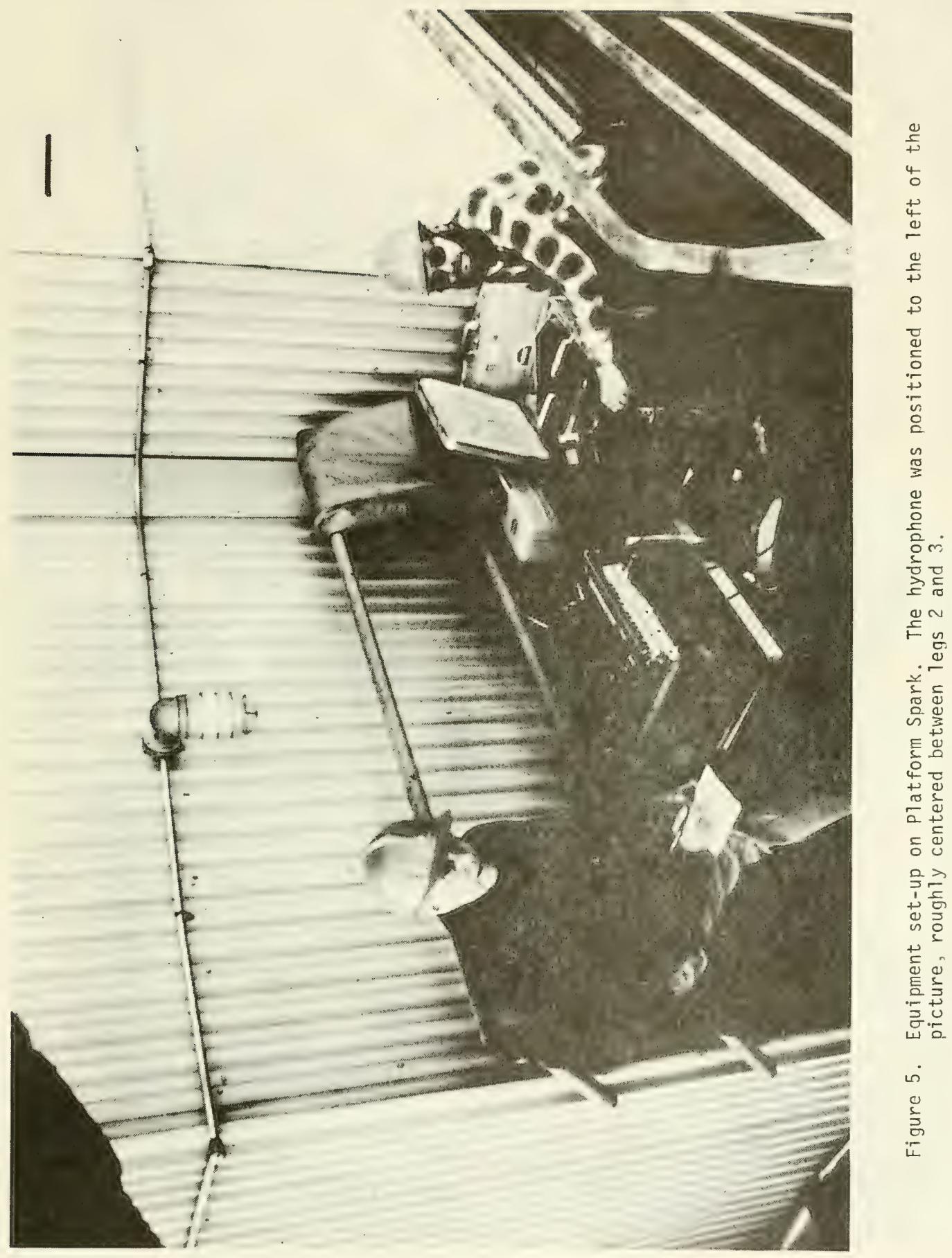




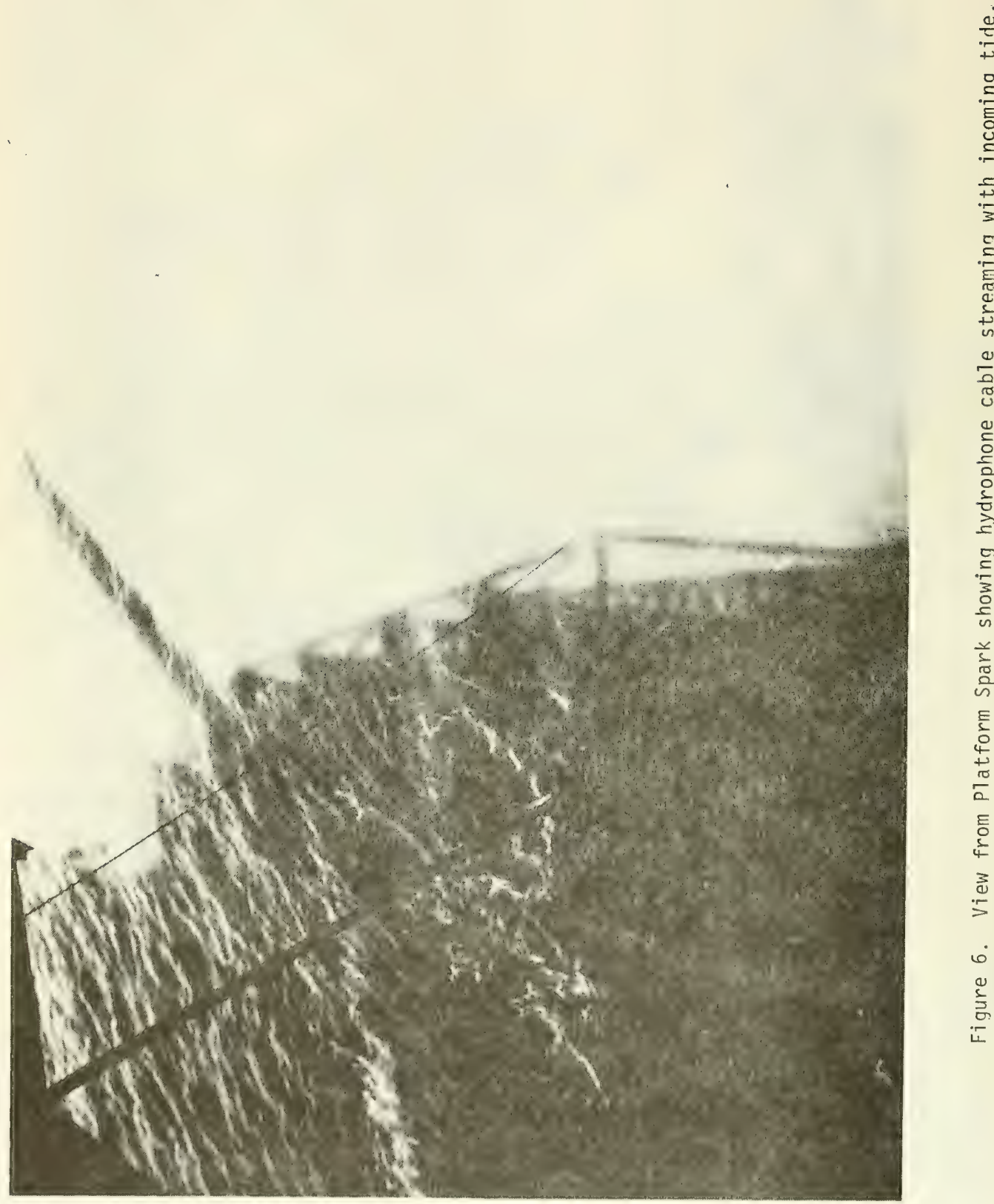




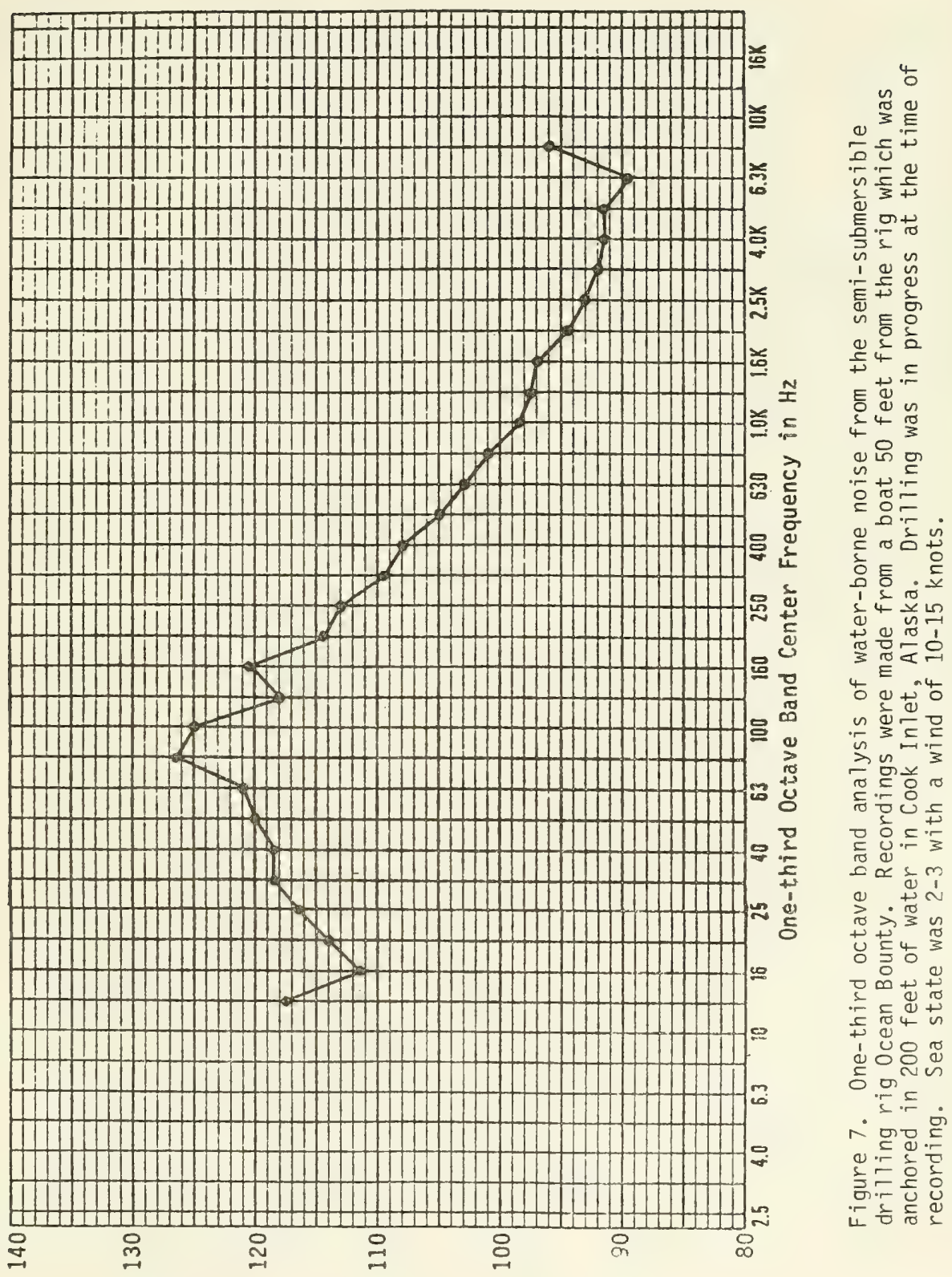

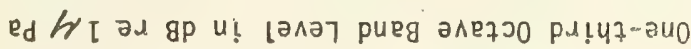

D-15 


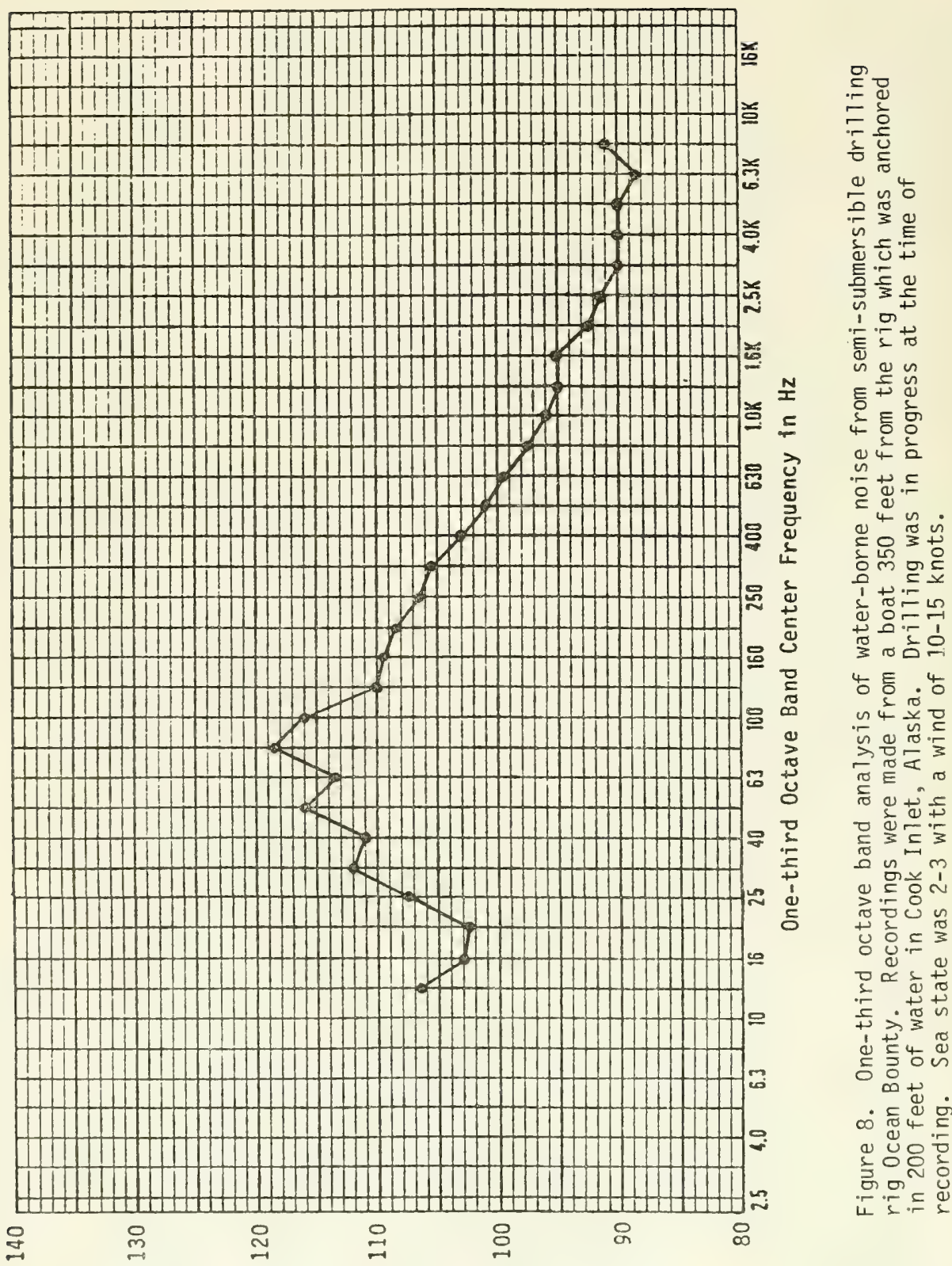

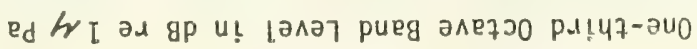




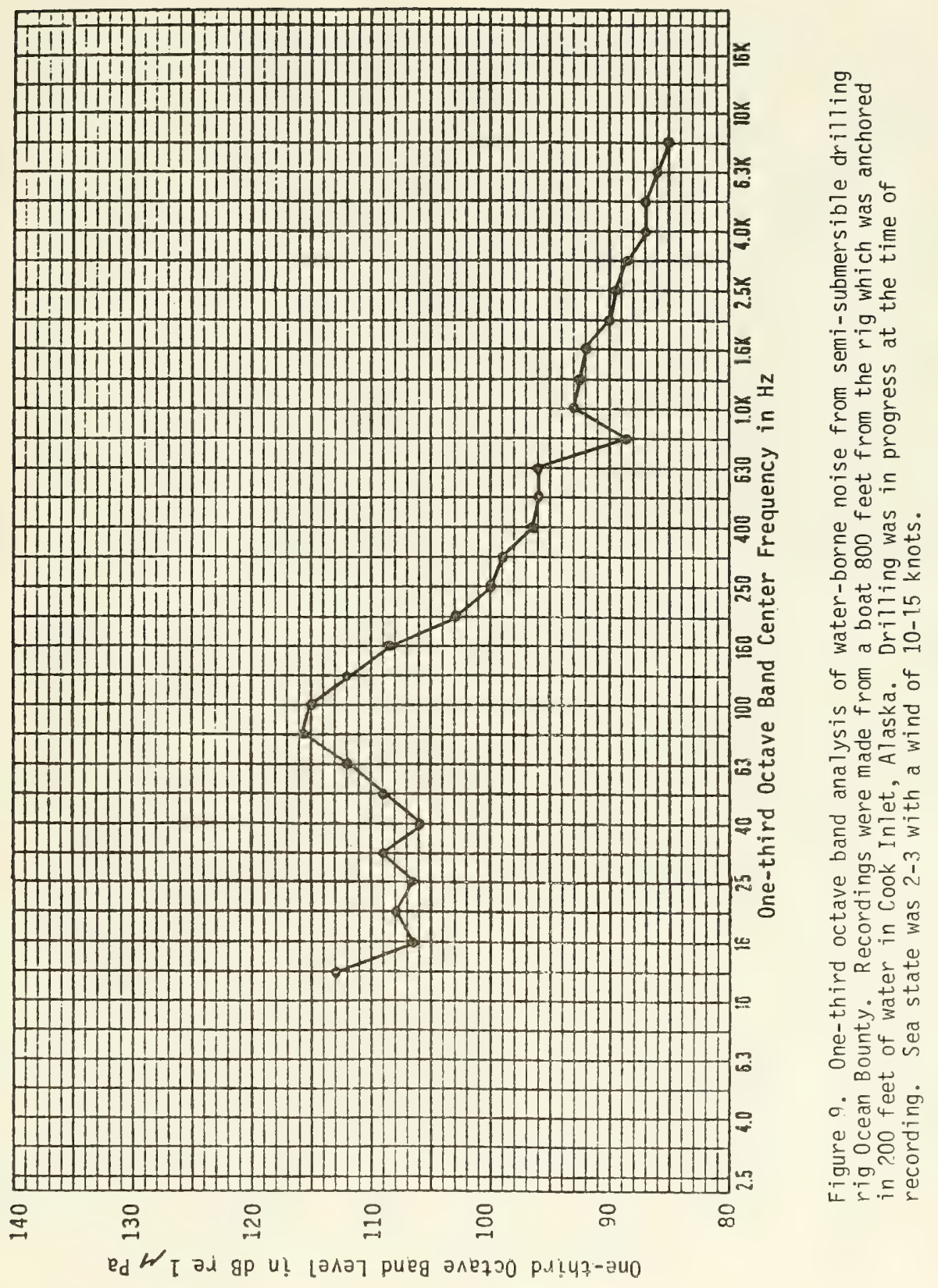




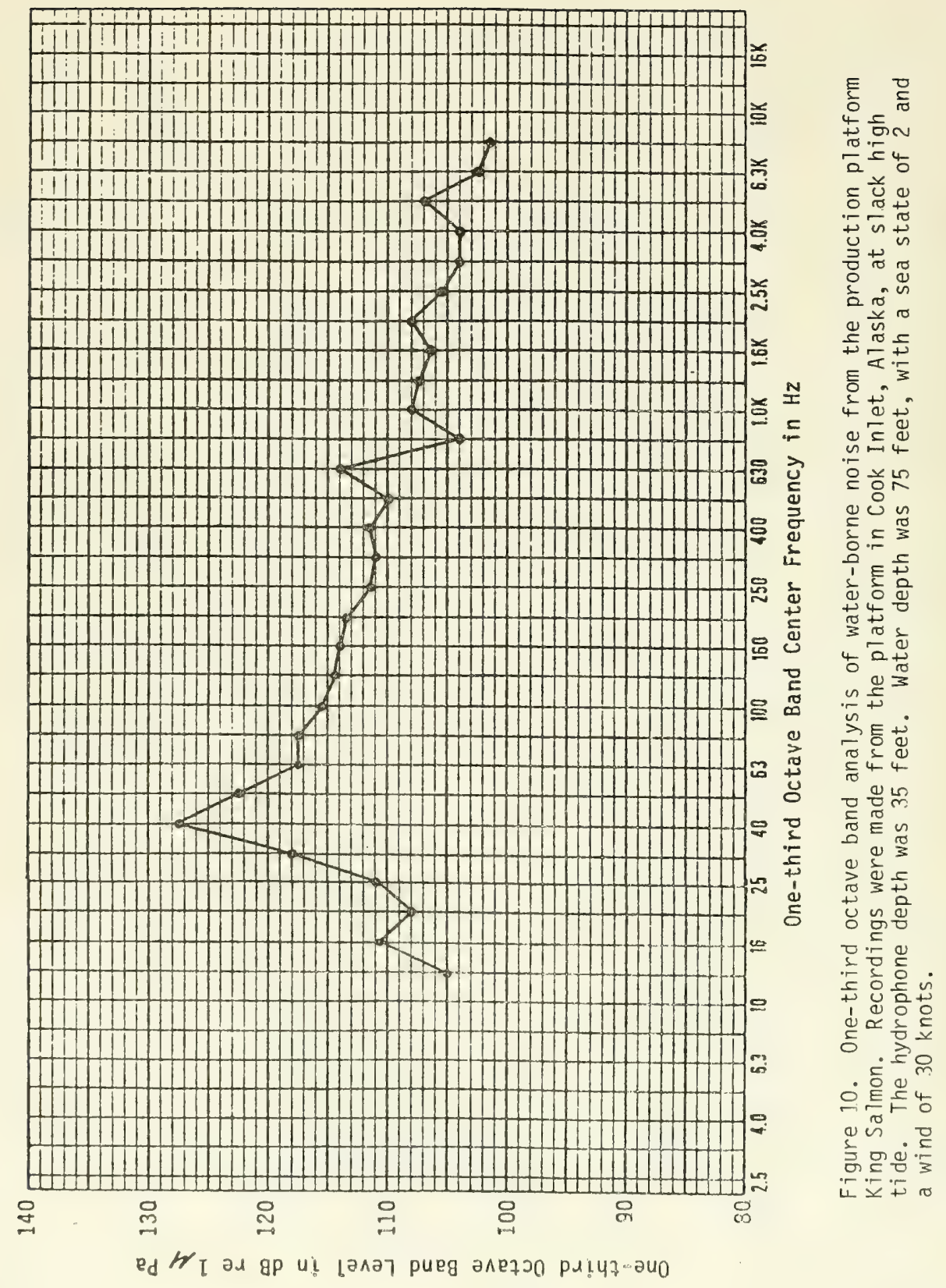




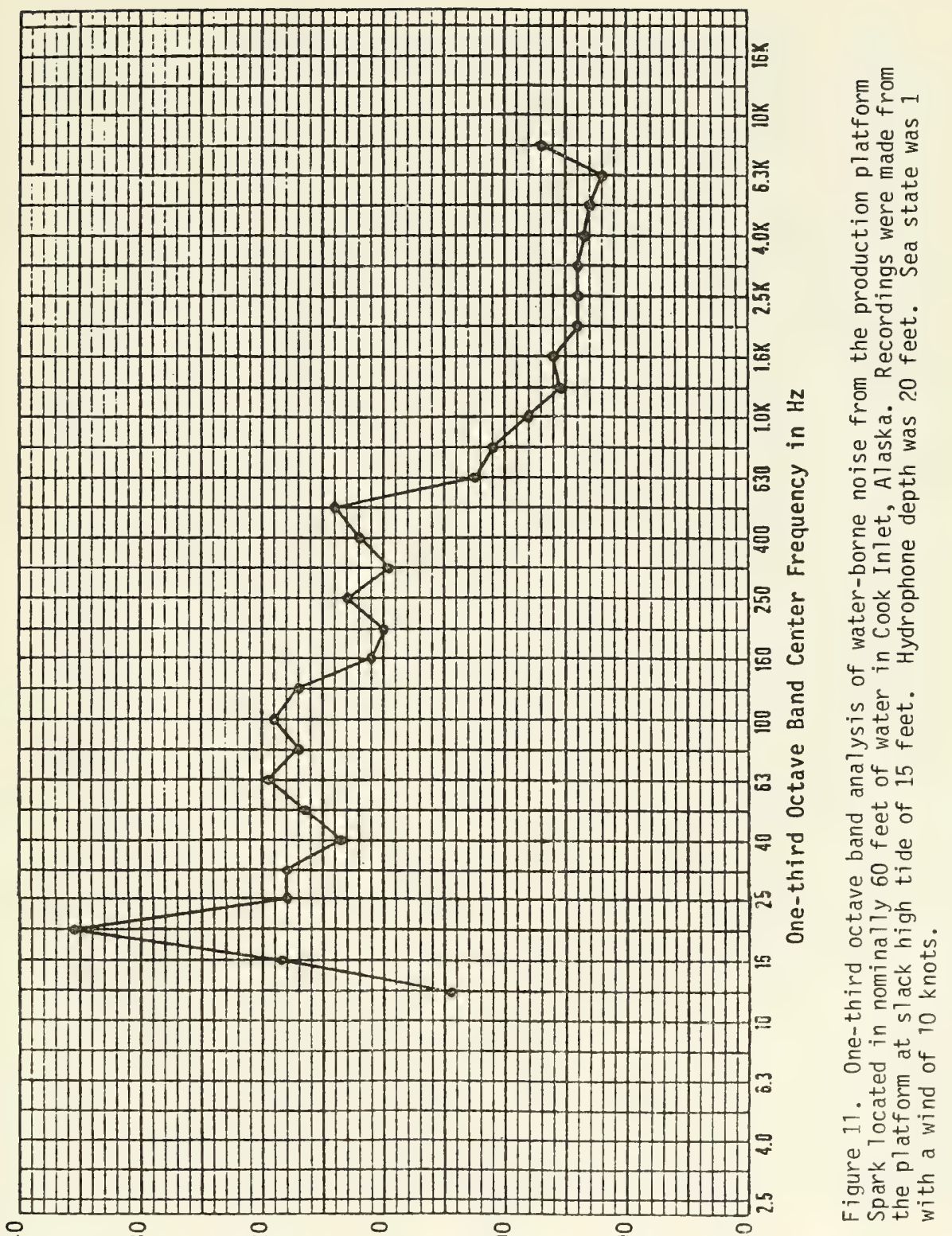




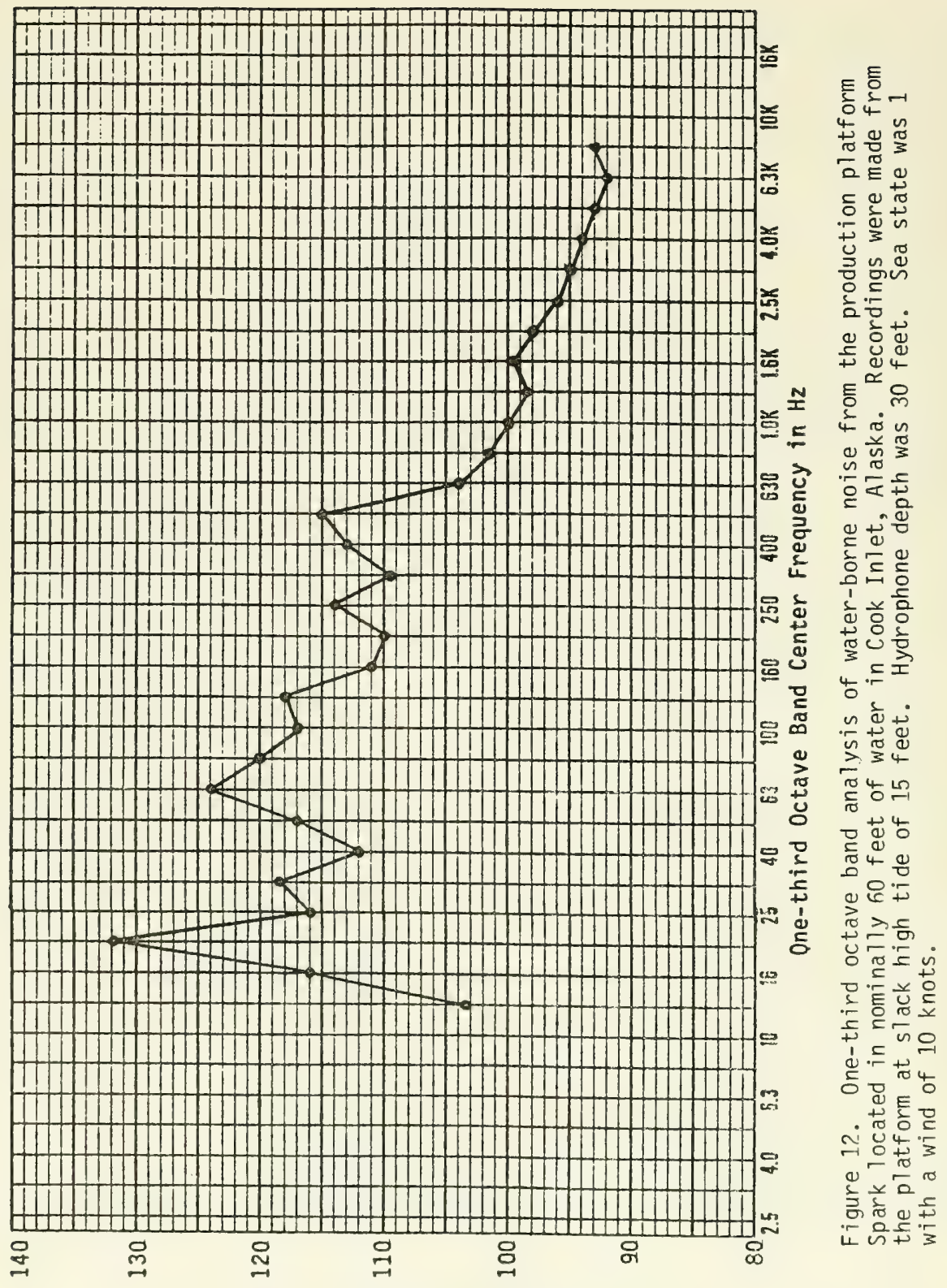

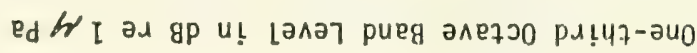




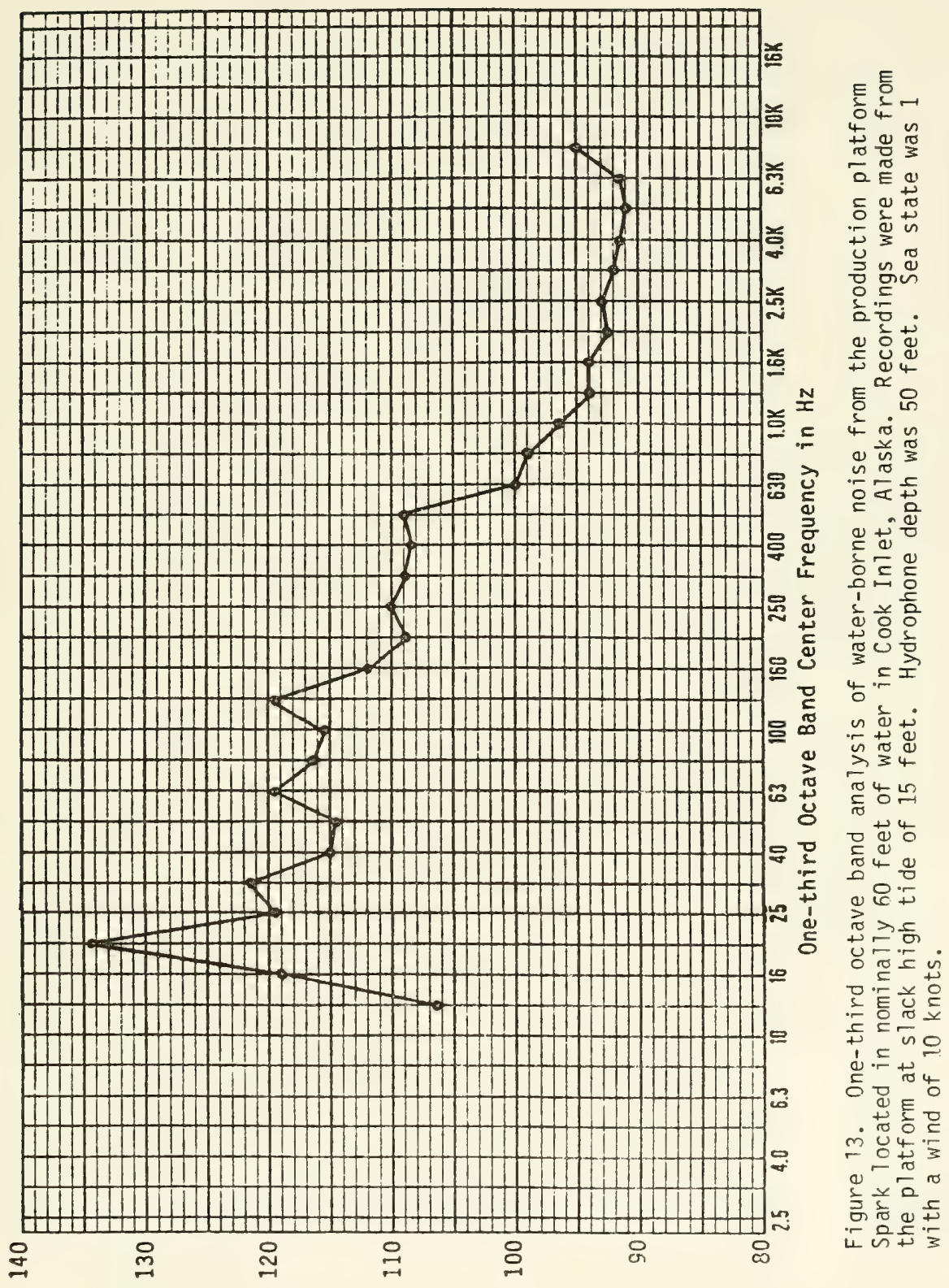

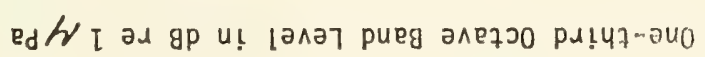

D-21 
APPENDIX E 


\section{SUMMARY REPORT OF 30 SEPTEMBER 1980 ON \\ BLM TASK: "STUDY OF THE EFFECTS OF SOUND ON MARINE MAMMALS"}

Robert S. Gales

Naval Ocean Systems Center

San Diego, CA 9215? 


\section{SUMMARY REPORT OF 30 SEPTEMBER 1980 ON \\ BLM TASK: "STUDY OF THE EFFECTS OF \\ SOUND ON MARINE MAMMALS"}

\section{Introduction}

This will summarize briefly the work conducted under Naval Ocean Systems Center Project MM28, BLM Project AA851-1A0-5 from the commencement of work in January to September 1980.

\section{Objective}

The overall objective is to assess the impact of underwater noise created by offshore oil drilling and production operations on marine mammals along the outer continental shelf of the U.S.

\section{Approach}

1. Conduct literature search on underwater noise from offshore $0 i 1$ operations, and on underwater hearing and sound production of marine mammals to estimate potential interference of man-made noise with endangered wildlife.

2. Initiate a program of interviews with platform operational and support personnel, and others who may provide data from personal observations of the behavior of marine mamals in the vicinity of offshore platforms and supporting equipment.

3. Obtain high-fidelity tape recordings and spectrum of underwater radiated noise in the vicinity of offshore oil operations in various geographic areas and employing various types of platforms. These should also sample a range of operating conditions.

4. Relate the noise levels and spectra to the machinery and other potential sources of noise and vibration on the platforms.

5. Calculate the expected maximum ranges of noise influence based on the source-path-receiver model.

6. Analyze data to determine what mitigating measures could be recomended in case it is found necessary to minimize the effect of any sounds created by OSC 017 and gas operation on cetaceans.

Results

\section{Literature Survey}

"Literature Review on: I. Underwater Noise from Offshore $0 i 1$ Operations, and V. Underwater Hearing and Sound Productions of Marine Mammals "compiled by $C$. W. Tur 7 and edited by $E$. Lindner as part of the first summary report was submitted to BLM in June 1980. 


\section{Interview Program}

The questionnaire-interview pilot survey program was contracted to Chambers Consultants and Planners. The work on this program was initiated on 1 August 1980, and the first draft of the questionnaire and the instructional material were reviewed by NOSC in September 1980 .

\section{Recording and Measurement of Source Data}

Instrumentation. A state-of-the-art recording system was selected, purchased, and assembled with the following properties: $\mathrm{kHz}$.

- Hydrophone: B\&K Type 8101 with useful frequency range from $1 \mathrm{~Hz}$ to 125

- Pre-amplifier and Filter: Ithaco Model 451 Data Acquisition Amplifier with gain adjustable in $1 \mathrm{~dB}$ steps, and low frequency rolloff selectable to 1 , $10,100,1 \mathrm{k}$, and $10 \mathrm{k} \mathrm{Hz}$.

- Magnetic Tape Recorder: Nagra Model TI, twin capstan instrumentation tape recorder, with four tracks, speed adjustable in 8 steps from 15/32 to 60 inches per second (ips). Frequency response is 0 to $10 \mathrm{kHz}$ in the FM mode and 0.1 to $125 \mathrm{kHz}$ in direct mode at 30 ips. Normal operating speed is 7.5 ips, which provides a frequency coverage of 0 to $2500 \mathrm{~Hz}$ on the FM channel and 0.1 to $30 \mathrm{kHz}$ on the direct channel. Both channels are recorded simultaneously to provide frequency coverage from 0 to $30 \mathrm{kHz}$.

The above system is capable of battery operation for field measurement, and may be packaged for ready transportation to field locations by air transport, boat, and/or helicopter. The hydrophone is equipped with 300 feet of cable and may be suspended from a special float system for stabilizing vertical mation.

\section{Field Measurements}

Tape recordings have been acquired for six different platforms located in three geographic areas: Santa Barbara, California; Cook Inlet, Alaska; and Atlantic City, New Jersey. General information on each is summarized below:

\section{Santa Barbara-Ventura, California, April 1980.}

Platfrrm Holly--ARCO production/drilling platform, 2-1/2 miles off shore from Goleta, California in water of 211 feet. The platform is supported on eight hollow steel legs driven into the ocean floor and filled with concrete. Prime power is supplied by diesel engines with mufflers. Measurements included airborne, structureborne, and underwater sound. Underwater measurements were made overside from a drifting boat. Underwater recordings utilized an interim system which did not achieve the high gain, wide bandwidth capability of the NOSC-developed system described above, and used at other locations. Measurements were made during production, drill pulling, and dyna drilling operations. Production was approximately 6000 barrels per day and dri11 depth, 850 feet. 
Is Tand Rincon--ARCO production island--man-made, approximately $1 / 2$ mile off shore, 10 mites north of Ventura, California. It is connected to shore via a pile supported trestleway. Power is supplied via electrical lines from shore. Measurements included airborne, structureborne, and underwater sound. Uncerwater measurements were made from a hydrophone lowered from the trestleway, and also overside from a small, drifting boat. All measurements were near the island in water depths less than 50 feet. Here also, the interim recorder-measurement system used at Platform Holly was used.

\section{Cook Inlet, Alaska, June 1980}

Ocean Bounty--ODECO operated, leased by ARCO, semi-submersible, located in Lower Cook Inlet, approximately 40 miles southwest of Homer. The platform is mounted on eight legs supported by a pair of submerged cylindrical hu?ls 26 feet in diameter. The rig is anchored by chains in an eight point moor in water 300 feet deep. Platform elevation is maintained by adjusting water level in ballast tanks. Prime power is derived from unmuffled diesel engines. Measurements included airborne, structureborne, and underwater sound. Underwater measurements were from a drifting 50 foot trawler, at ranges from 10 to 400 yards from the platform. Hydrophone depths varied from 20 to 110 feet.

Platform King Salmon--ARCO production platform located in Upper Cook Inlet, near Kenai, Alaska. It is a quadripod with legs 10 feet in diameter. Water depth is approximately 60 feet. Primary power is gas turbine. Measurements included airborne, structureborne, and underwater sound. Underwater measurements were obtained during periods near slack tide by lowering the hydrophone from the structure about midway between legs 1 and 2 . Hydrophone depths varied from 10 to 35 feet.

Platform Spark--ARCO production platform located in Upper Cook Inlet near Kenaj, Alaska. It is a tripod with legs 16 feet in diameter. Water depth is approximately 75 feet. Primary power is gas turbine. Measurements included airborne, structureborne, and underwater sound. Underwater measurements were taken during near slack tide with the hydrophone suspended from the edge of the platform approximately midway between legs 2 and 3 . Hydrophone depths were varied from 20 to 50 feet.

3. AtTantic City, New Jersey, August 1980

Ocean Victory--ODECO operated, leased by Tenneco, semi-submersible, located near Baltimore Canyon approximately 100 miles out of Atlantic City, New Jersey. This rig is nearly identical to the Ocean Bounty described earlier. It is anchored in approximately 500 feet of water. Measurements were made during drilling at a depth of approximately 15,000 feet. Primary power was from unmuffled diesel engines. Measurements were made of airborne sound (one location) and underwater sound. Underwater sound measurements were made by a rydrophone suspended from the deck edge at the bow location, approximately equaliy distant from the two submerged hulls. Hydrophone depths were 20 and 120 feet. 


\section{Field Data Analysis}

Preliminary one-third octave band analysis of data on the five platforms in the Santa Burbara and Cook Inlet areas is described in a report entitled, "Field Measur mments of Underwater Noise from Offshore $0 i 1$ Operations from January-June 1980" by David R. Schmidt, June 1980.

Narrow band analysis has been performed on the recordings from Cook Inlet and Atlantic City. These were obtained on the NOSC IDHACS (Intelligent Data Handling and Control System) facility using the Spectral Dynamics SD 360 analyzer to provide analyses of the FM channel from 1 to $300 \mathrm{~Hz}$ with an analysis bandwidth of $0.8 \mathrm{~Hz}$, and the $A M$ channel from 100 to $6000 \mathrm{~Hz}$ with an analysis bandwidth of $16 \mathrm{~Hz}$. Appendix A presents the hardcopy IDHACS printout for one measurement location on semi-submersible platform Ocean Bounty. The digitized data are for a station at a distance of approximately 50 feet from the Ocean Bounty structure, and with hydrophone depth of 50 feet. The two sets of data are identified by code numbers: OB50A2BDA for the $16 \mathrm{~Hz}$ analysis of the direct recording, and OBO5F28DA for the $0.8 \mathrm{~Hz}$ analysis of the FM recordings.

Representative spectra for both the 16 and $0.8 \mathrm{~Hz}$ analyses are presented in Figures 1 through 8 for platforms Ocean Bounty, King Salmon, Spark, and ocean Victory. Figures 1 and 2 are graphic presentations of the same data from 0 cean Bounty that is shown in digital form in Appendix $A$. The sharp spikes indicate the presence of line spectra, with muttiple single frequency components in the above four platforms. Such line spectra are representative of radiated noise from rotating machinery. Analysis is continuing in order to relate the frequency components to individual machinery sources, and to compare the magnitudes of noise on the various platforms. The magnitude data will be available to estimate zones of potential acoustical influence about the various platforms.

\section{Other Data Outputs}

Magnetic tape duplicates of portions of tape recordings of platforms Ocean Bounty, King Salmon, and Spark have been furnished to the ARCO, Anchorage office.

A magnetic tape duplicate of portions of two drift runs of Ocean Bounty has been provided to Polar Research, Inc. for use in connection with BLM-sponsored studies of marine mamal response to acoustic playback of platform radiated noise. 


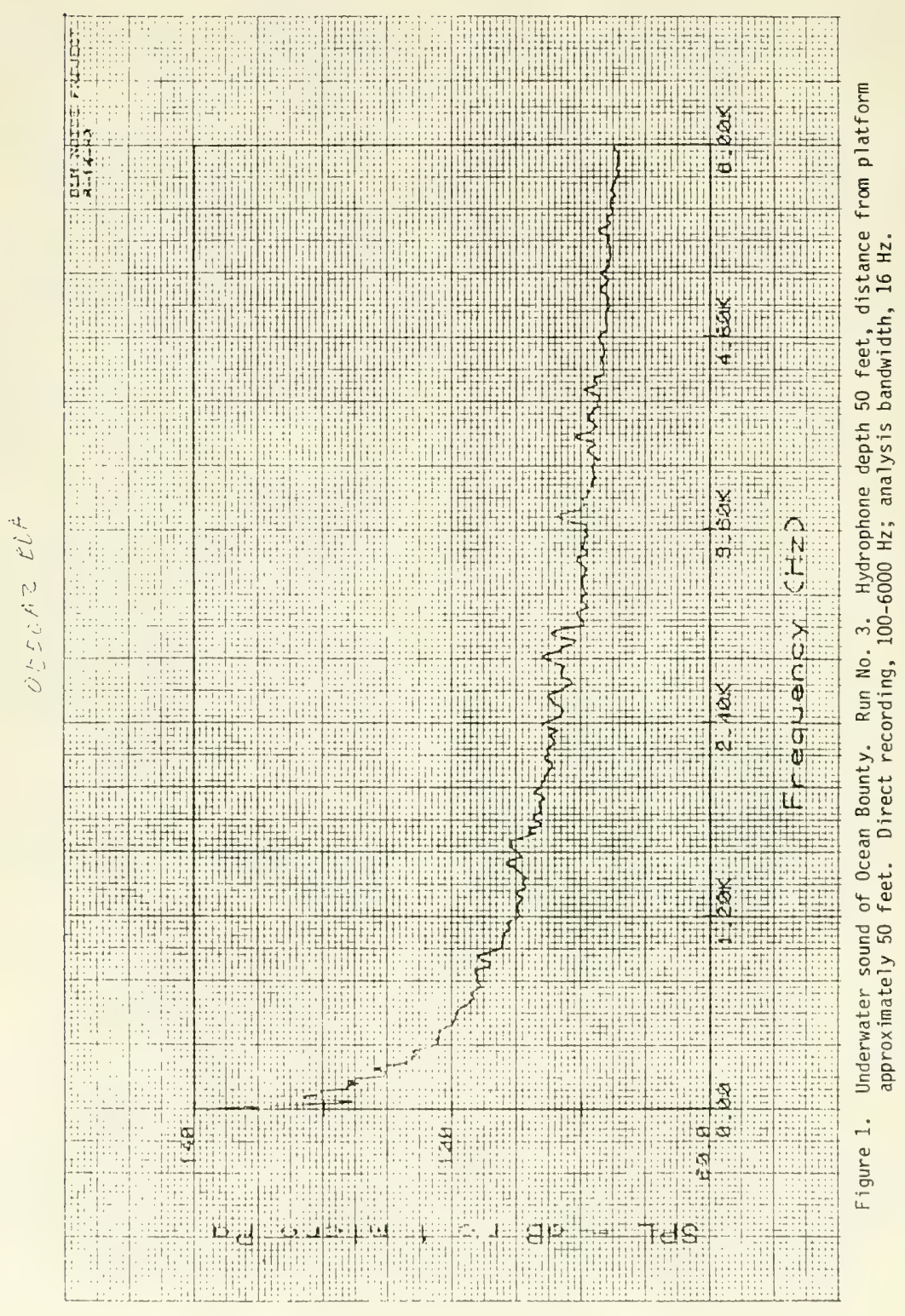




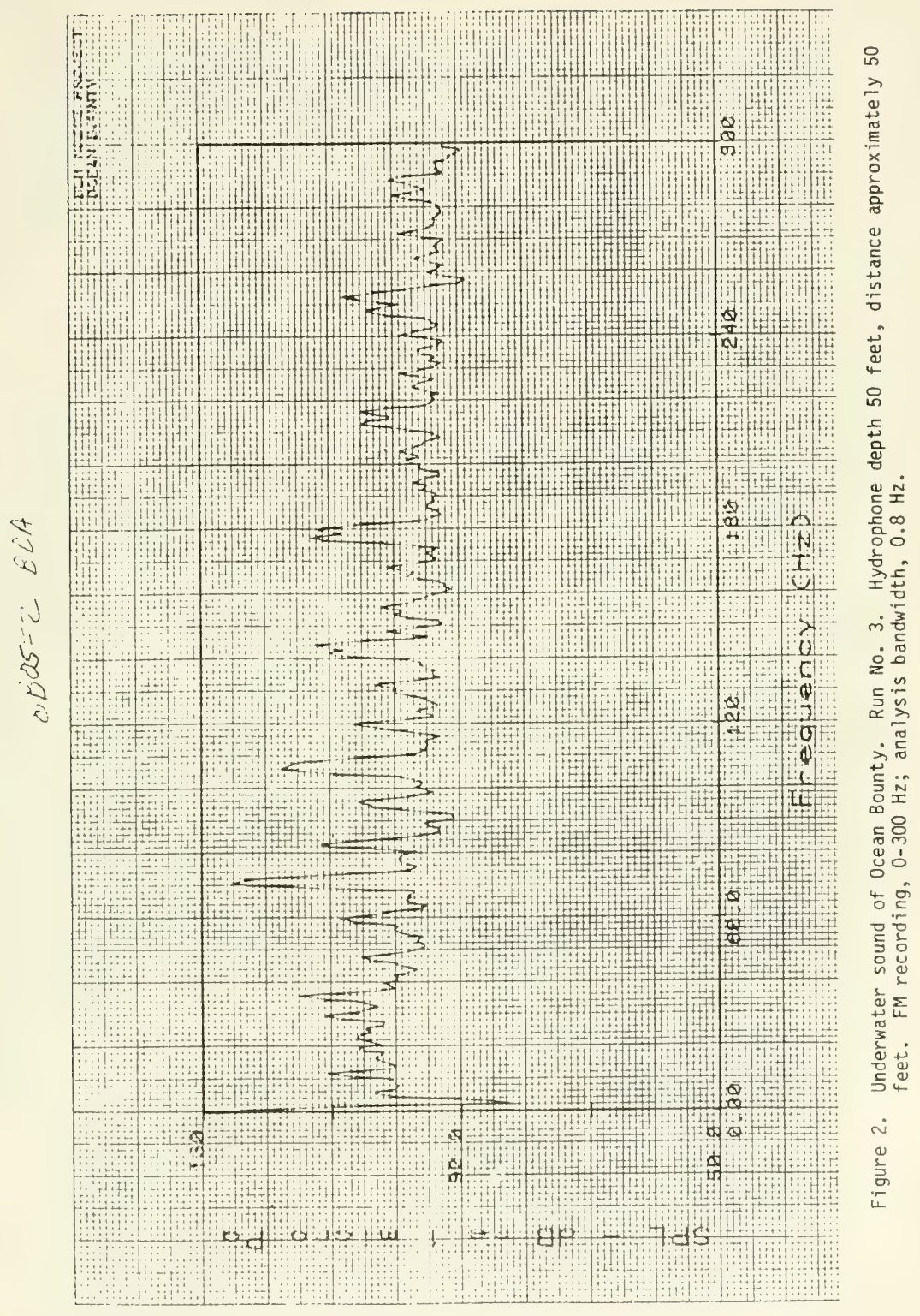




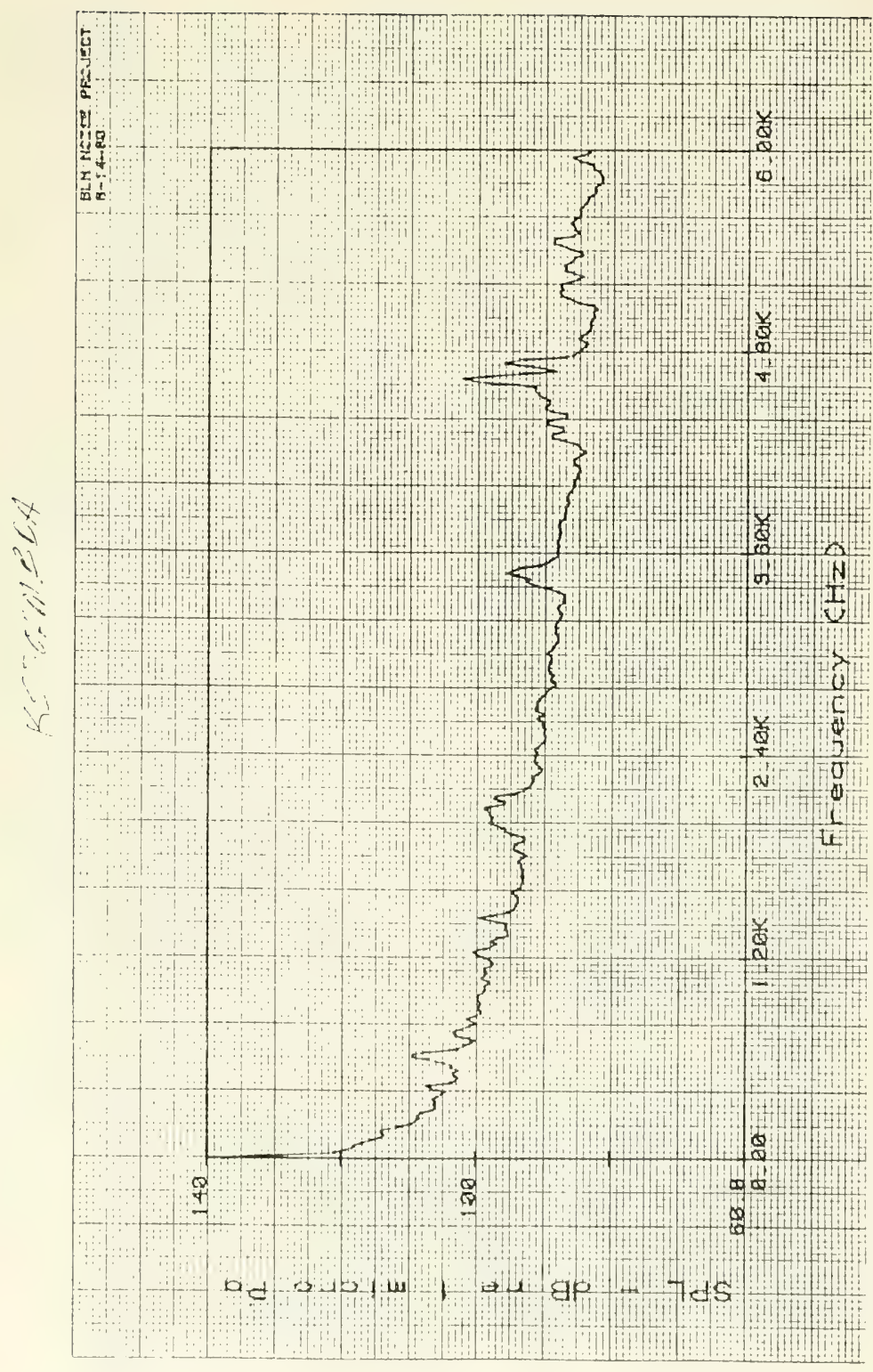

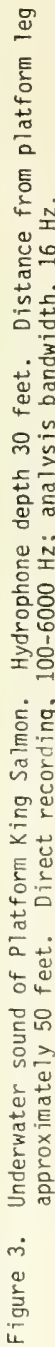




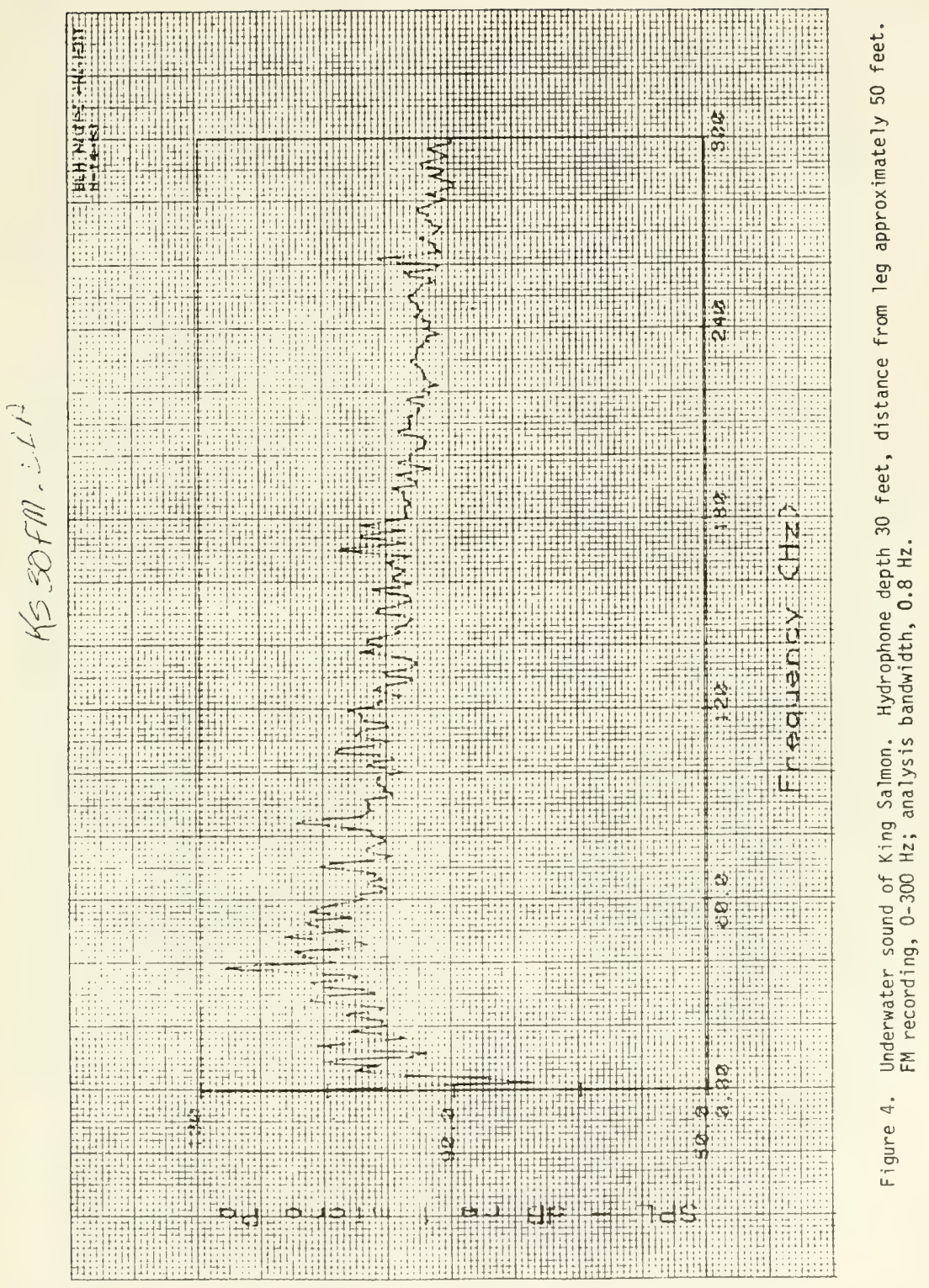




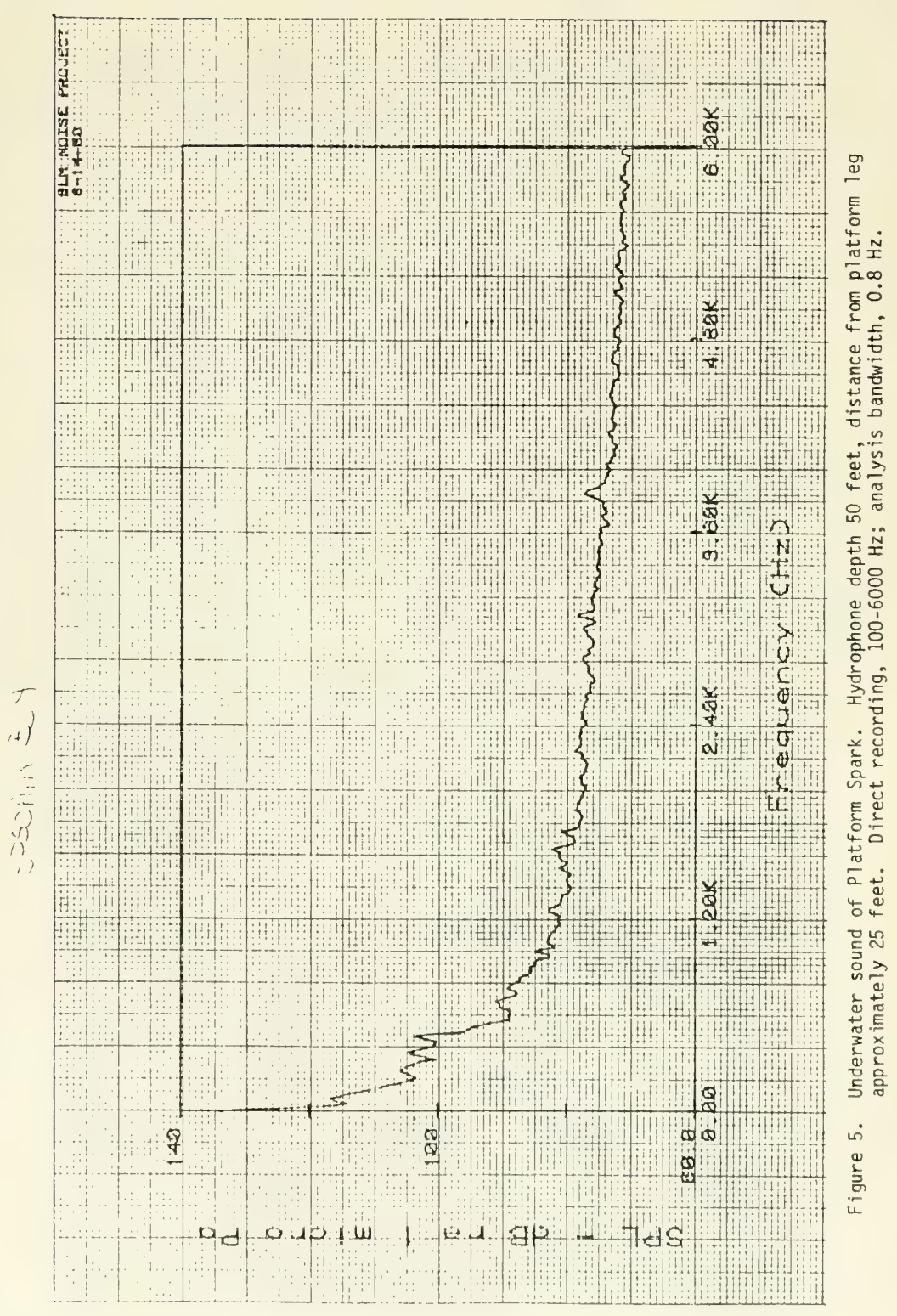




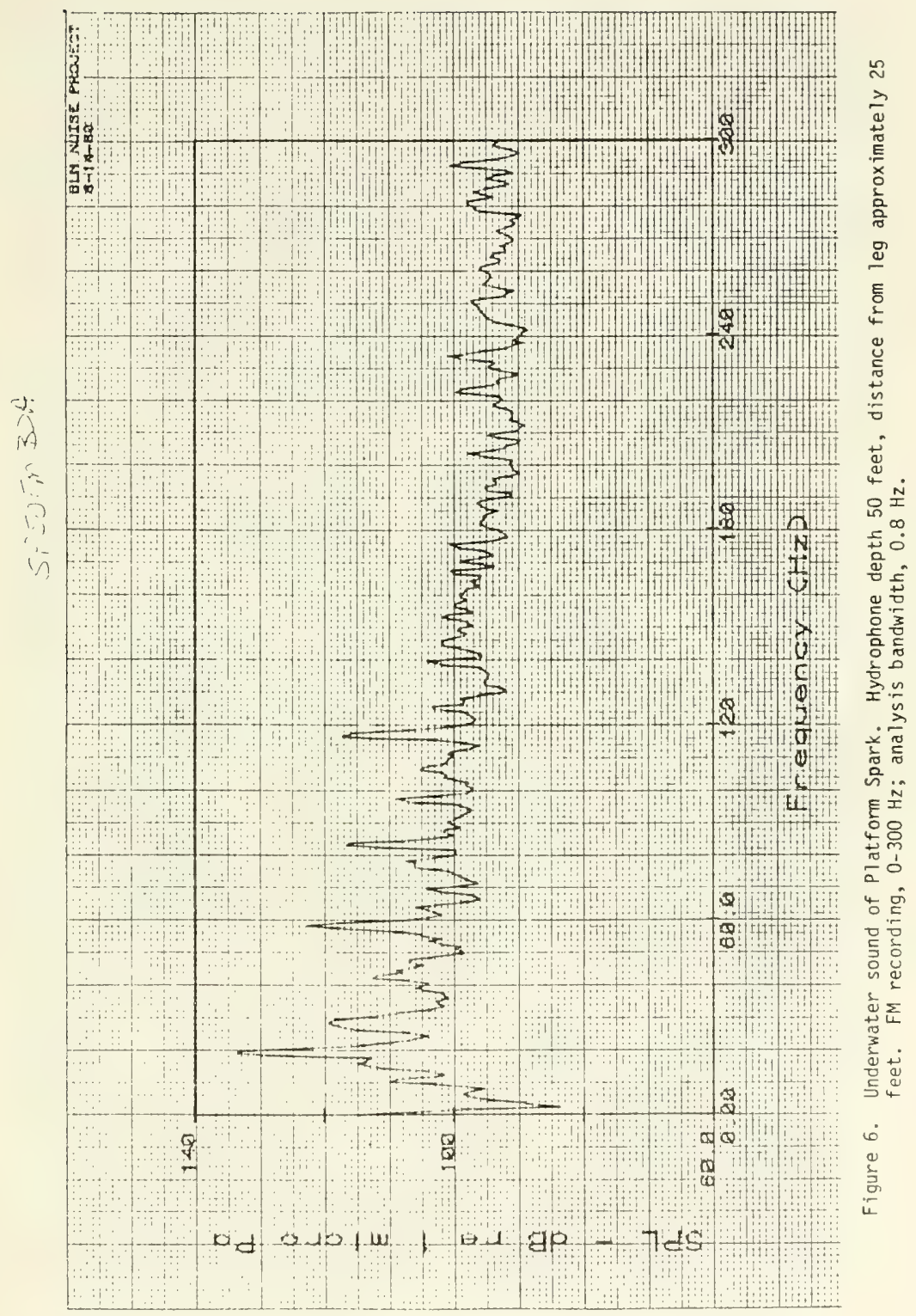




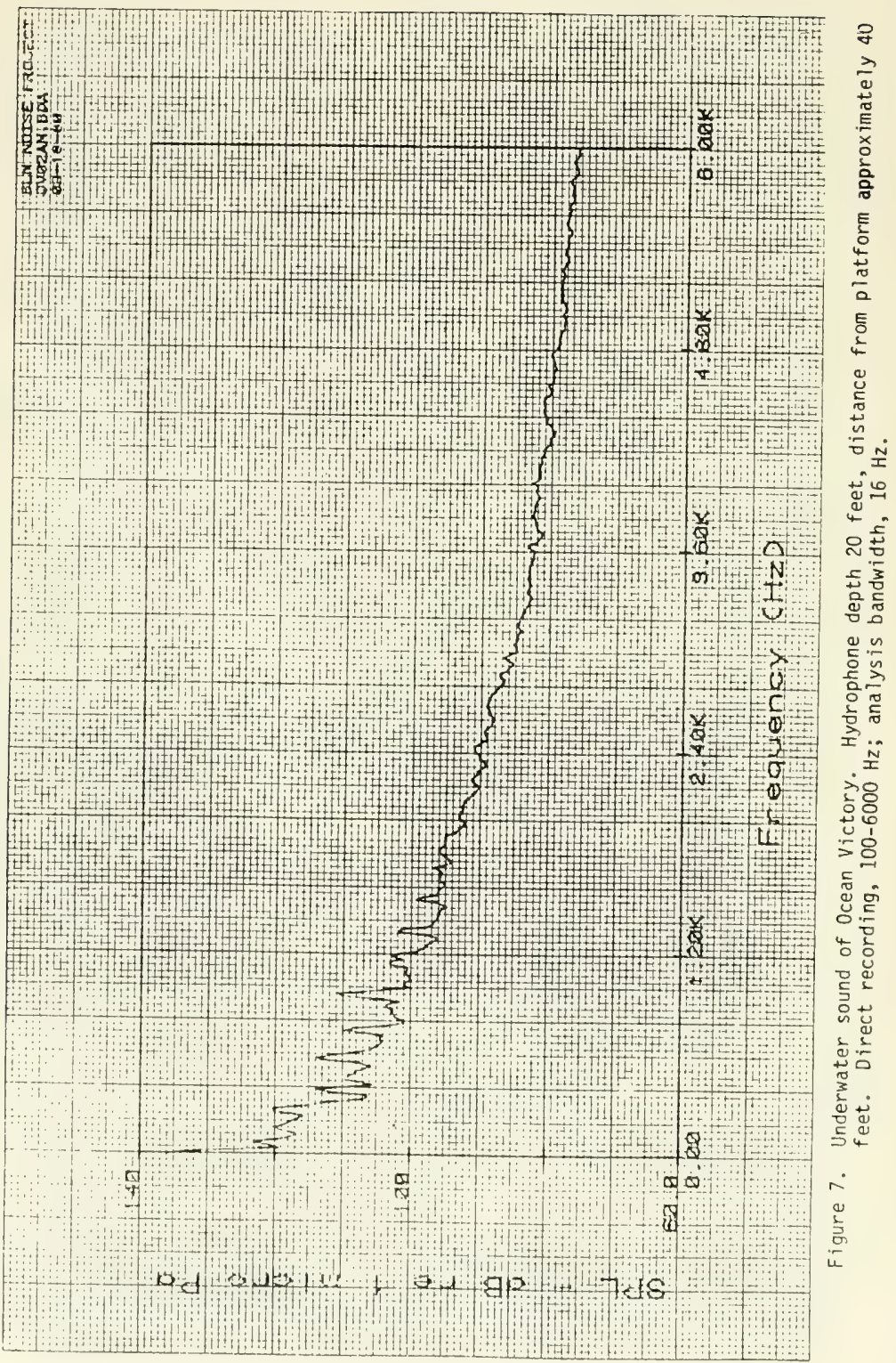




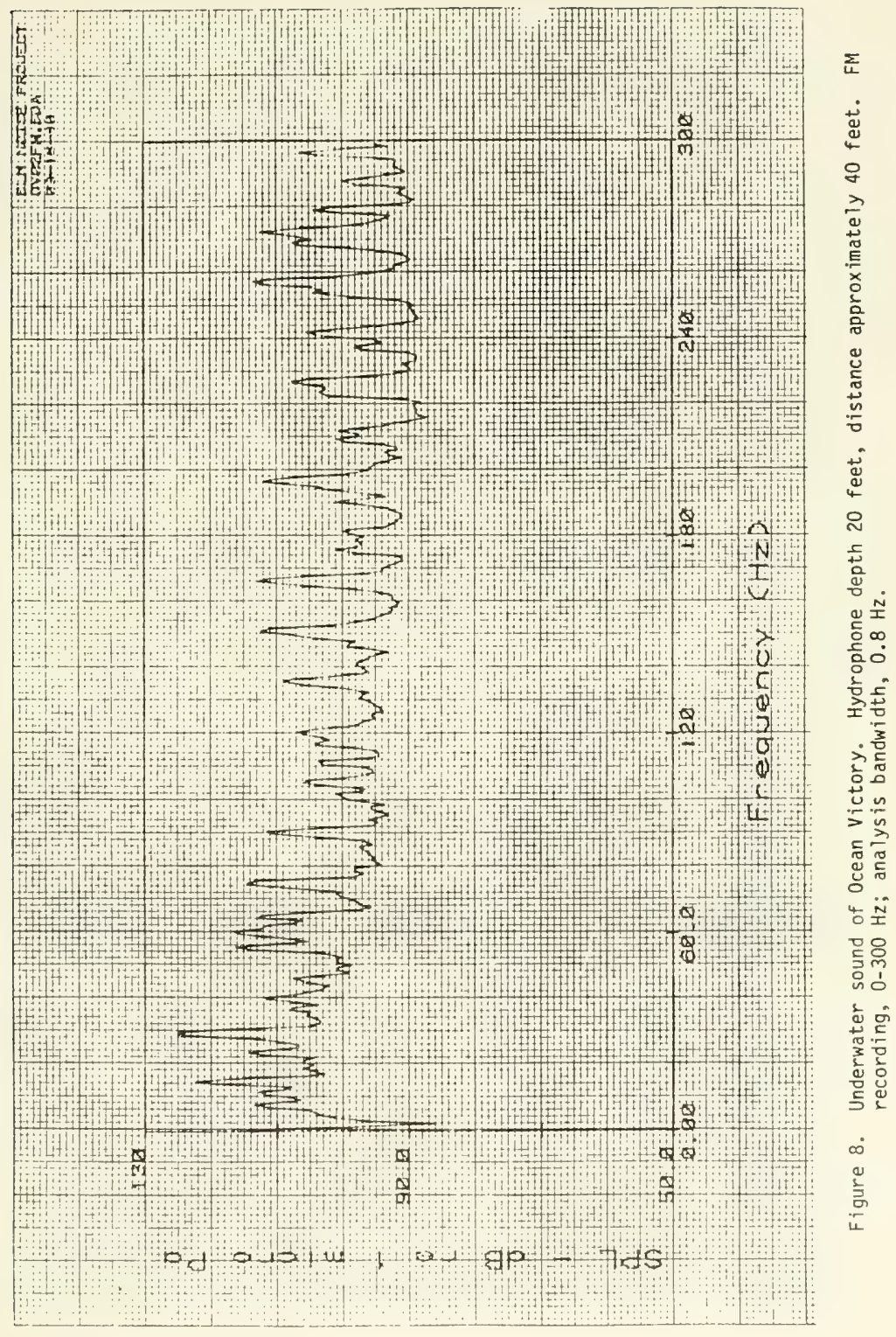


APPENDIX A

REPRESENTATIVE DIGITAL PRINTOUTS FROM SPECTRUM ANALYSES PERFORMED BY

THE NOSC IDHACS FACILITY 


\section{REPRESENTATIVE DIGITAL PRINTOUTS FROM \\ SPECTRUM ANALYSES PERFORMED BY \\ THE NOSC IDHACS FACILITY}

The following materials are copies of the digital printouts from the NOSC IDHACS (Intelligent Data Handling and Control System). These data are presented as representative examples of the hardcopy obtained from IDHACS on each analysis performed. The example presented here is for a measurement position approximating 50 feet from the bow structure of 0cean Bounty and hydrophone depth of 50 feet. Two analyses are presented, each preceded by an IDHACS status sheet. The first analys is is for $16 \mathrm{~Hz}$ analys is bandwidth on the AM recording; the second, for $0.8 \mathrm{~Hz}$ analysis of the $\mathrm{FM}$ recording. Graphic presentations of these same data are shown in Figures 1 and 2 of the report. 


\section{S[I-360 SFECTFIIM ANALYZER \\ DATA SHEET \\ I DHACS TEST FALILITY \\ 8-14-S0}

FFIOJECT: ELM NOISE FFIOI.JECT

DATA FILE: OESIOA2. BDA

CONFIGURATION COMMENTS: OCEAN EOUNTY

FUNCTION $=2-$ FWD TRANSFUFIM $A(1024)$

INPUT:

AT TENUATORE:

$$
\begin{aligned}
& A=23 \\
& E=16 .
\end{aligned}
$$

MEMCIRY HOLD:

$$
\begin{aligned}
& A=\text { OFF } \\
& E=\text { GIFF } \\
& \text { OLIT }=\text { OFF }
\end{aligned}
$$

FILTEFIS:

WTG $=$ QN

AL. IAS $=$ QN

STOFEFC: $=$ GFF

TRIANSIENT PACKAAGE:

CAFTLFE KNGE = GFF

LEVEL INT/EXT $=$ ON

$A F M=O F F$

DELAYE INT/EXT $=$ DFF

$1 / 2=15$
AVEFIAGING:

$N=8$

LIN

FFEQ $=0000 \mathrm{~Hz}$

TFOFME $=$ MAX

GLITFUT:

DISFLAY:
MEMIO = OFF
$4:$ OA
POLAR
CIIF $=$ OFF

$$
\begin{aligned}
\text { SCALEE: } \\
X=\text { LIN } \\
Y_{1}=\text { LOS } \\
Y_{2}=\text { LIN } \\
F^{\prime}=4 \\
9=1
\end{aligned}
$$

FLDTTEF:

FOINT

IIATA:

FCIFIMAT $=$ LOG OJE EIN \# $=>16$

BIN RANGE: 0 TO 1023

COMMENTS: 
::ローミSの DATA

'ROJECT: BLM NOISE FROJECT

DATE: $8-14-80$

FAGE 2 DF 4

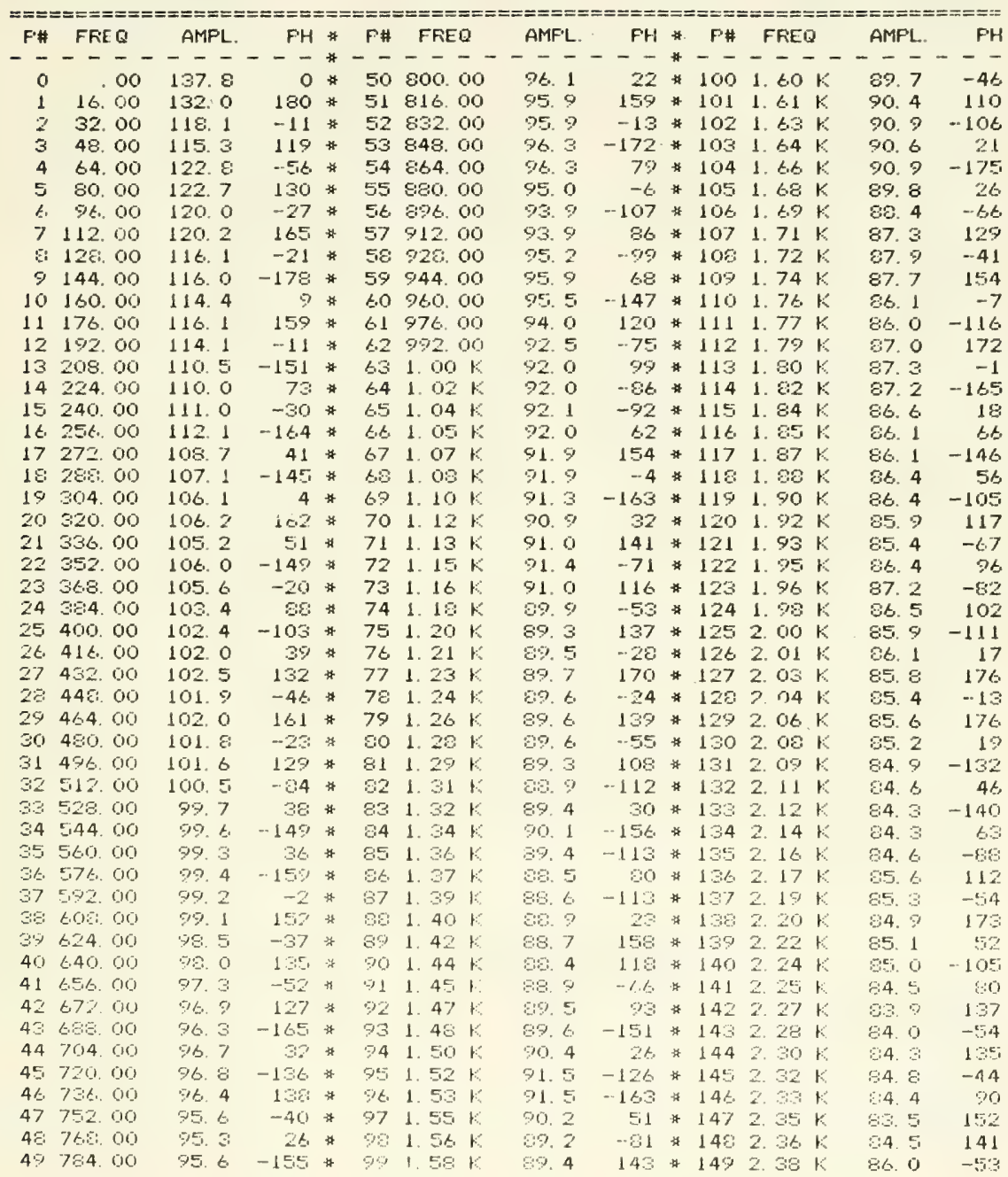


PFOJECT: ELM NOISE FKOUIECT

IIATE: $\quad \xi-14-80$

PAGE $:$ OF 4

\begin{tabular}{|c|c|c|c|c|c|c|c|c|c|c|c|c|c|c|c|c|}
\hline$F^{\prime} \#$ & FFE & & AMFL. & FH & * & $F \#$ & FFE & & AMFL. & F'H & * & F'\# & FFEE & & AMFL. & \\
\hline & -- & & - & - & * & & & & 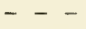 & 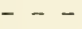 & * & 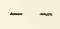 & 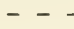 & & 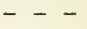 & \\
\hline 50 & 2. 40 & $K$ & 85.6 & 128 & * & 200 & 3.20 & $k$ & 79.1 & 47 & * & 250 & 4. 00 & $k$ & 78.0 & \\
\hline 51 & 2.41 & $K$ & 84.4 & -37 & * & 201 & 3.21 & $k$ & 79.4 & -112 & * & 251 & 4. 01 & $K$ & 77.7 & \\
\hline 52 & 2. 43 & $k$ & 53. 3 & 170 & * & 202 & 3.23 & $k$ & 79.6 & 95 & \# & 252 & 4. 03 & $k$ & 77.2 & \\
\hline 53 & 2. 44 & $k$ & 83.0 & 67 & $\#$ & 03 & 3. 24 & $k$ & $7 \% .7$ & -80 & * & 253 & 4. 04 & $K$ & 77.6 & \\
\hline 5.4 & 2. 46 & $k$ & 2. 7 & -71 & $\not \vec{x}$ & 204 & 3.26 & $k$ & 79.8 & 129 & * & 254 & 4. $0 t$ & $k$ & 78.3 & \\
\hline 55 & 2. 48 & $k$ & 82. 7 & 88 & \# & 205 & 3. 28 & $k$ & 79.8 & -31 & * & 255 & 4. 08 & $K$ & 78.7 & \\
\hline 56 & 2. 49 & $k$ & 83.0 & $-12 t$ & * & 06 & 3. 29 & $k$ & 79.6 & 158 & * & 256 & 4. 09 & $k$ & 70.7 & \\
\hline 57 & 2. 51 & $k$ & 53.6 & 13 & $*$ & 007 & 3. 31 & $K$ & $7 \% .4$ & -6 & * & 257 & 4. 11 & $K$ & 78.2 & \\
\hline 5 & 2. 512 & $k$ & 84. 4 & $16 t$ & * & 00 & 3.32 & $K$ & & 156 & * & 258 & 4. 12 & $k$ & 77.6 & \\
\hline 59 & 2. 54 & $K$ & 84. 5 & -14 & * & 200 & 3. 34 & K & 9. 3 & 57 & * & 259 & 4. 14 & $k$ & 78.4 & \\
\hline 6.0 & 2. 56 & $K$ & 5. 1 & 176 & * & 10 & 3. 36 & r & 2 & -99 & 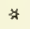 & $2+0$ & 4. 16 & $k$ & 79.9 & \\
\hline 61 & 2.57 & $K$ & 5. 0 & 137 & * & 11 & 3. 37 & $k$ & 6 & 108 & & 261 & 4. 17 & $k$ & 90.9 & -15 \\
\hline 6.2 & 2. 59 & $K$ & 93.5 & 48 & * & 12 & 3.39 & $K$ & 2 & -47 & & $2 t .2$ & 4. 19 & $k$ & 90.0 & \\
\hline 63 & 2.60 & $k$ & 52.8 & 114 & * & 13 & 3. 40 & 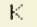 & & 139 & 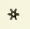 & 263 & 4. 20 & 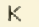 & 78.4 & -1 \\
\hline 6.4 & 2. 6.2 & $k$ & 52.3 & 88 & * & 14 & 3. 42 & $K$ & 4 & 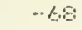 & * & 264 & 4. 22 & $k$ & 77.9 & 10 \\
\hline 65 & 2. 64 & $k$ & 81.4 & -60 & * & 215 & 3. 44 & $k$ & 4 & 126 & $x$ & 265 & 4. 24 & $K$ & 77.4 & -5 \\
\hline t.t. & 2. 6.5 & $k$ & E1. 4 & -141 & $\Rightarrow$ & 216 & 3.45 & $k$ & 5 & -22 & * & 266 & 4. 25 & $k$ & 77.9 & \\
\hline 67 & 2.67 & $k$ & 32.0 & 51 & * & 217 & 3.47 & $K$ & 4 & 170 & $*$ & 267 & 4. 27 & $K$ & 78.7 & \\
\hline$E B$ & 2. 6.8 & $k$ & 53.0 & 154 & $\approx$ & 218 & 3.45 & $k$ & .7 & -23 & * & $26 \theta$ & 4. 28 & $k$ & 79.8 & \\
\hline 69 & 2. 70 & $k$ & 83.1 & 0 & \# & 215 & 3. 50 & . & 6 & 152 & * & $26 \%$ & 4. 30 & $k$ & 78.7 & \\
\hline 70 & ․ 72 & $k$ & 3. 1 & 172 & * & 220 & 3.52 & r & 5 & -23 & * & 270 & 4. 32 & $K$ & 70.3 & \\
\hline 71 & 2. 75 & $\mathrm{r}$ & $2 \%$ & 4 & \# & 221 & 3.53 & t & & 159 & * & 271 & 4. 3 & r & 1 & 1 \\
\hline 72 & 2. 75 & $K$ & 2. 6 & 143 & *. & 222 & 3.55 & $k$ & 3 & -90 & & 272 & 4. 35 & 1 & 77.7 & \\
\hline 73 & 2. 76 & & E. 4 & 45 & * & 223 & 3.56 & $K$ & 9 & 46 & & 273 & 4. 36 & $k$ & 77. 2 & \\
\hline 74 & 2. 78 & $k$ & 4. 7 & 115 & $\not$ & 224 & 3.56 & $k$ & 3 & 104 & & 274 & 4. 38 & 1 & 77.4 & \\
\hline 75 & 2. 80 & $k$ & .7 & 83 & $*$ & 225 & 3. 60 & $k$ & 4 & 98 & & 275 & 4. 40 & $K$ & 77.2 & 1 \\
\hline 76 & 2. $: 1$ & $k$ & 8 & -143 & $\not$ & 226 & 3.61 & $K$ & 7 & --74 & स & 276 & 4. 41 & $\mathrm{r}$ & 76.9 & \\
\hline 77 & 2. 83 & $k$ & 4 & -76 & \# & 227 & 3.63 & $k$ & 2 & 95 & * & 277 & 4. 43 & $k$ & 77.1 & $-1:$ \\
\hline $7:$ & 2. 54 & 1 & E: 2 & 120 & * & 20 & 5.4 & $k$ & 5 & 128 & $\approx$ & 275 & 4. 44 & K. & 732 & \\
\hline 79 & 2. 56 & $\mathrm{~F}$ & 82.9 & -73 & $\forall$ & 220 & 3.6 & 1 & 0 & 4 & * & 274 & 4. 46 & $k$ & 79.5 & \\
\hline 00 & 2. 88 & 16 & E. 1 & 65 & \# & 230 & 360 & $k$ & $E$ & 179 & . & 250 & 4. 45 & $K$ & 78.7 & --7 \\
\hline 81 & 2. 39 & 1 & 81.0 & 60 & * & 231 & 369 & 1 & 0 & -22 & & 281 & 4. $4 \%$ & 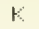 & 77.3 & \\
\hline 82 & 27 & $k$ & 00.7 & -102 & $x$ & 232 & 3.71 & $K$ & 1. 1 & 155 & & 292 & 4. 5il & $K$ & 7. 6 & 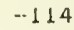 \\
\hline 83 & $=92$ & F & 2.4 & 135 & \# & 233 & 3. 72 & $k$ & 800 & 6 & & 263 & 4. 52 & $\mathrm{r}$ & 7.9 & \\
\hline$E: 4$ & 2. 94 & $t$ & 7. 4 & -29 & 7 & $2: 4$ & 3. 74 & $r$ & 4 & -162 & . & 294 & 4. 54 & . & 7 & \\
\hline $8^{x}$ & 2.76 & $k$ & 6 & 152 & * & 235 & 3. 76 & t: & 4 & -26 & * & 285 & 4. 56 & K & 76.6 & \\
\hline$E: \underline{t}$ & 2. 97 & $k$ & $b$ & -61 & * & 236 & 3.77 & $\mathrm{r}$ & 7 & $10 \%$ & * & 286 & 4. 57 & $K$ & 76.3 & \\
\hline 87 & 2. 99 & $k$ & 3 & 132 & * & 237 & 3.79 & $k$ & 6 & -80 & $*$ & 287 & 4. 50 & r & 76.5 & \\
\hline : & 3. 00 & $k$ & & 3 & * & 230 & 3.80 & $k$ & 0 & 59 & \# & 280 & 4. 60 & $k$ & 76.6 & \\
\hline & 3.02 & $K$ & 6 & 142 & * & 239 & 3. 82 & $k$ & 5 & 159 & $*$ & $28 \%$ & 4. 62 & $k$ & 76,3 & \\
\hline 0 & 3. 04 & $k$ & $\varepsilon$ & 6.6 & $\not$ & 240 & 3.94 & 16 & .7 & 50 & * & 290 & 4. 64 & $K$ & 76.5 & -17 \\
\hline 91 & 3. 05 & $k$ & 3 & -106 & * & 241 & 3. 85 & $k$ & 4 & -38 & $*$ & 291 & 4. 65 & $k$ & 76.7 & \\
\hline 92 & 3.07 & I. & 80.5 & 26 & $\not$ & 242 & 3.07 & $k$ & 1 & $-1 \leqslant 5$ & * & 292 & 4. 6.7 & $k$ & 76.5 & -17 \\
\hline 93 & 3. 08 & 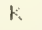 & $50 \mathrm{~b}$ & $12 \%$ & $\#$ & 243 & 3.88 & $k$ & 3 & 142 & * & 293 & 4. 68 & $r$ & 76.4 & - \\
\hline 54 & $\because 10$ & r & $7 \% 7$ & -87 & \# & 244 & 300 & $k$ & $78: 1$ & $\therefore 14$ & $*$ & 294 & 4. 70 & $k$ & 76.2 & \\
\hline 75 & 312 & $t$ & 75,6 & $9 \%$ & \# & $\div 45$ & 392 & $r$ & 775 & -170 & * & $=0$ & 4. 72 & $k$ & 76.4 & \\
\hline 96. & 313 & f & $7 \% 2$ & 50 & H & 246 & 393 & $k$ & 77. & -12 & $\not$ & at & 4. 73 & 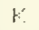 & 765 & \\
\hline 8 & 315 & 1 & フ・ & $-1: 0$ & $\forall$ & -47 & 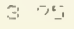 & r & $7:$ & 170 & 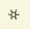 & $=2 \%$ & 4 & t & 76 & \\
\hline & 316 & 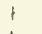 & $\sin 0$ & 12 & \# & 249 & $3 \%$ & t: & 761 & 4 & * & 200 & 476 & $r$ & 76.9 & \\
\hline & 315 & 1 & 70.7 & 144 & * & $24: 1$ & & 1. & $7 E::$ & $-14 \%$ & r & 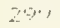 & 4. $7 E$ & $r$ & 77.2 & \\
\hline
\end{tabular}


:II-:Z:C.O DATA

'ROUECT: BLM NOISE FROUECT

IIATE: $8-14-80$

PAGE 4 OF 4

\begin{tabular}{|c|c|c|c|c|c|c|c|c|c|c|c|c|c|c|c|c|}
\hline P\# & FREE & & AMFL. & $\mathrm{PH}$ & 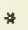 & F\# & FFEQ & & AMFL. & $\mathrm{FH}$ & * & P\# & FFEE & & AMFL. & $\mathrm{FH}$ \\
\hline 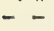 & $-\quad-$ & & & 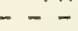 & 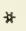 & & & & 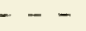 & & * & & -- & & -- & $-\cdots$ \\
\hline 800 & 4. 810 & $k$ & 77.0 & -127 & * & 325 & 5. 20 & $k$ & 76.6 & 90 & * & 350 & 5. 6.0 & $k$ & 75.1 & $18: 3$ \\
\hline 301 & 4. 81 & $k$ & 76.8 & 36 & * & 326 & 5. 21 & K & 76.0 & -56 & * & 351 & 5.61 & K & 75.3 & -100 \\
\hline 302 & 4. $8: 3$ & $k$ & 75.9 & -153 & * & 327 & 5. 23 & $k$ & 75. 6 & $1 t e$ & $*$ & 352 & 5.63 & $k$ & 75.3 & 50 \\
\hline 303 & 4. 84 & $k$ & 75.9 & -75 & * & 378 & 5. 24 & $K$ & 75.5 & -38 & \# & 353 & 5. 64 & $k$ & 75.3 & -137 \\
\hline 304 & 4. 86 & $k$ & 76.0 & 75 & * & 329 & 5. 26 & $k$ & 75.6 & 120 & $*$ & 354 & 5.66 & $k$ & 75.2 & 104 \\
\hline 305 & 4. 88 & $K$ & 76.0 & -156 & * & 330 & 5. 28 & $k$ & 75. 4 & 104 & * & 355 & 5. 6.8 & K & 74.6 & -170 \\
\hline$\$ 0 t$ & 4. $\Sigma: 9$ & $K$ & 76. 1 & -14 & * & $3=1$. & 5. 20 & $k$ & 75. 2 & -83 & * & 356 & 5.69 & $k$ & 74. 8 & -15 \\
\hline 307 & 4. 91 & $K$ & 76.1 & -134 & * & 332 & 5. 31 & $K$ & 75.3 & 110 & * & 357 & 5.71 & $K$ & 75.4 & 16.7 \\
\hline 308 & 4. 92 & $k$ & 76. 1 & -112 & \# & 333 & 5. 32 & $k$ & 75.4 & -54 & \# & 350 & 5. 72 & $k$ & 75.2 & 104 \\
\hline 309 & 4. 94 & $K$ & 76.1 & S6 & * & 334 & 5. 34 & k & 75.3 & 45 & * & 350 & 5.74 & $k$ & 74.6 & 45 \\
\hline 110 & 4. 96 & $K$ & 75.9 & -77 & * & 335 & 5.36 & $k$ & 75.3 & $-14,1$ & \# & 360 & 5.76 & $k$ & 74.7 & 180 \\
\hline 311 & 4. 97 & K & 75.5 & -165 & * & 336 & 5.37 & $k$ & 75.6 & 38 & * & 361 & 5. 77 & $k$ & 74.6 & -21 \\
\hline$\$ 12$ & 4. 50 & $k$ & 75.4 & se. & * & 397 & 5.39 & $k$ & 75.8 & -137 & \# & 362 & 5. 79 & $k$ & 74. 4 & 157 \\
\hline 13 & 5.00 & $K$ & 75.7 & -77 & * & 335 & 5.40 & k & 75.6 & 47 & * & 363 & 5.80 & $k$ & 74. 1 & -5 \\
\hline 14 & 5. 02 & $k$ & 75.9 & 132 & $\because$ & 339 & 5. 42 & $k$ & 75.5 & -39 & \# & 364 & 5.82 & $k$ & 74. 1 & $-12 t$ \\
\hline 315 & 5. 04 & $k$ & 75.5 & -42 & * & 340 & 5. 44 & K & 76.6 & -162 & * & 365 & 5.84 & K. & 74.5 & 46 \\
\hline 216 & 5.05 & $k$ & 75.9 & 121 & * & 341 & 5.45 & $k$ & 77.3 & 9 & * & 366 & 5.85 & $K$ & 74. 4 & -139 \\
\hline 317 & 5. 07 & $K$ & 76.6 & -101 & * & 342 & 5. 47 & $k$ & 77.0 & 63 & * & 367 & 5.87 & $k$ & 74.2 & 28 \\
\hline 316 & 5.08 & $k$ & 77. 0 & -116 & * & 343 & 5. 48 & $k$ & 76.0 & -165 & * & 360 & s. 89 & $K$ & 74.2 & 177 \\
\hline 319 & 5,10 & $k$ & 76.7 & 73 & * & 344 & 5.50 & $K$ & 75.2 & 1 & * & $36 \%$ & 5.50 & K & 74.3 & $\varepsilon$ \\
\hline 100 & 5. 12 & $k$ & 7b. 2 & -39 & * & 345 & 5.52 & $k$ & 756 & 175 & * & 370 & 5.92 & $K$ & 74. 2 & -125 \\
\hline 321 & 5.13 & $k$ & 75.6 & 142 & $*$ & 346 & 5.53 & $k$ & 75.9 & -58 & 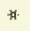 & 371 & 5.93 & $k$ & 74.1 & 38 \\
\hline 322 & $\therefore 15$ & $k$ & 75.6 & -101 & * & 847 & 5.5 & $k$ & 75. & 71 & * & $\because 72$ & 5.55 & $\mathrm{r}$ & 74. 2 & 157 \\
\hline$\because$ & 5. 16 & $k$ & 76.1 & 65 & * & 348 & 5.56 & $k$ & 75.0 & -114 & * & 573 & 5.96 & $K$ & 74.7 & -34 \\
\hline 24 & 5.18 & $K$ & 76.7 & -127 & * & 449 & 5. 58 & $k$ & 75.0 & 58 & $\#$ & $: 774$ & 5.95 & $F$ & 74. : & 151 \\
\hline
\end{tabular}




\section{SI--360 SFECTRUM ANAL YZEFi \\ IIATA SHEET \\ IDHACS TEST FACIL ITY \\ OCEAN BOUNTY}

FFIOUJECT: ELM NOISE PROJECT

DATA FILE: DEOSFZ2. EDA

CONFIGURATION COMMENTS: OCEAN BOUNTY

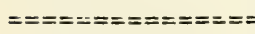

$$
\text { FUNCTION }=2-\text { FWI TRANSFORM } A(1024)
$$

INF'UT :

\begin{tabular}{|c|c|c|}
\hline $\begin{array}{l}\text { ATTENUATOFE: } \\
\qquad \begin{array}{c}A=23 \\
E=16\end{array}\end{array}$ & $\begin{array}{l}\text { FILTERS: } \\
\text { WTG = CN } \\
\text { ALIAS = DN } \\
\text { STOREFC = OFF }\end{array}$ & $\begin{array}{c}\text { AVEFAG ING: } \\
N=8 \\
\text { LIN }\end{array}$ \\
\hline $\begin{aligned} & \text { MEMEIRY HULD: } \text { H }=\text { OFF } \\
& E=\text { UFF } \\
& \text { OUT }=\text { OFF }\end{aligned}$ & $\begin{array}{l}\text { TFIANEIENT FACKAISE: } \\
\text { CAFTLIFE KNOE = ON } \\
\text { LEVEL INT/EXT = ON } \\
\text { AFM = OFF } \\
\text { IELAYE INT/EXT = DFF } \\
\mathrm{K} / Z=15\end{array}$ & $\begin{array}{l}\text { FFEQ }=400 \mathrm{~Hz} \\
\text { TFOFMS }=\text { MAX }\end{array}$ \\
\hline
\end{tabular}

OUTPUT:

DISFLAY:
MEMIO = OFF
$4 E$ AA
POLAR
COIF = OFF
SCALES:
$X=L I N$
$Y \perp=L O G$
$Y_{2}=\operatorname{LIN}$
$P=4$
$G=1$

PLOTTER:

POINT

DATA:

$\begin{array}{ll}\text { FORMAT }=L \text { OG } & \text { OdE EIN \# } \Rightarrow 312 \\ \text { BIN RANGE: } & 0 \text { TO } 1023\end{array}$

COMMENTS: 


\section{$\because D-\Xi S 0$ DATA}

'ROJECT: BLM NOISE PROJECT

LIATE: OCEAN EOUNTY

PAGE 2 OF 4

\begin{tabular}{|c|c|c|c|c|c|c|c|c|c|c|c|c|c|}
\hline F\# & FFIEQ & AMF'L. & $\mathrm{FH}$ & * & F’\# & FREQ & AMFL. & $\mathrm{FH}$ & * & F\# & FREQ & AMFL. & \\
\hline 0 & 00 & 127.7 & $\overline{0}$ & * & 50 & $40 . \overline{00}$ & 101.8 & 59 & * & 100 & 80.00 & $--\overline{3}$ & - \\
\hline 1 & 80 & 123.6 & -180 & * & 51 & 40.80 & 99.8 & -164 & * & 101 & 80.80 & 96.6 & 17 \\
\hline 2 & 1. 60 & 109.5 & 0 & * & 52 & 41.60 & 99.6 & -26 & $\not$ & 102 & 81.60 & 101.9 & 14 \\
\hline 3 & 2. 40 & 82. 4 & -71 & * & 53 & 42.40 & 100.3 & 155 & * & 103 & 82. 40 & 10.5 & -1 \\
\hline 4 & : 20 & 85. 4 & 136 & * & 54 & 43.20 & 98.0 & -21 & $\Rightarrow$ & 104 & $8 \approx 20$ & 11.4 & 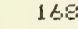 \\
\hline 5 & 4. 00 & 93.4 & -97 & \# & 55 & 44. 00 & 96.6 & -128 & * & 105 & 84. 00 & 06.5 & -- \\
\hline$E$. & 4. 20 & 100.3 & 73 & * & $5 t$ & 44. 80 & 97.5 & 42 & 4 & $10 t$ & 24. 80 & 01.8 & 12 \\
\hline 7 & 5.60 & 103.4 & -99 & * & 57 & 45.60 & 99.7 & -155 & r & 107 & 85.60 & 96.6 & \\
\hline $\mathrm{a}$ & t. 40 & 102.8 & 94 & \# & 50 & $4 t .40$ & 100.5 & $1 \%$ & * & 100 & 16. 4 & & \\
\hline 9 & 7. 20 & 100.0 & -43 & * & $5 \%$ & 47.20 & .2 & 174 & * & $10 \%$ & E7. 2 & 1 & -13 \\
\hline 10 & 0.00 & 99.7 & -114 & * & 8 & 00 & 3 & -6.1 & * & 110 & 80.0 & 2 & \\
\hline 11 & 8. 80 & 100.2 & 64 & * & 6. & 80 & & 101 & $*$ & 11 & 86. 8 & 8 & \\
\hline 12 & $\% .60$ & 100.6 & 147 & * & 8. & E. & & 105 & ") & 112 & 9.4 & $E$ & \\
\hline 13 & 10.40 & 101.1 & 57 & * & 6. & $50.4 r$ & 4 & 102 & * & 113 & 90 & 92.3 & -16 \\
\hline 14 & 11.20 & 107.1 & -92 & * & $\varepsilon$. & 51.20 & 3 & -7 & * & 114 & 91.2 & & 3 \\
\hline 15 & 12. 00 & 110.6 & 91 & * & 6 & 52.00 & & 174 & 4 & 115 & 92.0 & 1 & 12 \\
\hline 16 & 12. 50 & $10 t . ?$ & -93 & * & 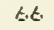 & 52.80 & 8 & -19 & * & 116 & 2. 8 & 92.2 & \\
\hline 17 & 13.60 & 100.3 & -88 & * & 6 & 5360 & & 133 & 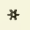 & & 3. 6 & & -8 \\
\hline $1 \varepsilon:$ & 14. 40 & 100.1 & $7 t$ & 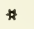 & & 7. 40 & 7 & -91 & $\not$ & 118 & 14. 4 & 3 & \\
\hline 17 & 20 & 101.1 & 108 & * & 6 & 55.20 & 4 & 12 & (4) & 9 & 5. 2 & 7 & 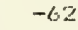 \\
\hline 20 & 16. & 3. 0 & -91 & * & 7 & 8.00 & 0 & 116 & 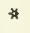 & 120 & 6. 0 & $b$ & -14 \\
\hline 2 & $\varepsilon$ & 8. 1 & 61 & * & & 80 & & -84 & * & 1 & $\varepsilon$ & 4 & \\
\hline & 1 & 2.2 & -170 & * & & $E$ & & 84 & * & 122 & . & & \\
\hline & 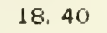 & 9 & -17 & * & & 4 & 2 & -1 & * & 123 & 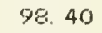 & & 20 \\
\hline 2 & 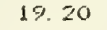 & 9 & -16.8 & * & & - & & 139 & \# & 124 & 2 & 1 & -2 \\
\hline 25 & 00 & 5 & -9 & * & & 0 & & 27 & * & 125 & ) & 6 & 1 \\
\hline $2 t$ & .80 & 3 & 56 & * & 7 & t.0. $\mathrm{El}$ & & $1 \leqslant 4$ & * & $12 t$ & 00.6 & .7 & -4 \\
\hline 27 & 21.60 & 8 & 176 & $\sharp$ & 7 & $B 1 . E C$ & 8 & 19 & 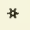 & 127 & 01.6 & .7 & 12 \\
\hline $2 E:$ & 22.40 & 5 & 137 & * & 7 & 62.40 & 9 & -140 & $x$ & $128:$ & 02.4 & 95.8 & -4 \\
\hline 25 & 23.20 & 106.1 & 20 & \# & 7 & 6.30 & .7 & 179 & 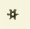 & 129 & 03.2 & 97.2 & \\
\hline 30 & 4. 00 & 105.1 & -158 & * & 8 & 64.00 & 2 & $E$ & * & 130 & 04.0 & 8 & - \\
\hline 3. & .80 & 8 & 1 & * & 8 & 64.80 & $t$ & 142 & it & 131 & 4. $\varepsilon$ & 2 & \\
\hline 3 & 60 & 8 & 163 & * & $\because$ & 6.5 .6 & 3 & 105 & * & 122 & aci. & .9 & \\
\hline 30 & 40 & .7 & -22 & * & $\varepsilon$ & $6 t .40$ & .6 & 11 & * & 123 & 16.4 & 6 & \\
\hline $3: 6$ & .20 & 8 & 128 & * & & 7.2 & 9 & 16.6. & H & 154 & 17 : & 5 & \\
\hline 35 & 0 & & 6 & * & & 0 & 1 & 18 & * & 135 & 80 & 7 & \\
\hline 3 & 280 & 8 & -172 & * & & er & 4 & 160 & $\approx$ & $\exists i$ & 6. & 5. & $1:$ \\
\hline 3 & 60 & 1 & 16 & H & & $6 \%, 60$ & 0 & 58 & * & 137 & G. 6 & 7. 3 & \\
\hline 38 & 30.40 & .0 & 157 & * & $\theta$ & 70.40 & 6 & 105 & $\not$ & 130 & 10.4 & 0. 1 & 13 \\
\hline 39 & 31.20 & .6 & 30 & H & & 71.20 & 2 & 68 & * & 159 & 111.2 & 6.5 & \\
\hline 40 & 32.00 & 6.7 & -16.5 & * & 9 & 72.00 & 1 & $: 23$ & * & 140 & 112 & 5.1 & -6 \\
\hline 41 & 32.80 & .9 & -1 & * & & 72.50 & 5 & 50 & * & 141 & 112. & $5 \leq 1$ & 1 \\
\hline 42 & 3560 & 7. 8 & -35 & * & $?$ & 73.60 & 0 & 44 & $\not$ & 142 & $11: t$ & 94.8 & \\
\hline 43 & 34.40 & 106.2 & 70 & * & 9 & 74. 40 & 0 & -121 & H & 143 & 114.4 & 95.2 & -6 \\
\hline 44 & $=20$ & 111.7 & 121 & * & $\%$ & 75.20 & s. & 94 & * & 144 & 1152 & 75.0 & 11 \\
\hline 45 & 36.00 & 4. 9 & 61 & * & 9 & 76.010 & 6 & -61 & 4 & 145 & 1160 & 93.1 & 12 \\
\hline $4 \leqslant$ & 3 t. $8: 0$ & 1. 5 & 115 & * & 9 & $7 t .80$ & 7 & $-1 t .4$ & \# & $14 t$ & $11 \mathrm{E}$ & 27 & -6 \\
\hline 47 & 37. 60 & 2. 6 & 62 & * & 9 & 77. 60 & & $4 \%$ & \# & 147 & 117.60 & 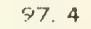 & \\
\hline 48 & zir: 40 & 100.1 & -143 & क & " & 76.40 & 5 & -6.4 & * & $14 i$ & 114 & 00.8 & -17 \\
\hline $4 \%$ & 37.20 & 100.9 & -17 & * & 95 & 79.20 & $5 \% 1$ & 143 & * & 149 & $11 \% .20$ & 102.8 & \\
\hline
\end{tabular}


'FOUJET: ELM NOISE PFI.JECT

\begin{tabular}{|c|c|c|c|c|c|c|c|c|c|c|c|c|c|}
\hline F'\# & FFiEG & AMF'L. & F'H & * & F”\# & FFIEQ & AMFL. & $\mathrm{F}^{\prime} \mathrm{H}$ & * & $F \#$ & FFIED & AMFL & FH' \\
\hline & 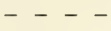 & - & - & * & & --- & -- & $-\quad-$ & , & & -- & - & -- \\
\hline 150 & 120.00 & 105.4 & $4 t$ & * & 200 & 160.00 & 73.6 & 173 & * & 250 & 200.00 & 95.9 & -109 \\
\hline 151 & 120.80 & 105.3 & -111 & * & 201 & 160.80 & 92.3 & -6 & * & 251 & 200.80 & 97.4 & -25 \\
\hline 152 & 121.60 & 98.4 & 123 & * & 202 & $1 \leqslant 1.60$ & 91.2 & $5 \%$ & $\not$ & 252 & 201.60 & 97.9 & 124 \\
\hline 153 & 122.40 & 93.9 & -35 & * & 203 & 162.40 & 92.3 & -118 & * & 253 & 202.40 & 96.2 & -106 \\
\hline 154 & $12 \% 20$ & 94.4 & 89 & * & 204 & 163.20 & 22.1 & 110 & * & 254 & 203.20 & 96.2 & -134 \\
\hline 155 & 124.00 & 96.5 & -144 & * & 205 & 164.00 & 93.3 & -47 & * & 255 & 204.00 & 99.0 & 48 \\
\hline 156 & 124.80 & ge. 0 & 22 & * & 206 & 164.80 & 95.7 & 156 & * & 256 & 204.80 & 98.8 & -85 \\
\hline 57 & 125.60 & 93.3 & -157 & * & 207 & 165.60 & 97.9 & -2 & * & 257 & 205.60 & 96.5 & -174 \\
\hline$E$ & $12 \varepsilon .40$ & 93.4 & 54 & * & 205 & $1 t t=40$ & 97.1 & $1 \leqslant 5$ & $\#$ & 258 & 206.40 & 95.4 & 44 \\
\hline 50 & 127. 20 & 94.5 & -71 & * & 209 & 167.20 & 96.9 & 1 & * & $25 \%$ & 207.20 & 95.3 & -36 \\
\hline 60 & $12 \varepsilon_{i} 00$ & 95.8. & -152 & * & 210 & $18 \mathrm{e} .00$ & 100.9 & -151 & $*$ & 260 & 208.00 & 93.7 & -147 \\
\hline 61 & 128. 80 & 96.7 & -42 & * & 211 & 168.80 & 101.0 & 30 & * & 261 & 208.80 & 92.6 & -91 \\
\hline 162 & 129.60 & 99.6 & 116 & * & 212 & 169.60 & 96. 3 & $-2 t$ & * & 262 & 209.60 & 3. 9 & 105 \\
\hline 163 & 130.40 & 100.2 & -68 & $*$ & 213 & 170.40 & 93.7 & $-1 \leqslant 0$ & * & 263 & 210.40 & 9.7 & -28 \\
\hline $1 \in 4$ & 131.20 & 99.7 & 42 & * & 214 & 171.20 & 93.5 & 78 & * & 264 & 211.20 & 78. 1 & -163 \\
\hline 165 & 132.00 & 102.9 & 170 & * & 215 & 172.00 & 94.5 & 30 & \# & 265 & 212.00 & 102.3 & 107 \\
\hline $1 t=0$ & 132.90 & 102.1 & -22 & * & 216 & 172.00 & 95.0 & -109 & * & $2 t 6$ & 212.60 & 04.? & -77 \\
\hline 167 & 133.60 & 6.8 & 120 & * & 217 & 173.60 & 93.8 & 110 & * & 267 & 213.60 & 104.1 & 95 \\
\hline $1 E: E$ & 134.40 & 93.0 & -152 & \# & 210 & 174.40 & 93.2 & -11 & अ & 268 & 214.40 & 00.7 & -30 \\
\hline 169 & 135. 20 & 94.0 & 46 & * & 219 & 175.20 & 96.6 & $-1 \leqslant 8$ & \# & 269 & 215.20 & 100.5 & 146 \\
\hline 70 & 136.00 & 94.2 & 5,4 & * & 220 & $17 t .00$ & 103.2 & 10 & $\sharp$ & 270 & $21 \leqslant .00$ & 104.2 & -105 \\
\hline 71 & 136.50 & 936 & 129 & \# & 221 & 176.80 & 10. 1 & 127 & * & 271 & 216.80 & 105,0 & 66 \\
\hline 72 & 137.60 & 55. & $4 \%$ & $\#$ & 222 & 177.60 & 12. 9 & -70 & $\not H$ & 272 & 217.60 & 101.3 & -62 \\
\hline 73 & 138.40 & 76.0 & -131 & * & 223 & 178.40 & 9.7 & 117 & * & 273 & 210.40 & 5.7 & 108 \\
\hline 74 & 139.20 & at. 1 & 6 & \# & -24 & 179.20 & 106.0 & -13 & * & 274 & 219.20 & 94.2 & -116 \\
\hline 75 & 140.00 & 96.2 & $1 \%$ & $*$ & 225 & 180.00 & 111.6 & -176 & * & 275 & 220.00 & 73.5 & 56 \\
\hline 176 & 140.50 & 103.9 & -179 & * & 226 & 150.60 & 0.7 & -10 & * & 276. & 220.80 & 5.4 & $-11 \varepsilon$ \\
\hline 77 & 141.60 & $10 \% .7$ & -67 & * & 227 & 181.60 & 105.7 & 114 & $*$ & 277 & 221.60 & 94.2 & 53 \\
\hline 178 & 142.40 & $10 \% ?$ & 27 & \# & 28 & $1 B 2.40$ & 90.9 & -111 & * & 276 & 222.40 & 72.5 & -146 \\
\hline 79 & 143. 20 & 107.7 & -21 & * & 229 & 163.20 & 94.7 & 110 & * & 279 & 223.20 & 94.7 & -6 \\
\hline 150 & 144.00 & 111.9 & -143 & * & 230 & 104.00 & 9.7 & -86 & * & 280 & 224.00 & 96.6 & 156 \\
\hline 81 & 144. $: 0$ & $11=2$ & 55 & * & 231 & 184.80 & 926 & 60 & $*$ & 281 & 224.80 & 96.8 & -21 \\
\hline 182 & 145.60 & 106.4 & -90 & * & $2: 2$ & 105.60 & 93.3 & 16.6 & * & 202 & 225.6 .0 & 95.8 & -67 \\
\hline 83 & 146.40 & 97.6 & 121 & * & 255 & 166.40 & 94.5 & $-1 \%$ & $*$ & 283 & 226.40 & 94.4 & 130 \\
\hline 64 & 147.20 & $74 . \leqslant$ & -32 & * & 234 & 187.20 & 94.9 & $16 \%$ & $*$ & 2844 & 227.20 & 93.4 & $1 \%$ \\
\hline 85 & 148.00 & 99.7 & -69 & * & 235 & 185.00 & 94.4 & -59 & * & 265 & 22800 & 97.3 & -97 \\
\hline $1 E$ is & 148.80 & 101.2 & 156 & * & $2: 6$. & 158.50 & 93.7 & 97 & $*$ & 286 & 220.80 & 99.0 & -43 \\
\hline 157 & $14 \% .60$ & 97.1 & 7 & \# & 2.57 & 15960 & 3.9 & 71 & $*$ & 287 & 229.60 & 66.0 & 134 \\
\hline 100 & 150.40 & 935 & .02 & \# & $28=$ & 190.40 & 93.4 & 96 & \# & 208 & 230.40 & 74. 3 & -116 \\
\hline $16 \%$ & 151.20 & 225 & 102 & \# & 239 & 191.20 & 93.2 & -88 & * & $28 \%$ & 231.20 & 932 & 58 \\
\hline 100 & 152.00 & 93.2 & 15 & * & 240 & $1 \geqslant 2.00$ & 5. & 103 & $*$ & 200 & 232.00 & 92.5 & -112 \\
\hline 171 & 152.60 & 87.2 & $13 \%$ & * & 241 & $1 \% 2.80$ & 95.3 & -67 & * & $2 \% 1$ & 232.20 & 94.4 & -16 \\
\hline 152 & $15 \%, 60$ & 799 & 41 & म & 242 & 190.60 & 34.7 & 110 & $*$ & 202 & 280.60 & 93.5 & 139 \\
\hline 195 & $154 \quad 40$ & $98 \%$ & -124 & * & 243 & 194.40 & 96.8 & -5.5 & * & 293 & $2 \approx 4.40$ & 9. 1 & -100 \\
\hline 194 & 155.20 & 78.7 & $\leq . \leq$ & H & 244 & 195.20 & 75.9 & 86 & * & 204 & 235.20 & $\theta \leq .1$ & 69 \\
\hline 195 & $15 \% 00$ & 1018 & -132 & \# & 245 & 19000 & 94.0 & -110 & * & 205 & 23600 & 96.0 & -91 \\
\hline 196 & 1 Ete. 00 & 1005 & -22 & * & 246 & $1 \% 2.80$ & 92.8 & 116 & $\#$ & 201 & 236.80 & 95 & 107 \\
\hline 177 & $15.7,8.6$ & 08 & 171 & * & 247 & 197.6 .0 & $\because 27$ & $-5 \%$ & * & 2.77 & 257.50 & 28 & -63 \\
\hline 10 & 1 5izi 40 & 96.9 & 59 & $\Rightarrow$ & $24:$ & 10040 & $5 ;$ & 44 & * & 24 & 230.40 & 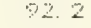 & 78 \\
\hline 150 & $15 \%$ & 1.5 1 & 5 & \# & $24 \Rightarrow$ & $1 \% 20$ & $\because$ & 150 & 4 & $2+4$ & 2820 & 92.4 & -1.69 \\
\hline
\end{tabular}




\section{$: \Xi:$ II-:E.O IIATA}

'ROJECT: BLM NOISE PRDJECT

DATE: OCEAN EOUNTY

PAGE 4 OF 4

\begin{tabular}{|c|c|c|c|c|c|c|c|c|c|c|c|c|c|}
\hline F'\# & FFIEQ & AMF:L. & $F H$ & $*$ & FH & FKEQ & AMFL. & $F^{\prime} H$ & \# & $\mathrm{PH}$ & FREO & AMF'L. & \\
\hline & - & - & & * & & -- & 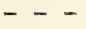 & - & \# & - & --- & - & \\
\hline 00 & 240.00 & 96.3 & 6.9 & * & 325 & 260.00 & 94.6 & 176 & * & 350 & 290.00 & 92.7 & \\
\hline 01 & 40.80 & 98.7 & -92 & \# & 326 & so. 80 & 93.5 & -1 & * & 351 & 280.80 & 92.8 & \\
\hline 02 & 41.60 & 96.6 & 105 & * & 327 & 61.60 & 92.7 & 145 & \# & 352 & 21. 60 & 3. 2 & \\
\hline 03 & 42. 40 & 94.9 & -58 & * & 328 & 62.40 & 92.1 & & 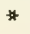 & 353 & 82. 4 & 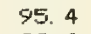 & \\
\hline 04 & 43. 20 & 93.4 & 94 & * & 329 & 63.2 & e. 8 & 105 & * & 354 & 283. & 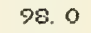 & -13 \\
\hline 05 & 44. 00 & 92.9 & 111 & * & 330 & 64. & 6.5 & 67 & s & 355 & 284. & & \\
\hline 05 & 44. 80 & 93.9 & 74 & * & 331 & 64. & 96.2 & 117 & * & $35 t$ & 284. & 7. 6 & 10 \\
\hline 07 & 45.60 & 94.4 & -61 & \# & 332 & 265 & 94.0 & 38 & * & 357 & 285.60 & 8 & \\
\hline 08 & 246.40 & 97.1 & $14 \%$ & \# & 333 & 266.4 & 92.7 & -167 & \# & 358 & 25.40 & 5 & \\
\hline 09 & 47. 20 & 101.3 & -44 & $\#$ & 334 & 67.20 & 93.0 & 4 & $\star$ & 359 & 287.20 & 96.7 & $-\varepsilon$ \\
\hline 110 & 248.00 & 104.0 & 98 & 4 & 335 & 268.00 & 93.5 & 151 & * & 350 & 200.00 & 98.6 & \\
\hline 11 & 248.80 & 103.8 & -93 & \# & 336 & 268.80 & 93.0 & 71 & \# & 361 & 288.80 & 100.5 & -11 \\
\hline 12 & $24 \% 6.0$ & 100.5 & 91 & * & 337 & 26.9 .60 & 92.4 & 111 & \# & 362 & $28 \% 60$ & 9.0 & -1 \\
\hline 13 & 250.40 & 99.0 & 133 & * & 338 & 270.40 & 92.1 & 65 & * & 363 & 290.4 & 94.7 & \\
\hline 14 & 51.20 & 102.3 & 44 & $\not$ & 389 & 271.2 & 96.1 & -100 & * & $\because 64$ & 291.2 & 2. 1 & \\
\hline 5 & 252. 60 & 106.8 & 145 & * & 340 & 272.0 & 99.0 & 8 & \# & 365 & 292. & . & -6 \\
\hline 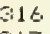 & 252.80 & $t$. & -12 & * & 341 & 272 & 5 & 10 & * & $3 t 6$ & 292. & & \\
\hline 7 & 253.60 & 6 & 8 & * & 342 & 273 & & & * & 367 & 293. & & $-1:$ \\
\hline : & 254.40 & $\varepsilon$ & -84 & * & 34 & 274. & & 15 & \# & 366 & 294. & & 10 \\
\hline 19 & 255.2 & 97.1 & 20 & $*$ & 344 & 275. & 93.3 & 4 & $\sharp$ & 369 & 295. & & \\
\hline 320 & 256.00 & 53.1 & $14 \%$ & $*$ & 345 & 276.00 & 93.3 & -147 & \# & 570 & 2916.00 & 1.0 & -12 \\
\hline 21 & 256.80 & 89.8 & 32 & * & 346 & 276.80 & 93.5 & 2 & \# & 371 & 296.80 & 90.2 & \\
\hline 322 & 257.60 & 89.7 & $-1: 4$ & \# & 347 & 277.60 & 92.8 & $1 t 6$ & \# & 372 & 297.60 & 59.2 & 8 \\
\hline 23 & 258. 40 & 89.8 & 111 & * & 348 & 278.40 & 92.4 & 27 & * & 373 & 298.40 & 89.6 & $-:$ \\
\hline 24 & $25 \% .20$ & 92. 5 & -17 & * & 549 & 279.20 & 92.2 & -119 & \# & 374 & $29 \% 20$ & 92.2 & \\
\hline
\end{tabular}

EOMMENTS

WITNESSES 
APPENDIX $F$ 
Underwater Noise Measured at Fourteen 011

Platforms off Santa Barbara, California

1 August 1981

Prepared for:

Dr. Elek Lindner, Code 5131

Naval Ocean Systems Center

San Diego, California 92152

Prepared by:

Robert S. Gales

Computer Sciences Corporation

4045 Hancock Street

San Diego, California 92110

Contract N00123-79-D-0272

Delivery Order No. 7N17 
Underwater Noise Measured at Fourteen

0il Platforms Off Santa Barbara, California

R. S. Gales

\section{INTRODUCTION}

This report is a brief summary of data from a series of measurements of underwater noise in the vicinity of fourteen oil and gas platforms engaged in offshore drilling and/or oil and gas production in the general area of Santa Barbara, California. This is an interim summary report on the field-data recording portions of the Bureau of Land Management Task: "Study of the Effects of Sound on Marine Mammals." This work was conducted under Naval Ocean Systems Center Project MM28, BLM Project AA851-1A0-5.

The scheduling of the measurement activity during Janury 1981 was selected specifically to coincide with the southward migration of the gray whales through the Santa Barbara offshore waters. During the time of the noise measurements, extensive observations were being made on the specific migration routes of the whales between Point Conception and Santa Barbara. These observations were being conducted by the Santa Barbara Museum of Natural History under contract in connection with BLM-sponsored studies of effects of oil concentration on animal behavior. It was hypothesized that oil seeps known to exist in the Santa Barbara area might influence the migratory behavior of the whales. Similarily, the possibility that noise from the extensive offshore drilling and production might also affect the whales made it important to gather noise data in the same general area. The noise data have not yet at this writing been related to the migratory behavior in any detailed fashion. 


\section{OBJECTIVE}

The overall objective of the Project is to assess the impact of underwater noise created by offshore oil drilling and production operations on marine mammals along the outer continental shelf of the U.S. and propose mitigating measures if necessary.

The measurements described in this report were directed at three goals:

(1) To broaden the data base on underwater noise radiated by offshore oil operations by gathering data on a large number of drilling and production platforms.

(2) To determine the general geographic distribution of underwater noise in the area off Santa Barbara, California, to provide data which might be correlated with the migration pattern of the California Gray whales which traverse this area.

(3) To determine the variability with time over a period of five days for a platform engaged in offshore drilling.

\section{APPROACH}

(1) Magnetic tape recordings were made of the underwater noise near each of fourteen platforms using a hydrophone-pre amplifier-filterrecorder package especially designed for broad frequency range, high sensitivity and low noise. This system is the one used in all field surveys conducted on this project since June 1980. Recordings were analyzed for spectrum content in the NOSC Intelligent Data Handling and Control System (IDHACS) facility. Both the recording system and the IDHACS facility are described in Ref. 1. 
(2) A continuous graphic record was obtained on one platform over a period of five days. This was accomplished by suspending a hydrophone to a depth of 30 feet below the oil platform and coupling the hydrophone output into a sound level meter with an ink-writing chart recorder.

\section{RESULTS}

The results of the underwater noise measurements in the Santa Barbara area are presented in two sections. The first will deal with the spectrum analyses of the noise from each of the fourteen platforms and will describe the location and operating characteristics of each. The second section will present the results of the five-day continous graphic record for a single platform.

\section{Spectrum Data}

A listing of the fourteen platforms, with an abbreviated code designation for each, is given in Table 1. The table lists the type of platform, its activity (drilling and/or production) at the time of the data recording, the prime power source, water depth, and a general noise rating to give a qualitative rating of quiet vs noisy rigs. The locations of the platforms are shown in Figures 1, 2, and 3 which are taken from hydrographic charts showing shoreline, water depth contours, and miscellaneous information, such as pipeline locations. Figure 4 is a chart showing the locations of the areas covered by figures 1,2 , and 3 (outlined in red). This chart shows the geographic relationship to Santa Barbara, its offshore islands, the 
general coastal configuration, and the coastwise shipping lanes. Platforms Hondo and Rincon, the most westerly and easterly of the platforms measured, are shown as blue circles.

The magnetic tape recordings of the underwater noise at the platforms were made on January 19, 20 and 28, 1981. Large swells of height approximately 5 to $10 \mathrm{ft}$ and period about 12 seconds were present from a storm offshore to the west. The wind varied from about 5 to 10 knots at Platforms Hondo, Holly, and Rincon to 15 to 20 knots for the remainder.

Recordings were made from several boats, each drifting freely with all motors secured. The boats were approximately 45 to 80 feet 1ong. The hydrophone was lowered overside to a depth of 100 feet for measurements reported herein. At times rolling motion of the recording boat generated interfering noise. Tape sections used for analysis were carefully selected to reject portions in which the self noise of the recording boat was noticeable.

Each tape sample was recorded on two channels. The FM channel recorded from 0 to $2500 \mathrm{~Hz}$ and the direct channel from 100 to $30000 \mathrm{~Hz}$. The analysis was performed on the NOSC IDHACS facility, which utilizes a Spectral Dynamics S.D. 360 to provide analysis of the FM channel from 1 to $300 \mathrm{~Hz}$ with an analysis bandwidth of $0.8 \mathrm{~Hz}$, and the direct channel from 100 to $6000 \mathrm{~Hz}$ with an analysis bandwidth of $16 \mathrm{~Hz}$. Data outputs were in the form of digital printouts, and spectrum plots in analog graphic form. Data from the latter were transcribed manually to spectrum plots of sound pressure spectrum level 
vs frequency. These plots are overlaid on standard ambient noise curves to show the relationship of the measured noise to expected naturai ambient sea noise. Such plots for each of the fourteen platforms are shown in Figures 5 through 9. They show tonal components (also called spectrum lines) as vertical lines with a dot at the top showing the sound pressure level of that component. In general, line components are produced by a repetitive mechanical process of very stable cyclic repetition rate, such as a rotating machine (engine, electric motor, turbine, pump, etc.). All platforms show such lines, as might be expected from their extensive use of rotating machinery. Also on each plot is a dashed curve showing the spectrum level (level in a one-hertz-wide band) of the continuous spectrum portion of the noise. A continuous spectrum is generated by a series of non-cyclic, or random events. Such noise generally covers a broad band of frequencies; hence, it is often called broad-band noise. The norma? ambient noise in the sea is generated by breaking waves and is dependent on sea state, and therefore wind speed. The spectra of such natural broadband noises for each of four selected sea-state conditions are plotted on each graph to serve as a reference to natural sea noise which is familiar to animais. Also shown are curves of the continuous spectrum noise (at lower frequencies) generated by the cavitating propellors of ships. The level of such noise depends on the number of cavitating ships in the general vicinity (shipping density). Note that the three curves are labeled heavy, moderate, and light. It is likely that the area off Santa Barbara would be characterized as "heavy" shipping. The two sets of ambient noise curves (sea state, and shipping) are widely used in underwater acoustics for prediction of oceanic noise (Ref. 2). 
A method for evaluating the noise of a platform is presented in which the highest of the ambient noise curves shown in Figs. 5-9 is used as reference norm for natural noise. The number of decibels by which the platform noise exceeds this reference is readily observable from the graphs. The maximum value of this was determined in each of three frequency regions, rather arbitrarily selected to cover the frequency range from 5 to $5000 \mathrm{~Hz}$ which encompasses the main noise of the platforms. The three frequency regions are: (1) $0-30 \mathrm{~Hz}$, (2) 30 to $300 \mathrm{~Hz}$, and (3) above $300 \mathrm{~Hz}$. The value of the maximum excess in each of these frequency regions is tabulated for each platform in Table I. Their values in decibels vary from a maximum of 45 decibels in the under $30 \mathrm{~Hz}$ band for platform $A$ to zero for platform Rincon. The right hand column of Table I gives a noise rating derived by rating the noise excess of each of the three frequency regions separately as follows: an excess of over 40 is designated: $N$, for noisy; 30 to 40: $M$ for moderate and under $30 \mathrm{Q}$, for quiet. The three ratings are combined to derive a total rating of Noisy, Moderate, Quiet, or Very Quiet. Note that only one platform, the man-made Rincon Island, rates a $Q$ in each frequency region, and so is rated very quiet. This is probably the result of its being supplied by shore power, so it does not need a local generator of prime power, and vibration from machinery on the island does not propagate effectively through the island material and does not radiate efficiently into the surrounding shallow water. The two platforms rated "noisy" have no obvious common relationship. Platform $C$ is a production platform driven by shore-generated power, so it might have been expected to be quiet. Its noisy rating results from relatively high-level spectrum lines in all. three frequency regions, especially those 
below 300 hertz. Platform Henry, also rated noisy, similarly was rated noisy in the two lower bands. It was engaged in drilling and production, and generated its own prime power with a gas turbine, so it might be expected to be noisy. A rise in the broad band spectrum in the frequency region above $2000 \mathrm{~Hz}$ was observed for some platforms, including man-made Rincon Island. It may be hypothesized that this is due to breaking waves, or surf-like noise which was prominent at some rigs, including Rincon Island. Because of the high swells, there was a great deal of water splashing and run-off from various structural members of the platforms, and from auxiliary boat landing aids, such as rubber tires, etc. This is visible in the photograph of Platform Houchin (Fig. 10). It may be noted that the broad-band spectra for the various platforms in general were shaped approximately like the sea-state spectrum curves, which are related to breaking waves at the sea surface. The variability in shape and level of the continuous spectrum portion for the various platforms might be expected, based on specific structural differences in those areas washed by the passing swells.

\section{Variation of Underwater Sound Level With Time}

A continuous chart record of the sound pressure level of the noise at Platform Hondo was made for five days starting at approximately 1000 hours on Monday, 19 January 1981. The termination of the data was inadvertently caused by a gradual loss of marking density by the recording pen. Although the trace began to fade at 1500 hours on Thursday, 22 January, it remained slightly visible through 24 January. 
The pen traced the overall sound pressure level in a wide frequency band. The band was determined by the "C" weighting on the sound level meter which has its -3 decibel roll-off points at 30 and $8000 \mathrm{~Hz}$. This indicates that the two spectral lines at 4 and 28 hertz (Fig. 4, Hondo) were out of the pass band, so that the overall level was principally made up of the components clustered between 70 and $280 \mathrm{~Hz}$, and those at 3.4 and $4.3 \mathrm{KHz}$, plus the broad band noise component which is estimated to have an overall level comparable to, or perhaps exceeding that of the spectrum Tines above $30 \mathrm{~Hz}$.

In general, the overall level was quite stable, except when a work boat, or personnel boat was in the near vicinity. It was quite apparent that the noise of these boats was dominant, particularly when their propellers were cavitating, as when maneuvering and when at cruising speed or above. Figure 11 shows a work boat alongside Platform Hope during drilling operations. Note that Hope and Heidi (in background) each have two large cylindrical legs.

Data presented will show the variability of the overall sound level at the hydrophone location below the west edge of the platform at a depth of 30 feet, and will relate the level to local activity. For reference purposes a value of 100 decibels is assigned to the minimum overall sound pressure level which was observed at midnight (2400 hours) on Wednesday, 21 January, at which time the wind and sea were probably relatively calm. At this time, and during other relatively quiet periods the level varied over about a four decibel range, rising repeatedly to maxima of about 104 to $105 \mathrm{~dB}$, and falling to minima of about 100 to $101 \mathrm{~dB}$. On one occasion, at approximately 0720 hours on Friday, 23 January the level rose to $114 \mathrm{~dB}$, with 
maxima of 117, and remained at this fairly stably until about 1400 hours, at which time the level returned to $102 \mathrm{~dB}$ with maxima of 104 . The ink trace at this point was very faint so details of the level variation during this period are not observable. The absence of an accurate time reference after Thursday, 22 January makes it impossible to state the times with much accuracy. The times are all estimated on the basis of the time mark at the start of the run on Monday, 19 January and the assumption that the nominal chart speed of $10 \mathrm{~cm}$ per hour was accurate.

The major noise increases were related to work boat activity nearby. The "Brazos Sea Horse", a 200 foot work boat, raised the level to about 115-116 dB with a maximum of 119. While it was maneuvering nearby it raised the level to $123 \mathrm{~dB}$ with a brief peak at $132 \mathrm{~dB}$. The "Tiger-Shark," an 80 foot boat with twin engines, produced levels of $120-130 \mathrm{~dB}$ with a maximum of 132 while maneuvering nearby. A somewhat similar vessel, the "Tap Tide," produced Tevels of 110-130 dB, also with a $132 \mathrm{~dB}$ maximum while it was maneuvering near the platform.

From the above, rather limited data, it would appear that the sounds of the drilling operations from platform Hondo are relatively stable, but that substantial increases in local noise occur during the times of arrival, departure and maneuvering of support boats. 


\section{References}

1. NOSC, Summary Report of 30 September 1980 on BLM Task: Study of the Effects of Sound on Marine Mammals".

2. Urick, Robert J. Principles of Underwater Sound, McGraw-Hill Book Co., New York, 1975. 


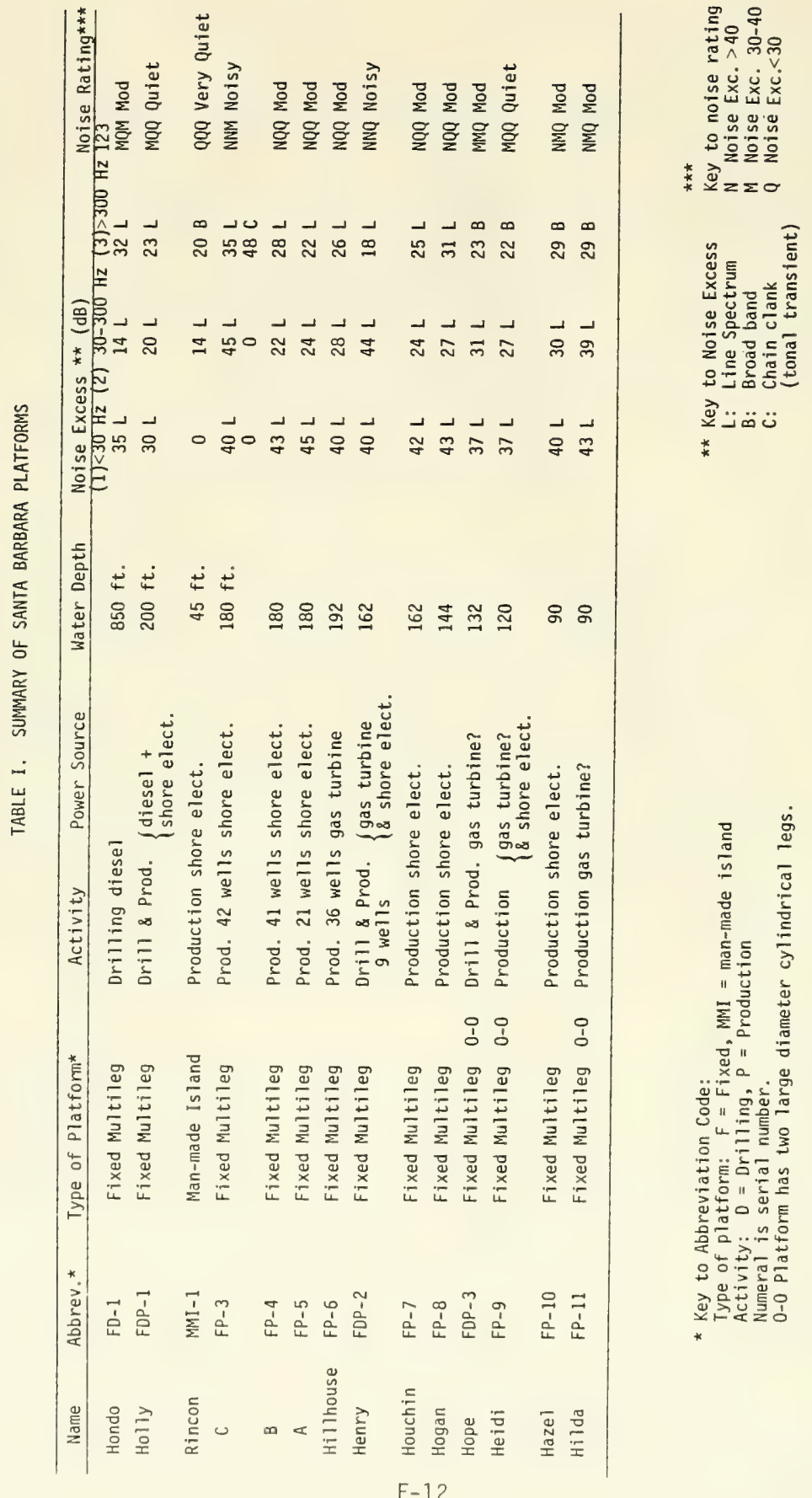




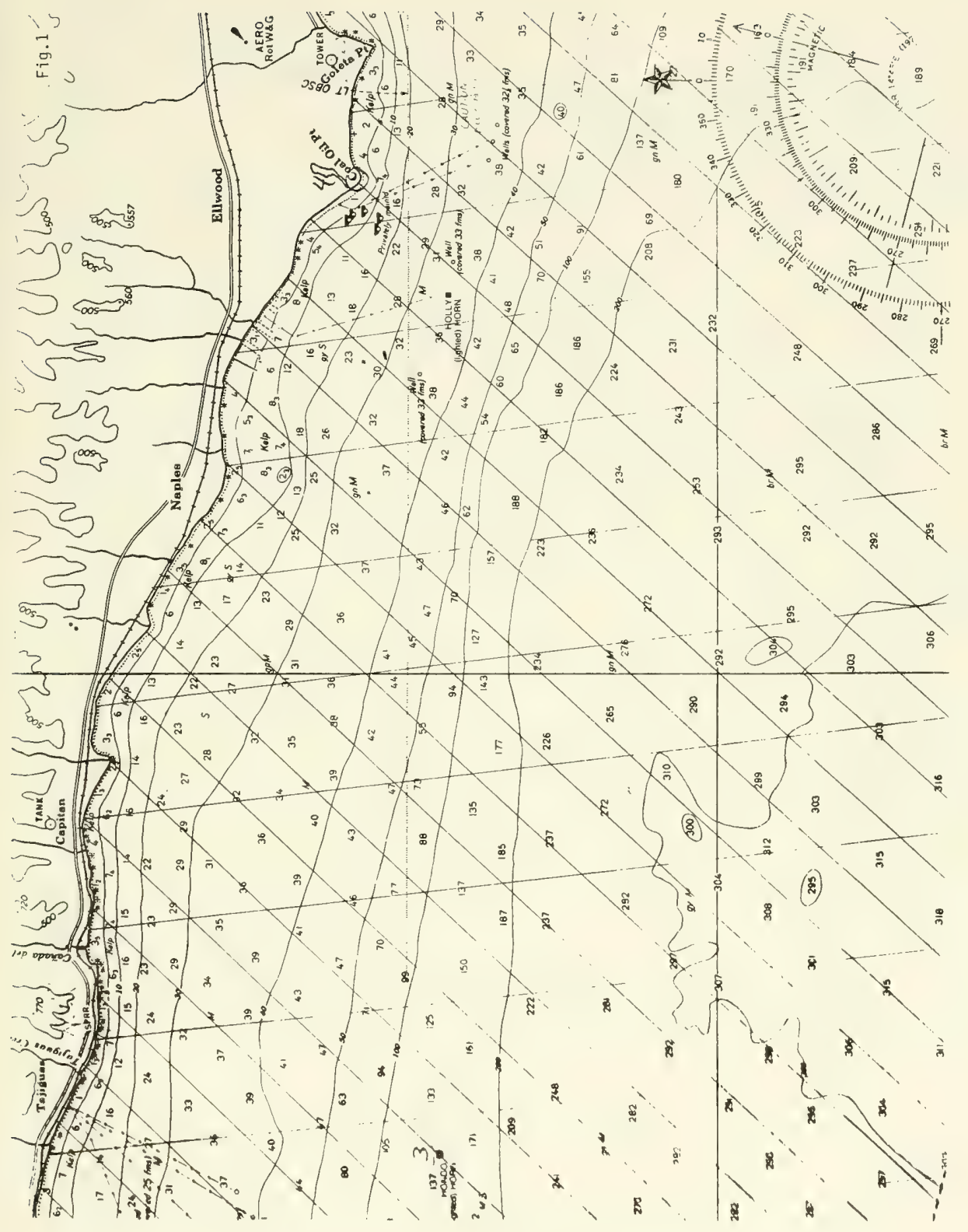




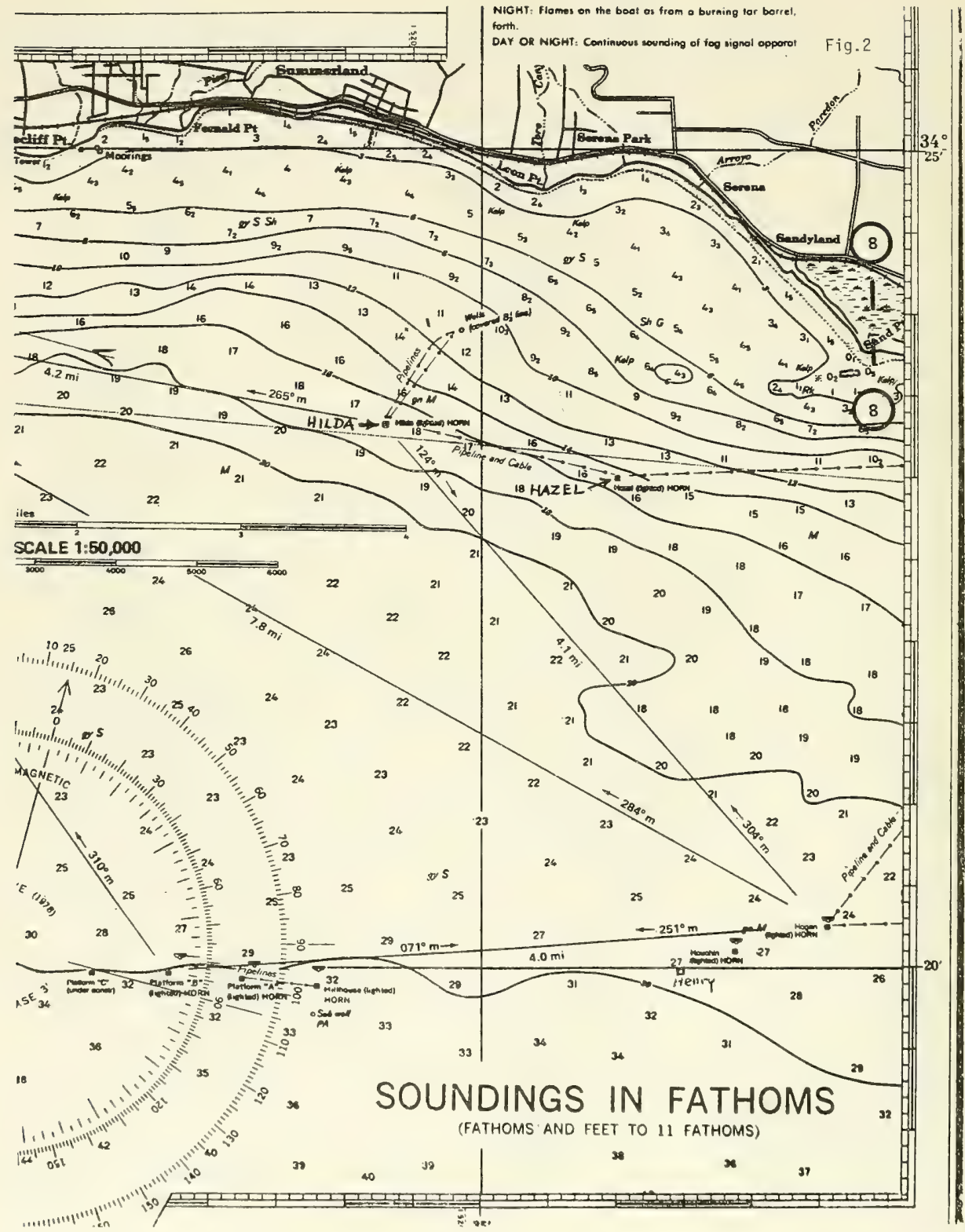




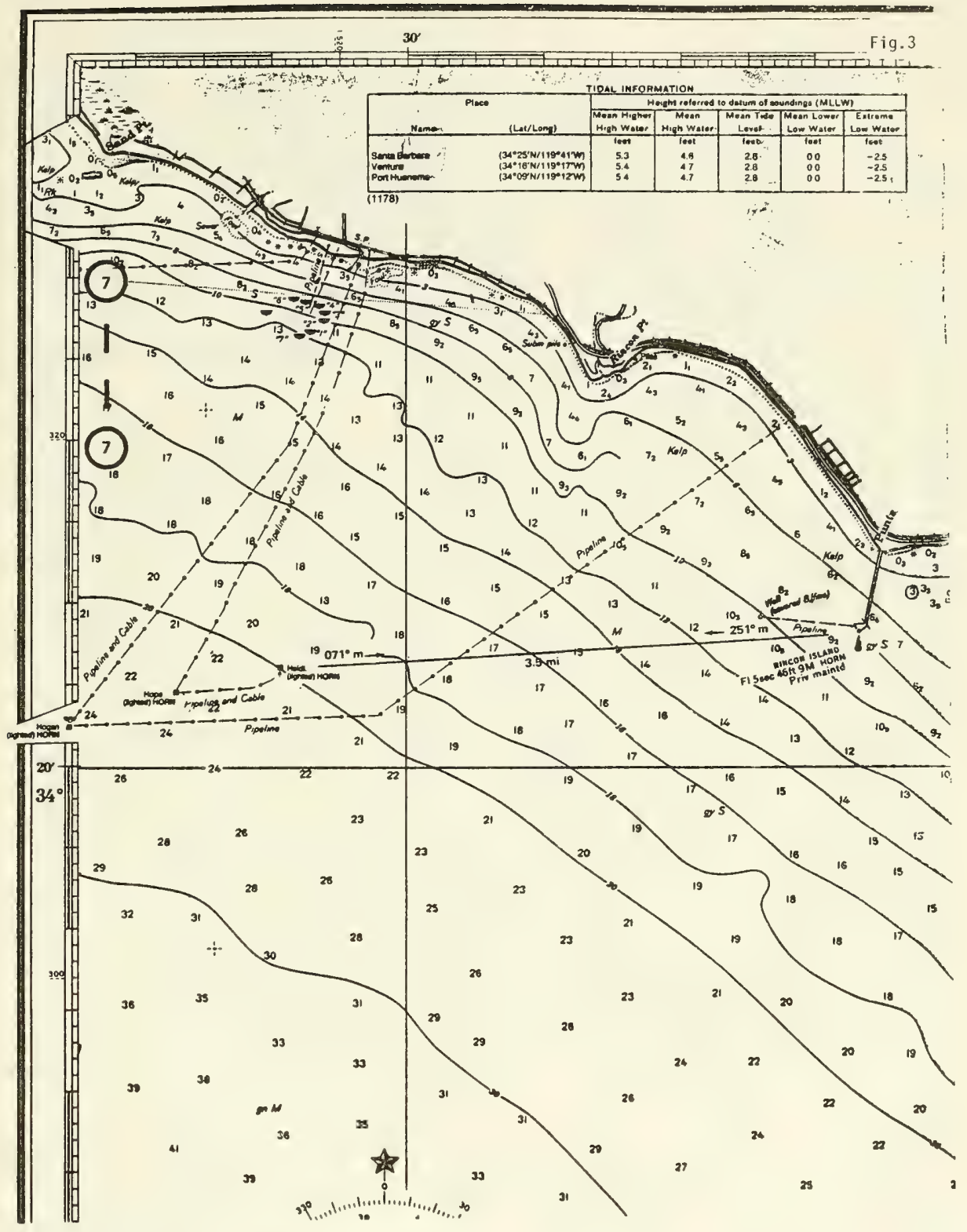




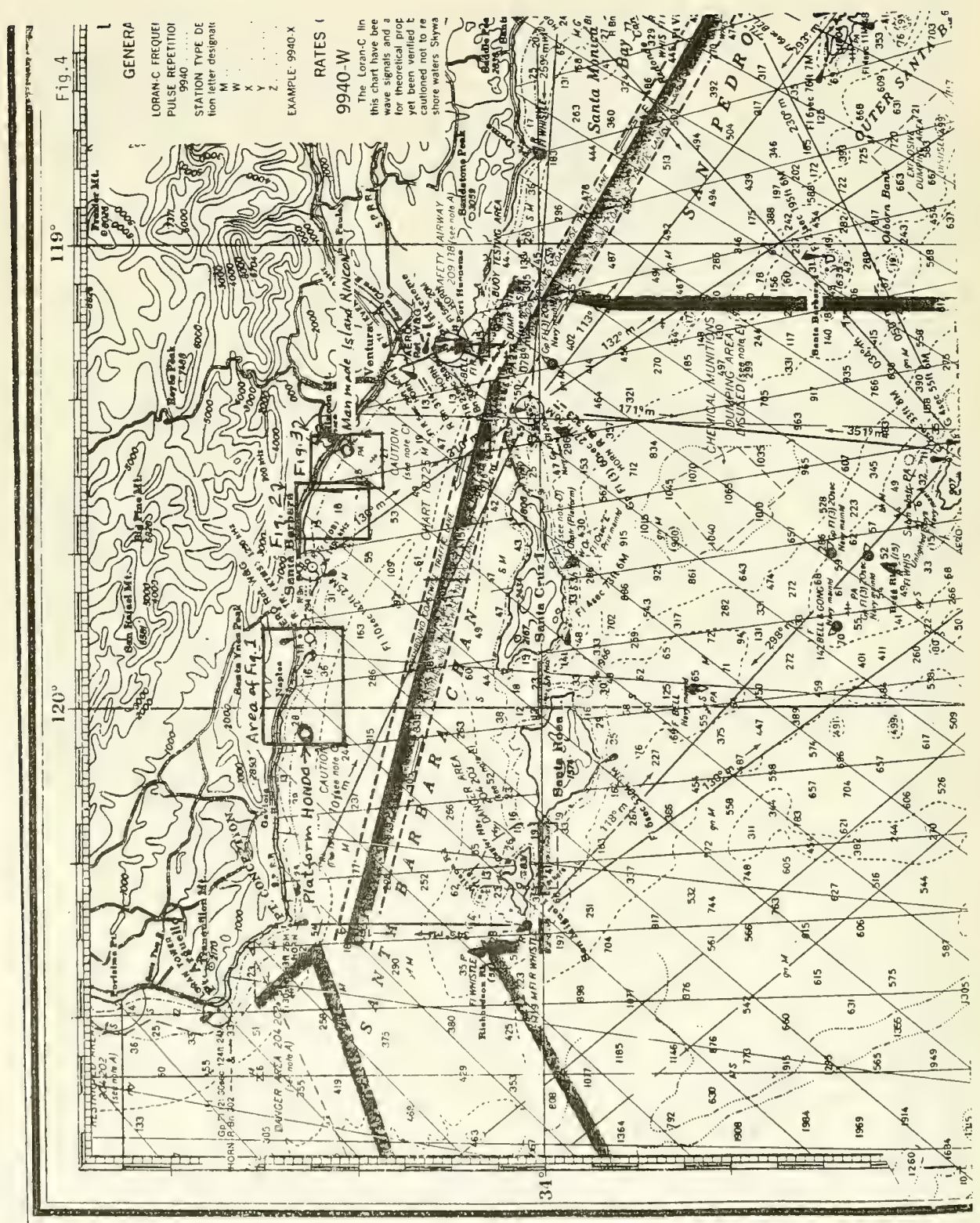



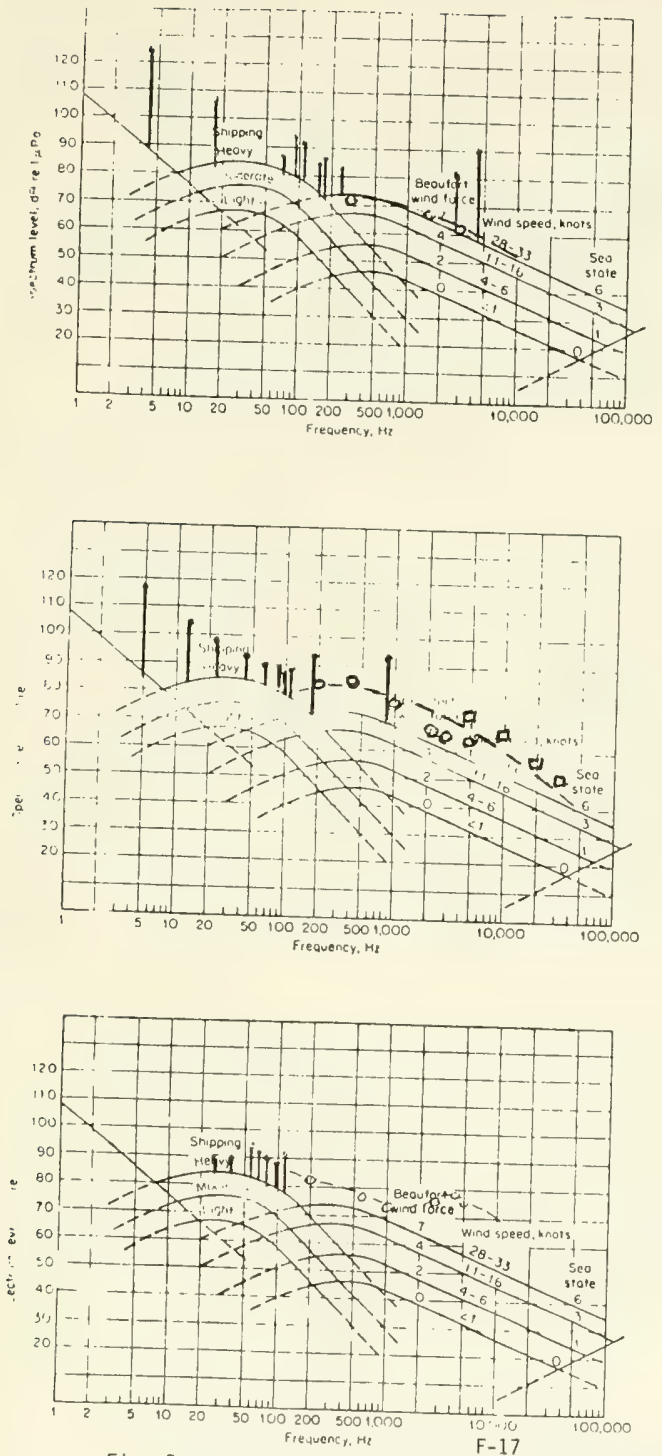

Fig. 5 Spectra of underwater noise of platforms Hondo, Holly and Rincon superimposed on average deep water ambient noise spectra
HONDO

Water Depth: $850 \mathrm{ft}$.

Hydrophone Depth: $100 \mathrm{ft}$.

Distance: Average $50,100,200 \mathrm{ft}$.

i Tonal (Spectrum line)

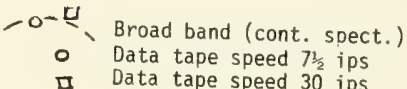

HOLLY

Water Depth: $210 \mathrm{ft}$.

Hydrophone Depth: $100 \mathrm{ft}$.

Distance: $100 \mathrm{ft}$.

\section{RINCON}

Water Depth: $30 \mathrm{ft}$

Hydrophone Depth: $20 \mathrm{ft}$

Distance: $110 \mathrm{ft}$. 

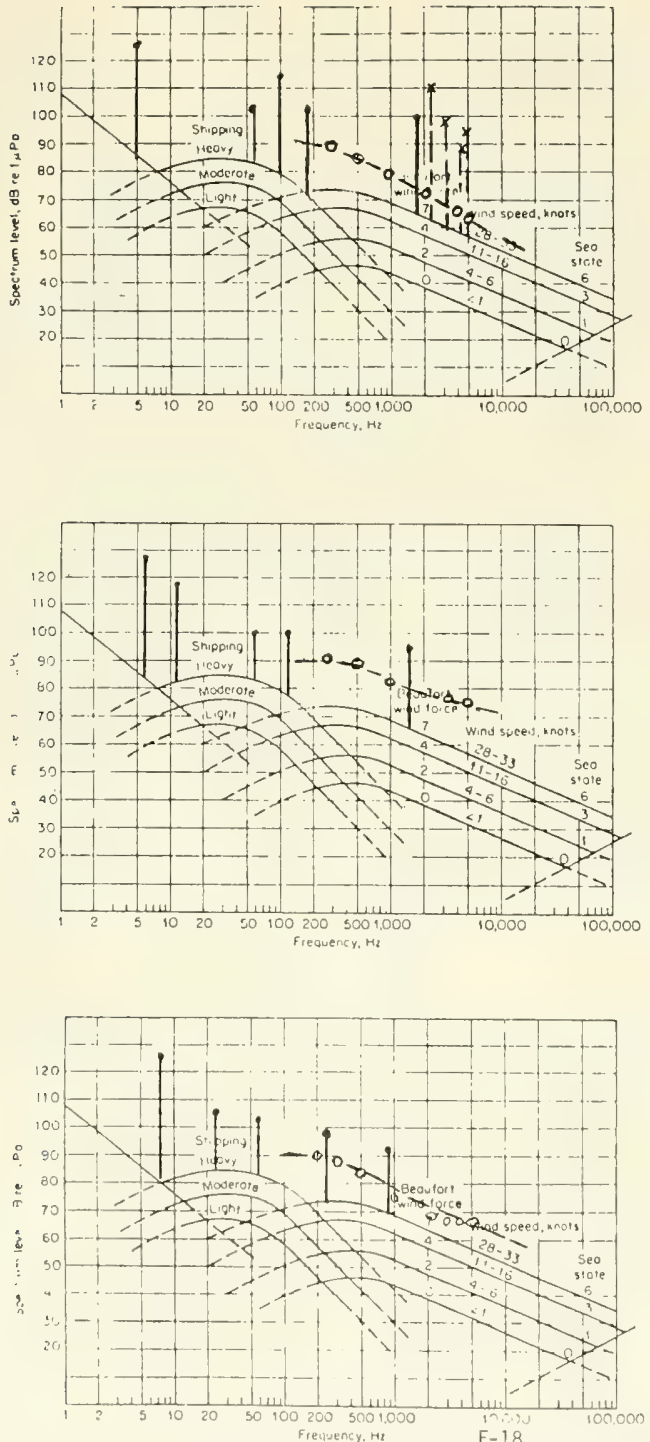

Fig. 6 Spectra of underwater noise of Platform C, Platform B and Platform $A$ superimposed on average deep water ambient noise spectra

Distance: $100 \mathrm{ft}$.
Platform C

Water Depth: $180 \mathrm{ft}$.

Hydroohone Depth: $100 \mathrm{ft}$.

Distance: Average $50,200,200 \mathrm{ft}$.

\section{Tonal (Spectrum line) \\ -O- Broad band (cont. spect.)}

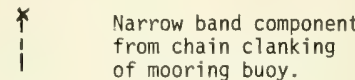

Platform B

Water Depth: $180 \mathrm{ft}$.

Hydrophone Depth: $100 \mathrm{ft}$.

Distance: $100 \mathrm{ft}$.

Platform A

Water Depth: $180 \mathrm{ft}$.

Hydrophone Depth: $100 \mathrm{ft}$. 


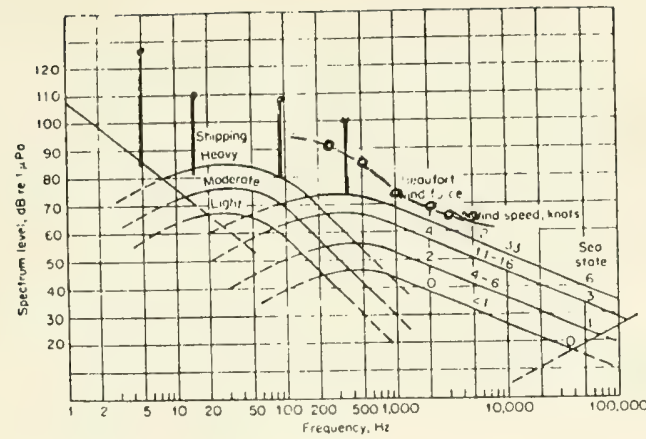

- - Broad band (cont. Spect.)
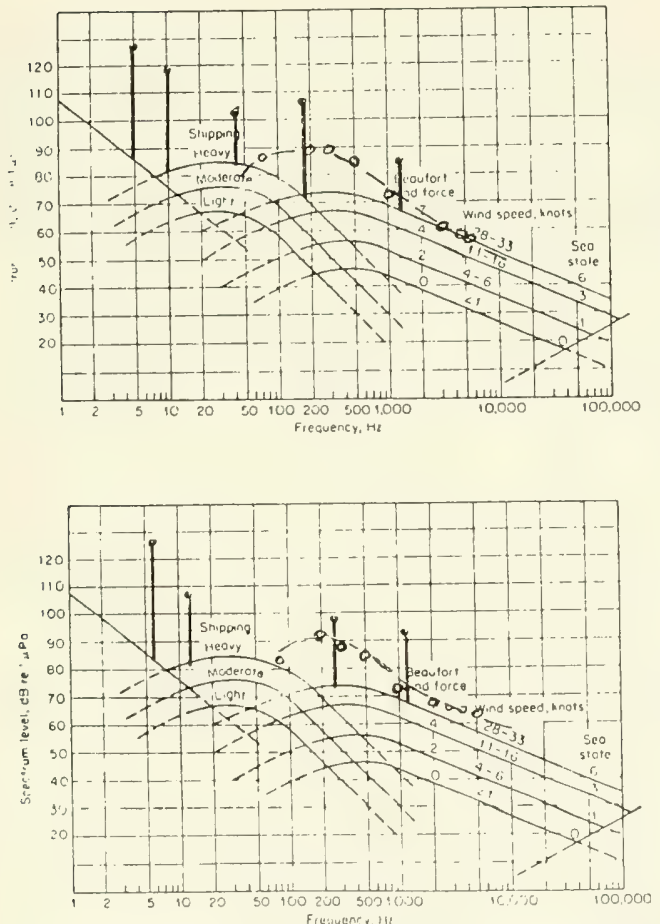

Fig. 7 Spectra of underwater noise of platforms Hillhouse, Henry and Houchin superimposed or averaje ceep water ambient noise spectra

\section{HOUCHIN}

Water Depth: $162 \mathrm{ft}$.

Hydrophone Depth: $100 \mathrm{ft}$. Distance: $100 \mathrm{ft}$.
HILLHOUSE

Water Depth: $192 \mathrm{ft}$.

Hydroohone Depth: $100 \mathrm{ft}$.

Distance: $100 \mathrm{ft}$.

Water Depth: $162 \mathrm{ft}$. Hydrophone Depth: $100 \mathrm{ft}$. Distance: $100 \mathrm{ft}$. 

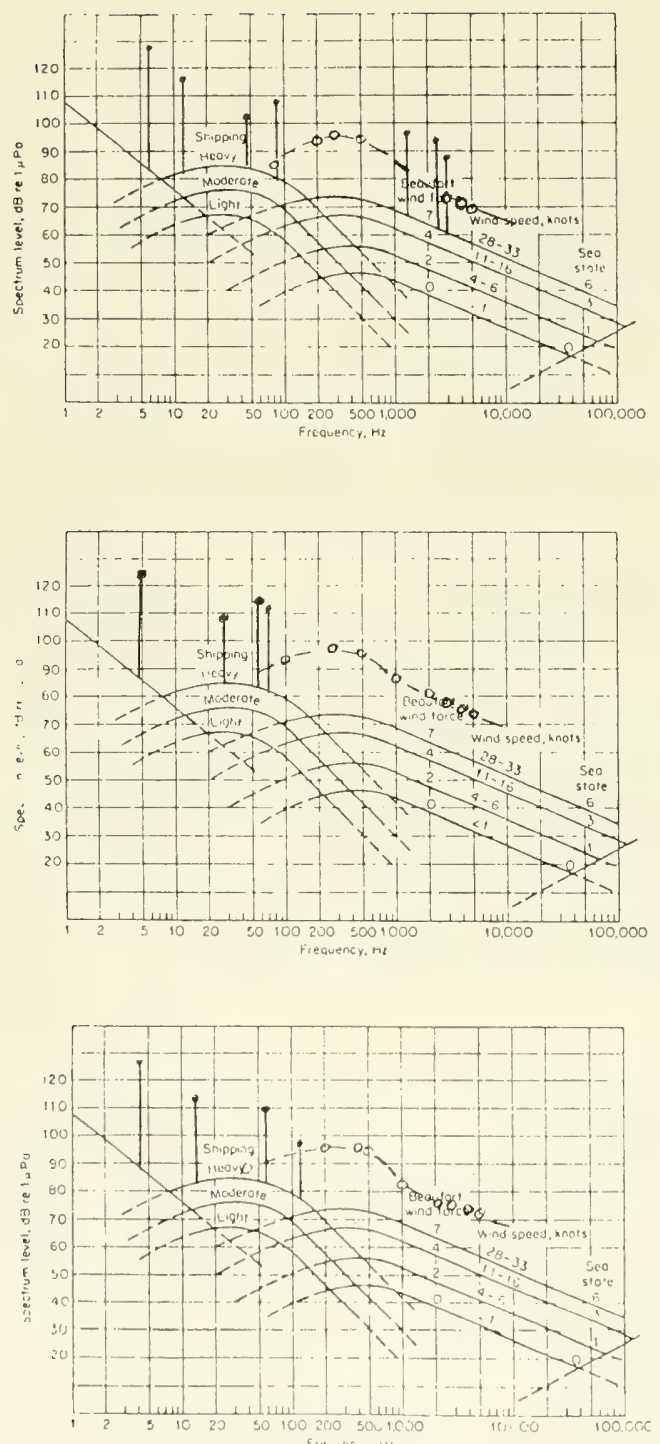

Fig. 8 Spectra of underwater noise of platforms Hogan, Hope and Heidi superimposed on average deep water ambient noise spectra

\section{HEIDI}

Water Depth: $120 \mathrm{ft}$.

Hydrophone Depth: $100 \mathrm{ft}$. Distance: $100 \mathrm{ft}$.

\section{HOGAN}

Water Depth: $144 \mathrm{ft}$.

Hydrophone Depth: $100 \mathrm{ft}$.

Distance: $100 \mathrm{ft}$.

Tonal (Spectrum line)

Broad band (cont. spect.)

\section{HOPE}

Water Ūepth: $132 \mathrm{ft}$.

Hydrophone Depth: $100 \mathrm{ft}$

Distance: $100 \mathrm{ft}$. 


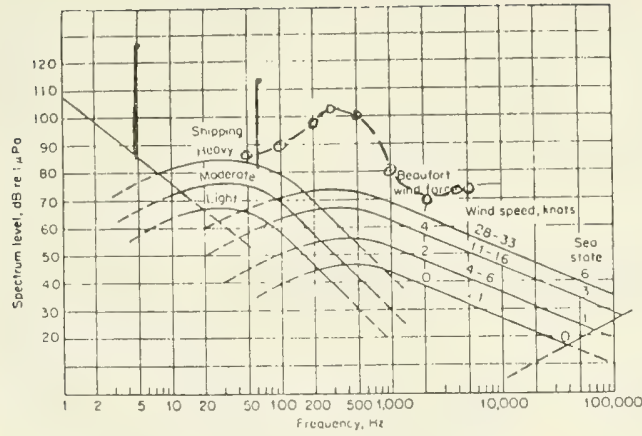

HAZEL

Water Depth: $90 \mathrm{ft}$.

Hydrophone Depth: $100 \mathrm{ft}$.

Distance: $100 \mathrm{ft}$.

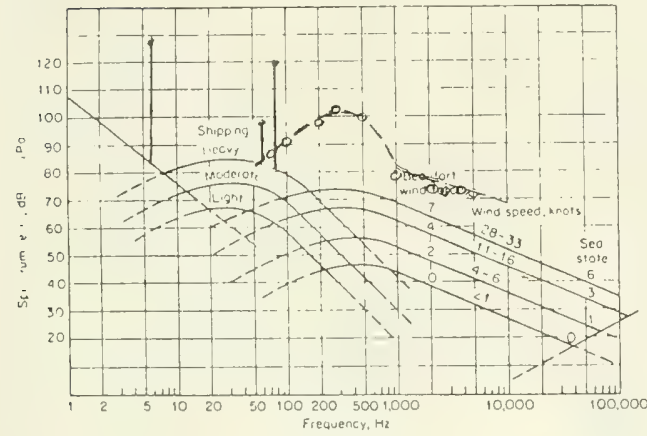

HILDA

Water Depth: $90 \mathrm{ft}$.

Hydrophone Depth: $100 \mathrm{ft}$

Distance: Average 50 and $200 \mathrm{ft}$.

Fig. 9 Spectra of underwater noise of platforms Hazel and Hilda superimposed on average deep water ambient noise spectra 


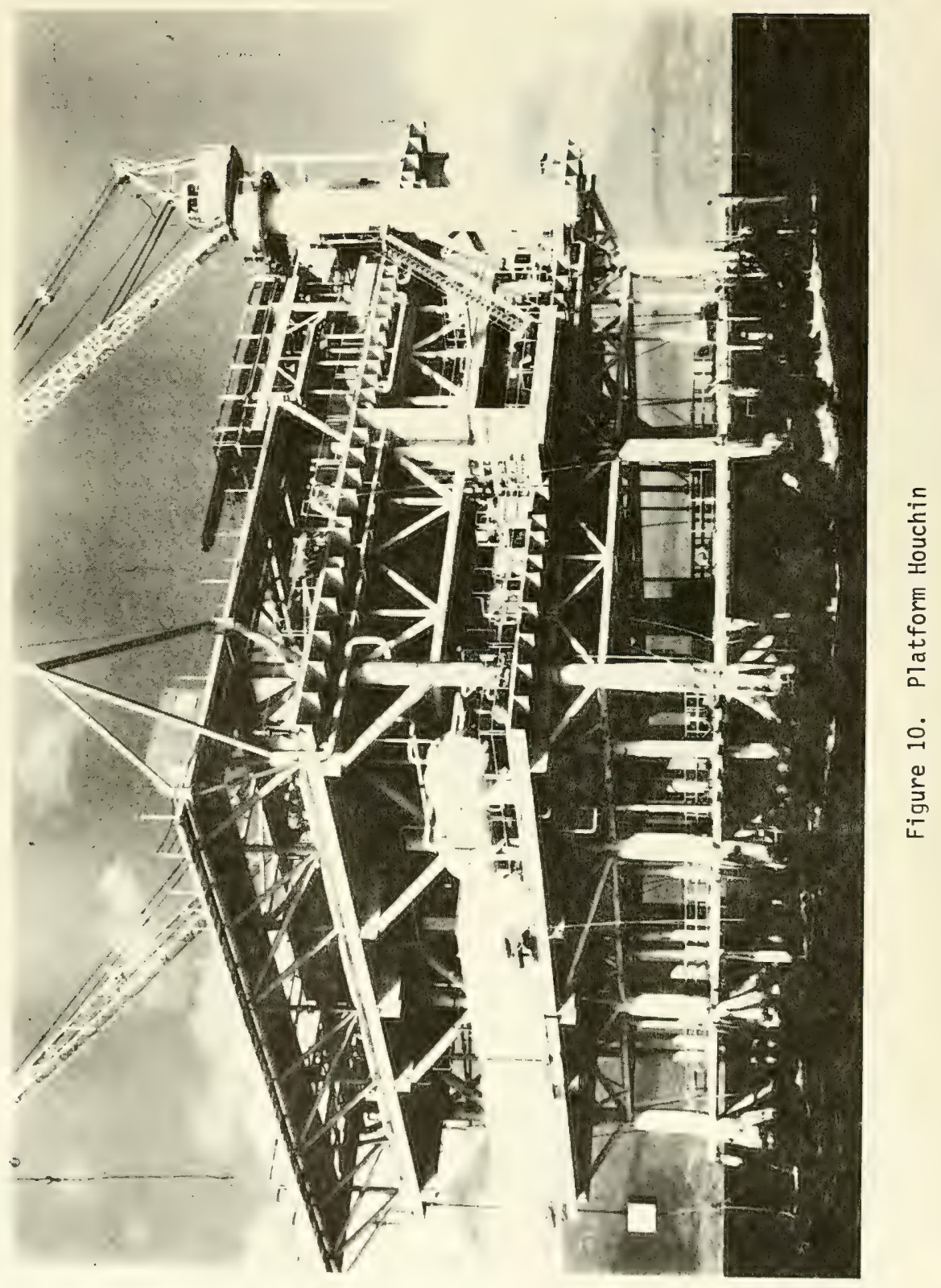




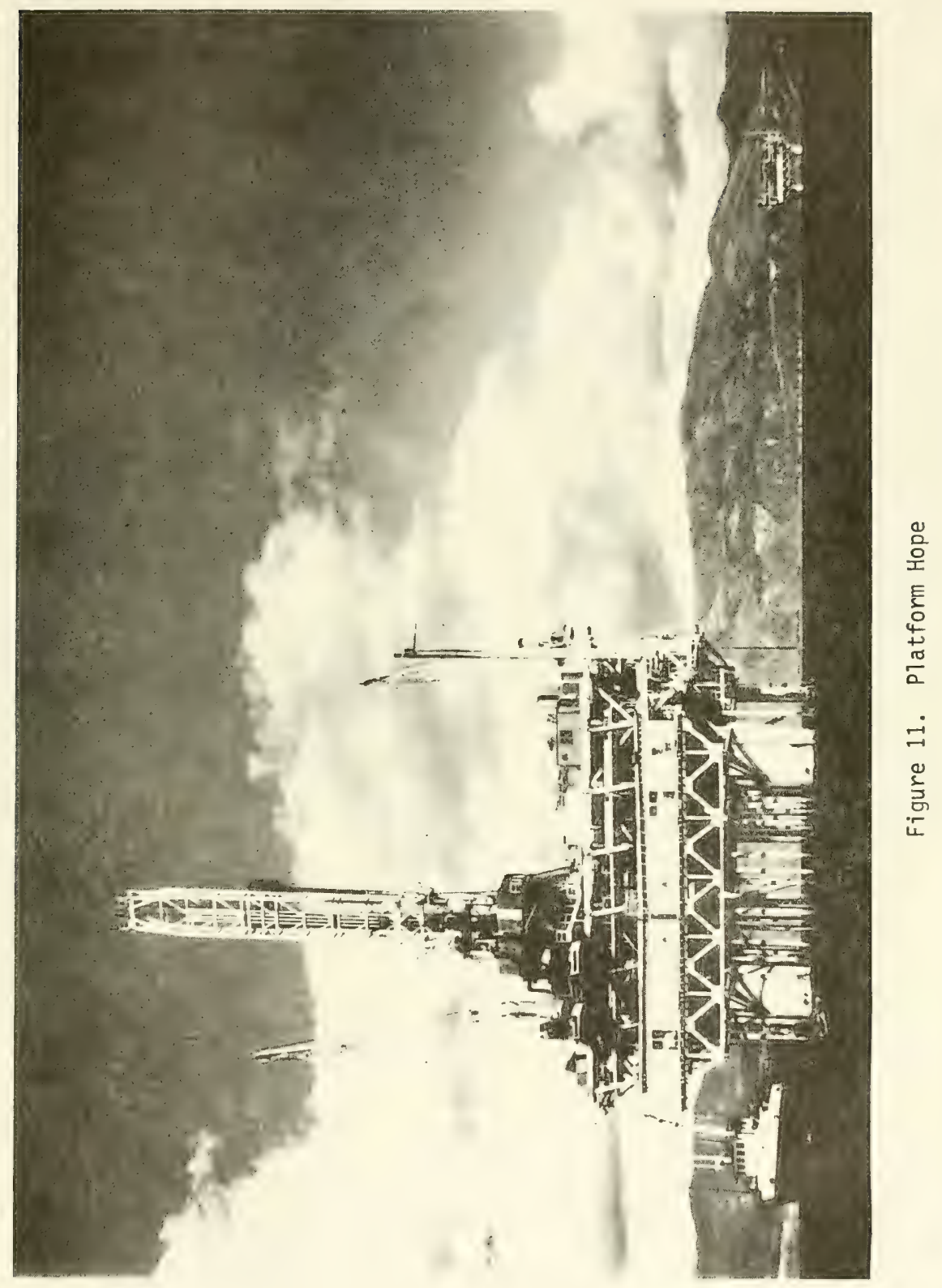


APPENDIX G 

ESTIMATED UNDERWATER DETECTION RANGES BY MARINE MAMMALS

OF NOISE FROM OIL AND GAS PLATFORMS

Robert S. Gales

Naval Ocean Systems Center

San Diego, California 92152 


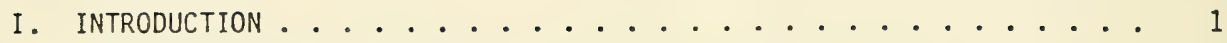

II. SOURCE-PATH-RECEIVER MODEL ..................... 5

A. Source........................ 5

B. Path .................. 6

C. Receiver.................... 6

III. ASSUMPTIONS FOR APPLICATION OF THE MODEL ........... 8

A. Source ...................... 8

B. Sound Propagation ................... 10

1. Spreading Loss ................. 10

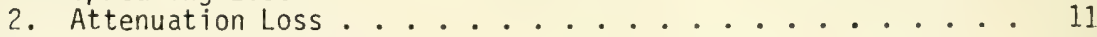

C. Receiver ..................... 16

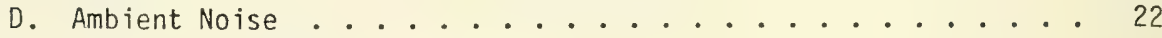

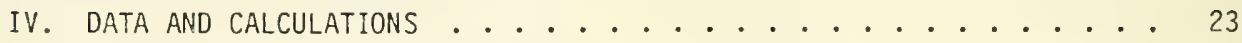

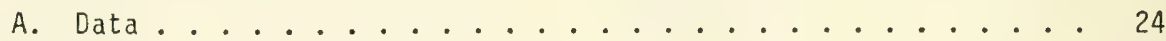

1. Source Level (SL)--Three Sources . . . . . . . . . 24

2. Minimum Detectable Signal (MDS $=N L+C R) \ldots 25$

3. Calculation of Detection Range .......... 27

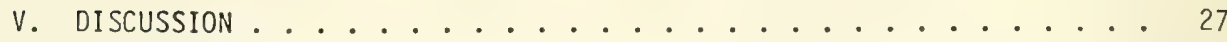

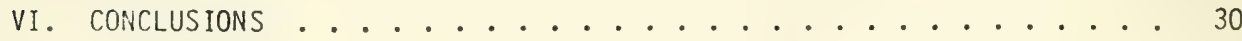

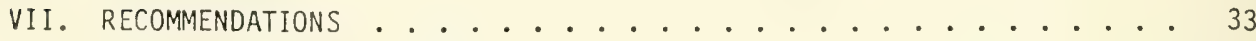




\section{LIST OF TABLES}

Page

1. Calculated Detection Ranges for Platform SSD-1 Platform Data

2. Calculated Detection Ranges for Platform FP-1 Platform Data

3. Calculated Detection Ranges for Platform FP-2 Platform Data

\section{LIST OF FIGURES}

1. Simplified diagram of hypothetical fixed drilling platform

2. Attenuation coefficients in decibels per kiloyard as a function of frequency for sound propagation in sea water

3. Sound transmission loss in sea water vs. distance

4. Critical ratio and critical band data for four animals as a function of frequency

5. Average deep-water ambient noise spectra

6. Ambient noise spectra at coastal locations with wind speed as a parameter

7. One-third octave band analys is of water-borne noise from the semisubmersible drilling rig SSD-1

8. One-third octave band analysis of water-borne noise from the production platform FP-1

9. One-third octave band analysis of water-borne noise from the production platform FP-2 


\section{ADMINISTRATIVE DATA}

The work described in this report was conducted in 1980 and 1981 for the Bureau of Land Management (BLM) of the U.S. Department of Interior under Interagency Agreement No. AA851-IA0-5 entitled, "Study of the Effects of Sound on Marine Mammals" (NOSC Project 513-MM28). The work was sponsored by the New York Outer Continental Shelf office of BLM under the general supervision of $J$. Philip Thomas and Eiji Imamura. Jeffrey P. Petrino of BLM Code 851 served as contracting officer.

NOSC was selected for this work because of its unique combination of experience and facilities in the areas of underwater sound and marine manmals. The work was done by a task group managed by Dr. Elek Lindner of the Marine Sciences Division. Principal members of the task team were: R. S. Gales, Acoustics, J. A. Hoke, Instrumentation, and D. R. Schmidt, Data Recording and Analysis.

The whole-hearted cooperation and assistance of all members of the team is gratefully acknowledged. In addition, thanks are due to other members of the Airborne Acoustics Branch who assisted at various times, particularly to Karen Wilcken, who typed the original manuscript.

Acknowledgements are also due to members of Computer Sciences Corporation (CSC) under contract to NOSC for their significant contributions to the later portions of the project. Participants from CSC were:

D. MacCormack and R. Christensen who performed the source spectrum anaiyses, and J. A. Hoke who performed under CSC after his retirement from government service in late 1980. 


\section{ESTIMATED UNDERWATER DETECTION RANGES OF \\ NOISE FROM OIL AND GAS PLATFORMS}

\section{INTRODUCTION}

The oil and gas resources of the outer continental shelf (OCS) are an important element of the energy plan of the United States, yet the development of these resources must be accomplished with minimum adverse effects on the coastal environment. High on the list of environmental concerns is the well being of the ecosystem.

Of the several agents which might impinge adversely on coastal animal life, noise is a potential pollutant which has to date received very little attention. Noise and vibration from offshore installations may be transmitted into the sea and sea floor, and may propagate for long distances in the underwater environment. It is known that underwater sound is important to many marine organisms, particularly marine maimals, such as the Cetacea (Tavolga, 1964; Myrberg, 1978). Therefore, it is important that a systematic study be made of the sounds radiated by OCS operations and of their potentia? effects on undersea animal life. 
This report is a brief initial look at this problem. It presents data on underwater noise measured in the vicinity of OCS oil and gas platforms, discusses propagation of this sound in the ocean, and considers potential interaction of the sounds with certain marine animals. Major attention is given to those species which are most likely to be sensitive to sound. The Cetacea (whales, dolphins, and porpoises) have been particularly selected for this analysis because of their known uses of, and observed sensitivity to, sound (Herman, 1980).

The littimate objective of this project is to describe the behavior of the various species of marine animals in response to the various noises produced by the OCS $0 i 1$ and gas operations. This is a very difficult goal, one which may be attainable with confidence only after comprehensive observations of behavior of many animals in the presence of many types and levels of noise. Such observations would need to be made for long periods of time in order to determine whether observed changes in behavior were temporary, and whether the animals readily adapt to the continuation of the noise with no sustained adverse effects. Furthermore, to predict a substantial adverse effect on a species, one must determine whether such effect is deleterious to the existence of the species or to its ecological interactions. Even a sustained effect of the noise, such as denying a favored habitat, might simply displace the habitat by a mile or two, with no serious adverse consequences. 
In view of the unavailability of a data base of direct behavioral observation as described above, this study is taking an alternative approach, using the source-path-receiver model. In this approach, the underwater noise is measured at a known distance from the oil platform, or other noise source, a sound propagation path is assumed, and the sound pressure level is calculated for various distances from the source. Estimates of the hearing sensitivity of various species of animals are then used to predict the range of audibility of the various sounds emitted from OCS operations under various weather and oceanographic conditions. Such estimates of detection range provide initial guidelines of maximum expected ranges of influence, the implicit assumption being that if the animal is unable to hear the sound, the animal will be unaffected by it. Of course, it must be pointed out that the fact that the animal is able to hear the sound (at ranges shorter than the detection range) does not assure a reaction. In fact, it is likely that unless the sound has an extremely threatening meaning to the animal, overt responses to the sound may not occur until its level is substantially above the threshold of detectability. The need for actual observational data on response thresholds of the animals to various OCS oil and gas platform-related sounds must be reiterated here. Field observations of animal behavior under conditions of known acoustic stimuli are essential, and should be strongly supported, but until they are available, maximum range estimates of the type presented in this report can serve as rough estimates of maximum ranges of possible influence. Although the type of response to be expected from animals within the maximum detection range is highly uncertain, the expectation of zero influence at distances beyond this range may be a very useful consideration in environmental planning. 
The project task statement lists five specific objectives as follows:

A. To determine and characterize the various sounds emitted from ocs $0 i 1$ and gas operations (exploration, development, and production) and from related vessel traffic.

B. To characterize the sounds emitted and perceived by various cetacean species.

C. To evaluate the sound spectra created by human activities which could disrupt the behavior of Cetaceans.

D. To determine the effects of a physical structure, such as a platform, on Cetacean behavior.

E. To propose a range of mitigating measures which would eliminate or minimize the im; act of sounds, offshore physical structures, and associated human activities on Cetaceans.

Of these five specific objectives, this report deals with the first three. It is intended to serve as an initial exploratory study illustrating (1) the relationships between sound emitted from $0 i 1$ and gas platforms, (2) perception of these sounds by cetaceans, and (3) distance limits to possible disruption of behavior of cetaceans. Effects of the physical structure, such as a platform, and noise mitigating measures will be treated in future reports. 
It must be emphasized that this report is intended to describe the factors which are involved in the interaction between noise and marine mammals, and to explore maximal ranges of possible influence. It is not intended to estimate zones of noise influence for any specific ocs locations.

\section{SOURCE-PATH-RECEIVER MODEL}

The source-path-receiver model has proved very useful for the estimation of the range to which a sound may be detected. Its greatest use has been in estimating detection of underwater sounds, and accordingly, the analytic expression for calculating detection range, given the proper quantitative data on source, path, and receiver, is called the sonar equation (Urick, 1975). It was developed for naval applications during World War II and is expressed in two forms: (a) active sonar involving detection of an echo reflected from an object in the ocean, and (b) passive sonar involving detection of sound emitted by a source. The passive sonar model is the one used exclusively in this report.

The elements of the source-path-receiver model as used in this report may be described as follows:

\section{A. Source}

The sound source is OCS oil- and gas-related, such as an oil drilling rig, a production platform, a supply boat, an impulse noise maker for seismic exploration, etc. 


\section{B. Path}

The sound propagation path is a one-way water path between source and receiver. Such paths are generaliy quite complex, involving vertical curvature due to sound velocity gradients in the water, and multiple reflections from the surface and bottom. In order to carry out the calculations of transmission loss in a reasonably tractable manner, a number of simplifying assumptions relating to the path and its boundaries are made. These have been validated by many years of use in naval applications related to detection of submarine and ship noises by passive sonar (Urick, 1975). The literature contains a large body of both theoretical and experimental data on underwater sound propagation (Urick, 1975). The sound propagation assumptions used in this report are described in Section III below.

\section{Receiver}

The receiver in the OCS model is the animal whose behavior is possibly subject to modification by hearing the sound. In order to estimate the greatest range at which a sound may be detected by the animal, it is necessary to determine the weakest sound that is detectable. This is called the "threshold of hearing," and is generally dependent on the frequency of the sound. If the animal is Tistening in an environment free of interfering noise, the threshold is termed the "absolute threshold." Ordinarily, however, the animal is in an environment in which certain normal sounds of the sea are present. These are caused by wind and waves at the sea surface, by breakers 
on shore, by distant ships, by natural seismic activity, by ice activity in frigid areas, and by various soniferous marine life, such as snapping shrimp, croakers, etc. The total sum of these is termed "ambient sea noise," and is generally at such a level that the audibility of a sound, such as that of a drilling platform, is 1 imited by interference or "masking" by this ambient sea noise (Myrberg, 1978). Therefore, in order to predict the audibility of a sound, one needs to know the "masked threshold" for the animal under the environmental sea conditions at the time. This masked threshold for a given animal is dependent on (1) the noise discrimination capability of the animal (aural critical ratio, or bandwidth), (2) frequency component to be detected, (3) background noise spectrum, which in turn depends on sea state, amount of shipping in the general area, local noise-making animals, etc. The various assumptions in this report relating to these are discussed below.

Frequency of the sound is a critical factor in each of the elements of the sonar equation: source, propagation, and receiver; therefore, each of these will be considered as a function of frequency. The source is described by its frequency spectrum at a known distance, sound transmission loss over the sound path is considered as a frequency-dependent quantity; and receiver minimum-detectable signal is approached in terms of a frequency-dependent threshold based on ambient noise spectrum. 
III. ASSUMPTIONS FOR APPLICATION OF THE MODEL

\section{A. Source}

The sound source is assumed to be a localized (point) source radiating into the water uniformly in all directions (omnidirectional source). The acoustic strength of each platform is characterized by "source level." This is a well established concept which describes the source by a sound pressure level in decibels relative to the underwater sound reference zero of one micropascal, and at a reference distance of one yard. The sound pressure level is actually measured at distances of ten to several hundred yards, and the source level at one yard is calculated by applying an appropriate level vs. distance rule, such as that of inverse square (6 dB per distance doubled). This concept of source level at a standard distance serves as a convenient means of comparing the acoustic source strength of various noise sources such as oil platforms, work boats, etc.; furthermore, it provides a standard input to sound propagation calculations of the sound pressure level at various distances from the source.

At this early point in the study, very little is known of the actual mechanism of radiation of sound from offshore oil platforms. Various mechanisms may contribute to the coupling of vibratory energy into the water. Possible pathways are illustrated in Figure 1. A major potential noise source is the prime energy source, $S$, usually a diesel or gas engine or turbine. Its 
vibratory energy may couple into the rig structure and radiate into the water from submerged portions of the structure, or couple into the ocean bottom from which noise may be re-radiated into the water. The engine or turbine exhaust may produce high noise levels in the air, and couple into the water to be radiated also as underwater noise. Various elements of the drill string may be noise sources, from the point of application of energy at the drill platform, along the drill string, and down to the bit itself as it bites into various rock formations. Vibratory energy from the drill system may radiate by various paths, including drill to earth to water, drill string to water, drill string to platform to water, etc.

The above discussion illustrates the complexity of the sound emission process at an oil platform. Studies conducted to date have been insufficient to determine which of the various individual source and radiation mechanisms are the important ones. It is expected that the mechanisms will vary from platform to platform, and with the particular operation on the platform, such as drilling vs. production, type of drilling, type of prime power source, and type of vibration isolation, muffling, etc. As stated earlier, the analytic approach used in this report treats the source as a simple, localized, omnidirectional source. Future work which looks in detail at the distribution of vibration in different parts of the structure and in the vicinity of various mechanical sources will be required to understand the noise radiation process, and to provide a scientific base for noise mitigation if it is required. 


\section{B. Sound Propagation}

As noted earlier, the calculation of sound transmission loss for various distances from an underwater source can be very complex and involve many oceanographic factors related to the water depth, temperature structure, bottom type, etc. Basically, sound transmission loss can be considered as made up of two components: (1) spreading loss, which results from the energy in the wave front being spread out over a greater total area as the sound travels, and (2) attenuation, which is the loss of sound energy due to absorption and scattering in the medium.

The following discussion is presented as an aid in understanding the nature of spreading loss, and attenuation loss.

1. Spreading Loss. Assume that a sound radiates one watt of sound power into the ocean, and that this sound radiates equally in all directions (omnidirectional source). The sound wave-front propagates outward from the source as an ever-expanding sphere, with an ever-increasing surface area which, at distance $r$ from the source, is given by $4 \pi r^{2}$. The intensity of the sound is defined as power per unit area of the wave. The unit of source intensity is watts per square meter. For the above example of a source power of 1 watt, the intensity at a distance $r=1$ meter is 1 divided by $4 \pi=.08$ watts per square meter. At a distance of 2 meters, the intensity is 1 divided by $4 \pi(2) 2=.02$ watts per square meter. Thus, doubling this distance reduces the sound intensity by a factor of 4 . Expressed in decibels, this reduction is $10 \log 4=6$ decibels. 
2. Attenuation Loss. This is a second form of loss of intensity of a sound wave as it propagates in a given medium such as water. The total loss, out to a given distance, $r$, is the sum of the spreading loss and attenuation loss, each expressed in decibels. Attenuation loss results from sound power being extracted from the wave as it propagates. The extraction of power results when some of the energy of the wave is scattered in various directions by various inhomogeneities in the medium, such as small organisms, gas bubbles, etc. Loss of power also occurs when some energy is absorbed by molecular interactions, and is converted into heat. In either case the attenuation loss is proportional to the intensity of the wave, and the loss is given by a certain fraction of the intensity per unit distance of travel. This fraction is known as the attenuation coefficient per meter or per foot, or per kiloyard. it is usually expressed in decibels as so many decibels per unit distance. Figure 2 shows values of the attenuation coefficient for sea water in decibels per kiloyard. These particular units are much used in underwater sound.

These two components of sound propagation loss discussed above are treated quantitatively as follows:

1. For the most common form of spreading, spherical spreading, the wave front is an ever-expanding sphere, and the spreading loss is 6 decibels (dB) per doubling of distance (inverse square law). This was descrihed in the example above. A second common form, where the sound is confined between two reflecting planar boundaries (the surface and a reflective bottom) is called cylindrical spreading. Here the spreading loss is proportional to the first power of distance, so it is $3 \mathrm{~dB}$ per doubling of distance. 
2. The second form of sound transmission loss, attenuation, results, as mentioned above, from loss of energy by such processes as absorption by molecular interaction in sea water, and scattering of energy by inhomogeneities such as marine organisms and bubbles. Attenuation loss is very dependent on frequency, as is shown in Figure 2, and sightly dependent on temperature.

Figure 2 shows the attenuation coefficient in $\mathrm{dB}$ per kiloyard plotted as a function of frequency. Note the very low loss at low frequency $(.001 \mathrm{~dB} / \mathrm{kiloyard}$ at $0.1 \mathrm{kilohertz})$. This leads to very long range transmission of low frequency sound. For example, sound at 100 hertz is attenuated only $1 \mathrm{~dB}$ over a distance of 1000 kiloyards (493 nautical miles). of course, one must recognize that the spherical spreading loss from a range of 1 yard to $1000 \mathrm{ki}$ loyards is $120 \mathrm{~dB}$, so at low frequencies, where attenuation loss is small, spreading loss is dominant.

The equations for calculating transmission loss (TL) as a combination of spreading loss and attenuation are, for TL in decibels:

$$
\begin{array}{lll}
\text { For spherical spreading: } & T L=20 \log r+a r \times 10-3 \\
\text { For cylindrical spreading: } & T L=10 \log r+a r \times 10-3
\end{array}
$$

where

$$
\begin{aligned}
& r=\text { range in yards } \\
& \alpha=\text { absorption loss in } d B \text { per kiloyard }
\end{aligned}
$$


The above discussion deals with the most general aspects of propagation of sound in the ocean. In practice, sound propagation in any given situation depends on a very complex set of parameters, including water depth, source depth, water temperature and salinity, surface roughness, surface cover (e.g., ice), bottom type, bottom profile, etc. Although sound propagation can be predicted roughly by employing the general concepts of spreading and absorption presented in the section above, accurate prediction is virtually impossible without specific knowledge of each of the above listed factors. Continental shelf operations pose a particularly difficult problem because of the fact that they generally occur in shallow water (depth less than 100 fathoms) for which the bottom plays an important role, and the water structure is often quite variable. Discussing shallow water propagation, Urick (1975) states, "Because of these complexities, the transmission loss to be expected at a shallow water location may be said to be, for many purposes, unpredictable. Resource to direct measurements is necessary."

In view of this complexity, it is beyond the scope of this report to attempt to predict the propagation at specific OCS sites. Instead, the basic equations of spreading loss and absorption loss (expressions (1) and (2) above will be used to provide general estimates of propagation of OCS-related noise. 
For the purposes of this report, these two expressions will be used to provide two estimates of sound transmission to bracket roughly the upper and lower ranges of expected sound transmission. Spherical spreading provides a low limit, for conditions where sound propagation is not enhanced by sound reflections from the sea surface and ocean bottom. This occurs for water so deep that reflections from it may be ignored and for shallow water where the bottom and/or surface are highly absorptive. This occurs where the bottom is soft and muddy, and where the surface is covered with old ice which may have a mushy, rough underside. Normally the ocean surface is reflective, except in the case of a highly agitated sea state, with many breaking waves.

Cylindrical spreading gives an upper limit for sound propagation. It is used for cases where sound is propagated efficiently, as between a reflective bottom and surface. Hard, smooth bottoms, such as sand and relatively uniform rock tend to be reflective, and as mentioned above, the sea surface is normally reflective at low and moderate sea states (less than state 3 ). This report will give estimates for detection range under both spherical and cylindrical propagation conditions. Figure 3 shows the transmission loss for both cylindrical and spherical spreading out to a range of 10,000 kiloyards. The effect of normal attenuation loss is clearly evident by the fall-off beyond 1000 yards. Note that this effect is greatest for high frequencies and is nearly negligible at the lowest frequencies of 16 and 32 hertz. 
Under certain conditions, propagation losses may greatly exceed the more normal ones cited above. The presence of large quantities of scatterers or absorbers such as bubbles, fish with swim bladders, squid, certain euphausiids and other small crustaceans, and even plankton in large numbers may greatly increase absorption loss particularly at certain frequencies, related to specific scatterers. Accurate prediction of such losses must be based on detailed oceanographic observations of the specific area under consideration. A second factor which may lead to abnormally high propagation losses is vertical refraction, or bending of the sound beam. This occurs when temperature and/or salinity varies with depth. For example, higher temperatures near the surface, as of ten happens because of solar heating of the ocean surface, cause downward bending of sound rays so that the loss effect of an absorptive bottom is accentuated.

Not all departures from standard progagation appear as excess loss. Under some conditions propagation is enhanced such as to give rise to higher sound levels than predicted by the simple expressions (1) and (2) above. One such mechanism involves penetration of sound (particularly low frequency) energy into the ocean bottom which may act as a better sound path than the water above. Sound so conducted may leak back into the ocean far down the path and appear again as underwater sound. A second mechanism is the so called "megaphone effect," whereby sound transmission over a downward sloping bottom, as from the continental shelf out into deep water, is enhanced because consecutive bottom reflections tend to direct the sound into the horizontal path. 


\section{Receiver}

A critical element in the application of the source-path-receiver model to estimate animal response to sound is the specification of the particular species of animal which will be the receiver, and the conditions under which the listening will be done (quiet background, or high ambient noise due to high sea state, ship traffic, or activities of other noisy animals). The outer continental shelves comprise habitats for almost all species of marine mammals. This includes the large whales, both mysticete (baleen) and odontocete (toothed), smaller odontocetes (dolphins and porpoises), and pinnipeds (seals and sea lions). Their hearing capability varies markedly from species to species, particularly with respect to the frequency of maximum sensitivity. Much is known about the hearing of the smaller odontocetes and pinnipeds (Herman and Tavolga, , 1980) as a result of many experiments on captive animals. On the other hand, very little is known about the hearing of the large whales, because of the great difficulty of conducting controlled experiments on these animals. 
Experimental data on the odontocetes show them to have excellent underwater hearing, particularly at high frequencies (10 to upwards of 100 $\mathrm{KHz}$ ). These animals generally emit click-like sounds with components in this general frequency region for the purpose of echolocation which is an important sensory tool for many species such as the bottlenosed dolphin. These animals make very effective use of echolocation sounds to detect, locate, and identify underwater objects such as fish and other food items. It has often been postulated that other mammals such as baleen whales and pinnipeds also employ echolocation, a: they also emit click-like sounds on occasion. Their use of these sounds for echolocation, however, has not been satisfactorily demonstrated. Many of the marine mammals are observed to emit tonal sounds, and it is generally agreed that an important use is for communication. These sounds vary greatly in frequency, from around $15 \mathrm{~Hz}$ for the Blue Whale to $4-20 \mathrm{KHz}$ for the bottlenosed dolphin. The sounds also vary widely in duration and wave-form. Some are nearly pure tones, whereas others have a very complex harmonic structure.

It is clear that the use of sound by the various marine animals is very complex; so much so that it is not within the scope of this report to address the many species, sounds, and uses in any sort of a comprehensive way. The approach used here is to select a single class of animal, one with maximal relevance to the oCS environmental issues. The mysticete (baleen) whales have been selected for several reasons: (a) they comprise several endangered species (bowhead, humpback, etc.), (b) they are very critical and controversial components of the Alaska, North Slope-Beaufort Sea area slated 
for 0CS development, (c) they are believed to have very sensitive hearing in the low frequency region in which oil platforms have been found to produce high noise levels. The odontocetes, on the other hand, also have sensitive hearing, but it is mainly employed at high frequencies, generally above those emitted from the oil platforms in data obtained from studies up to this time. This, together with the directional sound discrimination capability of most odontocetes suggests that they are least liknly to be affected adversely by oi] platform noise.

For the purpose of this report, the receiver is assumed to be a mysticete (baleen) whale. At this point it is probably not necessary to select a pärticular single species (bowhead, gray, humpback, etc.), as the available data on the hearing of any specific species is minimal. In order to predict the threshold of audibility of sounds it will be necessary to make a number of assumptions regarding the whales' hearing. In the main, these assumptions follow those of Payne and Webb (1971) in their paper on acoustic signaling by baleen whales. 
The mysticetes are known to emit sounds in the low-frequency range, approximately between 10 and $1000 \mathrm{~Hz}$, with particular emphasis on the region around $20 \mathrm{~Hz}$. At these low frequencies, the wave length is very long (500 feet at $10 \mathrm{~Hz}$ and 50 feet at $100 \mathrm{~Hz}$ ). Since physical considerations require that a receiving body have dimensions at least approximating the wavelength in order to have appreciable directivity, and since even the head of a large whale does not reach 50 feet in size, it is assumed in this report that the animals' hearing sensitivity is equal in all directions, yielding a receiver directivity index1 of zero. This is a useful assumption for the purpose of simplifying the analytic treatment. It will be essentially true for the lowest frequencies, up to about $100 \mathrm{~Hz}$. Above this some directivity will be expected, but the directivity index is not expected to exceed $10 \mathrm{~dB}$ at frequencies below $500 \mathrm{~Hz}$. For the general estimates of this report this will be ignored. It should be pointed out that a directivity index of zero does not mean that the acoustic receiver is not capable of determining the direction of a sound source. The human ear, for example, by using interaural phase information, makes excellent determinations of direction of sounds at low frequencies whre the ear-head size is less than 0.1 wavelength, so is functioning as an omni-directional system with directivity index near zero.

1Directivity index of a receiving sensor system, such as a hydrophone or hydrophone array is a number used to quantify the discrimination of the system against omnidirectional noise as a result of its directional sensitivity pattern. A receiver which is equally sensitive in all directions has no capability to discriminate directionally against noise, so it has a directivity index of zero. 
It is believed that the sounds of these baleen whales are used for communication, and that it is likely that the whales have their most sensitive hearing at frequencies in the 10 to $500 \mathrm{~Hz}$ region in which so many of their vocalizations lie. It is also interesting to observe that human hearing is most sensitive in the frequency region between 500 and $3000 \mathrm{~Hz}$, which is the frequency band which contains most of the acoustic energy of those sounds most important to the understanding of human speech. Furthermore, as with human hearing, it is assumed that the whales' absolute hearing threshold is sufficiently sensitive that under normal conditions, sound detection is limited by the masking of ambient water noise (Payne \& Webb, 1971). In order to predict the masked threshold, it is necessary to know the critical ratio or critical bandwidth for the animal. The critical ratio in decibels is the number of decibels a pure tone or narrow band signal must exceed the level of background noise in a band one hertz wide at the signal frequency in order to be heard in the presence of the noise. The critical bandwidth is the effective frequency anatysis bandwidth of the animal's auditory system. The critical band theory assumes that an animal can hear a tone or narrow-band signal in a broad band noise if the tone is $D \mathrm{~dB}$ above the level of the noise in a critical band at the frequency of the tone. A conservative assumption is that $D=0$. With this assumption, the critical ratio in $d B=10$ log critical band in hertz. The lower the critical ratio, the better the animal can detect weak tonal signals in noise. This critical ratio is a function of frequency, and ordinarily has a minimum value near the low frequency end of the range of frequencies of importance to the animal. Experimental data are available on only a few animals, but this general trend is shown in data for man, cat, bottlenosed dolphin, and ringed seals, as plotted in Figure 4. 
These data indicate a critical ratio of 16 to $18 \mathrm{~dB}$ (for frequencies below $500 \mathrm{~Hz}$ ) for man and cat, the only two animals for which data are available at these low frequencies. An estimate of the critical ratio for a whale at frequencies near $20 \mathrm{~Hz}$ may be done by extrapolating downward at a slope which conforms to a constant percentage bandwidth. Payne and Webb (1971) assumed a one-third octave bandwidth which is about $4 \mathrm{~Hz}$ at a frequency of $20 \mathrm{~Hz}$. This gives a critical ratio of $10 \log 4=6 \mathrm{~dB}$. This would seem to be a reasonable value for the critical ratio, but in recognition of the possibility that it may be somewhat on the optimistic side of detectability, a substantially more conservative assumption of a critical ratio of $20 \mathrm{~dB}$, corresponding to a masking critical bandwidth of $100 \mathrm{~Hz}$, is also used in this report at frequencies below $450 \mathrm{~Hz}$. At frequencies above $450 \mathrm{~Hz}$, a critical ratio based on the $1 / 3$ octave critical band relationship of Figure 4 may be considered conservative, since it tends to lie along the upper bound of the experimental points.

For the mysticete whales, for which the hearing estimates in this report are made, it is likely that the assumption of the third-octave critical ratio is fairly realistic, and may even be slightly conservative. This view follows observations by various researchers based on studies of both cochlear anatomy (Fleischer, 1976) and on evolutionary considerations related to the use of low-frequency communications for the maintenance of the species (Herman, 1980; Thompson, Thomas, Winn, \& Perkins, 1979). These same considerations make the alternative assumptions of a critical ratio of $20 \mathrm{~dB}$ (100 Hz critical band) at frequencies below $450 \mathrm{~Hz}$ highly conservative. 


\section{Ambient Noise}

In order to calculate the masked threshold it is necessary to know the ambient noise level at the frequency of interest, as well as the animals' critical ratio. This is necessary, since a tonal signal of frequency, $f$, is detectable when its sound pressure level equals or exceeds a level which is the sum of the pectrum level (Tevel in a one $\mathrm{Hz}$ band) of the ambient noise at $f$ and the critical ratio at $f$.

The fact that ambient noise varies widely in level and spectrum shape, depending on the nature of noise sources in the areas, makes it necessary to specify certain ambient noise levels to he introduced into the sonar equation for calculation of the detection range of the oil platform sounds.

Comprehensive data on ambient noise levels and spectra have been published by Wenz (1962) for various conditions of wind, sea state, and ship traffic. These and other data have been combined by Urick (1975) to give sets of curves for obtaining sound spectrum level for deep (Figure 5) and coastal (Figure 6) waters. The curves from Figure 5 are used for data inputs in the calculations in the following section. 
IV. DATA AND CALCULATIONS

The source-path-receiver model is used in this section to calculate the range at which a hypothetical baleen whale may be expected to hear various oil platform sounds under several stated environmental conditions. The analytic expression used for these calculations is the passive sonar equation which states mathematically that the source level (SL) minus the transmission loss (TL) equals the minimum detectable signal (MDS). The MDS under the masking limited conditions assumed is equal to the spectrum level of the ambient noise (NL) plus the critical ratio (CR). The directivity index is omitted here as we have assumed it to be zero (omnidirectional hearing). Therefore,

$$
\begin{aligned}
& S L-T L=N L+C R \text {, or } \\
& T L=S L-N L-C R
\end{aligned}
$$

For known values of source level, ambient noise level, and critical ratio, the transmission loss acceptable to enable the source sound to just be heard is calculated. Then the distance at which this TL occurs is obtained by calculation using the transmission loss expressions (equations (1) or (2)) or graphically from Figure 3 or similar plots. 
A. Data

1. Source Level (SL)--Three Sources. At this writing, source level analysis has been performed on three drilling rigs: SSD-1, semi-submersible drilling rig, Lower Cook Inlet, Alaska; SSD-2, semi-submersible drilling rig, Baltimore Canyon, Atlantic; and FDP-1, fixed drilling and production platform, Santa Barbara, California; and three production only platforms: FP-1, fixed, 4-legged production platform, Upper Cook InTet, Alaska; FP-2, fixed, 3-legged production platform, Upper Cook Inlet Alaska; and MMIP, man-made island, production, Santa Barbara, California. The noise measured in the water from FDP-1 and MMIP was so low that the measurements are considered doubtful and are being repeated. Noise radiated from SSD-1 and SSD-2 and FP-1 and FP-2 waS substantially above the ambient background noise, and contained prominent low frequency tonal components of the type expected to be detectable by whales. Figures 7,8 , and 9 show the third-octave band spectra measured by NOSC for the three platforms selected as sources for this study. In view of the similarity between the two drilling semi-submersibles (one in lower cook Inlet, Alaska, and the other off Baltimore Canyon in the Atlantic) source Tevel data for the Alaskan rig only will be used. Table 1 shows source levels 
for four principal tonal components, including what appears to be the fundamental frequency at $12 \mathrm{~Hz} .2$ The two production platforms differed in several respects, as did their radiated noise spectra, so source levels of both are being presented in Tables 2 and 3 .

2. Minimum Detectable Signal $(M D S=N L+C R)$. Minimum detectable signal level is obtained at each of the signal frequencies in the SL data for three ambient noise conditions (NL) and one or two critical ratio (CR) assumptions, depending on whether the frequency is above or below $450 \mathrm{~Hz}$ where the $C R=20 \mathrm{~dB}$. Above $450 \mathrm{~Hz}$ the $\mathrm{CR}$ is that of the solid line in Figure 4 . Below $450 \mathrm{~Hz}$ a "best estimate" is taken from the solid line, and a "conservative estimate" is taken as $20 \mathrm{~dB}$.

2In describing a spectrum containing many discrete lines, each representing a tonal component of the spectrum, the term fundamental frequency is often used. These spectra, often called "line spectra" frequently contain a series of components, wach at a frequency $\left(f_{n}\right)$ which equals an integer $(n=1,2$, $3,4,5$, etc.) multiplied by a number which is called the fundamental frequency $\left(f_{0}\right)$; thus $f_{n}=n f_{0}$. When $n=1, f_{n}=f_{0}=$ fundamental frequency. If $n=3, f_{n}=3 f_{0}$. This is the third harmonic, etc. For the example of the Alaska drilling (SSD-1) the spectrum shown in Figure 7 shows line frequency components at 12, 72, 180, and 250 hertz. These correspond to $n=1, n=6, n=15$, and $n=21$ respectively. Therefore, the fundamental is at a frequency of 12 hertz and the other components are the 6 th, 15th, and 21st harmonics. 
The three ambient noise conditions are:

High Noise: Sea state 6 , heavy shipping

Moderate: Sea state 2, moderate shipping

Low:

Sea state 0 , light shipping

These three conditions span the essential variability of expected anbient noises, and so should give a good estimate of the range in minimum detectable signal levels to be expected. The MDS levels for the three ambient noise conditions and appropriate critical ratios are given in Tables 1,2 , and 3 in the frequency columns representing the components of each source.

In the absence of an exhaustive analysis of the various ocs sites, it would appear that the moderate case, represented by sea state 2 and moderate shipping might be most representative of ocs areas in general. The high noise condition would be expected in areas near major ports and shipping lanes during high winds, and the low noise condition would occur at locations remote fror. shipping such as certain Alaskan waters during periods of calm winds. It should be pointed out that the three combinations of sea state and shipping density 1 isted above were selected to demonstrate the dependence of detection distance on the noise generation parameters. The sea state 6 , heaving shipping, represents the highest noisc background ?ikely to be encountered by a listening animal, while the sea state 0 , light shipping, represents a minimal background condition. It must be emphasized that, in 
practice, any combination of sea state and shipping may be encountered. As may be seen from Figure 5 , the sea state noise dominates the high frequencies, and shipping noise controls the low frequency region of the ambient noise spectrum.

3. Calculation of Detection Range. The detection range calculations are carried out for two sound propagation conditions:

a. Spherical (inverse square law) spreading, where

$$
T L=20 \log r+r \times 10-3
$$

b. Cylindrical spreading, where

$$
\mathrm{TL}=10 \log r+r \times 10-3
$$

The latter is the better sound transmission, and leads to the upper limiting detection ranges. In all cases the value of attenuation coefficient ( ) is taken from Figure 2. The calculated detection ranges are given at the bottom of Tables 1, 2, and 3 .

\section{DISCUSSION}

It is clear from the calculations above that there is a distinct possibility that the sounds radiated from the noisier oil platforms, either in drilling or production mode, may be audible to whales out to great ranges under favorable sound propagation and noise conditions. It must be noted that the range is very dependent on the specific propagation and ambient noise 
situation. For example, as shown in Table 1, Case IA3, the semi-submersible drilling rig is audible under quiet ambient conditions out to the tremendous range of 1230 nautical miles with cylindrical spreading loss, but with the more conservative spherical spreading, it is audible only to the moderate range of 1.2 nautical miles.

The ambient noise condition at the location of the receiving animal has important influence on detection as may be noted in Table 1, Case IAI vs. Case IA3, and Case IIA1 vs. Case IIA3. Case I (optimal propagation) shows that for high ambient noise, the detection range is reduced to 13 nautical miles as compared to 1230 in low ambient. Case II (conservative propagation) shows a range of only 190 yards under high ambient noise, compared to 2400 yards (1.2 nautical miles) for low ambient conditions.

It is important to note that the above estimates are intended to provide initial guidelines of maximum and minimum ranges as upper and lower limiting conditions for general planning. The upper limit, Case IA3, is an extreme situation, highly unlikely to be met in practice. Reflection losses at the surface and bottom result in propagation which will in general fall between the Case I and Case II curves of Figure 3, probal)ly more of ten nearer the spherical spreading of Case II. For example, an estimate of propagation loss out to 50 nautical miles (101 kiloyards) for the continental shelf off the northern coast of Alaska is 80 to $120 \mathrm{~dB}$ for a frequency of 100 hertz (Underwater Systems, Inc., 1974). This is much greater than the $50 \mathrm{~dB}$ shown for cylindrical spreading in Figure 3, and, in fact, brackets the $100 \mathrm{~dB}$ shown for spherical spreading. 
A second factor which makes unlikely the extreme ranges calculated for low ambient noise is the upward trend in ship noise during the last few decades (Ross, 1976). At low frequencies the present levels of shipping make it highly unlikely the light shipping noise shown in Figure 4 will be experienced, except in very remote locations. The moderate curve serves as a much more probable lower limit to low-frequency ambient noise.

The above considerations suggest that a realistic interpretation of maximum expected ranges in Table 1 would best depreciate the possibility of the extreme ranges associated with Case I (cylindrical spreading) and ambient noise condition 3 (low). This suggests that the more probable limiting ranges would fall between Case IIA2 (0.22 nautical miles) and Case IA2 (99 nautical miles).

Another important consideration is the apparent wide variation in anount of underwater noise radiated by different platforms, both drilling and production. Some, like those used for the calculations in this report, are quite noisy, particularly at the low frequencies in the 10 to $1000 \mathrm{~Hz}$ range considered important to whales, while other platforms, with no highly obvious mechanical differences, appear to be quiet underwater. The fact that such differences occur suggests that it is possible to construct and operate oil drilling and production platforms such that they do not produce great underwater noise levels. It is highly important that the differences between the noisy and quiet platforms be carefully analyzed to determine the critical noise-determining factors in design, machinery type and mounting, and 
operation. Such analysis should include such considerations as type of prime power source (turbine, reciprocating, etc.); its inherent balancing and vibration; method of mounting (isolation mounts or coupled solidly to structure); exhaust method (muffler vs. direct exhaust into air); and location and direction of exhaust outlet. The analysis should also consider platform structural features, such as dimensions of legs and other elements which might serve as underwater radiators. Other features for study are the mass, thickness, and damping of structural members. For example, one quict platform had legs filled with concrete, which might be a factor. This platform also had excellent muffling of its engine exhaust, while in contrast the relatively noisy semi-submersible platform had unmuffled exhaust stacks directed down toward the ocean surface. Of course, it may be misleading to make simple comparisons between these platforms, since they differ in many ways. The semi-submersible, for example, possesses two large submerged hulls, which could serve as excellent underwater sound radiators.

Understanding the differences in noise radiation by the various platforms will require criticai analyses of sound and vibration data from a large number of platforms, sampling a wide varipty of types, construction details, and operating and environmental conditions.

\section{CONCL.USIONS}

The following must be considered tentative, as they are derived from a very elementary, initial analysis of data from a very small number of platforms, and from calculations using many assumptions, some of which are not yet validated. 
A. Noisy platforms radiate low-frequency underwater sounds with line-frequency components capable of detection at ranges of the order of hundreds of miles under favorable conditions of propagation and ambient noise.

B. Under conditions unfavorable for detection (i.e., poor propagation and high ambien' noise), detection of all platforms, including the noisy ones, is expected to be limited to ranges of the order of 100 yards.

C. The existence of quiet platforms conducting both drilling and production operations indicates that these systems can be engineered for minimal underwater noise pollution.

D. Accurate prediction of expected detection range will require a scenario which defines (a) acoustic source spectrum for the particular platform, (b) propagation conditions for the particular location and season, (c) ambient noise condition as specific to sea state, ship traffic, and biological noise sources in the area, and (d) species of animal involved as listener. Additional data are needed on all of the above elements in order to employ the source-path-receiver model effectively for accurate predictions of detectability.

E. The estimates of detection range given in this report are the distances at which a mysticete whale may be expected to just detect the presence of a tonal component radiated by a platform. No prediction is made of animal behavior to be expected as a result of this detection. 0vert animal behavior may result from several considerations: 
1. The animal may associate the sound with previous experience. Such recognition, for man, normally requires a sound level many $d B$ above that of bare detection.

2. The sound may become so loud that the magnitude of the hearing sensation alone elicits aversive behavior. With man, for example, most sounds do not become uncomfortably loud until they are about 100 or more $d B$ above the auditory threshold.

F. This report does not address the interfering, or masking effects, that the platform noise may have on sounds such as communication signals emitted by marine animals. Data for some such predictions are now available. This is an important area for future analysis.

Estimates of such interference require a knowledge of the frequency spectrum, source level, and directional properties of the communication sounds of the species of animal under consideration. Data on spectrum and source level of sounds thought to be communication signals emitted by several species of cetacea are available. Directional data are meager. However, calculations assuming omi-directionality could be useful as an initial exploratory step. 


\section{RECOMMENDATIONS}

The recommendations below are prepared in recognition of the fact that this study is, at the point of this report, a very limited and brief overview of a very complex operation. The recommendations are nearly all related to additional data and studies needed for an adequate understanding of this complex problem. It is understood that certain of these recommendations are scheduled as future elements of this program.

A. Under ater Noise Source Levels of OCS $0 i 1$ and Gas Platforms. Obtain additional field measurements and recordings on existing platforms of all types. Particular emphasis should be placed on drill ships, jack-up rigs, and monopods, for which no data are yet in hand.

Large differences in underwater noise from platform to platform indicate that a broad sampling of many platforms embracing various types of construction, machinery, installation, and types of ongoing operations is needed to attain a reasonable degree of confidence in the sound source level predictions .

B. Detection Distances for Specific OCS Locations. Employ the source-path-receiver model to calculate expected detection range for selected scenarios involving specific OCS locations, noise sources, and seasonal weather conditions. Sound propagation and ambient noise parameters should be selected as appropriate to the specific locality, season, and weather. The receiving animal species should be selected as appropriate to locale. 
C. Estimation of Animal Behavioral Response. Conduct studies of the behavioral response of various species of marine mammals to noise stimuli. These studies could involve playback of selected sounds, such as tape recordings of sounds emitted from OCS platforms, at carefully controlled levels and for animals in selected settings of location and season. Tape recordings suitable for such studies are available at NOSC.

Such studies should also obtain direct observational data on behavior of various species of marine animals subjected to noise stimuli in the actual vicinity of oil and gas operations. These data should include both initial responses as might occur at a new installation, and responses over a long period as might relate to animals who have had an opportunity to adapt to the sounds.

D. Estimation of Interference with Anima? Communication Sound Signals. Apply the source-path-receiver model to calculate the expected masking effects which the noises from OCS operations might impose on acoustic communication signals between marine animals at various distances from the platform.

E. Detailed Measurements on OCS Platforms. Conduct measurements of airborne noise, platform vibration, and underwater noise in such a manner that the mechanisms of sound generation and transfer into water can be understood, and the specific transmission paths defined. Such understanding is required to specify engineering procedures for noise control where needed to meet future noise goals. 
1. Fleischer, G. Hearing in extinct cetaceans as determined by cochlear structure. Journal of Paleontology, 1976, 50(1), 148.

2. Gales, R. S. Second summary report on the Bureau of Land Management project, "Study of the Effects of Sound on Marine Mammals (NOSC Rep.). San Diego, CA: Naval Ocean Systems Center, September 1980.

3. Herman, L. M., \& Tavolga, W. N. The communications systems of cetaceans. In: Cetacean Behavior, L. M. Herman (Ed.), Wiley, New York, 1980.

4. Myrberg, A. A., Jr. Ocean noise and the behavior of marine animals: Relationships and implications. In Effects of Noise on Wildlife, J. L. Fletcher \& R. G. Busnel (Eds.), Academic Press, 1978.

5. Payne, R., \& Webb, D. Orientation by means of Tong-range acoustic signaling in baleen whales. Annals of New York Academy of Sciences, 1971, 188, $110-142$.

6. Ross, D. Mechanics of Underwater Noise. Pergamon Press, 1976.

7. Schmidt, D. R. Field measurements of underwater noise from offshore oil operations from January-June 1980 (NOSC Interim Report). San Diego, CA: Nava] Ocearı Systems Center, June 1980.

8. Tavolga, W. N. (Ed.). Marine Bio-Acoustics, Pergamon Press, 1964. 
9. Thompson, T. J., Winn, H. E., \& Perkins, P. J. Mysticete sounds. In: Behavior of Marine Animals, Vol. 3, H. E. Hinn \& B. L. 011a (Eds.), Plenum Publishing Corporation, 1979.

10. Underwater Systems, Inc. Hydroacoustic noise generated by off shore oil operations (Report 3128, ONR Contract No. N00014-71-C-0312), Apri1 1974.

11. Urick, R. J. Principles of Underwater Sound for Engineers, McGraw-Hi11 Book Company, Inc., 1975.

12. Wenz, G. M. Acoustic ambient noise in the ocean: Spectra and sources. Journal of Acoustical Society of America, 1962, 34(12), 1936-1956. 


\section{Table 1}

Calculated Detection Ranges for Platform SSD-1

Platform Data: Semi-submersibie, drilling, twin hulls, $26 \mathrm{ft}$. dianteter.

Prime power-diesel engines. Water depth-- 300 feet

\begin{tabular}{ll}
\hline Frequency & Source Level (1/3 Octave Band at 1 Yard) \\
\cline { 2 - 3 } $12 \mathrm{~Hz}$ & $129 \mathrm{~dB}$ re 1 micropascal \\
$72 \mathrm{~Hz}$ & 138 \\
$180 \mathrm{~Hz}$ & 132 \\
$250 \mathrm{~Hz}$ & 125
\end{tabular}

Case I: Optimal Propagation (Cylindrical Spreading).

Animal Listening Assumption

A. Good Detection

(1/3 octave crit. band)
B. Conservative Detection (100 $\mathrm{Hz}$ crit. band)

Ambient Noise Condition Frequency Detection Range Frequency Detection Range

1. High Ambient

2. Medium Ambient

3. Low Ambient
$72 \mathrm{~Hz} \quad 30 \mathrm{kyd} \quad 13 \mathrm{~nm}$

$72 \mathrm{~Hz} 200 \mathrm{Kyd} 99 \mathrm{rm}$

$180 \mathrm{~Hz} 2500$ Kyd $1230 \mathrm{~nm}$
$180 \mathrm{~Hz} \quad 66.5 \mathrm{kyd} 3.2 \mathrm{~nm}$

$180 \mathrm{~Hz} \quad 80 \mathrm{Kyd} 39 \mathrm{rm}$

$180 \mathrm{~Hz} \quad 800$ Kyd $395 \mathrm{~nm}$

Case II: Conservative Propagation (Spherical Spreading).

Animal Listening Assumption

A. Good Detection

( $1 / 3$ octave crit. band)

Ambient Noise Condition

1. High Ambient

2. Medium Ambient

3. Low Ambient
Frequency Detection Range

$72 \mathrm{~Hz} \quad 190$ yds $0.09 \mathrm{~nm}$

$72 \mathrm{~Hz} \quad 450$ yds $0.22 \mathrm{~nm}$

$180 \mathrm{~Hz} 2400$ yds $1.20 \mathrm{~nm}$
B. Conservative Detection (100 Hz crit, hand)

Frequency Detection Range

$180 \mathrm{~Hz} \quad 80$ yds $0.04 \mathrm{~nm}$

$180 \mathrm{~Hz} 290$ yds $0.14 \mathrm{~nm}$

$180 \mathrm{~Hz} \quad 1500$ yds $0.40 \mathrm{~nm}$ 
Calcuiated Detection Rariges for Platform $\mathrm{FPl}$.

Platform Data: Fixed, production, four legs - 10 fit diameter.

Prime power - gas turbine, water depth - 60 feet

Frequency

$40 \mathrm{~Hz}$

$630 \mathrm{~Hz}$

$2000 \mathrm{~Hz}$

$5000 \mathrm{~Hz}$
Source Level ( $1 / 3$ Octave Band at I Yard)

$137 \mathrm{~dB}$ re 1 micropascal

124

118

117

Case I: Optimal Propagation (Cylindrical Spreading).

Animal Listening Assumption

A. Good Detection

(1/3 octave crit. band)

Ambient Noise Condition

Frequency Detection Range

$40 \mathrm{~Hz} \quad 15 \mathrm{Kyd} \quad 7.4 \mathrm{~nm}$

$40 \mathrm{~Hz} \quad 120 \mathrm{Kyd} \quad 59.0 \mathrm{~nm}$

$40 \mathrm{~Hz} \quad 600$ Kyd $296.0 \mathrm{~nm}$
B. Conservative Detection (100 $\mathrm{Hz}$ crit. band)

Frequency Detection Range

$40 \mathrm{~Hz} \quad 1.5 \mathrm{Kyd} 0.74 \mathrm{~nm}$

$40 \mathrm{~Hz} 12.0 \mathrm{Kyd} 5.90 \mathrm{~nm}$

$40 \mathrm{~Hz} \quad 60.0 \mathrm{Kyd} 29.60 \mathrm{~nm}$

\section{Case II: Conservative Propagation (Spherical Spreading)}

Animal Listening Assumption

A. Good Detection

(1/3 octave crit. band)
B. Conservative Detection (100 Hz crit. band)

Ambient Noise Condition Frequency Detection Range Frequency Detection Range

1. High Ambient

2. Medium Ambient

3. Low Ambient
$40 \mathrm{~Hz} \quad 130$ yds $0.60 \mathrm{~nm}$

$40 \mathrm{~Hz} \quad 350$ yds $0.17 \mathrm{~nm}$

$40 \mathrm{~Hz} \quad 800$ yds $0.39 \mathrm{~nm}$
$40 \mathrm{~Hz}$

$40 \mathrm{~Hz}$

$40 \mathrm{~Hz}$
40 yds $0.02 \mathrm{~nm}$

110 yds $0.05 \mathrm{~nm}$

250 yds $0.12 \mathrm{~nm}$ 
Table 3

Calculated Detection Ranges for Platform FP-2

Platform Data: Fixed, production, three legs - $16 \mathrm{ft}$ diameter.

Prime power - gas turbine, water depth - 75 feet

\begin{tabular}{rll}
\hline Frequency & & Source Leve1 (1/3 Octave Band at I Yard) \\
$20 \mathrm{~Hz}$ & & $142 \mathrm{~dB} \mathrm{re} 1$ micropascal \\
$63 \mathrm{~Hz}$ & & 134 \\
$125 \mathrm{~Hz}$ & 128 \\
$250 \mathrm{~Hz}$ & 124 \\
$500 \mathrm{~Hz}$ & 125 \\
$1600 \mathrm{~Hz}$ & 110
\end{tabular}

Case I: Optimal Propagation (Cylindrical Spreading).

Animäi Listening Assumption

A. Good Detection

( $1 / 3$ octave crit. band)
B. Conservative Detection (J00 $\mathrm{hz}$ crit. band)

Ambient Noise Condition Frequency Detection Range Frequency Detection Range

1. High Ambient

2. Medium Ambient

3. Low Ambient
$20 \mathrm{~Hz} \quad 120$ Kyd $59 \mathrm{~nm}$

$20 \mathrm{~Hz} 1000$ Kyd $490 \mathrm{~nm}$

$20 \mathrm{~Hz} 6000$ Kyd $2960 \mathrm{~nm}$
$20 \mathrm{~Hz}$

$20 \mathrm{~Hz}$

$20 \mathrm{~Hz}$
5 Kyd $2.50 \mathrm{~nm}$

35 Kyd $17.00 \mathrm{~nm}$

300 Kyd $148.00 \mathrm{~nm}$

Case II: Conservative Propagation (Spherical Spreading)

Animal Listening Assumption

A. Good Detection

(1/3 octave crit. band)
B. Conservative Detection (100 Hz crit. band)

Ambient Noise Condition Frequency Detection Range Frequency Detection Range

1. High Ambient

2. Medium Ambient

3. Low Ambient
$20 \mathrm{~Hz} \quad 350$ yds $0.17 \mathrm{~nm}$

$20 \mathrm{~Hz} \quad 1000$ yds $0.49 \mathrm{~nm}$

$20 \mathrm{~Hz} 3000$ yds $1.50 \mathrm{~nm}$
$20 \mathrm{~Hz}$

$20 \mathrm{~Hz}$

$20 \mathrm{~Hz}$
70 yds $0.02 \mathrm{~nm}$

200 yds $0.05 \mathrm{nn}$

600 yds $0.12 \mathrm{~nm}$ 


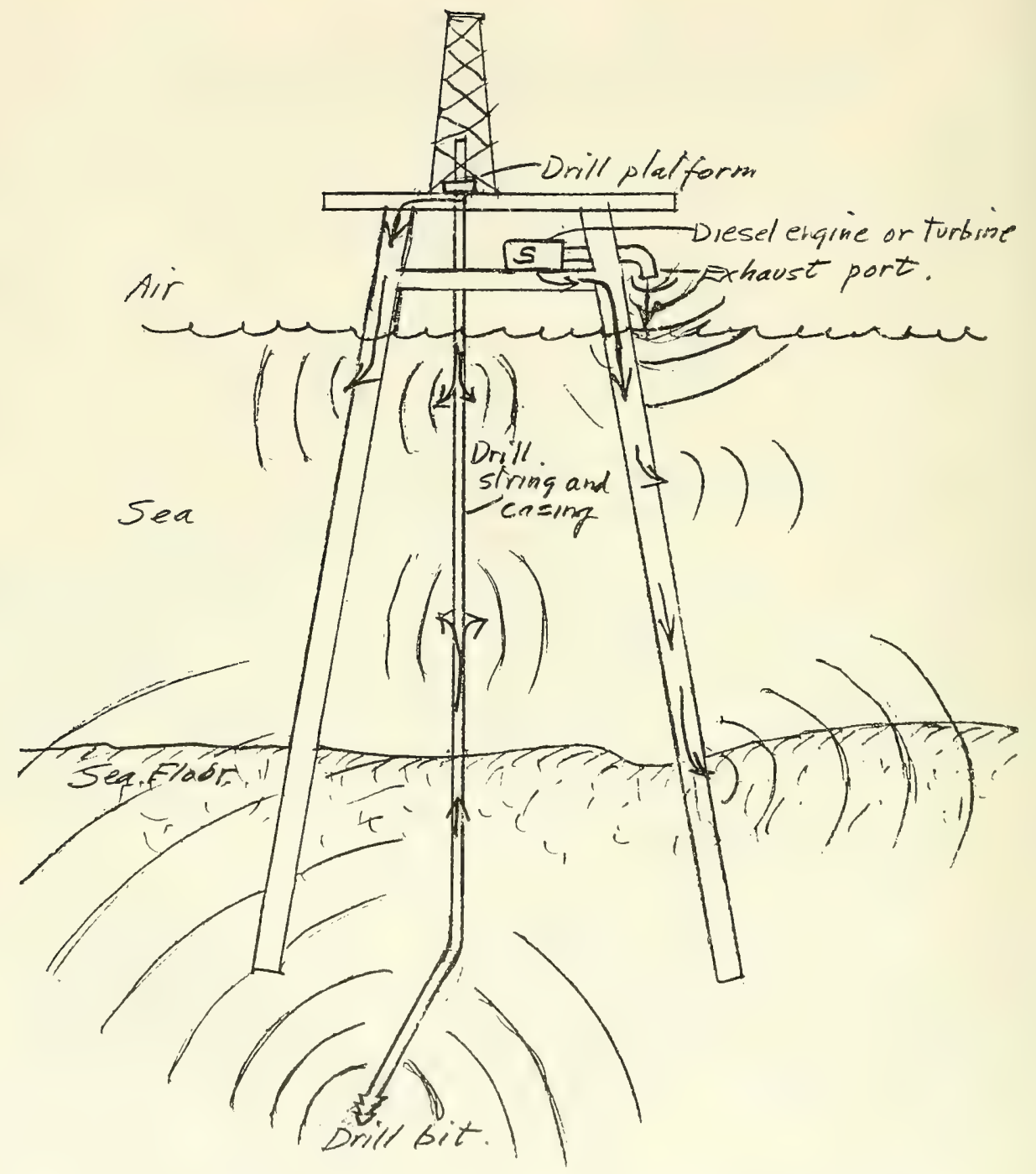

Figure 1. Simplified diagram of hypothetical fixed drilling platform, showing possible sound pathways from source points: diesel engine or turbine, drill platform, and drill bit. Possible paths include: structure-borne, air-borne, drill string and casing-borne, ground-borne, and water-borne sound. 


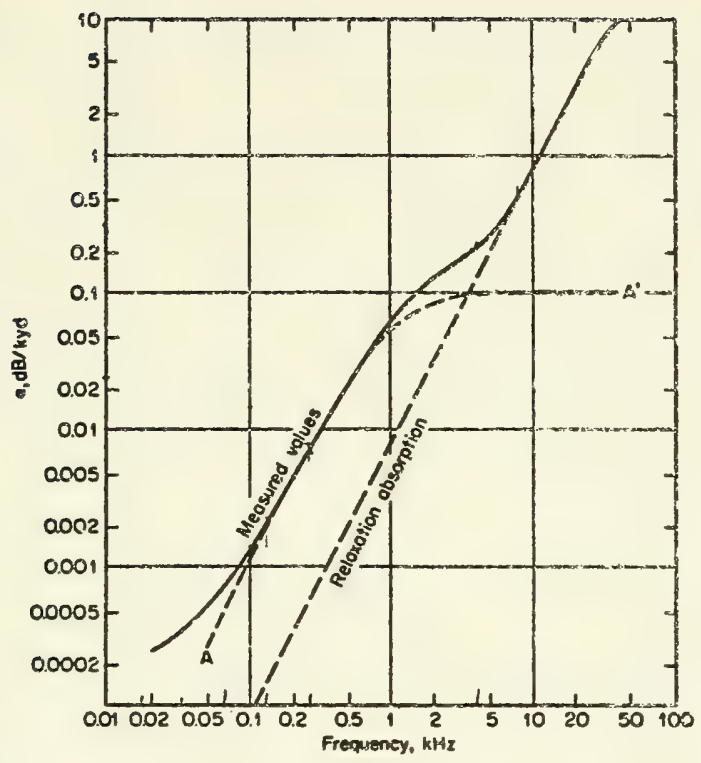

Figure 2. Atteriuation coefficients in decibels per kiloyard as a function of frequency for sound propagation in sea water (Urick, 1975). 


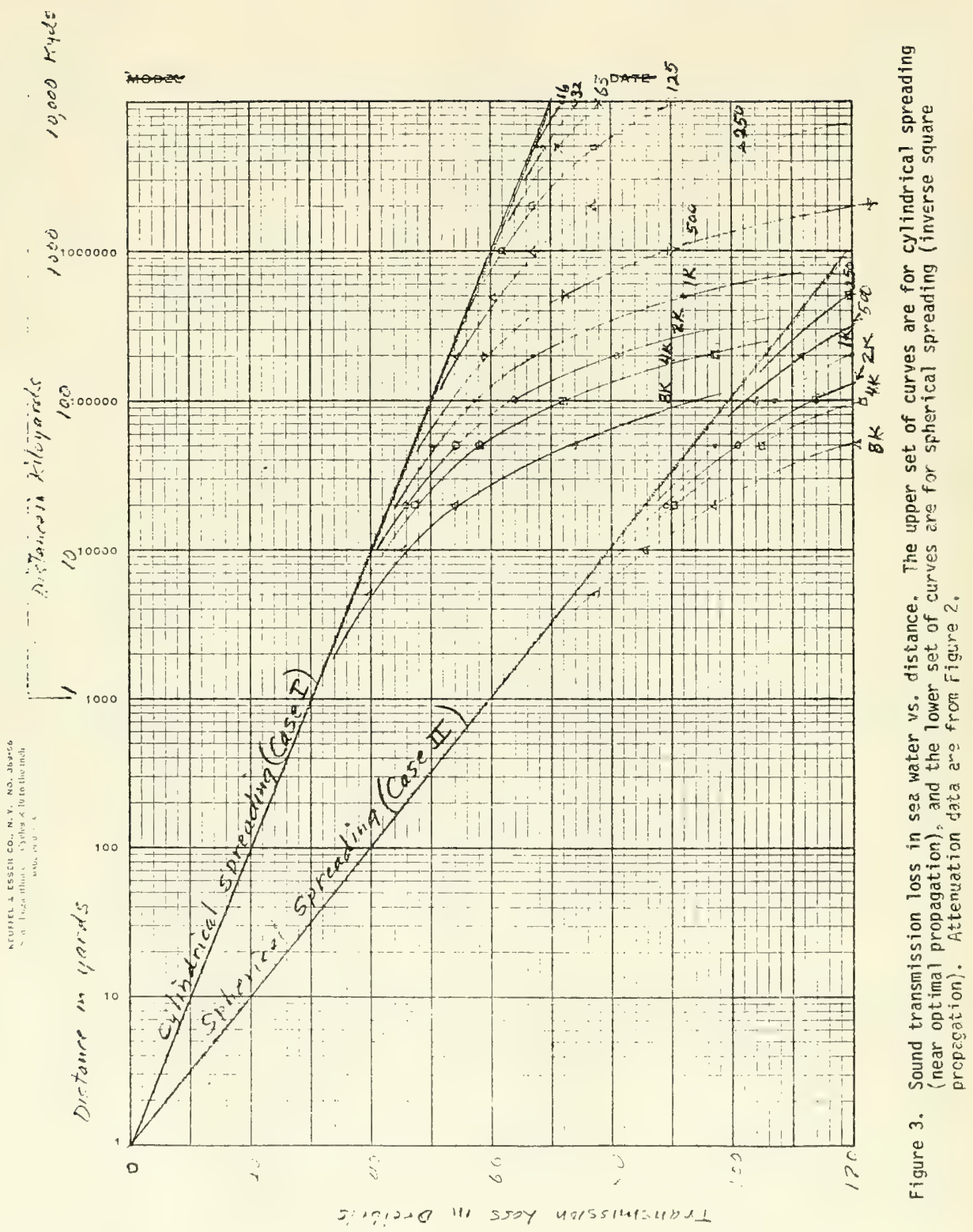




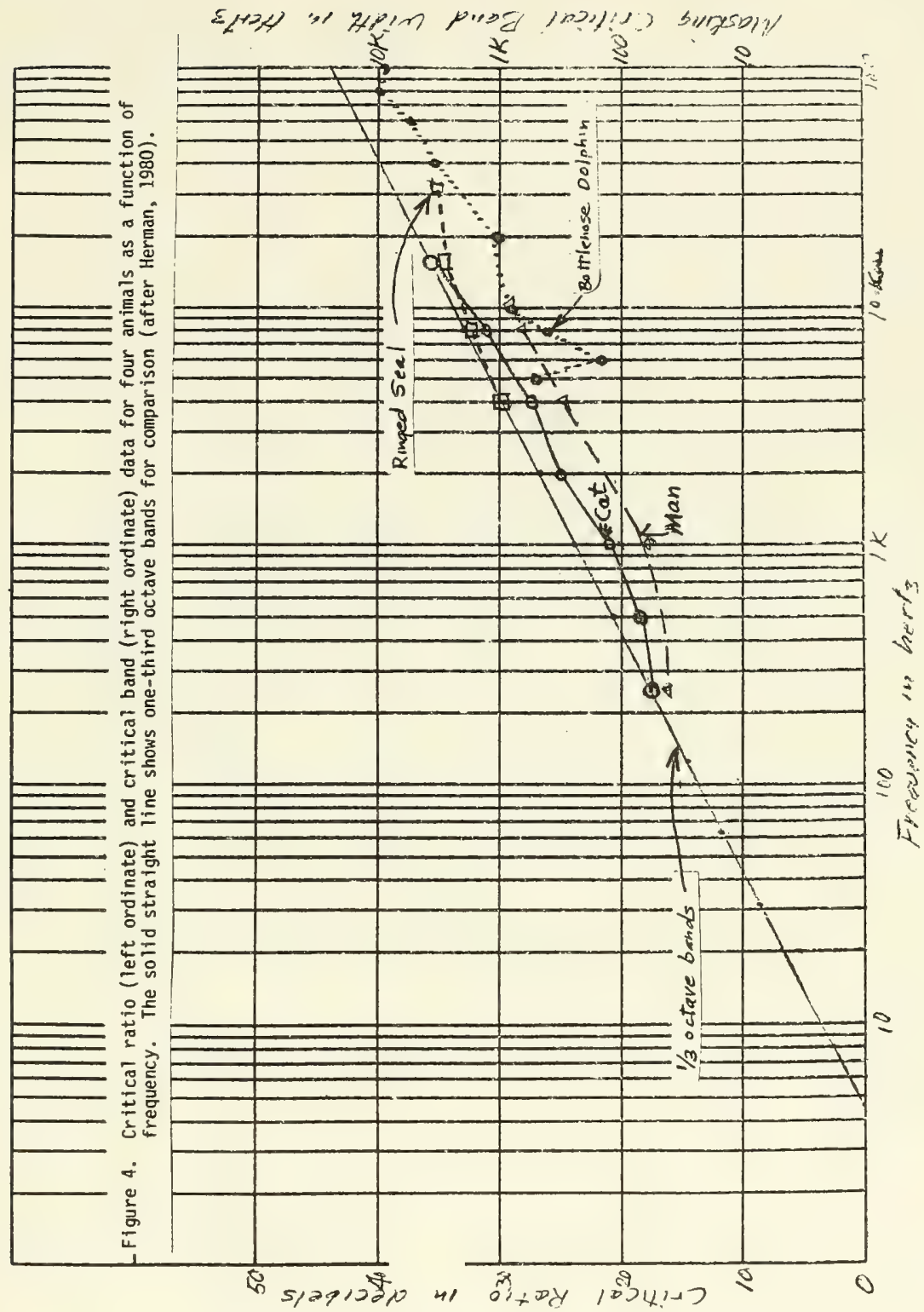




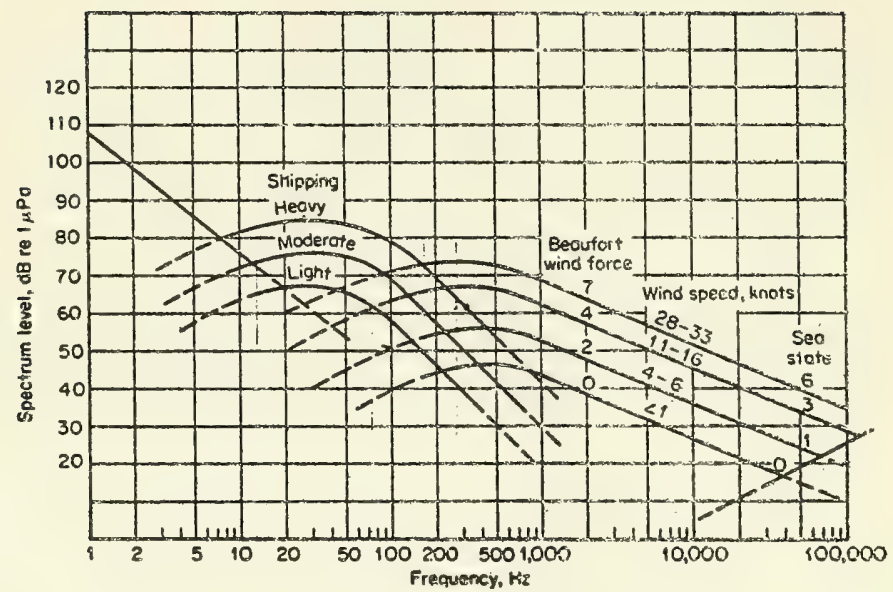

Figure 5. Average deep-water ambient noise spectra. Spectrum level is the level in a one hertz band (Urick, 1975) (after Wenz, 1962). 


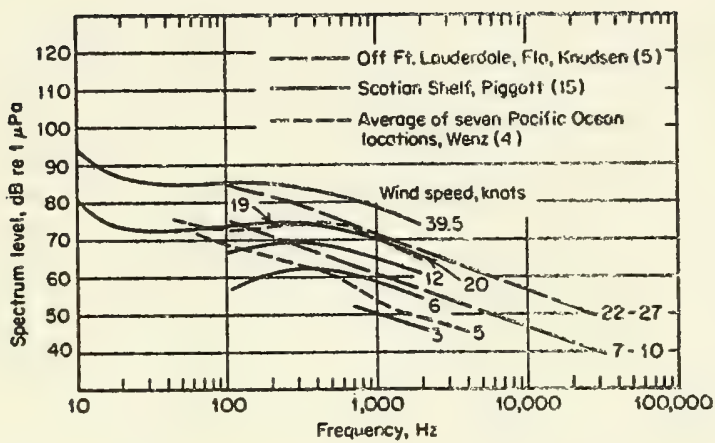

Figure 6. Ambient noise spectra at coastal locations with wind speed as a parameter (Urick, 1975). 


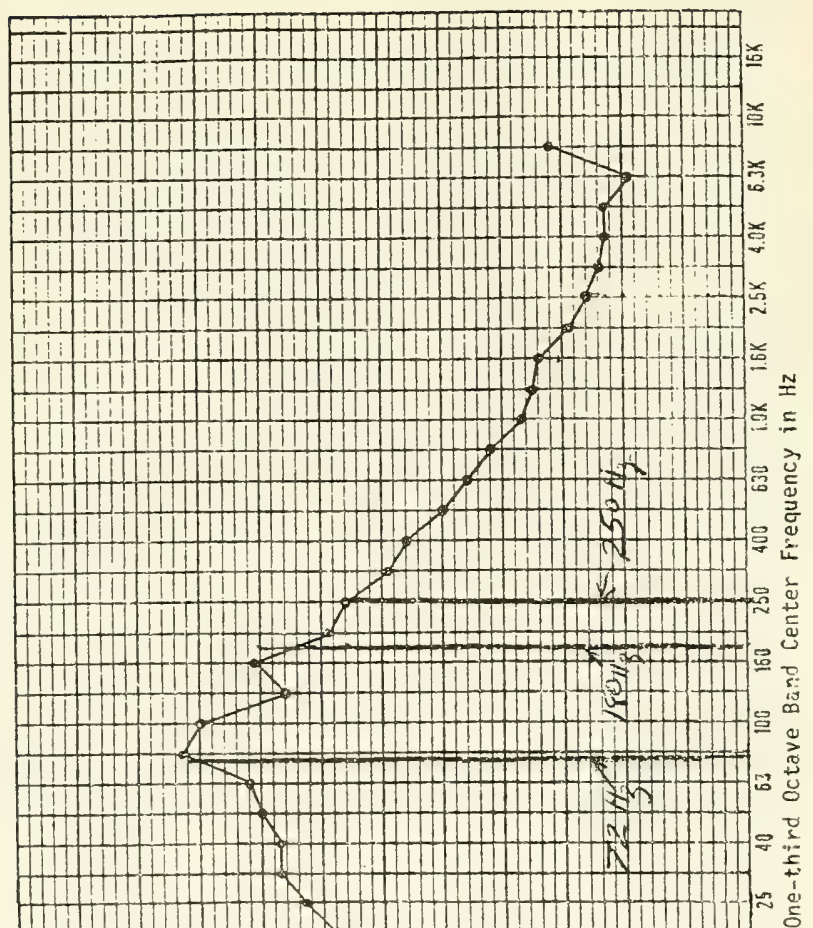

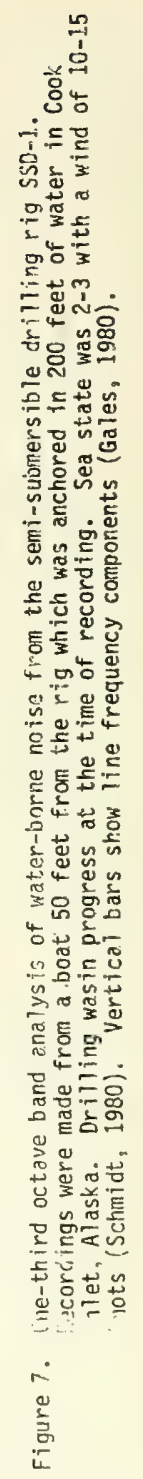




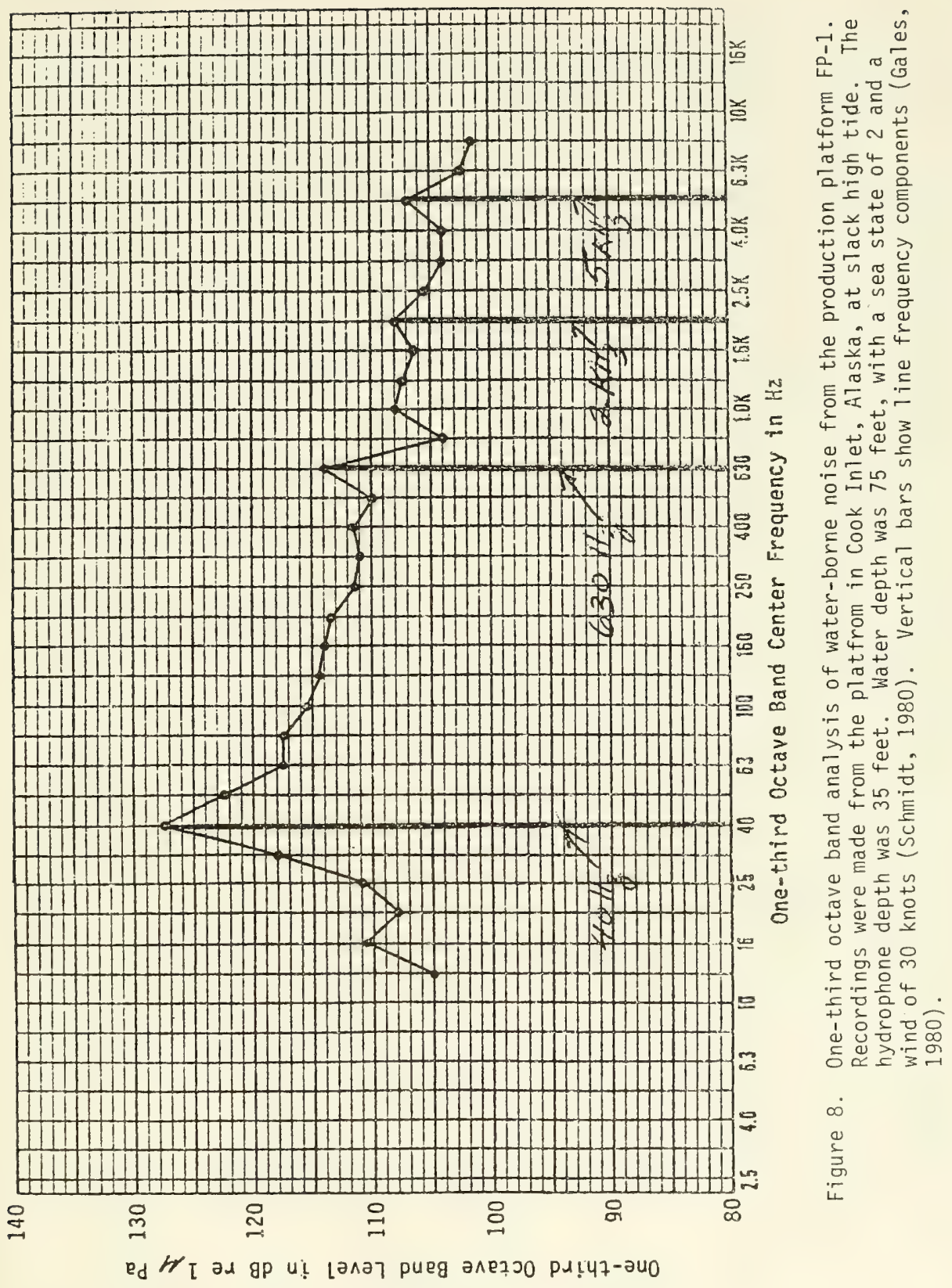




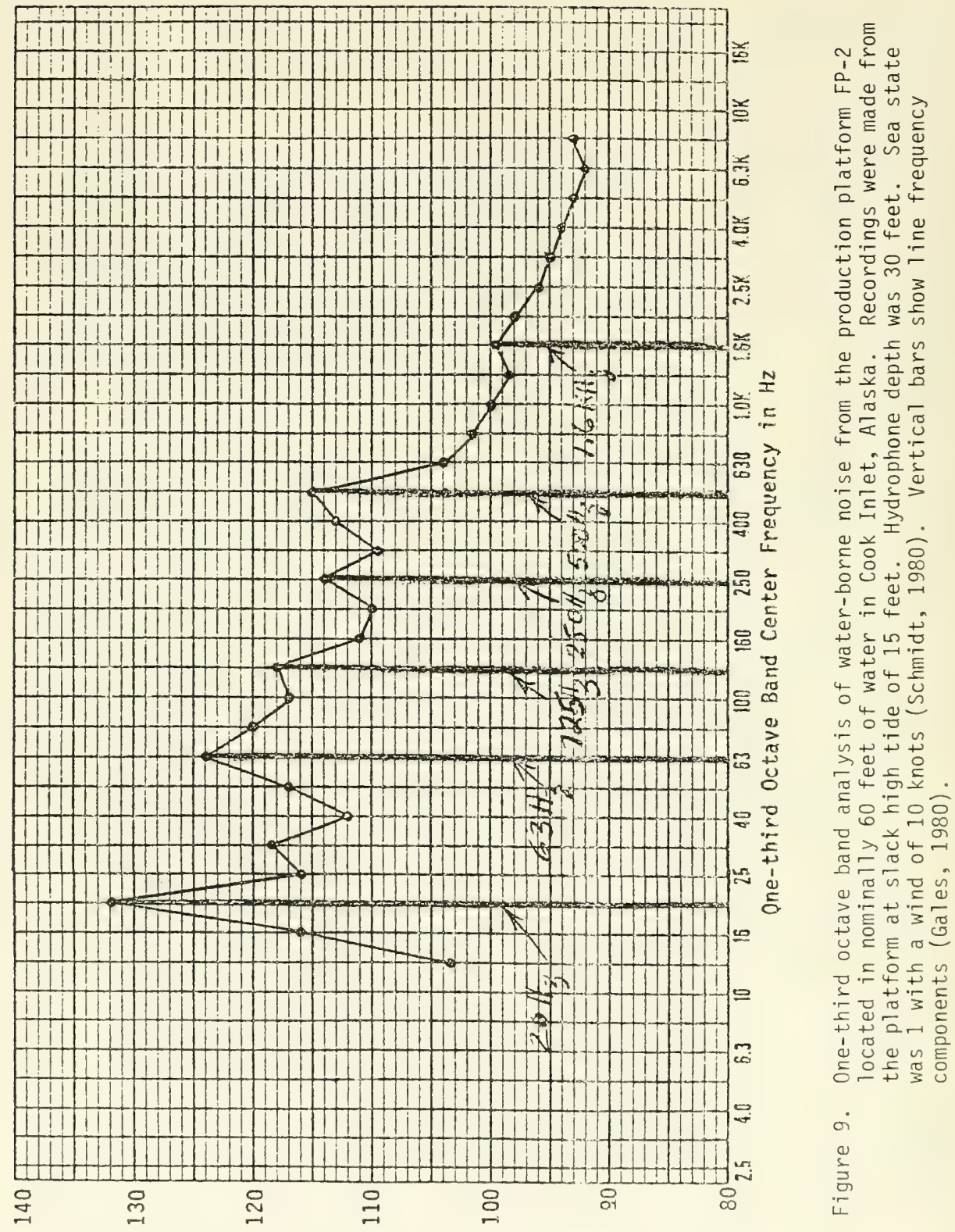

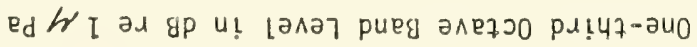


APPENDIX $\mathrm{H}$ 



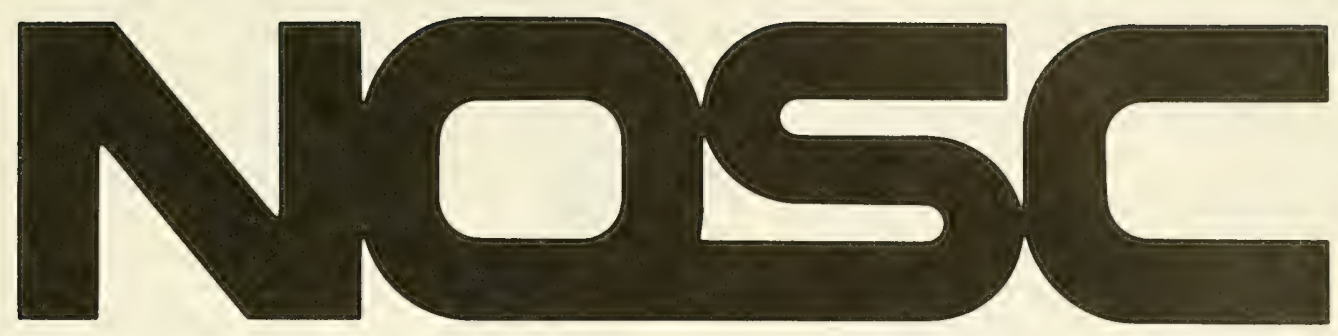

Technical Report 776

POSSIBLE EFFECTS OF NOISE FROM OFFSHORE OIL AND GAS DRILLING ACTIVITIES ON MARINE MAMMALS: A SURVEY OF THE LITERATURE

CW Turl

January 1982

Prepared for

The Bureau of Land Management 


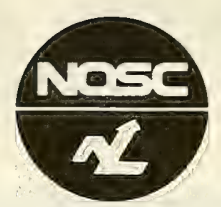

NAVAL OCEAN SYSTEMS CENTER, SAN DIEGO, CA 92152

A N ACTIVITY OF THE NAVAL MATERIAL COMMAND

SL GUILLE, CAPT, USN

Commander
HL BLOOD

Technical Director

\section{ADMINISTRATIVE INFORMATION}

The work reported here was performed under NOSC work unit FGOV BLM 0 513-MM28. It was manged by the Bureau of Land Management, New York Office, from the Bureau of Land Management, Washington, D. C.

The author thanks W. A. Friedl, NOSC Code 512, for his assistance and suggestions in the preparation of this report.

Released by:

JM Stallard, Head

Bioacoustics \& Bionics Division
Under authority of:

HO Porter, Head

Biosciences Department 


\begin{tabular}{|c|c|}
\hline REPORT DOCUMENTATION PAGE & $\begin{array}{l}\text { READ INSTRUCTIONS } \\
\text { BEFORE COMPLETING FORM }\end{array}$ \\
\hline $\begin{array}{l}\text { 1. REPORT NUMBER } \\
\text { NOSC Technical Report } 776 \quad \text { (TR 776) }\end{array}$ & 3. RECIPIENT'S CATALOG NUMBER \\
\hline \multirow{2}{*}{$\begin{array}{l}\text { 4. TITLE (and Subtite) } \\
\text { POSSIBLE EFFECTS OF NOISE FROM OFFSHORE OIL AND GAS } \\
\text { DRILLING ACTIVITIES ON MARINE MAMMALS: A SURVEY OF } \\
\text { THE LITERATURE }\end{array}$} & $\begin{array}{l}\text { 5. TYPE OF REPORT \& PERIOD COVERED } \\
\text { Final: FY } 80\end{array}$ \\
\hline & 6. PERFORMING ORG. REPORT NUMBER \\
\hline $\begin{array}{l}\text { 7. AUTHOR(s) } \\
\text { C. W. Turl }\end{array}$ & 8. CONTRACT OR GRANT NUMBER( \\
\hline $\begin{array}{l}\text { 9. PERFORMING ORGANIZATION NAME AND ADDRESS } \\
\text { Naval Ocean Systems Center, Hawaii Laboratory } \\
\text { P.O. Box } 997 \\
\text { Kailua, Hawaii } 96734\end{array}$ & $\begin{array}{l}\text { 10. PROGRAM ELEMENT, PROJECT, TASK } \\
\text { AREA \& WORK UNIT NUMBERS } \\
\text { FGOV BLM O } 513-\mathrm{MM} 25\end{array}$ \\
\hline \multirow{2}{*}{$\begin{array}{l}\text { 11. CONTROLLING OFFICE NAME ANO ADDRESS } \\
\text { Bureau of Land Management, New York Office } \\
26 \text { Federal Plaza } \\
\text { New York, NY } 10007\end{array}$} & $\begin{array}{l}\text { 12. REPORT DATE } \\
\text { January } 1982\end{array}$ \\
\hline & 13. NUMBER OF PAGES 24 \\
\hline \multirow[t]{2}{*}{ 14. MONITORING AGENEY NAME \& ADDRESS(If different from Controlling Olfice) } & $\begin{array}{l}\text { 15. SECURITY CLASS. (of thia roport) } \\
\text { Unclassified }\end{array}$ \\
\hline & $\begin{array}{l}\text { 15a. DECLASSIFICATION DOWNGRADING } \\
\text { SCHEDULE }\end{array}$ \\
\hline
\end{tabular}

Approved for public release; distribution unlimited.

17. DISTRIBUTION STATEMENT (of the abstract entored in Block 20, if dilforont trom Report)

18. SUPPLEMENTARY NOTES

19. KEY wORDS (Continue on roverse alde if neceasary and tdentify by block number)

Behavior

Outer Continental Shelf

Underwater Noise

Dolphins

Sea Lions

Whales

Marine Mammals

Offshore Drilling Activities

Seals

Offshore Drilling Noise

Sound Production

Underwater Hearing

20. ABSTRACT (Conlinue on roverse side if necessary and idenlify by block number)

The acoustic environment in the area of offshore oil and gas drilling activities may influence the behavior of marine mammals. Increased noise levels may mask their acoustic signals. Offshore structures and the increased level of human activities in outer continental shelf areas could displace marine mammals from traditional feeding and breeding areas. No conclusions about the effects of noise on natural populations have been verified under controlled conditions. 


\section{OBJECTIVES}

1. Summarize the data on underwater noise generated from offshore drilling activities.

2. Summarize the data on underwater hearing capabilities of marine mammals.

3. Estimate the possible impact of noise from offshore drilling operations and associated human activities on natural populations of marine mammals.

\section{RESULTS}

1. Noise measurements from of fshore drilling operations are sparse. Existing measurements are limited in bandwidth and are variable.

2. Some information is available on the underwater hearing sensitivity for a few species of marine mammals. However, without direct measurement of a species it is impossible to extrapolate to other species.

3. Information on the effects of subcritical levels of noise on animals is inconclusive. The effects of noise on natural populations of marine mammals is largely anecdotal. Therefore, the effects of offshore drilling noise on these animals based on present data cannot be determined.

4. No conclusions about the effects of stress on natural populations of marine mammals has been verified under controlled conditions.

\section{RECOMMENDATIONS}

1. Measure the noise generated from current and future offshore drilling operations. Include sensitive frequency ranges from known marine mammal audiograms.

2. Identify lease areas where offshore oil development is anticipated. Identify species of marine mammals that inhabit these areas.

3. Identify lease areas where introduction of increased sustained noise might disrupt a critical life cycle of marine mammals. For example, feeding, breeding, transit or congregation areas.

4. Initiate a monitoring program when a lease area is opened. Monitor both acoustic and population parameters in the lease area as development progresses.

5. Develop a program to monitor the effects of controlled introduction of noise to a marine mammal population. Quantify the effects of the noise on the population.

6. Obtain underwater audiograms of marine mammals that occur in the selected lease areas.

7. Determine the effects of noise on marine mammals under controlled conditions. 


\section{CONTENTS}

INTRODUCTION . . p page 5

SUMMARY OF LITERATURE . . 6

SUMMARY OF PUBLISHED DATA . . . 8

Estimated Source Levels . . . 8

Offshore Drilling Activities in the Prudhoe Bay Area . . . 8

Tufts Point Dredging Site/Arnak Artificial Island Construction Site . . 12

Logistic Traffic Noise at the Tufts Point Site . . 12

Semi-Submersible Platform in the North Atlantic . . . 12

UNDERWATER HEARING OF MARINE MAMMALS . . 14

Sound Production and Hearing of Large Whales . . . 16

DISCUSSION ... 18

RECOMMENDATIONS . . . 20

REFERENCES . . . 21

\section{ILLUSTRATIONS}

1 Average source level of noise generated from two drilling sites in Prudhoe Bay ... 9

2 Average source level of noise generated from a construction site in the Beaufort Sea . . 9

3 Average source level of noise generated from a construction site in the Beaufort Sea . . 10

4 Maximum source levels of transient noise generated from a construction site in the Beaufort Sea ... 10

5 Maximum source levels of the noise generated by logistic support traffic measured in the vicinity of a construction site in the Beaufort Sea . . 11

6 Maximum source levels of the noise generated from a semi-submersible drilling platform located in the Atlantic Ocean ... 11

7 Behavioral underwater audiograms (smoothed curves) for the beluga whale and the bottlenosed porpoise... 15

8 Behavioral underwater audiograms (smoothed curves) for the harbor porpoise and the killer whale.

9 Behavioral underwater audiograms (smoothed curves) for the California sea lion, the harp seal, the ringed seal and the harbor seal . . 16

10 Summary of possible effects of offshore drilling noise on marine mammal population... 19

\section{TABLES}

1 Estimated distances from which noise from oil and gas drilling activities might be detected by marine mammals . . 13

2 Summary of source level data for cetaceans ... 17 


\section{INTRODUCTION}

Increasing noise levels are the result of advanced technologies and rapidly growing human populations. Noise is a by-product of almost every aspect of human activity. Areas previously thought to be remote and nonpolluted by noise may soon have noise pollution from a variety of sources.

Offshore petroleum operations increased rapidly during the last decade and an even more rapid increase is anticipated for the next two decades. Noise generated during offshore drilling operations may become noise pollution for some acoustic sensors (ref 1). Early offshore drilling activities were concentrated in shallow water regions (eg, the Gulf of Mexico), but future exploration and production facilities will extend to water several thousand feet deep. These deep water noise sources will have better acoustic coupling to deep oceanic waters, and thus the noise may impact larger areas.

The Environmental Protection Agency (EPA) has identified the need for information on the effects of noise on wildlife (ref 2). The EPA recommended studies to determine (1) the effects of low-level chronic noise on animals, and (2) the effects of noise on animals in their natural habitat (ref 3,4).

The Bureau of Land Management has identified two aspects of outer continental shelf gas and oil activities that may impact marine mammals: (1) the effects of underwater sounds emitted from oil and gas operations on cetacean behavior, and (2) the impact of offshore structures and associated human activities on cetacean populations.

The effects of noise on man and animals has been documented (see ref 5, 6 for review). The effects of noise are classified as (1) effects on the auditory system resulting in loss of hearing or damage to the auditory mechanism, or (2) nonauditory effects of noise.

In the first case, loss of hearing or damage to auditory structures can be produced by brief exposures to very intense sounds or prolonged exposures to moderate levels of sound. Noise with different frequency spectra have different effects on auditory structures. High frequency pure tones or narrow bands of noise tend to produce changes in localized regions of the inner ear. Low frequency or random and broadband noise tend to produce changes throughout the cochlea. The extent of noise-induced damage to the auditory system depends on the intensity, spectrum, duration and the exposure pattern of the noise source. Rest intervals between periods of exposure significantly reduce the extent of permanent damage.

1 Underwater Systems, Inc. Note 312-5, Noise measurements from Offshore Oil Rigs, p 17, Silver Springs, MD, 1973.

2 Information on Levels of Environmental Noise Requisite to Protect Public Health and Welfare with an Adequate Margin of Safety, Environmental Protection Agency, Superintendent of Documents, U.S. Government Printing Office, Washington, D.C., 1974.

3 The White House, Executive Order No. 11644, as amended May 24, 1977.

4 Janssen, R, Noise and Animals: Perspectives of Government and Public Policy, In: Effects of Noise on Wildlife, JL Fletcher and RG Busnel, ed, p 287-301, Academic Press, New York, NY, 1978.

5 Kryter, KD, The Effects of Noise on Man, p 633, Academic Press, New York, NY, 1970

6 Welch, BL and AS Welch, ed, Physiological Effects of Noise, p 365, Plenum, 1970. 
Nonauditory effects of noise may produce physiological stress, with symptoms analogous to exposure to extreme heat or cold (ref 7,8). An animal's response to stress includes a variety of measurable physiological changes: eg, increased blood pressure. increased cortiosteriod levels, and changes in adrenal gland weight. Prolonged stress can exhaust an animal's resistance to infection and disease and, in extreme cases, can result in the animal's death.

Noise produces the same general effects in animals and humans: namely, hearing loss. masking of signals, behavioral changes, and nonauditory physiological effects. Laboratory studies with animals indicate temporary and permanent noise-induced threshold shifts. However, damage risk criteria for most species of animals have not been developed. Physiological effects of noise exposure have been demonstrated in laboratory and farm animals, but the degree to which the results apply to wildlife is unknown. Animals' physiological and behavioral adaptations to noise stimuli are also yet unknown, and definitive research criteria to assess such adaptation have not been developed. In this report, however, judgments of environmental impact will be based on existing, though incomplete, information (ref 2).

The acoustic environment in areas of offshore drilling activities may influence the behavior of marine mammals. Increased noise levels may mask acoustic signals or reduce the range at which the mammals detect the signals (ref 9).

The impact of offshore structures and the associated increase in the level of human activities in outer continental shelf areas could disrupt normal migratory routes or displace marine mammals from traditional feeding and breeding areas. Such disruptions could reduce the biological fitness of a population.

This report summarizes (1) acoustic data from offshore drilling activities, and (2) the hearing capabilities of cetaceans and pinnipeds and presents data on the underwater hearing of large whales. The report also discusses the possible impact of offshore drilling activities on natural populations of marine mammals.

\section{SUMMARY OF LITERATURE}

Underwater noise measurements from offshore drilling activities are sparse. Published surveys and the author's personal contacts with private industry reveal that available information is bandwidth limited: ie. the measurements at high frequency were limited or the low frequencies were rolled off due to high ambient noise. Shallow water ambient noise measurements also are limited. In the shallow water of most offshore drilling operations (ie, less than $250 \mathrm{~m}$ ) accurate source level noise measurements are difficult because of multipath propagation (ref 10). Variability is inherent in the data because sound propagation characteristics vary greatly in shallow water and ambient background noise is strong and variable in sheif areas.

7 Selye, H, Stress and Disease, Science. 122(3171), p 625-631, 1955.

8 Selye. H, The General Adaptation Syndrome and the Diseases of Adaptation, J Clin Endocrin \& Metab, 6(2), p 117-230, 1946.

9

Myrberg, AA, Ocean Noise and the Behavior of Marine Animals: Relationships and Implications, In: Effects of Noise on Wildlife, JL Fletcher and RG Busnel, ed, p 168-208, Academic Press, New York, NY, 1978.

10 Drouin, AH, Design and Field Operation of an Underwater Acoustic Telemetry System, Offsinore Tech. nology Conference, 6th, OTC 1965, p 9. 
The source level data from offshore drilling activities specify the amount of sound energy radiated by a projector measured $1 \mathrm{~m}$ from the source.

The anatomy and function of the auditory and audio-neural structure of several species of small cetaceans have been reviewed (ref 11-16). Electrophysiological recordings and cochlear microphonic measurements (ref 13) support the hypothesis that sound is received via bone conduction through the fat layer of the lower jaw (ref 16) for small toothed whales.

The anatomical structure of the mysticete (large whales) auditory structure has been reviewed (ref 17-19). Mysticete cochlea are structurally sensitive to low frequency sounds; however, these animals may he capable of hearing higher frequencies (ref 20). Anecdotes suggest that large whales respond to ship noise, sonar pings and low flying aircraft (ref 21).

The pinniped external ear accommodates in-air and underwater hearing. Underwater, the pinniped head may conduct sound directly to the organ of Corti, whereas aerial sound transmission apparently is typically mammalian (ref 22 ).

${ }^{11}$ Morgane, JP and NS Jacobs, Comparative Anatomy of the Cetacean Nervous System, In: Functional Anatomy of Marine Mammals, Vol 1, RJ Harrison, ed, p 117-244, Academic Press, New York, NY, 1972.

12 Bullock. TH, AD Grinnel, E Ikezono, K Kameda, Y Katsuki, M Nomoto, N Sato and K Yanagisawa, Electrophysiological Studies of the Central Auditory Mechanism in Cetaceans, Z Vergl Physiol 59, p 117 $156,1968$.

13 McCormick, JG, EG Wever, J Palin and SH Ridgway, Sound Conduction in the Dolphin Ear, J Acous Soc Amer, 48(6), p 1418-1428, 1970.

14 Wever, EG, JG Mc Cormick, J Palin and SH Ridgway, The Cochlea of the Dolphin, Tursiops truncatus: General Morphology, Proc Nat Acad Sci, 68(10), p 2381-2385, 1971.

${ }^{15}$ Fraser, FC and PE Purves, Hearing in Cetaceans, Bull of Brit Mus, 7, p 1-140, 1960.

16 Norris. KS. The Echolocation of Marine Mammals. In: The Biology of Marine Mammals, HT Harrison, ed, p 391-423, Academic Press, New York, 1969.

${ }^{17}$ Reysenback de Haan, FW, Hearing in Whales, Acta Otolaryngal, 134, p 1-114, 1957.

18 Dudok van Heel, WH, Sound and Cetacea, Neth J Sea Res, 1(4), p 407-507.

${ }^{19}$ Purves, PE, Anatomy and Physiology of the Outer and Middle Ear in Cetacea, In: Whales, Dolphin and Porpoise, KS Norris, ed, Univ of Calif Press, p 320-380, 1966.

${ }^{20}$ Fleischer, G, Hearing in Extinct Cetaceans as Determined by Cochlear Structure, J Paleontol, 50(1), p 133-152, 1976.

21 Norris, KS and RR Reeves, eds, Report on a Workshop on Problems Related to Humpback Whales (Megaptera novaeangliae) in Hawaii, US Dept Comm, NTIS PB-280-794, p 90, 1978.

22 Reppening, CA, Underwater Hearing in Seals, In: Functional Anatomy of Marine Mammals, RJ Harrison, ed, p 307-331, Academic Press, New York, 1972. 
The techniques used to measure auditory thresholds of mammals have been reviewed (ref 23). Both behavioral or electrophysiological methods have been used to measure the hearing thresholds of marine mammals. Although an audiogram (ie, a measurement of hearing sensitivity as a function of frequency) describes an animal's hearing limits and regions of maximum sensitivity, it does not describe the animal's ability to hear a signal in the presence of background noise. To determine such detection ability, critical band or critical ratio data are required.

Audiograms indicate that cetaceans and pinnipeds are capable of hearing noise from offshore drilling activities. Data concerning marine mammals' reactions to such sounds are incomplete and essentially lacking.

\section{SUMMARY OF PUBLISHED DATA}

Source levels ( $\mathrm{dB}$ re $1 \mu \mathrm{Pa}$ at $1 \mathrm{~m}$ ) for six offshore drilling activities are shown in figures 1 through 6 . Estimated source levels were computed by taking the absolute received level measured at the hydrophone and applying propagation loss for the distance from the source so as to estimate the absolute level $1 \mathrm{~m}$ from the source.

Transmission loss in shallow water is sensitive to the environment, eg, sea surface, water depth and bottom type; therefore, spherical spreading loss $(20 \log R)$ is not appropriate. Reference 24 (figure 1) cites $40 \log \mathrm{R}$ to approximate sound propagation in the shallow water of Prudhoe Bay. Reference 25 (figures 2 through 5) approximates transmission loss as $(20 \log \mathrm{R}+\mathrm{XR})+\mathrm{S}^{1}$. For figure $2, \mathrm{X}=.0045 \mathrm{~dB}$, and for figures 3 through 5 , $\mathrm{X}=.0075 \mathrm{~dB}$. Spherical spreading $(20 \log \mathrm{R})$ was used to approximate the transmission loss in computing source levels for figure 6 (ref 26).

The source levels of specific frequency components contained in the noise spectrum shown in figures 1 through 3 (ref 24,25) are based on maximum received levels measured at several distances from the source; therefore, the data in these figures are plotted as average source levels. Source levels shown in figures 4 and 5 (ref 25) and in figure 6 (ref 26) are based on maximum received levels measured at a single distance from the source. The data in these figures are plotted as maximum source levels.

\section{ESTIMATED SOURCE LEVELS}

\section{Offshore Drilling Activities in the Prudhoe Bay Area}

Figure 1 shows the major noise components from two drilling sites in the Prudhoe Bay area: the NIAKUK 3 well, on a man-made gravel island, and the Reindeer Island Cost Well, on a natural barrier beach island (ref 24). The source levels plotted are averages for received levels measured at ranges from 1000 to $1600 \mathrm{~m}$.

\footnotetext{
23 Francis, RL, Behavioral Audiometry in Mammals: Review and Evaluation of Techniques, Symp Zool Soc Lond, 37, p 327-280, 1975.

${ }^{24}$ Bolt Beranek and Newman Inc Tech Memo 513, Measurements of Underwater Acoustic Noise in the Prudhoe Bay Area, by CI Malme and R Mlawski, p 16, 1979.

25 Ford, J White Whale Offshore Exploration Acoustic Study, Report submitted to Imperial Oil Co, FF Slaney and Co, Ltd, Vancouver, Canada, p 21, 1977.

${ }^{26}$ Bell Laboratories, APEX Final Report, by SA Kramer and TE Wing, 1976.
} 


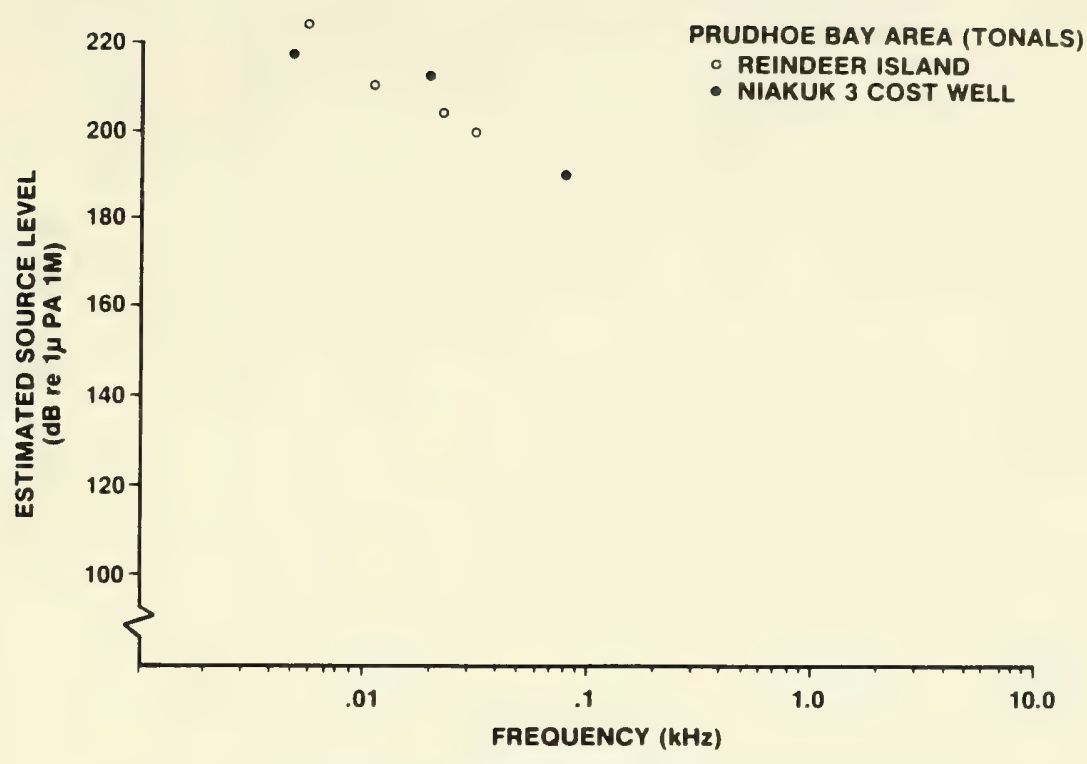

Figure 1. Average source level of noise generated from two drilling sites in Prudhoe Bay.

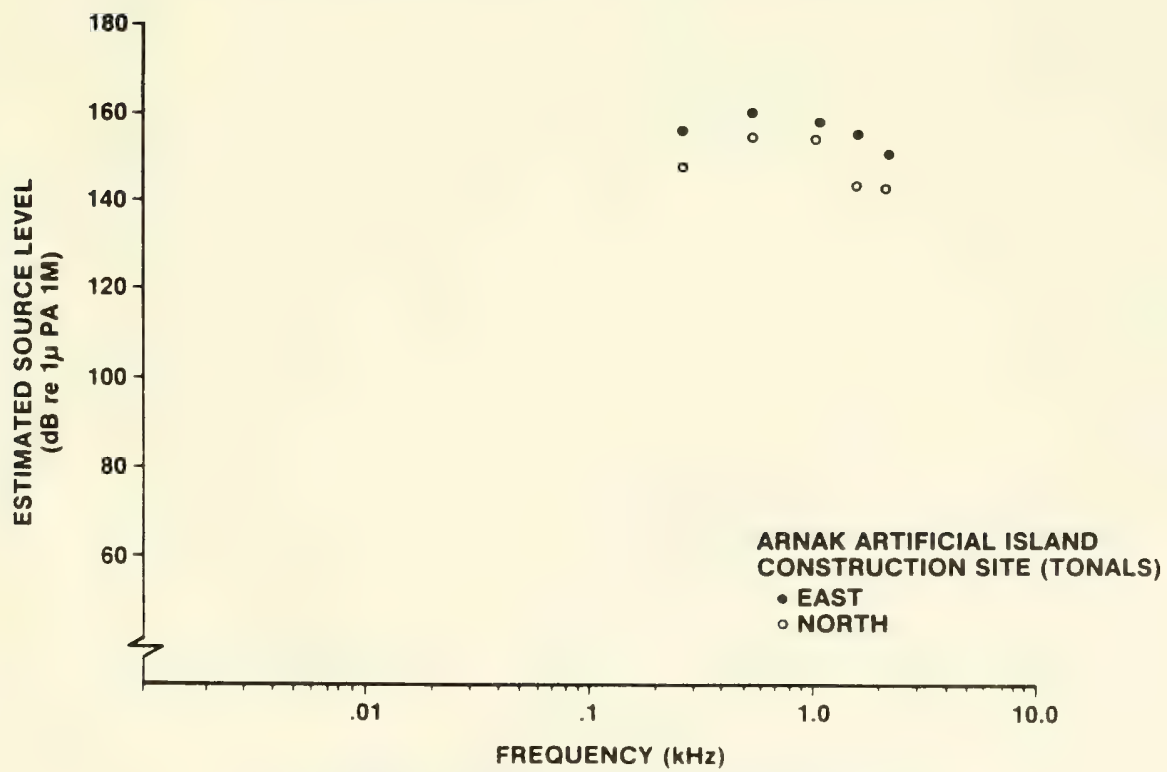

Figure 2. Average source level of noise generated from a construction site in the Beaufort Sea. 


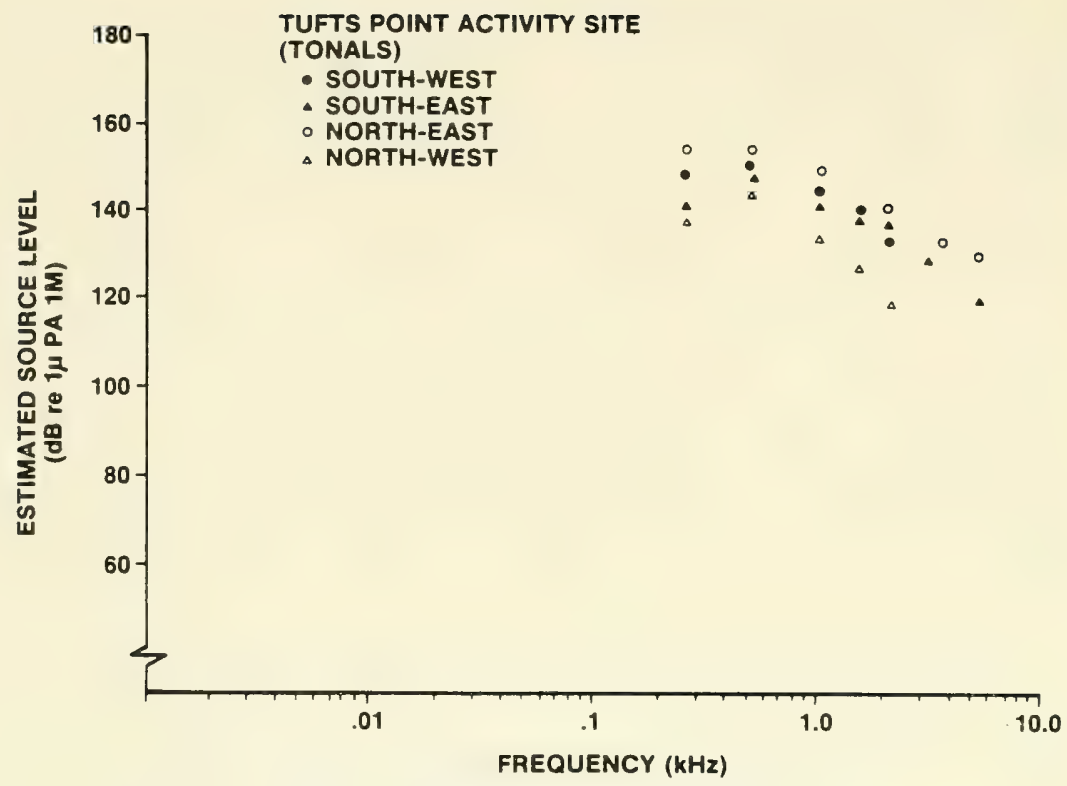

Figure 3. Average source level of noise generated from a construction site in the Beaufort Sea.

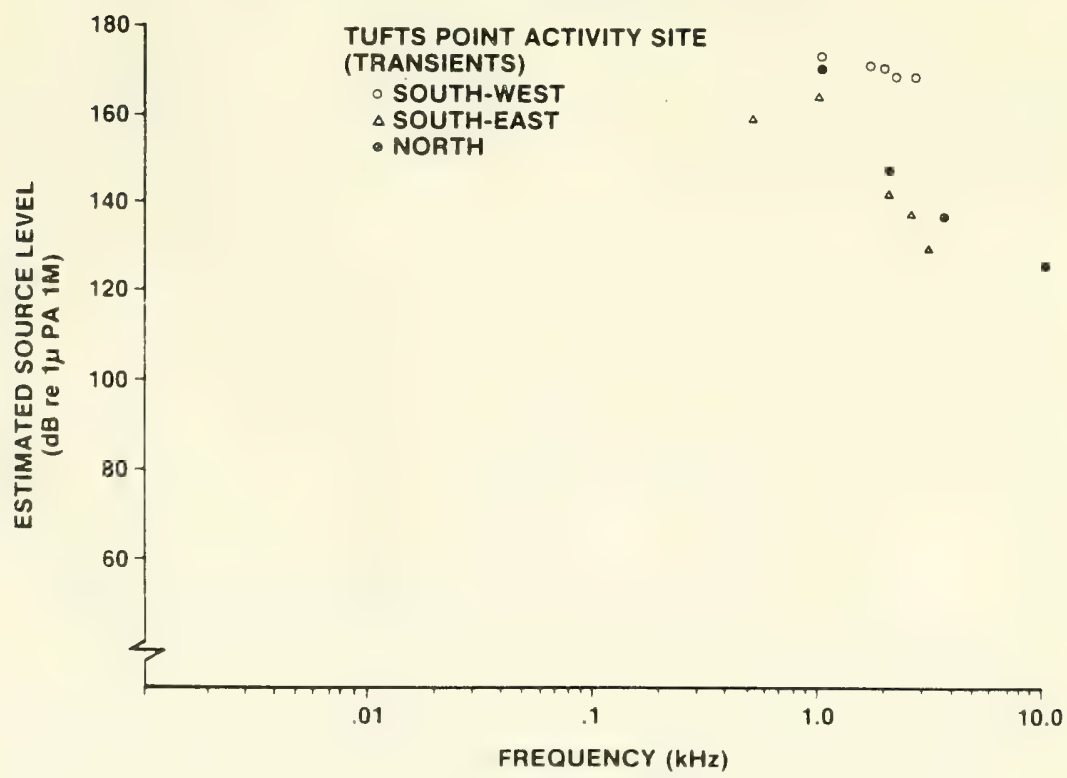

Figure 4. Maximum source levels of transient noise generated from a construction site in the Beaufort Sea. 


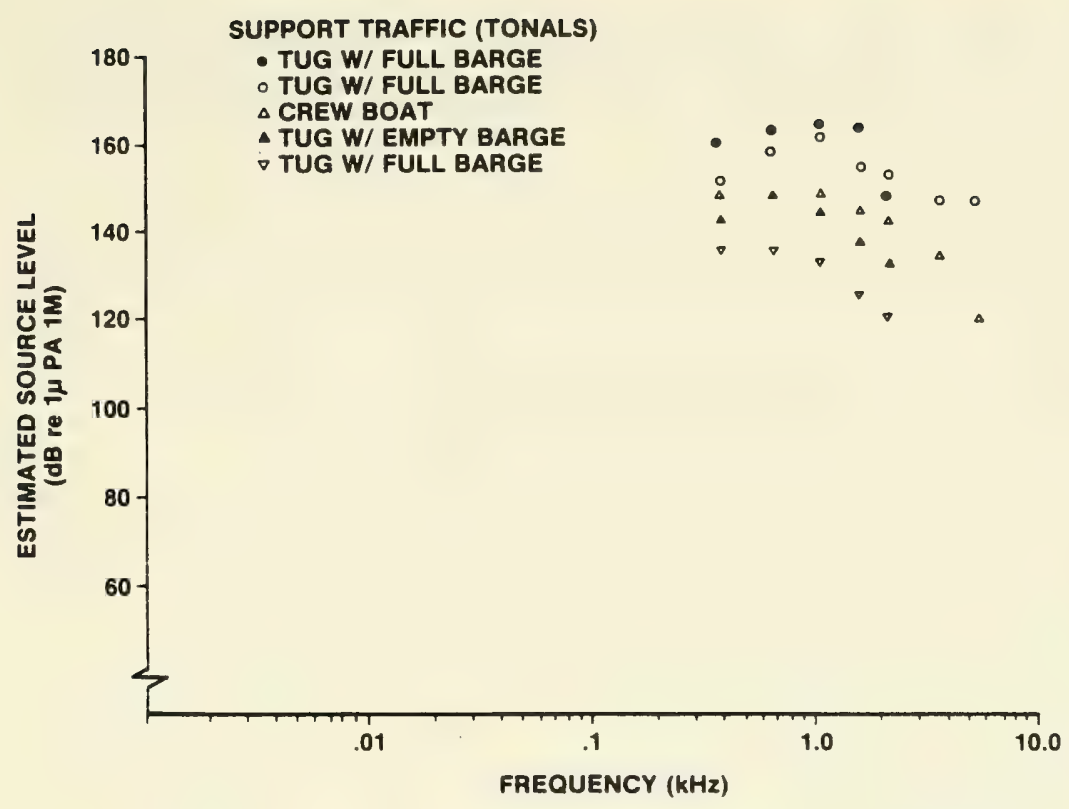

Figure 5. Maximum source levels of the noise generated by logistic support traffic measured in the vicinity of a construction site in the Beaufort Sea.

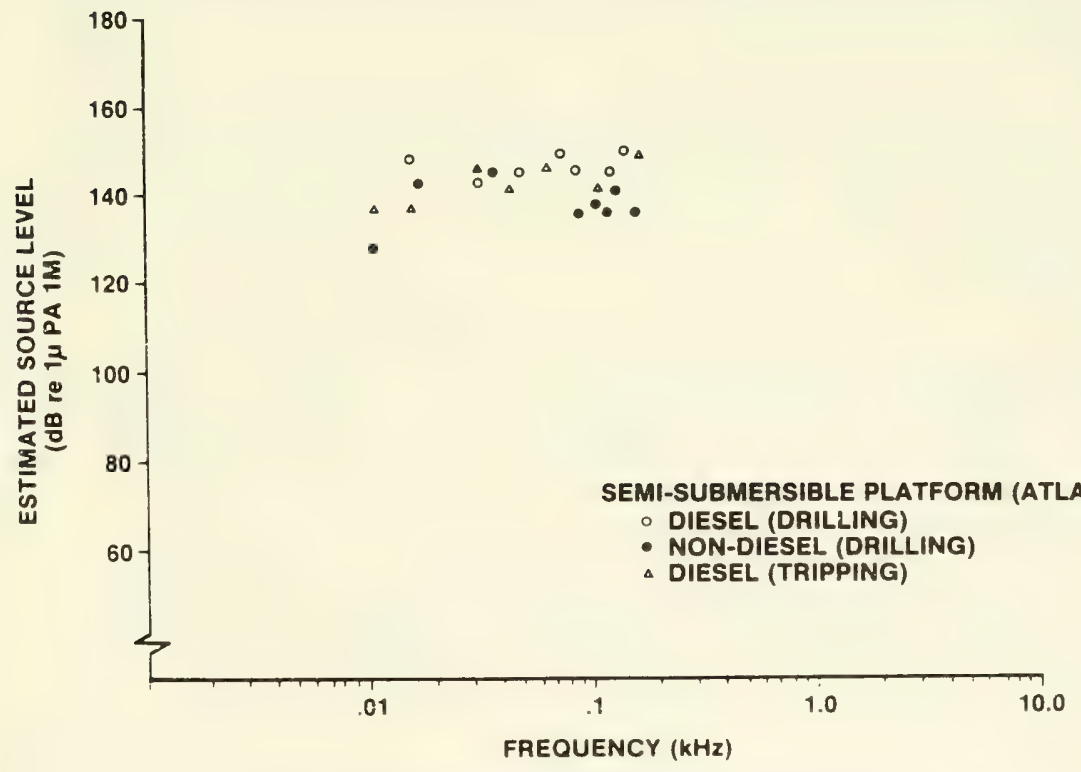

Figure 6. Maximum source levels of the noise generated from a semi-submersible drilling platform located in the Atlantic Ocear. 
Although the Prudhoe Bay data show little difference in noise level, the noise components at each site differ. The authors (ref 24) note that the noise levels above $8 \mathrm{kHz}$ were low.

\section{Tufts Point Dredging Site/Arnak Artificial Island Construction Site}

Figures 2, 3 and 4 show the noise generated from two construction locations in the Beaufort Sea (ref 25). The sounds are from construction activities associated with development of of fshore operations.

At the Arnak artificial island site, operating machinery included a suction dredge, a tending tug, a clamshell shovel, and several crew boats. Figure 2 shows the noise components from this site. The frequency band and amplitudes from the Tufts Point and Arnak sites are similar. Data were not reported for frequencies below $250 \mathrm{~Hz}$ (ref 25).

At the Tufts Point dredging site, noise sources included a suction dredge, crew boats and tugs. Noise measurements were made at ranges from 90 to $4000 \mathrm{~m}$ in four different directions from the site. An artificial breakwall extends northwest from the site and probably limited noise from that direction (fig 3 ). The average noise levels from the other three directions are similar in frequency and higher than values measured from the northwest.

Transient sounds also were recorded at the Tufts Point site. Noisy couplings in the floating pipeline probably produced the short-duration sounds plotted in figure 4.

\section{Logistic Traffic Noise at the Tufts Point Site}

Figure 5 shows the noise generated from tugs, tugs pushing barges (empty and full) and crew boats at the Tufts Point site. The frequency spectra and amplitudes are comparable to those in figure 2. The isolated sources shown in figure 5 also were included in the composite sounds shown in figure 2.

\section{Semi-Submersible Platform in the North Atlantic}

Figure 6 shows source levels for low frequency component noise from a semi-submersible drilling platform in the North Atlantic (ref 26). These values are similar to those shown in figure 1, but the amplitude varies less with frequency. The Atlantic measurements are from a single. distant measuring site in deep water, and thus likely less variable than the Arctic measurement.

Data in figures 1-6 show noise from offshore oil and gas drilling activities is in the frequency range from $10 \mathrm{~Hz}$ to $10 \mathrm{kHz}$, with peak source levels between 130 and $180 \mathrm{~dB}$. Signal-to-noise $(\mathrm{S} / \mathrm{N})$ ratios may approach 80 to $100 \mathrm{~dB}$ above background noise levels (ref 27). Depending on the detection threshold of the receiver and the prevailing background noise levels, $\mathrm{S} / \mathrm{N}$ levels of these magnitudes could be detected at considerable ranges from the source.

To estimate distances at which a marine mammal could detect a component of noise with source levels shown in figures 1-6, a transmission loss model for deep or shallow water propagation must be selected. Either model includes a number of assumptions concerning the characteristics of the receiving system. (Information on the hearing for large whales is discussed in the following section.) These assumptions are:

\footnotetext{
27 Urick, RJ, Principles of Underwater Sound, p 384, McGraw-Hill Book Co, 1967.
} 
- The underwater hearing of large whales is optimized. Because the ocean is a noisy place, an acoustic system will be limited by noise before it is limited by sensitivity; therefore, a detection threshold of $0 \mathrm{~dB}$ will be required for a signal to be heard 50 percent of the time.

- The hearing bandwid th is $1 / 3$ octave.

- The receiver is omnidirectional.

In deep water (greater than 100 fathoms), a good approximation for transmission loss is given by spherical spreading $(20 \log \mathrm{r})$. The estimation detection range can be approximated by:

$$
\text { Range }(m)=10\left[\frac{S_{(\text {peak })}-\left(\mathrm{N}_{\mathrm{S}}+10 \log \mathrm{BW}\right)}{20}\right]
$$

Where: $\quad \mathrm{SL}_{\text {(peak) }}=$ Peak source level $(\mathrm{dB}$ re $1 \mu \mathrm{Pa}$ at $1 \mathrm{~m})$

$\mathrm{N}_{\mathrm{S}} \quad=$ Background noise level $(\mathrm{dB}$ re $1 \mu \mathrm{Pa})$

BW $=$ Critical bandwidth at the frequency of the signal.

Attenuation is also a factor in range determinations. The attenuation coefficient $(\alpha)$ is frequency dependent, and at frequencies below $1 \mathrm{kHz}$ is approximately $0.05 \mathrm{~dB} / \mathrm{kyd}$. In the following calculations attenuation was considered insignificant and was ignored.

In shallow water, transmission loss is sensitive to many variables, particularly the sea surface, the water medium and the bottom. Thus, in the absence of specific knowledge of the variables, especially the sound velocity and density structure of the bottom, transmission loss in shallow water is only approximately predictable (see ref 27). Therefore, for shallow water, the formula above at best approximates a "minimal detectable range" in the absence of further information.

The values in table 1 show that noise generated from oil and gas drilling activities may be detected at considerable distances from the drilling sites. Favorable propagation characteristics could extend these ranges further.

\begin{tabular}{|c|c|c|c|c|c|c|}
\hline \multirow{2}{*}{$\begin{array}{c}\text { FREQUENCY } \\
(\mathrm{kHz})\end{array}$} & \multirow{2}{*}{$\begin{array}{l}\text { SOURCE } \\
\text { LEVEL } \\
\text { (dB) }\end{array}$} & \multirow{2}{*}{$\begin{array}{l}\text { BACKGROUND } \\
\text { NOISE } \\
\text { (dB) }\end{array}$} & \multirow{2}{*}{$\begin{array}{c}\text { BANDWIDTH } \\
(\mathrm{Hz})\end{array}$} & \multicolumn{2}{|c|}{ RANGE } & \multirow{2}{*}{$\begin{array}{l}\text { AREA OF A } \\
\text { CIRCLE WITH } \\
\text { A RADIUS = } \\
\text { TO RANGE } \\
\text { (SQ NMI) }\end{array}$} \\
\hline & & & & Kilometers & NMI & \\
\hline 0.02 & 160 & 60 & 8 & 38 & 21.0 & $1.3 \times 10^{3}$ \\
\hline 0.10 & 150 & 50 & 15 & 17.4 & 9.3 & $2.7 \times 10^{2}$ \\
\hline 1.00 & 180 & 50 & 25 & 174 & 94.0 & $2.8 \times 10^{4}$ \\
\hline
\end{tabular}

Table 1. Estimated minimum distances from which noise from oil and gas drilling activities might be detected by marine mammals. 


\section{UNDERWATER HEARING OF MARINE MAMMALS}

Behavioral underwater audiograms have been made for the bottlenose dolphin, Tursiops trincatus (ref 28), the harbor porpoise, Phocoena phocoena (ref 29), the killer whale, Orcinus orca (ref 30), the white whale, Delphinapterus leucas (ref 31), and the Amazon river dolphin, Inia goeffrensis (ref 32). Audiograms for the bottlenosed dolphin, the killer whale, the harbor porpoise and the white whale are shown in figures 7 and 8 .

Underwater audiograms also have been made for four species of pinnipeds: the California sea lion, Zalophus californianus (ref 33), the harp seal, Pagophilus groenlandicus (ref 34), the ringed seal, Pusa hispida (ref 35), and the harbor seal, Phoca vitulina (ref 36).

Figure 9 shows the underwater audiograms for these four species.

Electrophysiological audiograms have been made for both cetaceans and pinnipeds. Bullock et al (ref 12) tested anesthetized animals, including the striped dolphin, Stenella coeruleoalba, the spotted dolphin, Stenella attenuata, the rough-toothed dolphin, Steno bredanensis, and the Pacific bottlenosed dolphin, Tursiops gilli. Interspecific sensitivities were similar and resembled the behavioral audiogram for Tursiops truncatus (ref 28). Evoked potentials were used to determine an audiogram for an unrestrained, alert grey seal, Halichoerus grypus (ref 37).

Figures 7 through 9 show underwater audiograms for eight species of marine mammals. The data shown in these figures indicate that the marine mammals tested were relatively insensitive at low frequencies. Most underwat ir threshold experiments have been conducted in small tanks that introduced serious measurerient problems because of the sound field in the tank (ref 38). Consequently, the low freque : y thresholds for marine mammals have not been documented adequately.

28 Naval Ordance Test Station TP 4178, Aud. iory Thresholds in the Bottlenose Porpoise, Tursiops truncatus, by CS Johnson, p 22, 1966.

29 Andersen, S, Auditory Sensitivity in the Hor Porpoise, Phocoena phocoena, In: Investigations on Cetacea, Vol 2, G Pilleri, ed, p 255-258, 1970.

${ }^{30}$ Hall, JD and CS Johnson, Auditory Threshold of a Killer Whale, Orcinus Orca, J Acous Soc Amer, 41(1), p 515-517, 1971.

${ }^{31}$ Hubb Sea Work Research Institure Technical Report 78-109, Auditory Thresholds of Two Beluga Whales (Delphinapterus leucas), by MJ White, JC Norris, LK Ljunblad, KS Baron and GN DeSciara, p 13, 1978.

32 Jacobs, DW and JD Hall, Thresholds of a Freshwater Dolphin, Inia geoffrensis, J Acous Soc Amer, 51(1), p 530-533, 1972.

33 Schusterman, RJ, RF Balliet and J Nixon, Underwater Audiogram of the California Sea Lion by Conditioned Vocalization Techniques, J Exp Anal Beh, 17, p 339-350, 1972.

${ }^{34}$ Terhune, JM and K Ronald, The Harp Seal, Pagophilus groenlandicus, III, The Underwater Audiogram, Can J Zool, 50, p 565-569, 1975.

35 Terhune, JM and K Ronald, Underwater Hearing Sensitivity of Two Ringed Seals (Pusa hispida), Can J Zool, 53, p 227-231, 1975.

36 Mohl. B, Auditory Sensitivity of the Common Seal in Air and Water, J Aud Res, 8, p 27.38, 968.

37 Ridgway, SH and PL joyce, Studies on Seal Brain by Radiotelemetry, In: Biology of the Seal, $\mathrm{n}$ Ronaic? and AW Mansfield, eds, p 81-91, 1975.

38 Parvulescu, A, The Acoustics of Small Tanks. In: Marine Bioacoustics, WN Tauolga, ed, p 7-13. Pergammon Press, 1967. 


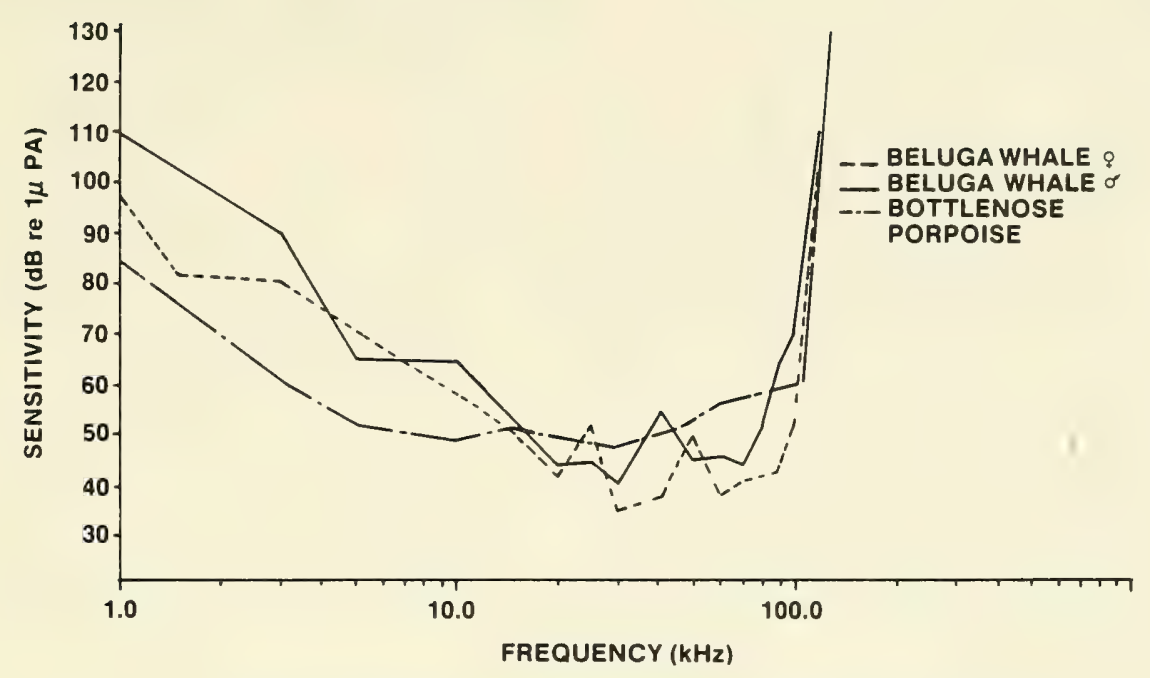

Figure 7. Behavioral underwater audiograms (smoothed cưrves) for the beluga whale and the bottlenosed porpoise.

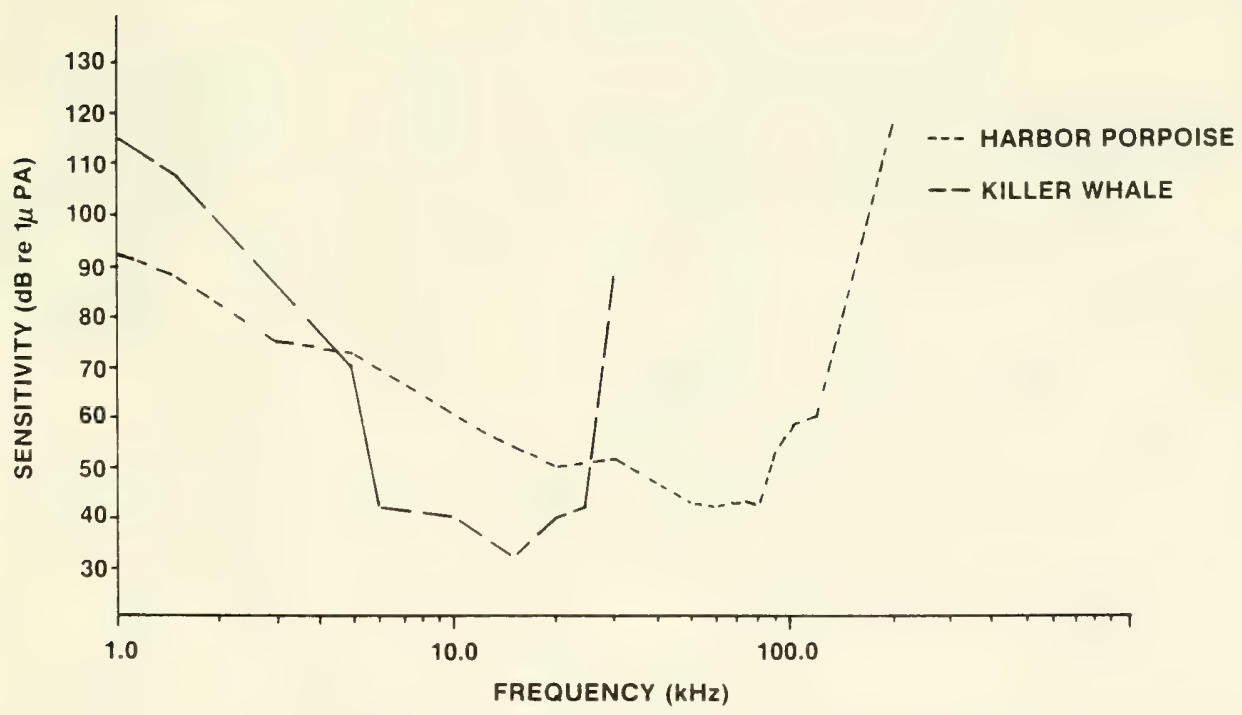

Figure 8. Behavioral underwater audiograms (smoothed curves) for the harbor porpoise and the killer whale. 


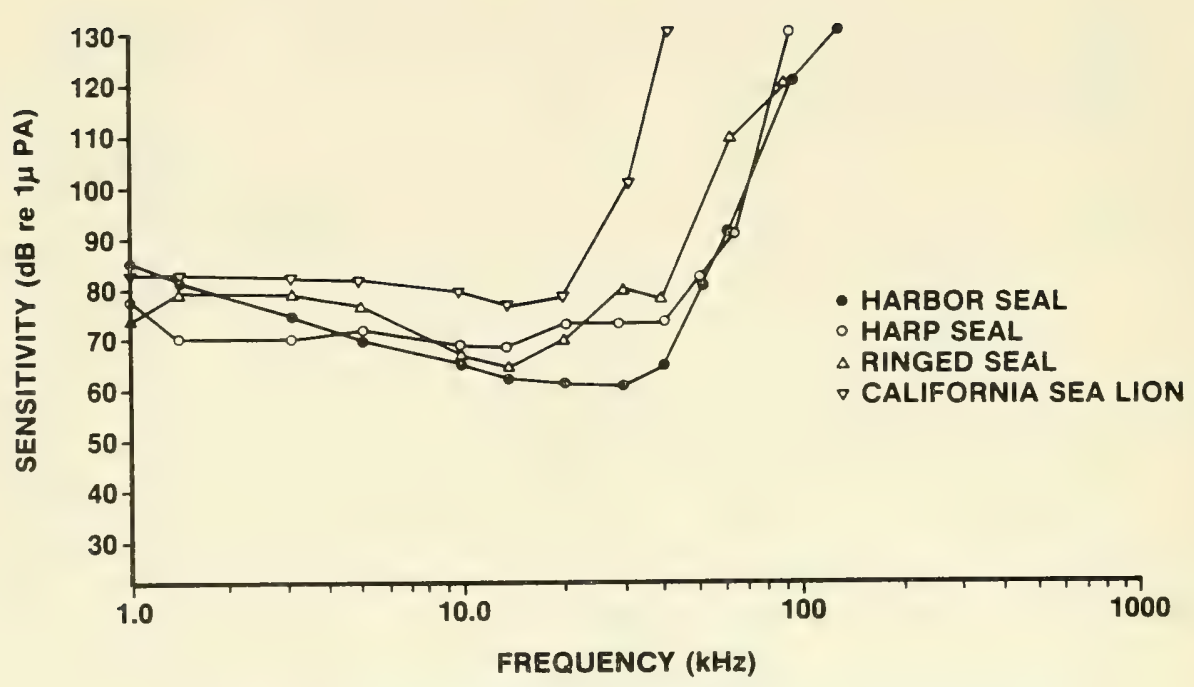

Figure 9. Behavioral underwater audiograms (smoothed curves) for the California sea lion, the harp seal, the ringed seal and the harbor seal.

\section{SOUND PRODUCTION AND HEARING OF LARGE WHALES}

The hearing sensitivities of large whales have not been measured. It is assumed that most animals can hear the sounds they produce; however, we cannot determine the limit of the receiving band width of large whales without direct measurements. Source level and frequency data for cetaceans are summarized in table 2. These reported values are peak energy levels in relatively narrow bands. Broadband source level measurements are presented in reference 39 for four species of small toothed whales (the common dolphin, the northern right whale dolphin, the Pacific pilot whale and the Pacific bottlenosed dolphin). The values shown in table 2 suggest that sounds produced by large whales are restricted in frequency: however, these values probably reflect the manner in which source level data normally are presented as narrow band measurements.

Reference 58 classifies mysticete sounds into four categories. Group I includes low frequency moans with fundamental frequencies from 12 to $500 \mathrm{~Hz}$. The moans generally contain harmonically structured pure tones. Except for the sei and minke whales, all mysticetes make these sounds. Group II sounds include grunt-like thumps and knocks of short duration. The humpback, right, bowhead, grey, fin and minke whales produce these sounds. Major energy in Group II sounds is between 40 and $200 \mathrm{~Hz}$. Group III sounds contain chirps, cries and whistles above $1.0 \mathrm{kHz}$. Chirps generally are pulses of short. discrete.

\footnotetext{
${ }^{39}$ Naval Undersea Center TP 547, Acoustic Source Levels of Four Species of Small Whales, by JF Fish and CW Turl, p 14, 1976.

58 Thompson, TJ, HE Winn and PJ Perkins, Mysticete Sounds. In: Behavior of Marine Mammals, Vol 3. Cetaceans, HE Winn and BL Olla, eds, p 403-431, Plenum Press, 1979.
} 


\begin{tabular}{|c|c|c|c|}
\hline SPECIES & $\begin{array}{l}\text { SOURCE LEVEL } \\
(\mathrm{dB} \text {, re } 1 \mu \mathrm{Pa} @ 1 \mathrm{~m})\end{array}$ & FREQUENCY & $\begin{array}{l}\text { EFERENCE } \\
\text { NUMBER }\end{array}$ \\
\hline \multicolumn{4}{|l|}{ ODONTOCETE } \\
\hline \multirow[t]{2}{*}{ Tursiops truncatus } & $217-228$ & Broadband peak-to-peak level of clicks. & 40 \\
\hline & 175 & Broadband peak-to-peak level of clicks. & 41 \\
\hline Lagenorhynchus australis & 80 & Broadband RMS level of clicks. & 42 \\
\hline Orcinus orca & 160 & Broadband RMS level of screams (click trains) & 43 \\
\hline Stenella lognirostris & $\begin{array}{c}108-115 \\
109-125 \\
85-95\end{array}$ & $\begin{array}{l}\text { Broadband R,S levels of pulse bursts. } \\
\text { "squeals" } \\
\text { clicks }\end{array}$ & 44 \\
\hline Inia geoffrensis & 165 & Broadband peak-to-peak levels of clicks. & 45 \\
\hline \multirow[t]{2}{*}{ Phocena phocena } & 100 & Broadband RMS level of clicks. & 46 \\
\hline & 140 & Mean and range of peak broadband levels of click. & 43 \\
\hline \multirow[t]{3}{*}{ Physeter catadon } & 135 & $\begin{array}{l}\text { Peak broadband level of pulses thought to be } \\
P \text {. catadon. }\end{array}$ & 47 \\
\hline & 173.5 & Mean 1/3-octave level of clicks at $1 \mathrm{kHz}$. & 48 \\
\hline & $171.5(165.5-175.3)$ & Mean and range of broadband level of clicks. & 49 \\
\hline \multicolumn{4}{|l|}{ MYSTICETE } \\
\hline Megaptera novaeangliae & $\begin{array}{c}138.6 \\
148.6 \\
155.4(144.3-174.4)\end{array}$ & $\begin{array}{l}\text { Mean } 1 / 3 \text {-octave level at } 5 \mathrm{kHz} \text {. } \\
\text { Mean } 1 / 3 \text {-octave level at } 1 \mathrm{kHz} \text {. } \\
\text { Mean and range of broadband levels of various } \\
\text { types of signals. }\end{array}$ & 50 \\
\hline Eubalaena glacialis & $172-187$ & Levels in the $25-2500-\mathrm{Hz}$ band for belch-like sounds. & 51 \\
\hline Eschrichtius glaucus & $138-152$ & $\begin{array}{l}\text { Mean broadband levels for several different types of } \\
\text { low-frequency signals. Highest level measured. }\end{array}$ & 52 \\
\hline \multirow[t]{2}{*}{ Balaenoptera musculus } & 159.2 & Maximum broadband level of clicks. & 53 \\
\hline & 188 & Mean level of moans in a $14-222 \cdot \mathrm{Hz}$ band. & 54 \\
\hline \multirow[t]{2}{*}{ Balaenoptera physalus } & $173 \cdot 181$ & Source level for $20-\mathrm{Hz}$ pulses. & 55 \\
\hline & & $\begin{array}{l}\text { Source level of } 20-\mathrm{Hz} \text { pulses thought to be from } \\
\text { B. physalus, based on source level calculations } \\
\text { as cited in reference. }\end{array}$ & 56 \\
\hline Balaenoptera acutorostrata & $152-6$ & Maximum broadband level of clicks. & 57 \\
\hline
\end{tabular}

Table 2. Summary of source level data for cetaceans (from reference 39). 
nonharmonic tones which change frequency rapidly. Cries and whistles are pure tones with or without harmonics. Group IV are clicks or pulses which have peak energy at high frequencies, often between 20 and $30 \mathrm{kHz}$.

Two types of sounds have been recorded from bowhead whales: a short duration and a long duration sound. The sounds' fundamental frequencies are $50-80 \mathrm{~Hz}$ and $100-195 \mathrm{~Hz}$, respectively (ref 59).

The hearing thresholds for large whales have not been measured. If the sounds produced by these whales are indications of sounds they could receive, then the whales' hearing band width extends from $12 \mathrm{~Hz}$ to $30 \mathrm{kHz}$.

\section{DISCUSSION}

Excess or increased environmental noise could impact animals that rely on acoustic signals to maintain biological functions such as feeding, mating, and protecting and raising voung. No standards exist to evaluate the effects of noise on marine mammals and we lack data on the auditory sensitivity for many species of marine mammals, particularly the large whales. Data on the effects of sustained, low levels of noise on biological functions also is sparse. Thus, in this report we cannot quantify the effects of offshore drilling operations on marine mammals.

The acoustic characteristics of the $20-\mathrm{Hz}$ sound produced by the fin whale, Balaenoptera physalus (ref 60), is described as a signal well suited for long range communications. The authors surmise that a decrease in the signal-to-noise ratio, either at the source or the receiver, could sustantially reduce the detection range.

Reference 61 showed that as the noise level in the vicinity of an echolocating dolphin increased, the number of clicks increased (echolocation effort). Furthermore. overall detection performance was degraded with increased noise levels.

Reference 62 suggests that increased shipping activities in Japanese waters have resulted in altering the historical migration routes of the Baird's beaked whale. Beraraius bairdi, and the minke whale, Balaenoptera acutorostrata. Although additional factors may be affecting these populations, the impact of increased maritime activities in whaling grounds should be considered as a potential disrupting influence.

Figure 10 summarizes some possible effects of offshore drilling noise on marine mammal populations. Noise can be classified as either chronic or acute. Chronic noise will either mask signals or induce stress that may become manifest either physiologically or behaviorally. Acute noise may reduce the animal's ability to perceive a signal. Both acute and chronic noise can cause short-term disruption of critical behaviors or mask intraspecific transmission of information. If a population cannot adapt or accommodate to the short-term

59 Ljungblad, DK, S Leatherwood and ME Dahleim, Sounds Recorded in the Presence of an Adult and Calf Bowhead Whale, Balaena mysticetus, Naval Ocean Systems Center TR 420, p 1-7, 1979

${ }^{60}$ Payne, R and D Webb, Orientation by Means of Long Range Acoustic Signaling in Baleen Whales, New York Acad Sci, 188, p 110-141, 1971.

61 Penner, RH and J Kadane, Tursiops Biosonar Detection in Noise. In: Animal Sonar Systems. RF Busnel and JF Fish, eds, p 957-959, Plenum Press, 1980.

62 Nishiwake, M and A Sasao, Human Activities Disturbing Natural Migration Routes of Whales, Sci Rep Whales Res Inst, 29, p 113-120, 1977 

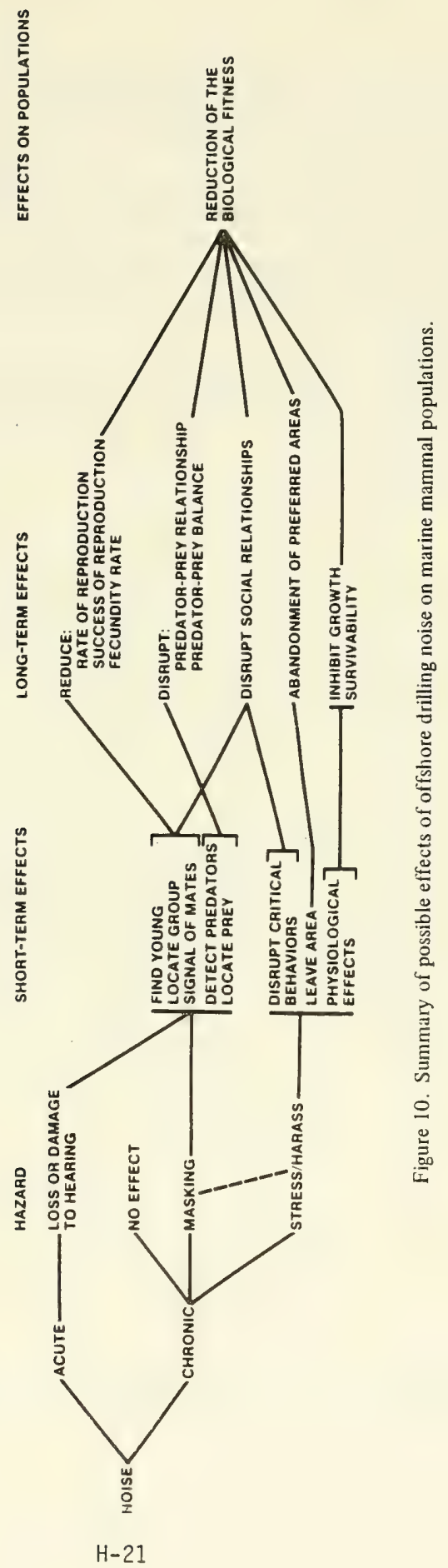
effects, then the long-term effects of noise may reduce the population's reproductive capabilities, disrupt predator-prey relationships, or cause a population to abandon preferred breeding or feeding areas.

The above discussion deals only with the possible effects of noise on marine mammals. Data are not yet available to determine the probability of such effects occurring or to evaluate the severity of the effects on wild populations of animals. Damage risk criteria that have been established for humans may not be appropriate in evaluating possible effects of noise on wildlife (ref63), because the amount of physiological and behavioral adaptation that occurs in response to noise stimulus is unknown.

Continuous noise levels above $90 \mathrm{dBA}$ (approximately $115 \mathrm{~dB}$ re $1 \mu \mathrm{Pa}$ at $1 \mathrm{~m}$ in water) have potentially detrimental effects on human performance and noise levels of less than $90 \mathrm{dBa}$ can be disruptive (ref 2). Until noise standards are established for wild animals, we may assume that animals will be at least partially protected by applying maximum levels identified for humans.

\section{RECOMMENDATIONS}

1. Measure the noise generated from current and future offshore drilling operations. Include sensitive frequency ranges from known marine mammal audiograms.

2. Identify lease areas where offshore oil development is anticipated. Identify species of marine mammals that inhabit these areas.

3. Identify lease areas where introduction of increased sustained noise might disrupt a critical life cycle of marine mammals. For example, feeding, breeding, transit or congregation areas.

4. Initiate a monitoring program when a lease area is opened. Monitor both acoustic and population dynamic parameters in the lease area as development progresses.

5. Develop a program to monitor the effects of controlled introduction of noise to a marine mammal population. Quantify the effects of the noise on the population.

6. Obtain underwater audiograms of marine mammals that occur in the selected lease areas.

7. Determine the effects of noise on marine mammals under controlled conditions.

63 Fletcher, JL and RF Busnel, eds, Summary and Discussion, In: Effects of Noise on Wild life, p 303-305, Academic Press. 1978. 


\section{REFERENCES}

1. Underwater Systems, Inc. Note 312-5, Noise measurements from Offshore Oil Rigs, p 17, Silver Springs, MD, 1973.

2. Information of Levels of Environmental Noise Requisite to Protect Publich Health and Welfare with an Adequate Margin of Safety, Environmental Protection Agency, Superintendent of Documents, US Government Printing Office, Washington, DC, 1974.

3. The White House, Executive Order No. 11644, as amended May 24, 1977.

4. Janssen, R, Noise and Animals: Perspectives of Government and Public Policy, In: Effects of Noise on Wildlife, JL Fletcher and RG Busnel, ed, p 287-301, Academic Press, New York, NY, 1978.

5. Kryter, KD, The Effects of Noise on Man, p 633, Academic Press, New York, NY, 1970.

6. Welch, BL and AS Welch, ed, Physiological Effects of Noise, p 365, Plenum, 1970.

7. Selye, H, Stress and Disease, Science, 122(3171), p 625-631, 1955.

8. Selye, H, The General Adaptation Syndrome and the Diseases of Adaptation, J Clin Endoctrine \& Metab, 6(2), p 117-230, 1946.

9. Myrberg, AA, Ocean Noise and the Behavior of Marine Animals: Relationships and Implications, In: Effects of Noise on Wildlife, JL Fletcher and RG Busnel, ed, p 168-208, Academic Press, New York, NY, 1978.

10. Drouin, AH, Design and Field Operation of an Underwater Acoustic Telemetry System, Offshore Technology Conference, 6th, OTC 1965, p 9.

11. Morgane, JP and NS Jacobs, Comparative Anatomy of the Cetacean Nervous System, In: Functional Anatomy of Marine Mammals, Vol 1, RJ Harrison, ed, p 117-244, Academic Press, New York, NY, 1972.

12. Bullock, TH, AD Grinnel, E Ikezono, K Kameda, Y Katsuki, M Nomoto, N Sato and K Yanagisawa, Electrophysiological Studies of the Central Auditory Mechanisms in Cetaceans, Z Vergl Physiol 59, p 117-156, 1968.

13. McCormick, JG, EG Wever, J Palin and SH Ridgway, Sound Conduction in the Dolphin Ear, J Acous Soc Amer, 48(6), p 1418-1428, 1970.

14. Wever, EG, JG McCormick, J Palin and SH Ridgway, The Cochlea of the Dolphin, Tursiops truncatus: General Morphology, Proc Nat Acad Sci, 68(10), p 2381-2385, 1971.

15. Fraser, FC and PE Purves, Hearing in Cetaceans, Bull of Brit Mus, 7, p 1-140, 1960.

16. Norris, KS, The Echolocation of Marine Mammals, In: The Biology of Marine Mammals, HT Harrison, ed, p 391-423, Academic Press, New York, 1969.

17. Reysenback de Haan, FW, Hearing in Whales, Acta Otolaryngal, 134, p 1-1 14, 1957.

18. Dudok van Heel, WH, Sound and Cetacea, Neth J Sea Res, 1(4), p 407-507. 


\section{REFERENCES (CONTINUED)}

19. Purves PE, Anatomy of Physiology of the Outer and Middle Ear in Cetacea, In: Whales, Dolphin and Porpoise, KS Norris, ed, Univ of Calif Press, p 320-380, 1966.

20. Fleischer, G, Hearing in Extinct Cetaceans as Determined by Cochlear Structure, J Paleontol, 50(1), p 133-152, 1976.

21. Norris, KS and RR Reeves, eds, Report on a Workshop on Problems Related to Humpback Whales (Megaptera novaeangliae) in Hawaii, US Dept Comm, NTIS PB-280-794, p 90, 1978.

22. Reppening, CA, Underwater Hearing in Seals, In: Functional Anatomy of Marine Mammals, RJ Harrison, ed, p 307-331, Academic Press, New York, 1972.

23. Francis, RL, Behavioral Audiometry in Mammals: Review and Evaluation of Techniques. Symp Zool Soc Lond, 37, p 237-280, 1975.

24. Bolt Beranek and Newman Inc Tech Memo 513, Measurements of Underwater Acoustic Noise in the Prudhoe Bay Area, by CI Malme and R Mlawski, p 16, 1979.

25. Ford, J, White Whale Offshore Exploration Acoustic Study, Report submitted to Imperial Oil Co, FF Slaney and Co, Ltd, Vancouver, Canada, p 21, 1977.

26. Bell Laboratories, APEX Final Report, by SA Kramer and TE Wing, 1976.

27. Urick, RJ, Principles of Underwater Sound, p 384, McGraw-Hill Book Co, 1967.

28. Naval Ordance Test Station TP 4178, Audiotory Thresholds in the Bottlenose Porpoise, Tursiops truncatus, by CS Johnson, p 22, 1966.

29. Andersen, S, Auditory Sensitivity in the Harbor Porpoise, Phocoena phocoena, In: Investigations on Cetacea, Vol 2, G Pilleri, ed, p 255-258, 1970.

30. Hall, JD and CS Johnson, Auditory Threshold of a Killer Whale, Orcinus Orca, J Acous Soc Amer, 4l(1), p 515-517, 1971.

31. Hubb Sea Work Research Institute Technical Report 78-109, Auditory Thresholds of Two Beluga Whales (Delphinapterus leucas), by MJ White, JC Norris, DK Ljunblad, KS Baron and GN DeSciara, p 13, 1978.

32. Jacobs, DW and JD Hall, Thresholds of a Freshwater Dolphin, Inia geoffrensis, J Acous Soc Amer, 51(1), p 530-533, 1972.

33. Schusterman. RJ, RF Balliet and J Nixon, Underwater Audiogram of the California Sea Lion by Conditioned Vocalization Techniques, J Exp Anal Beh, 17, p 339-350, 1972.

34. Terhune, JM and K Ronald, the Harp Seal, Pagophilus groenlandicus, III, The Underwatar Audiogram, Can J Zool, 50, p 565-569, 1975.

35. Ternune, JM and K Ronald, Underwater Hearing Sensitivity of Two Ringed Seals (Pusa hispida), Can J Zool, 53, p 227-231, 1975.

36. Mohi, B, Auaiitory Sensitivity of the Common Seal in Air and Water, J Aud Res, 8 . p 27-38, 1968. 


\section{REFERENCES (CONTINUED)}

37. Ridgway, SH and PL Joyce, Studies on Seal Brain by Radio-telemetry, In: Biology of the Seal, K Ronald and AW Mansfield, eds, p 81-91, 1975.

38. Parvulescu, A, The Acoustics of Small Tanks, In: Marine Bioacoustics, WN Tauolga, ed, p 7-13, Pergammon Press, 1967.

39. Naval Undersea Center TP 547, Acoustic Source Levels of Four Species of Small Whales, by JF Fish and CW Turl, p 14, 1976.

40. Au, WWL, RW Floyd, RH Penner and AE Murchinson, Measurements of Echolocation Signals of the Bottlenose Dolphin, Tursiops truncatus, in Open Water, J Acous Soc Amer, 56, p 1280-1290, 1974.

41. Ref 40, p 2 .

42. Schevill, WE and WA Watkins, Pulsed Sounds of the Porpoise Lagenorhyncus australis, Brevoria, 366, p 1-10, 1971.

43. Schevill. WE and WA Watkins, Sound Structure and Directionality in Orcinus (Killer Whale), Zoologica, 51, p 71-76, 1966.

44. Watkins, WA and WE Schevill, Listening to Hawaiian Spinner Porpoises, Stenella of longirostris, with a Three-Dimensional Hydrophone Array, J Mamm, 55, p 319-328, 1974.

45. Schevill, WE, WA Watkins and C Ray, Click Structure in the Porpoise, Phonoena phocoena, J Mamm. 50, p 721-728, 1969.

46. Mohl. B and S Andersen, Echolocation: High-Frequency Components in the Click of the Harbour Porpoise (Phocoena ph L), J Acous Soc Amer, 54, p 1368-1372, 1973.

47. Corcell. AT and M Green, Investigations of Impulsive Deepsea Noise Resembling Sounds Produced by a Whale, J Acous Soc Amer, 44, p 483-487, 1968.

48. Dunn, JL. Airborne Measurements of the Acoustic Characteristics of a Sperm Whale, J Acous Soc Amer, 46, p 1052-1054, 1969.

49. Levenson. C. Source Level and Bistatic Target Strength of the Sperm Whale (Physter (atodon) Measured from an Oceanographic Aircraft, J Acous Soc Amer, 55, p 1100 $1103,1974$.

50. Levenson, C, Characteristic of Sounds Produced by Humpback Whales (Megaptera novaeangliae), NAVOCEAN Technical Note 7700-6-72, p 1-10, 1972.

51. Cummings, WC, JF Fish and PO Thompson, Sound Production and Other Behavior of Southern Right Whales, Eubalaena glacialis, Trans San Diego Soc Nat Hist, 17. p 1-13, 1972.

52. Cummings, WC, PO Thompson and R Cook, Underwater Sounds of Migrating Gray Whales, Eschrichtius glaucus (Cope), J Acous Soc Amer, 44, p 1278-1281, 1968. 


\section{REFERENCES (CONTINUED)}

53. Beamish, P and E Mitchell, Ultrasonic Sounds Recorded in the Presence of a Blue Whale, Balaenoptera musculus, Deep-Sea Res, 18, p 803-809, 1971.

54. Cummings, WC and PO Thompson, Underwater Sounds from the Blue Whale, Balaenoptera musculus, J Acous Soc Amer, 50, p 1193-1198, 1971.

55. Patterson, B and TF Hamilton, Repetitive 20 Cycle per Second Biological Hydrostatic Signals at Bermuda, In: Marine Bio-Acoustics, WN Tavolga, ed, p 125-145, Pergammon Press, 1964.

56. Schevill, WE, WA Watkins and RH Backus, The 20-Cycle Signals and Balaenoptera (Fin Whales), In: Marine Bio-Acoustics, WN Tavolga, ed, p 147-157, Pergammon Press, 1964.

57. Beamish, P and E Mitchell, Short Pulse Length Audio Sounds Recorded in the Presence of a Minke Whale (Balaenoptera Acutorostrata), Deep-Sea Res and Ocean Abst, 20, p 375-386, 1973.

58. Thompson, TJ, HE Winn and PJ Perkins, Mysticete Sounds, In: Behavior of Marine Mammals, Vol 3, Cetaceans, HE Winn and BL Olla, eds, p 403-431, Plenum Press, 1979.

59. Ljungblad, DK, S Leatherwood and ME Dahleim, Sounds Recorded in the Presence of an Adult and Calf Bowhead Whale, Balaena mysticetus, Naval Ocean Systems Center TR 420, p 1-7, 1979.

60. Payne, R and D Webb, Orientation by Means of Long Range Acoustic Signaling in Baleen Whales, New York Acad Sci, 188, p 110-141, 1971.

61. Penner, RH and J Kadane, Tursiops Biosonar Detection in Noise, In: Animal Sonar Systems, RF Busnel and JF Fish, eds, p 957-959, Plenum Press, 1980.

62. Nishiwake, M and A Sasao, Human Activities Disturbing Natural Migration Routes of Whales, Sci Rep Whales Res Inst, 29, p 113-120, 1977.

63. Fletcher, JL and RF Busnel, eds, Summary and Discussion, In: Effects of Noise on Wildlife, p 303-305, Academic Press, 1978. 


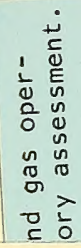

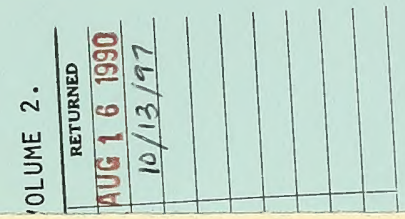

NOSC Tech. Report 844

Volume 2

JAN 231986

DEMCO : 
